\title{
MEASUREMENT OF FISSION PRODUCT ACTIVITY IN THE PEACH BOTTOM REACTOR PRIMARY COOLANT LOOP
}

\author{
by
INTELCOM RAD TECH CORPORATION
}

Prepared under

Subcontract SC 565234

Contract E(04-3)-167

Project Agreement No. 56

for the San Francisco Operations Office

U.S. Energy Research and Development Administration

and the Electric Power Research Institute 


\section{DISCLAIMER}

This report was prepared as an account of work sponsored by an agency of the United States Government. Neither the United States Government nor any agency Thereof, nor any of their employees, makes any warranty, express or implied, or assumes any legal liability or responsibility for the accuracy, completeness, or usefulness of any information, apparatus, product, or process disclosed, or represents that its use would not infringe privately owned rights. Reference herein to any specific commercial product, process, or service by trade name, trademark, manufacturer, or otherwise does not necessarily constitute or imply its endorsement, recommendation, or favoring by the United States Government or any agency thereof. The views and opinions of authors expressed herein do not necessarily state or reflect those of the United States Government or any agency thereof. 


\section{DISCLAIMER}

Portions of this document may be illegible in electronic image products. Images are produced from the best available original document. 
ABSTRACT

The distribution of gamma-emitting radionuclides deposited in the primary circuit of the Peach Bottom High-Temperature Gas-Cooled Reactor (HTGR) at end-of-life has been determined by in situ gamma scanning. The work was part of the Peach Bottom End-of-Life Program* and was performed by the IRT Corporation under subcontract to General Atomic Company. The measurements were made to support a design method verification exercise. The specific activity on the ducts was measured by external scans at local points with a Ge(Li) detector and by internal scans with a travelling intrinsic germanium detector (after destructive removal of trepan samples); the activity on the steam generator tube bundle was determined by traversing selected tubes with travelling CdTe detectors from the water side. Calibration measurements on mockups allowed reduction of the spectra to specific activity.

Cesuim-137 and -134 were the only major gamma-emitters detected in the primary circuit; their relative plateout distributions were similar but not identical. The specific activity was locally uniform in the ducting with a gradual decrease in the direction of coolant flow. A significant entrance effect was observed in the superheater section of the steam generator; the activity was highest where the inlet jet of helium impinged and lowest at the ends of the bundle despite the presence of a flow baffle. The effect damped out with penetration into the bundle, resulting in an essentially uniform axial profile at the economizer exit.

*Jointly sponsored by ERDA and EPRI. Contract AT(04-3)-167, PA56. 


\section{FOREWORD}

The Peach Bottom Atomic Power Station Unit No. 1 was the first installation of a High-Temperature Gas-Cooled Reactor (HTGR) in the United States. Power operation began in January 1967 and commercial operation on June 1, 1967. The plant was operated successfully through October 31, 1974 when it was shut down for decommissioning.

In March 1975, the Peach Bottom End-of-Life Program, cosponsored by ERDA and EPRI, was initiated. The prime objective of this program is to validate specific HTGR design codes and predictions by comparison of actual and predicted physics, thermal, fission product, and materials behavior in Peach Bottom. These design methods verifications, to be completed in CY-77, utilize the data determined during three consecutive phases of the program, together with the data determined in a complementary program of Peach Bottom driver fuel element PIEs at ORNL. The three phases are (1) nondestructive fuel and circuit gamma scanning at the Peach Bottom site, (2) removal of Peach Bottom steam generator and primary circuit components, (3) 1aboratory examinations of removed components.

This data compilation report was prepared by IRT Corporation to fulfill the contractual requirements of General Atomic Subcontract SC 565234 under the Peach Bottom End-of-Life Program. The report covers the circuit gamma scanning work referenced above, the objective of which was to determine fission product activity distributions in the Peach Bottom reactor primary coolant loop for comparison with PAD code predictions. 
IRT 0029-001

(GA-A14059)

\section{MEASUREMENT OF \\ FISSION PRODUCT ACTIVITY IN THE \\ PEACH BOTTOM REACTOR PRIMARY COOLANT LOOP}

FINAL REPORT

WORK DONE BY:

REPORT WRITTEN BY:

J. K. MacKenzie

W. E. Selph

D. E. Bryan

W. E. Selph

V. V. Verbinski

A. L. Weiman

W. E. Gober

D. E. Bryan

WORK PERFORMED UNDER

GENERAL ATOMIC

SUBCONTRACT SC 565234 
$\bullet$ 
CONTENTS

1. INTRODUCTION . . . . . . . . . . . . . . . . . . . I

1.1 Peach Bottom End-of-Life Program . . . . . . . . . . 1

2. EXTERNAL SCAN OF PRIMARY COOLANT DUCT . . . . . . . . . . . 3

2.1 Duct Geometry and Measurement Positions . . . . . . . . 3

2.2 Detector Description and Calibration . . . . . . . . . . 3

2.3 Electronics and Data Recording.............. 13

2.4 Data Reduction.................... . 15

2.5 Data Summary . . . . . . . . . . . . . . . 18

3. STEAM GENERATOR TUBE SCANS . . . . . . . . . . . . . . . . 21

3.1 Steam Generator Description . . . . . . . . . . . . 21

3.2 Detector Description and Calibration . . . . . . . . 27

3.2.1 CdTe Detector Description . . . . . . . . . 27

3.2.2 CdTe Detector Calibration . . . . . . . . . . . 28

3.2.3 GM Counter Description . . . . . . . . . . . . 39

3.2.4 GM Tube Calibration . . . . . . . . . . . . . 39

3.3 Detector Positioning . . . . . . . . . . . . . . . 39

3.4 Electronics and Data Recording . . . . . . . . . . . . 40

3.5 Reduction of Steam Generator Gamma Scan Data . . . . . . . 43

3.6 Data Presentation . . . . . . . . . . . . 50

3.7 Error Analysis . . . . . . . . . . . . . 57

3.7.1 Calibration Errors . . . . . . . . . . . . 57

3.7.2 Data-Taking Errors . . . . ......... 58

3.7.3 Data Reduction................ 58

3.7.4 Composite Uncertainty . . . . . . . . . . 59

4. INTERNAL DUCT SCANS . . . . . . . . . . . . . . . . . . . 61

4.1 Duct Scan Locations . . . . . . . . . . . . . . . . 61

4.2 Detector/Collimator Description and Calibration . . . . . 61

4.3 Detector Transport Mechanism . . . . . . . . . . 66

4.4 Electronics and Data Recording... . . . . . . . . 66

4.5 Data Reductions ................. 70

4.5.1 Application of Calibration Data . . . . . . . 70

4.5.2 Correction for Interference from Adjacent Ducts . 71

4.6 Data Presentation . . . . . . . . . . . . . 73

REFERENCES ......................... 77

APPENDIX A: PEACH BOTTOM STEAM GENERATOR TUBE FISSION PRODUCT

PLATEOUT VALUES . . . . . . . . . . . . . . 79

APPENDIX B: TRACEABILITY OF CALIBRATION SOURCES TO AN NBS STANDARD . . . . . . . . . . . . . . . . 191 


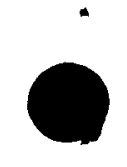

This page intentionally left blank.

$x$

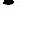




\section{LIST OF ILLUSTRATIONS}

\section{Figure}

1 Isometric of primary coolant system . . . . . . . . . . 4

2 Cross section of the standard helium duct in Peach Bottom I . 6

3 Cross section of the concentric helium duct in Peach Bottom I . . . . . . . . . . . . . . . . . . . . . . 7

4 Efficiency curve Ge(Li) S/N 697 point source at $10 \mathrm{~cm}$. . . . 8

5 Position of the detector relative to the standard helium duct. 10

6 Position of the detector relative to the concentric helium duct.......................... 11

7 Collimated efficiency for the $G e(L i)$ detector used in the external duct scans . . . . . . . . . . . . . 12

8 Signal conditioning and data storage system . . . . . . . 14

9 Peach Bottom external duct scan (position 1-7) . . . . . . . 16

10 Steam generator cross section . . . . . . . . . . . . . 22

$11 \gamma$-scan of 79 tubes from water side . . . . . . . . . . 23

$12 a$ Tube numbering scheme for economizer section of Peach Bottom I steam generator .................. 24

$12 \mathrm{~b}$ Tube numbering scheme for evaporator section of Peach Bottom I steam generator ................... 25

12c Tube numbering scheme for superheater section of Peach Bottom I steam generator . . . . . . . . . . . . . . 26

13 Typical ${ }^{134}$ Cs spectrum with CdTe detector with Ta shield . . 29

14 Typical ${ }^{137}$ Cs spectrum with CdTe detector with Ta shield . . 30

15 Early CaTe measurement of economizer tube 102 . . . . . . . 31

16 Steam generator mockup .................. . 32

17 Location of each class of steam generator tube relative to tube being measured (tube 1) . . . . . . . . . . 34

18 CdTe detector calibration for $0.796 \mathrm{MeV}$ gamma ray of ${ }^{134} \mathrm{Cs}$ in superheater tubes ............... 35

19 CaTe detector calibration for $0.662 \mathrm{MeV}$ gamma ray of ${ }^{137} \mathrm{Cs}$ in superheater tubes ................. 36

20 CaTe detector calibration for $0.796 \mathrm{MeV}$ gamma ray of ${ }^{134} \mathrm{Cs}$ in

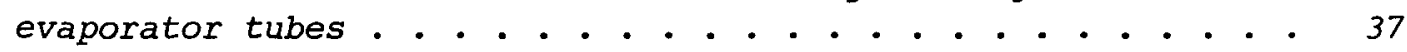

21 CdTe detector calibration for $0.662 \mathrm{MeV}$ gamma ray of ${ }^{137} \mathrm{Cs}$ in evaporator tubes................ . . 38

22 CdTe detector positioning apparatus . . . . . . . . . 41 
Figure

23 Equipment configuration for steam generator scans . . . . . . 42

24 Typical spectrum of a steam generator tube taken with an unshielded cdTe detector ................. 44

25 Typical spectrum of a steam generator tube taken with a shielded CdTe detector . . . . . . . . . . . . . . 45

26 Superimposed spectra of ${ }^{134}$ Cs and ${ }^{137}$ Cs taken with a shielded cate detector . . . . . . . . . . . . . . . . 46

27 Radial profile of average activity across steam generator tube sheet bundle on axis of symmetry . . . . . . . . . . . . . . 51

28 Radial profile of activity across steam generator tube sheet bundle at $4 \mathrm{ft}$ depth. . . . . . . . . . . . . . . 52

29 Radial profile of activity across steam generator tube sheet bundle at $7.5 \mathrm{ft}$ depth . . . . . . . . . . . . . 53

30 Radial profile of activity across steam generator tube sheet at $11 \mathrm{ft}$ depth..................... . 54

31 Radial profile of activity across steam generator tube sheet at $15 \mathrm{ft}$ depth... . . . . . . . . . . . . . . 55

32 Radial profile of activity across steam generator tube sheet bundle at $18 \mathrm{ft}$ depth . . . . . . . . . . . . . . . 56

$33 \mathrm{Ge}(\mathrm{Li})$ detector, preamplifier, collimator, and carriage . . . 63

34 Efficiency for the collimated intrinsic Ge detector for counting activity on the inner surface of the 13-9/16-inch inner radius duct . . . . . . . . . . . . . . . . . . .

35 Efficiency for the collimated NaI(Tl) detector for counting activity on the inner surface of the 13-9/16-inch inner radius duct .................. 65

36 Detector location control circuitry . . . . . . . . . 67

37 Electromechanical positioner for internal scans . . . . . . 68

38 Block diagram for internal duct scanning . . . . . . . . . . 69

39 Internal duct scans specific activity vs depth . . . . . . . 75 


\section{INTRODUCTION}

\subsection{PEACH BOTTOM END-OF-LIFE PROGRAM}

The Peach Bottom I reactor, owned and operated by Philadelphia Electric Power Company, was shut down on 31 October 1974 after a successful operating history extending over seven years.

Following shutdown, a systematic performance evaluation program (Ref. 1) was performed under joint funding from ERDA and EPRI. Prime contractor on this program was the General Atomic Company. Major subcontractors were the Catalytic Corporation of Philadelphia and IRT Corporation of San Diego. The primary role of IRT was to determine by physical, nondestructive means the level of fission-product plateout at various points in the primary coolant circuit. In modeling of the HTGR reactor for performance and for safety parameters, analytical methods have been devised for predicting the release of fission products from the graphite fuel elements [e.g., FIPER or TRAFIC (Refs. 2,3)], and for predicting the plateout of these fission products on surfaces within the He coolant stream (Ref. 4). The measurements reported in this volume, as well as the radiochemical analysis of trepanned samples reported elsewhere, provide an excellent data base against which to evaluate the analytical models.

The measurements are reported in the order in which they were performed at the Peach Bottom reactor. The first series of measurements involved using a collimated $\mathrm{Ge}(\mathrm{Li})$ detector to measure the activity in the large-diameter ducts in the primary circuit. The second series involved using a small CdTe detector to measure the plateout on steam generator tubes by making measurements from inside (the water side) of the tubes. The third series involved placing a mobile intrinsic germanium detector inside two long vertical runs of the primary duct to 
determine the uniformity of the plateout as a function of position along the length of the tube.

Prior measurements had been made by Oak Ridge National Laboratory (ORNL) during the operation of the reactor, as well as after shutdown for various points on the ducts in coolant loop 1. The points selected for scanning by IRT overlapped the ORNL measurements in loop 1 as a check on consistency, but concentrated primarily on loop 2 . 


\section{EXTERNAL SCAN OF PRIMARY COOLANT DUCT}

Measurements were made of the activity at selected points inside the large-diameter primary ducts of the Peach Bottom I reactor by external gamma scans of the duct. This work was done in conformance with References 5 and 6.

\subsection{DUCT GEOMETRY AND MEASUREMENT POSITIONS}

Portrayal of the intricate geometry of a large, three-dimensional power plant always suffers when projected onto two dimensions. An attempt is made, however, in Figure 1 to show the location of paints at which measurements were made. Table 1 itemizes the points and describes their location.

Points 1-2, 2-1, and 2-2 were located on the large concentric duct leading from the reactor to the heat exchanges, while the remainder of the points were located on standard ducting of 28-inch $0 . d$. and 7/16-inch wall thickness. The cross sections of the ducts are defined in Figures 2 and 3 .

\subsection{DETECTOR DESCRIPTION AND CALIBRATION}

The Ge(Li) detector employed in the measurements reported in this section was a Canberra Model 7229, with a cryostat model 7905-15. The active volume is a right circular cylinder drifted coaxially with one end open, $38 \mathrm{~mm}$ diameter $\times 43.5 \mathrm{~mm}$ long. The active area of the closed end facing the window is $10.7 \mathrm{~cm}^{2}$. The counting efficiency of the detector for a point source at $10 \mathrm{~cm}$ in front of the center of the window is shown in Figure 4 as a function of gamma-ray energy. This curve, supplied by the detector manufacturer, was verified by IRT for the energies of interest in ${ }^{134} \mathrm{Cs}$ and ${ }^{137} \mathrm{Cs}$ measurements. For the $662-\mathrm{keV}$ gamma from ${ }^{137} \mathrm{Cs}$ the resolution is $79 \mathrm{keV}$ (FWHM), with a peak-to-Compton ratio of $36: 1$. 
a ORNL Y SCANS (EXTERNAL)

a iRT Y sCans (EXTERnal)

- SUNTAC tREPANNEd SAMPle

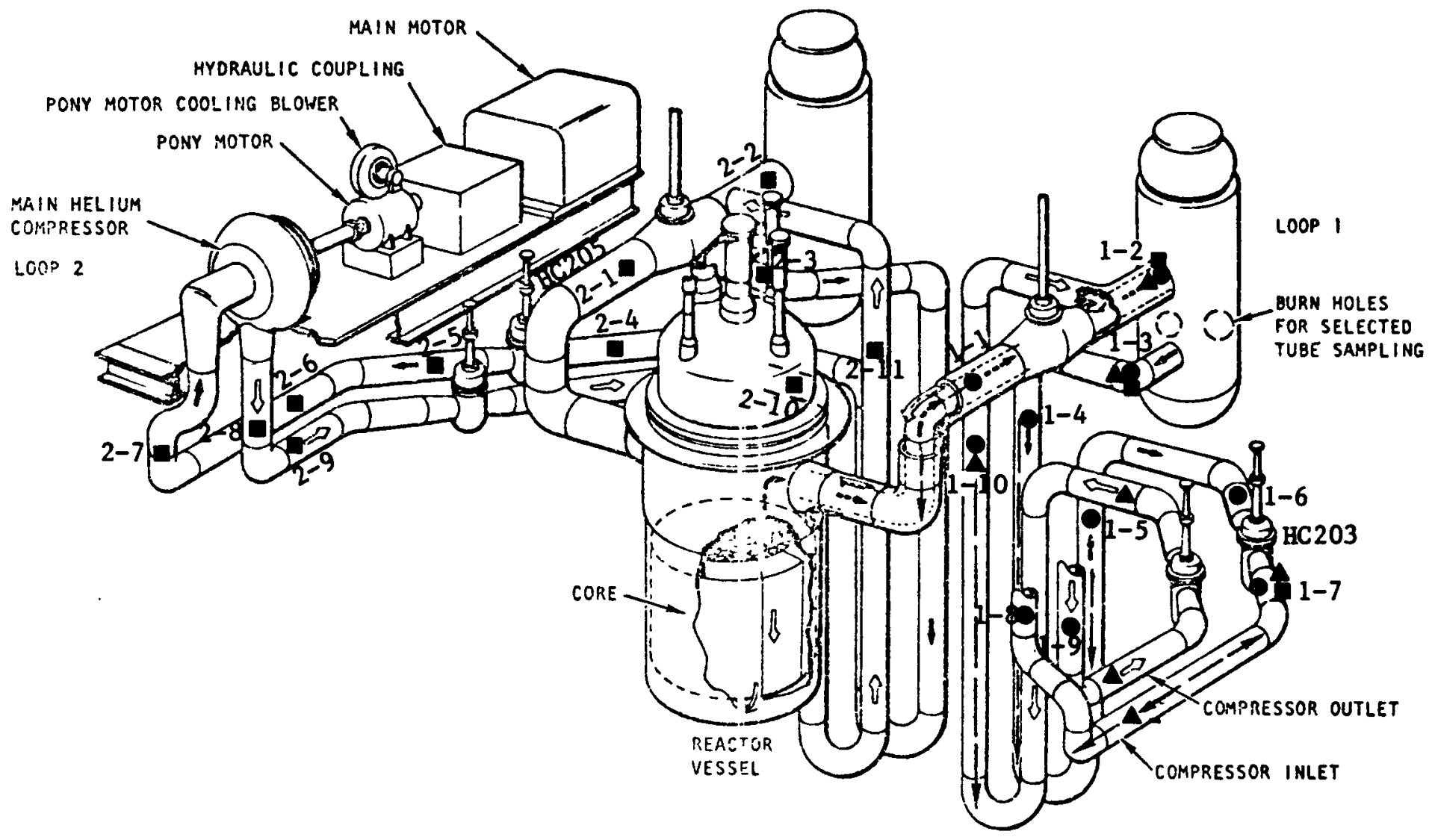

RT -13246

Figure 1. Isometric of Primary coolant system 
Table 1

DUCT GAMMA SCANNING LOCATIONS

\begin{tabular}{lll}
\hline Loop & $\begin{array}{c}\text { Identification } \\
\text { Number }\end{array}$ & Location \\
\hline 1 & $1-2$ & Midpoint of cold return to concentric duct \\
1 & $1-3$ & $3 \mathrm{ft}$ downstream of first elbow \\
1 & $1-7$ & $7 \mathrm{ft} 6$ inches downstream of valve HC 203 \\
2 & $2-1$ & $4 \mathrm{ft}$ upstream of hot valve centerline \\
2 & $2-2$ & Midpoint of cold return to concentric duct \\
2 & $2-3$ & $3 \mathrm{ft}$ downstream of first elbow 2 inches upstream of valve HC 205 \\
2 & $2-4$ & $7 \mathrm{ft} 6$ inches downstream of valve HC 205 \\
2 & $2-5$ & $3 \mathrm{ft}$ downstream of second elbow upstream of \\
2 & $2-7$ & $10 \mathrm{ft} 8$ inches downstream of compressor outlet \\
2 & $12 \mathrm{ft}$ upstream of 1ast elbow before concentric \\
$2-8$ & $2-11$ & duct
\end{tabular}




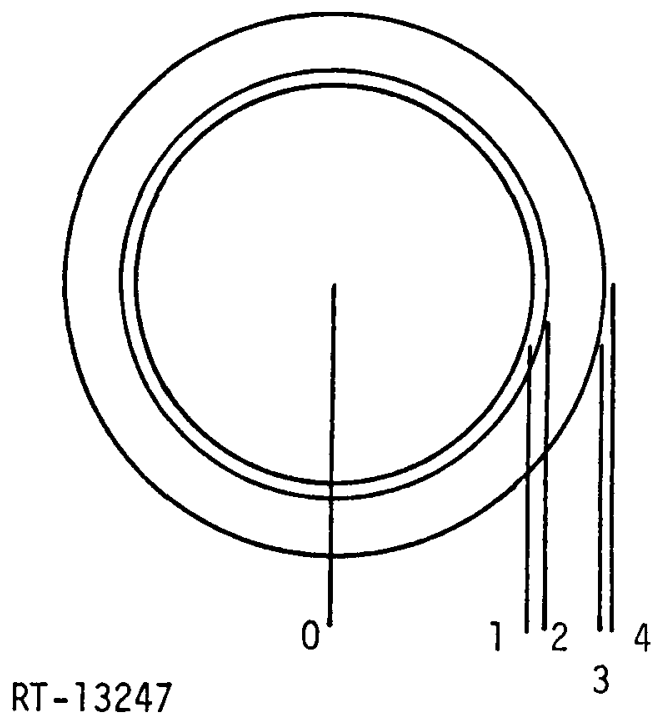

\begin{tabular}{|c|c|c|c|c|c|c|c|}
\hline \multirow[b]{2}{*}{ Point } & \multicolumn{2}{|c|}{ Radius } & \multirow{2}{*}{$\begin{array}{l}\text { Radial } \\
\text { Region }\end{array}$} & \multicolumn{4}{|c|}{ Thickness } \\
\hline & In. & $\mathrm{cm}$ & & Material & In. & $\mathrm{cm}$ & $\mathrm{g} / \mathrm{cm}^{2}$ \\
\hline 1 & $13-9 / 16$ & $(34.45)$ & $0-1$ & Void & $13-9 / 16$ & 34.45 & 0 \\
\hline 2 & 14 & 35.56 & $1-2$ & Steel & $7 / 16$ & 1.11 & 8.61 \\
\hline 3 & 17 & 43.18 & $2-3$ & Insulation & 3 & 7.62 & 1.04 \\
\hline 4 & 17.04 & 43.27 & $3-4$ & Aluminum & 0.04 & 0.1 & 0.02 \\
\hline
\end{tabular}

Figure 2. Cross section of the standard helium duct in Peach Bottom I. 


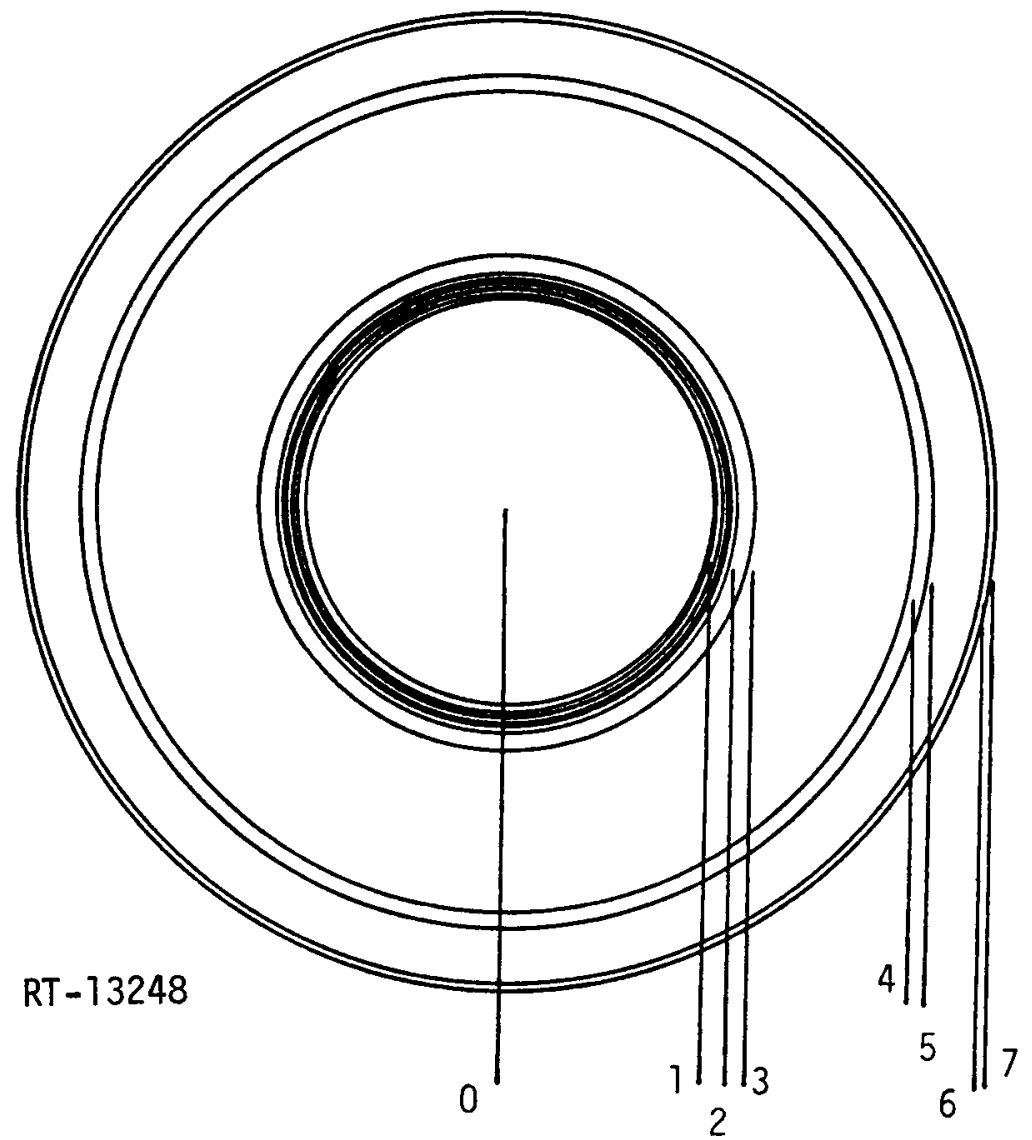

\begin{tabular}{|c|c|c|c|c|c|c|c|}
\hline \multirow[b]{2}{*}{ Point } & \multicolumn{2}{|c|}{ Radius } & \multirow[b]{2}{*}{ Region } & \multirow[b]{2}{*}{ Material } & \multicolumn{2}{|c|}{ Thickness } & \multirow[b]{2}{*}{$\mathrm{g} / \mathrm{cm}^{2}$} \\
\hline & In. & $\mathrm{cm}$ & & & In. & $\underline{\mathrm{cm}}$ & \\
\hline 1 & $13-5 / 8$ & 34.61 & $0-1$ & Void & $13-5 / 8$ & 34.61 & 0 \\
\hline 2 & $14-5 / 8$ & 37.15 & $1-2$ & $\begin{array}{l}\text { Stainless } \\
\text { Steel } \\
\text { Insulation }\end{array}$ & 1 & 2.54 & 4.62 \\
\hline 3 & $15-7 / 8$ & 40.32 & $2-3$ & Steel & 1.25 & 3.18 & 24.64 \\
\hline 4 & 20 & 50.86 & $3-4$ & Void & $4-1 / 8$ & 10.48 & 0 \\
\hline 5 & $21-1 / 4$ & 53.98 & $4-5$ & Steel & 1.25 & 3.18 & 24.64 \\
\hline 6 & $24-1 / 4$ & 61.60 & $5-6$ & Insulation & 3 & 7.62 & 1.04 \\
\hline 7 & 24.29 & 61.70 & $6-7$ & Aluminum & 0.04 & 0.1 & 0.02 \\
\hline
\end{tabular}

Figure 3. Cross section of the concentric helium duct in Peach Bottom I. 


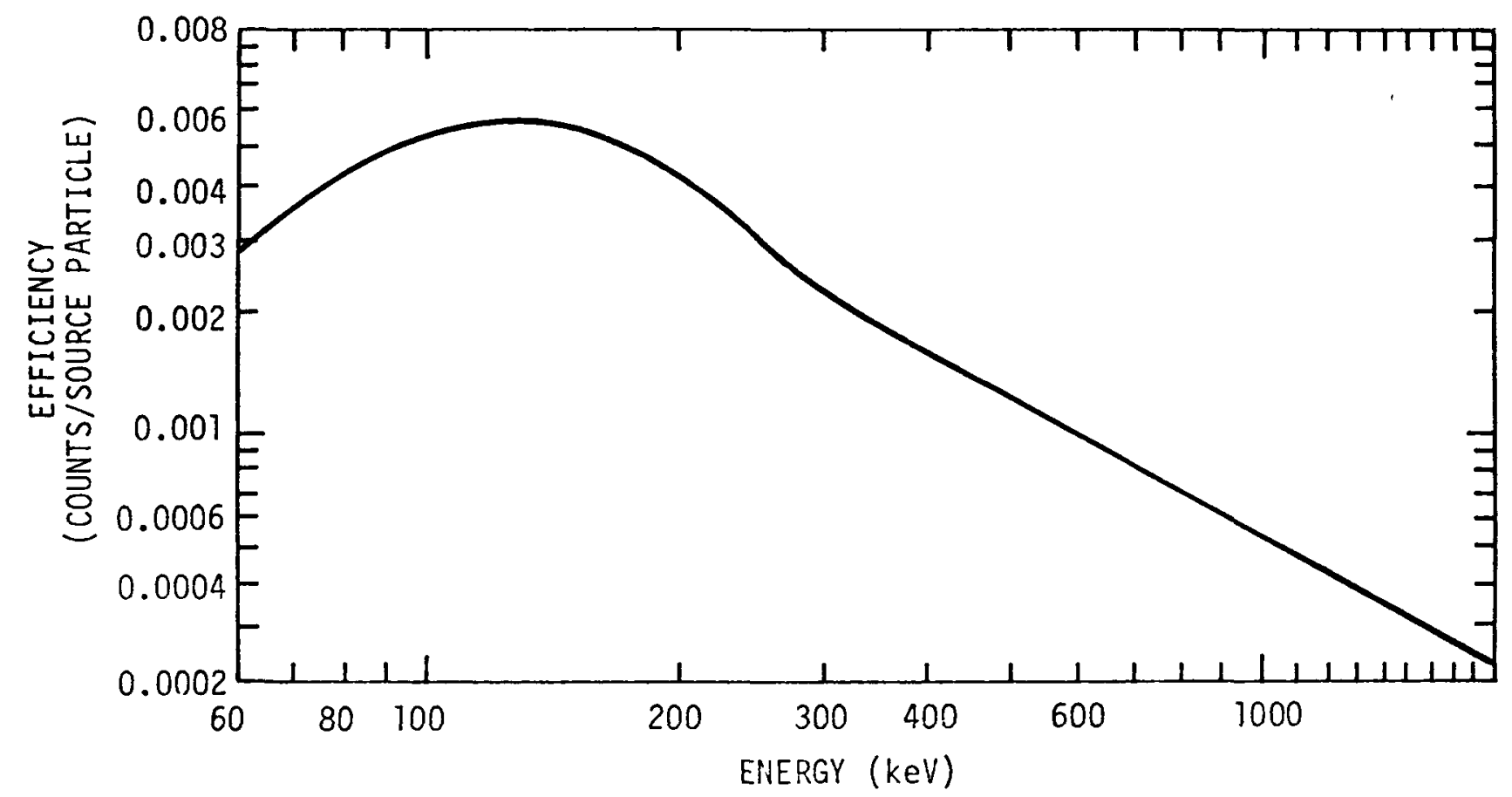

RT-13249

Figure 4. Efficiency curve Ge(Li) S/N 697 point source at $10 \mathrm{~cm}$. 
As used in these measurements, the detector was housed in a lead shield with interchangeable collimator inserts. The geometry of the shielded detector is shown in Figure 5. The penetration of gamma rays through the back end of the shield was reduced by stacking bags of lead shot around the housing, and where possible, placing lead bricks behind the dewar.

At each location to be measured, the detector/collimator was placed against the insulation on the side of the duct, and readings were obtained with the shield totally closed, followed by a reading with the collimator open. Sketches of the detector in position at the standard and concentric ducts are shown in Figures 5 and 6 .

The detector-collimator geometry is such that a right cone defines the volume that the detector "sees". The axis of this cone is the detector-collimator centerline. The surface on the duct which is counted is defined by the intersection of this cone with a right circular cylinder. Since the duct is relatively large, and is close to the collimator, the surface counted on the near side of the duct is assumed to be planar and bounded by a circle (neglecting the slight curvature of the duct). The center of the circle is the intersection of the detector-collimator centerline with the duct. The radius of this circle is approximately 1.5 inches. With no collimator, the counts obtained from a source at the center of the circle will be essentially the same as those obtained with the source at the circumference. With the collimator, however, the count rate drops off as the source is moved along the radius of the circle from the center toward the circumference.

In order to determine this collimated detector efficiency as a function of the distance along the radius of the circle, calibrations were performed in the laboratory using pieces of insulation and duct wall material to mock up the materials separating the detector and the source on the inner surface of the duct. The sources on the duct wall adjacent to the detector were simulated by a small isotopic source of ${ }^{137} \mathrm{Cs}$. Counts were obtained with the source at various points along the radius with the collimator in place, as well as at the center and circumference with no collimator. These two curves are shown in Figure 7. 


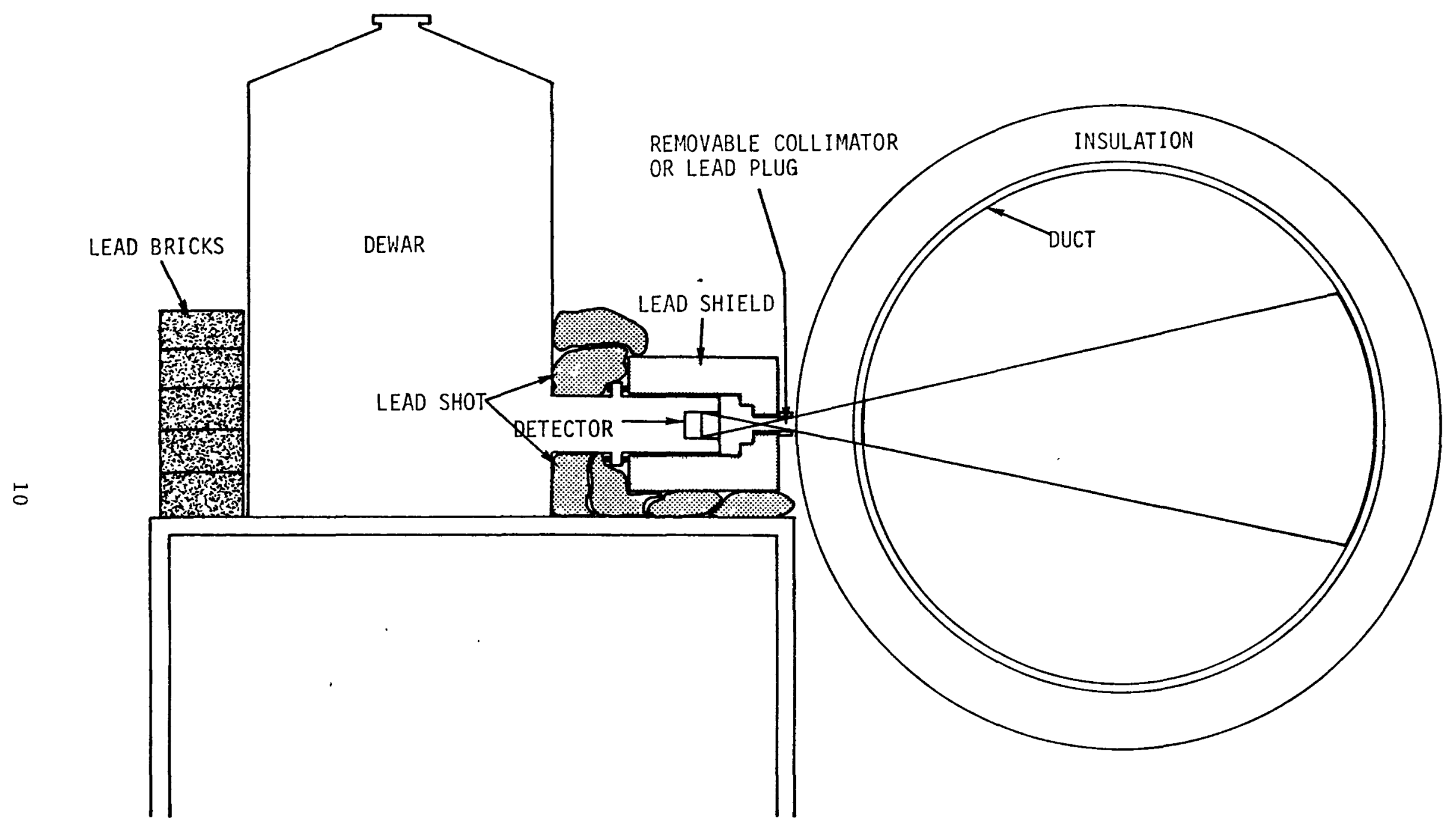

RT -13250

Figure 5. Position of the detector relative to the standard helium duct 


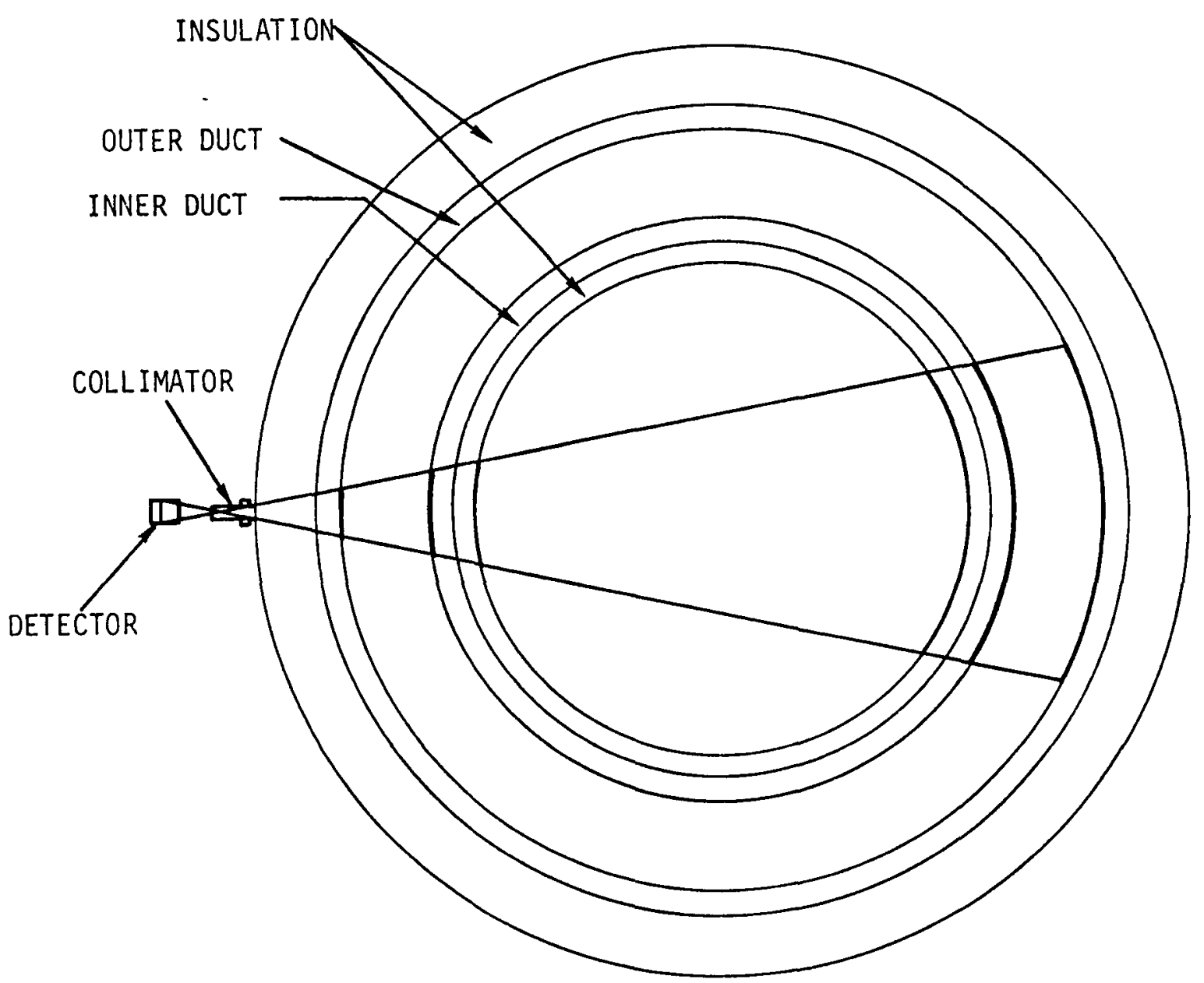

RT-13251

Figure 6. Position of the detector relative to the concentric helium duct. 


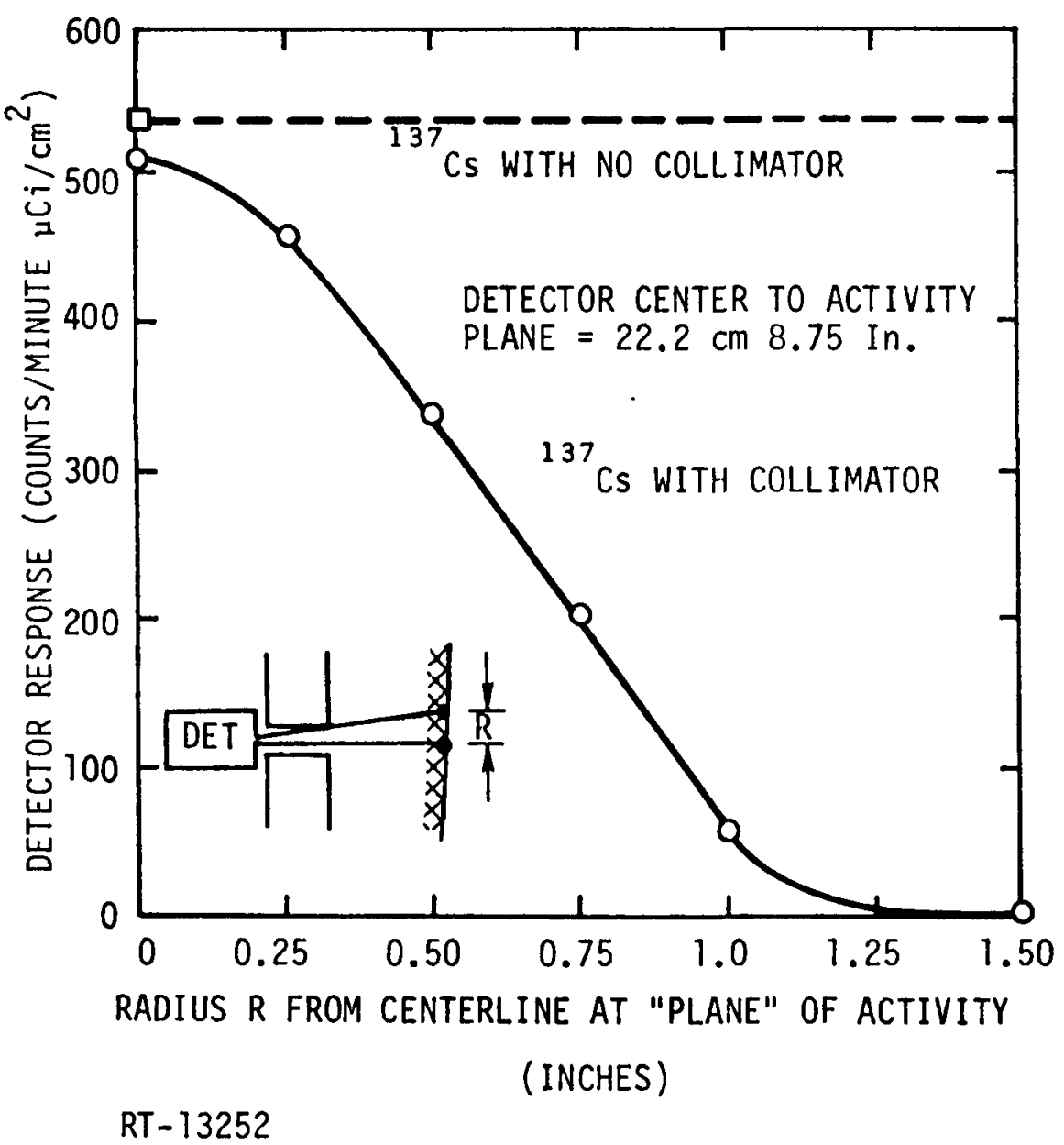

Figure 7. Collimated efficiency for the Ge(Li) detector used in the external duct scans 
Since the altitude of the cone and the radius of the circle are known, these curves can be expressed as a function of the angle from the detector-collimator centerline. By so doing, these curves can then be applied to the other surfaces of the ducts which the detector "sees". As the distance from the detector becomes greater, the area on the duct intersected by the cone becomes larger and the surface counted can no longer be considered to be planar. The result is that there are varying source-to-detector distances over the area counted. These variances are small compared to the centerline distance and they were accounted for as explained in Section 2.4. The curves in Figure 7 are valid for all duct surfaces when reduced to an angle-dependent efficiency.

The application of these curves to the reduction of the measured data to deposition intensities is reviewed in Section 2.4.

\subsection{ELECTRONICS AND DATA RECORDING}

A block diagram of the electronics used to acquire and store the data is shown in Figure 8.

The pulse output from gamma interaction with the detector is conditioned, shaped, and amplified in the preamplifier located on the detector. The output pulse from the preamp is transmitted to the amplifier (AMP). The AMP further shapes and amplifies the signal to condition it for the 4096-channel multichannel analyzer (MCA). A baseline restorer (BLR) positioned between the AMP and MCA provides a final shaping of the signal to reduce undershoot of the amplifier signal, and provide an optimized signal to the MCA which converts the incoming analog-to-digital count proportional to the energy of the gamma ray striking the detector.

The signal from the amplifier is also transmitted to a single-channel analyzer (SCA), and then to a scaler set to monitor the ${ }^{137} \mathrm{Cs}$ activity. After a significant number of counts have been accumulated in the MCA, the data, along with the counting time and identification information, is stored on magnetic tape. The scaler data is printed out on a teletype, and recorded in the $\log$ book as precautionary backup to the magnetically recorded data. Fortunately, all magnetic tapes were properly recorded and read so that the less precise scaler data were not used. 


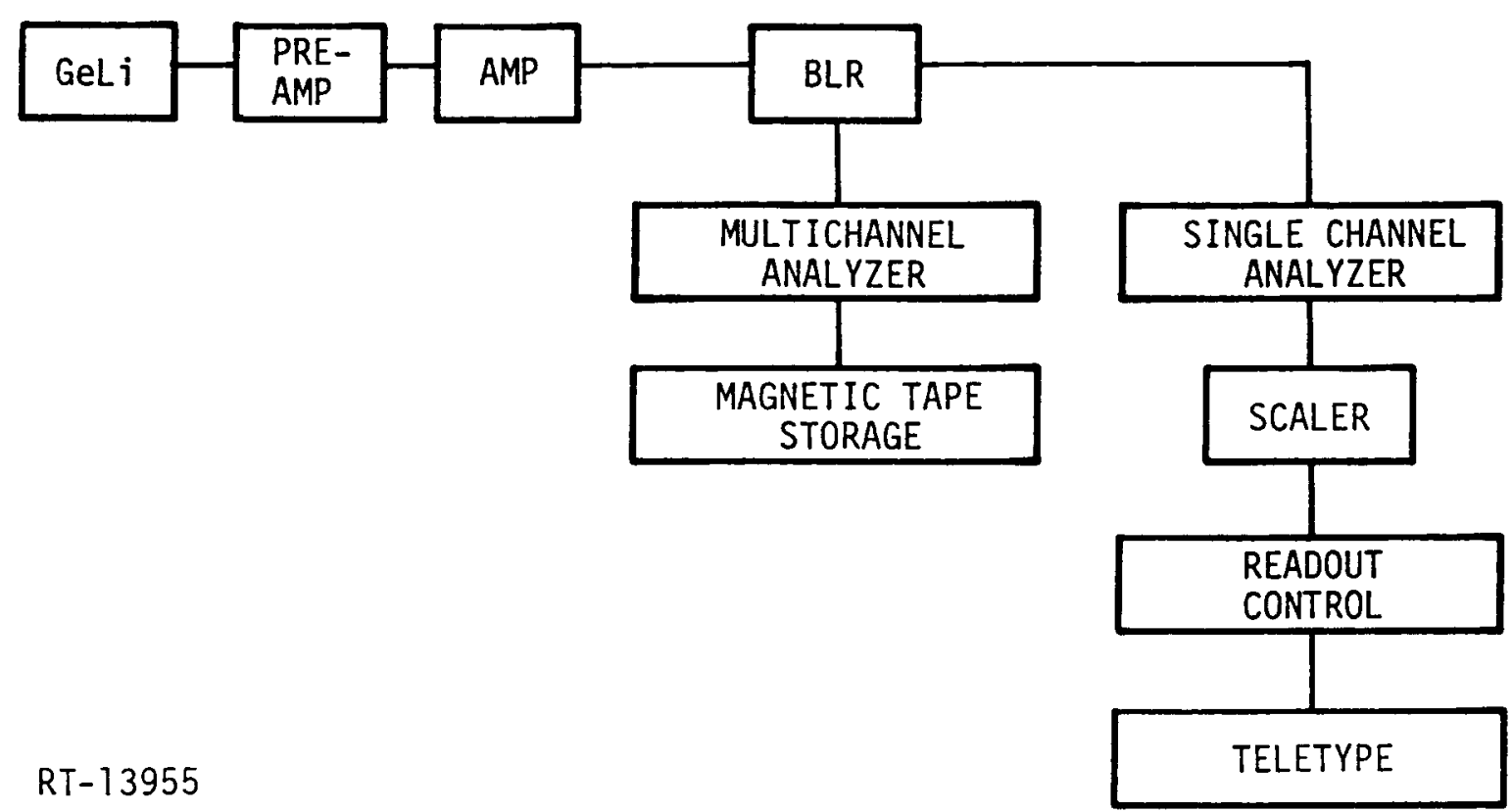

Figure 8. Signal conditioning and data storage system 


\subsection{DATA REDUCTION}

The external scan data were returned from the site in the form of magnetic tape files giving spectrum number, count time, and counts per channel for 4095 channels. The data included spectra from both on-site calibrations and duct readings. The tapes were processed using the IRT "SHERRY" code to perform peak integrals. An example of a curve drawn by the computer of the raw data is shown in Figure 9. The upper curve is with the collimator, and the lower curve is with the lead plug. Integrals of the peaks were printed in tabular form. The two peaks at low energy are lead $x$ rays produced by the interaction of the gamma rays with the lead collimator and shielding. One small peak at $1.33 \mathrm{MeV}$ is tentatively identified as ${ }^{60} \mathrm{Co}$. The $1.173 \mathrm{MeV}$ gamma ray of ${ }^{60} \mathrm{Co}$ is not evident in the spectrum. However, it may be obscured by the $1.165-\mathrm{MeV}$ gamma ray of ${ }^{134} \mathrm{Cs}$, as well as the Compton continuum from the $1.365-\mathrm{MeV}$ gamma ray of ${ }^{134} \mathrm{Cs}$. All other peaks in the spectrum are due either to ${ }^{134} \mathrm{Cs}$ or $137 \mathrm{Cs}$.

Calibration data were applied to these data to convert to plateout activity. The first step in reducing the data was to determine the count rate $C_{0}$ due to gamma rays coming through the opening in the collimator, as opposed to those coming through the shield. For a particular energy line, $C_{0}$ is given by

$$
C_{0}=\frac{C_{c}-C_{p}}{1-e^{-\mu t}} \text {, }
$$

where

$$
\begin{aligned}
C_{c}= & \text { net peak area count rate obtained with collimator; } \\
C_{p}= & \text { net peak area count rate obtained with solid plug; } \\
1-e^{-\mu t}= & \text { correction due to gamma rays passing through the } \\
& \text { solid plug of thickness } t \text { cm and attenuation coef- } \\
& \text { ficient } \mu \mathrm{cm}^{-1} .
\end{aligned}
$$




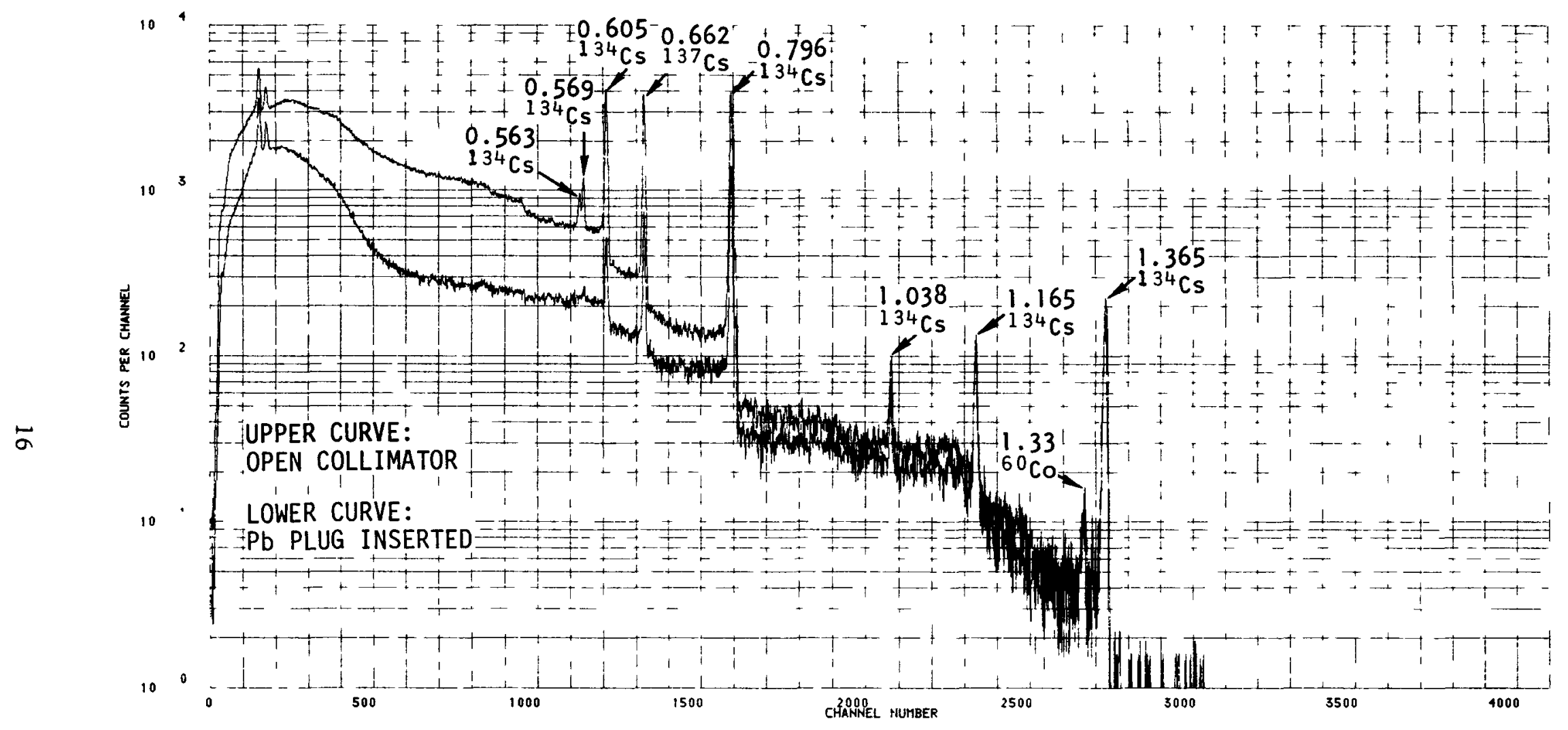

RT -13253

Figure 9. Peach Bottom external duct scan (position 1-7) 
The next step in data reduction was to relate the count rate through the collimator to plateout activities. To do this, the assumption is made that the activity is locally uniform inside the duct (assumption supported by the Phase 2 scans), and the relative importance of near-side to far-side contributions is calculated from the geometry of the setup. The angular efficiency $E(\alpha)$ of the collimated detector was obtained from calibrations. The projection angle off detector centerline onto the near and far surface of the duct defines certain spot sizes (see Figure 6). It is thus possible to perform a point kernel integration over the area seen by the detector on both surfaces. This integral takes the form:

$$
C_{n}=\int_{\alpha=0}^{\alpha} \frac{E(\alpha) d A}{R^{2}} \text { count rate } / \text { curie } / \mathrm{cm}^{2},
$$

where

$$
\begin{aligned}
C_{n} & =\text { near-side contribution (count rate) } \\
\mathrm{dA}(\alpha) & =\text { area increment; } \\
\mathrm{E}(\alpha) & =\text { angular efficiency (count rate/curie) } \\
\alpha_{1} & =\text { angle where efficiency goes to zero; and } \\
\mathrm{R} & =\text { distance from dA to detector center. }
\end{aligned}
$$

The angular efficiency as described here has built in the slant attenuation through the duct wall and insulating material. It was obtained by taking count rate/curie for a given source point on the inner surface of the duct, and then multiplying by $R^{2}$ where $R$ is the source-to-detectorcenter distance for the calibration point.

By the same equation, the contribution from the far side of the duct $\mathrm{C}_{f}$ can be obtained. The count rate due to near-side activity is then given by

$$
C=C_{o}\left(\frac{C_{n}}{C_{f}+C_{n}}\right) \text {. }
$$


The plateout activity is then given by

$$
A=\frac{C}{C_{n}} \mathrm{Ci} / \mathrm{cm}^{2}
$$

These evaluations were made for the $605-$ and $796-\mathrm{keV}$ lines of ${ }^{134} \mathrm{Cs}$, and for the $662-\mathrm{keV}$ line of ${ }^{137} \mathrm{Cs}$.

A typical result is that about $48 \%$ of the total counts after background corrections are due to activity on the near surface.

For the case of the concentric ducts between the reactor vessel and the heat exchanger, the detector "views" activity at six different surfaces. Two are the near and far inner surfaces of the outer duct. The other four are the inner and outer surfaces of the near and far sides of the inner duct (see Figure 6).

The approach used in getting the contribution due to the near surface was similar in this case, but required that an assumption be made regarding the ratio of activity per unit area in the outer annulus to that inside the inner duct. From extrapolation of measurements made elsewhere, this ratio was estimated at 0.5 . Using this ratio, point kernel integrations were performed over all applicable surfaces to arrive at the ratio of nearsurface contribution to total counts. Final values used in reducing the data are given in Table 2 .

\subsection{DATA SUMMARY}

The concentration of the two measurable isotopes of cesium measured externally are given in Table 3. These data have been corrected for radioactive decay back to reactor shutdown, October 31,1974 .

Activities are reported in both curies and the newly adopted SI unit becquerel ( 1 curie $=3.7 \times 10^{10} \mathrm{~Bq} ; 1 \mathrm{~Bq}=1 \mathrm{DPS}$ ), which is to replace both curie and DPM as a unit of radioactivity measurement. The increasing position numbers in a particular loop indicate distances further down the loop from the reactor outlet. It will be noted that the trend is generally to decreasing activity with increasing distance from the reactor outlet. 
Table 2

EXTERNAL SCAN CONVERSION CONSTANTS $\left(\mu \mathrm{Ci} / \mathrm{cm}^{2} / \mathrm{CPM}\right)$

\begin{tabular}{lcc}
\hline & ${ }^{137} \mathrm{Cs}$ & ${ }^{134} \mathrm{Cs}$ \\
\hline Outer Concentric Duct $^{\mathrm{a}}$ & $8.7 \times 10^{-4}$ & $8.0 \times 10^{-4}$ \\
Nonconcentric (or cold) Duct & $3.4 \times 10^{-4}$ & $2.9 \times 10^{-4}$ \\
\hline
\end{tabular}

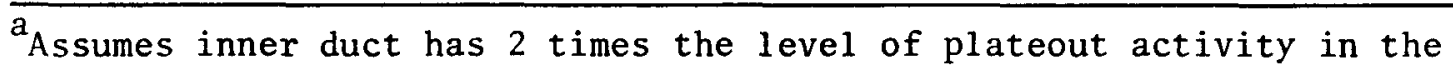
outer duct. 
Table 3

HELIUM DUCT CESIUM PLATEOUT INTENSITIES AS MEASURED EXTERNALLY

\begin{tabular}{|c|c|c|c|c|c|}
\hline \multirow[b]{2}{*}{ Position } & \multicolumn{2}{|c|}{${ }^{137} \mathrm{Cs}$} & \multicolumn{2}{|c|}{$13{ }^{4} \mathrm{Cs}$} & \multirow{2}{*}{$\frac{\text { Ratio }}{1{ }^{37} \mathrm{Cs} /{ }^{1{ }^{34}} \mathrm{Cs}}$} \\
\hline & $\mathrm{Ci} / \mathrm{cm}^{2}$ & $\mathrm{~Bq} / \mathrm{cm}^{2}$ & $\mathrm{Ci} / \mathrm{cm}^{2}$ & $\mathrm{~Bq} / \mathrm{cm}^{2}$ & \\
\hline Loop 2 & & & & & \\
\hline $2-1$ (inner) & $2.08 \times 10^{-6}$ & $7.70 \times 10^{4}$ & $2.16 \times 10^{-6}$ & $7.99 \times 10^{4}$ & 0.96 \\
\hline $2-2$ (inner) & $1.5 \times 10^{-6}$ & $5.6 \times 10^{4}$ & $1.9 \times 10^{-6}$ & $7.0 \times 10^{4}$ & 0.79 \\
\hline $2-3$ & $2.65 \times 10^{-6}$ & $9.80 \times 10^{4}$ & $3.07 \times 10^{-6}$ & $1.14 \times 10^{5}$ & 0.86 \\
\hline $2-4$ & $1.60 \times 10^{-6}$ & $5.92 \times 10^{4}$ & $2.01 \times 10^{-6}$ & $7.44 \times 10^{4}$ & 0.80 \\
\hline $2-5$ & $1.47 \times 10^{-6}$ & $5.44 \times 10^{4}$ & $1.62 \times 10^{-6}$ & $5.99 \times 10^{4}$ & 0.91 \\
\hline $2-7$ & $1.49 \times 10^{-6}$ & $5.51 \times 10^{4}$ & $1.83 \times 10^{-6}$ & $6.77 \times 10^{4}$ & 0.81 \\
\hline $2-8$ & $1.36 \times 10^{-6}$ & $5.03 \times 10^{4}$ & $1.69 \times 10^{-6}$ & $6.25 \times 10^{4}$ & 0.80 \\
\hline $2-10$ & $1.24 \times 10^{-6}$ & $4.59 \times 10^{4}$ & $1.53 \times 10^{-6}$ & $5.66 \times 10^{4}$ & 0.81 \\
\hline $2-11$ & $1.32 \times 10^{-6}$ & $4.88 \times 10^{4}$ & $1.72 \times 10^{-6}$ & $6.36 \times 10^{4}$ & 0.77 \\
\hline $2-1$ (outer) & $1.04 \times 10^{-6}$ & $3.85 \times 10^{4}$ & $1.08 \times 10^{-6}$ & $4.00 \times 10^{4}$ & 0.96 \\
\hline $2-2$ (outer) & $7.7 \times 10^{-7}$ & $2.8 \times 10^{4}$ & $9.6 \times 10^{-7}$ & $3.6 \times 10^{4}$ & 0.80 \\
\hline Loop 1 & & & & & \\
\hline 1-2 (inner) & $1.3 \times 10^{-6}$ & $4.8 \times 10^{4}$ & $1.8 \times 10^{-6}$ & $6.7 \times 10^{4}$ & 0.72 \\
\hline $1-3$ & $2.22 \times 10^{-6}$ & $8.21 \times 10^{4}$ & $2.62 \times 10^{-6}$ & $9.69 \times 10^{4}$ & 0.85 \\
\hline $1-7$ & $1.82 \times 10^{-6}$ & $6.73 \times 10^{4}$ & $2.17 \times 10^{-6}$ & $8.03 \times 10^{4}$ & 0.84 \\
\hline $1-2$ (outer) & $6.6 \times 10^{-7}$ & $2.4 \times 10^{4}$ & $8.8 \times 10^{-7}$ & $3.3 \times 10^{4}$ & 0.75 \\
\hline
\end{tabular}




\section{STEAM GENERATOR TUBE SCANS}

The fission-product plateout distribution on the tubes in the loop 1 steam generator at the Peach Bottom reactor was determined by lowering a miniaturized CdTe detector and associated preamplifier into the tubes on the water (or steam) side. A small geiger counter was also used for measurement in the economizer where low energy gamma rays tended to saturate the CdTe detector. By means of extensive calibrations of these detectors in tube arrays, it was possible to reduce the activity measurements to plateout density on the He side of the tubes.

\subsection{STEAM GENERATOR DESCRIPTION}

The Peach Bottom I steam generator, in which these measurements were made, was of the vertical $U$ tube design, as shown schematically in Figure 10. Access to the tube sheet was obtained from above after removal of the channel head and cutting away internal baffles. This exposed the watersteam side of the tubes. Scans were performed by inserting detectors into the tube to sense the fission-product plateout density on the helium side of the tubes.

The array of tubes at the tube sheet level is shown schematically in Figure 11. Those tubes with black dots were scanned in the semicircle shown. Those with an $X$ indicate that both that tube and the corresponding tube in the opposite semicircle were scanned. For purposes of accounting and reporting, a tube numbering system was adopted, as shown in Figure 12 . The makeup of individual tubes is shown in Table 4. 


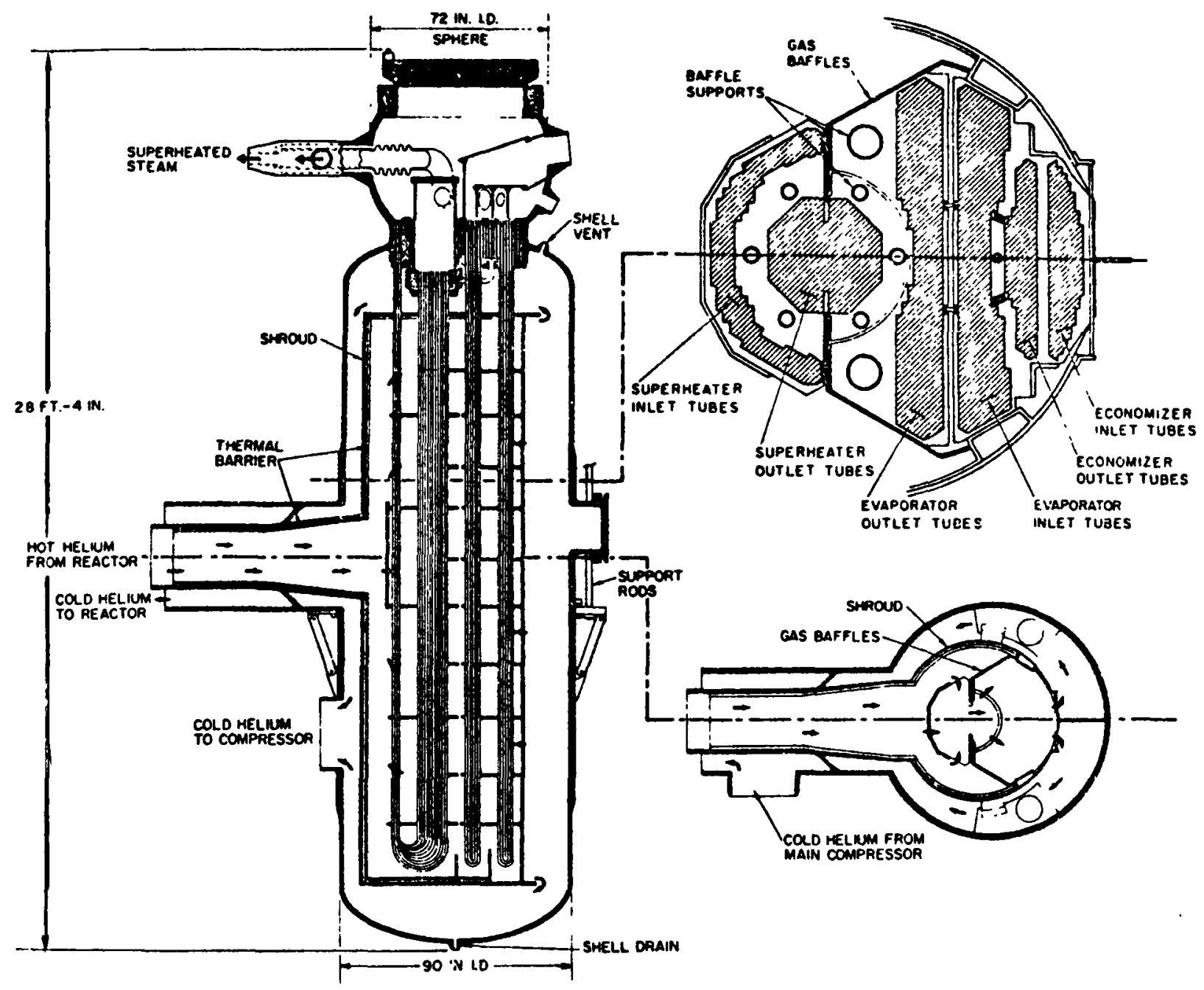

RT-13254

Figure 10. Steam generator cross section 


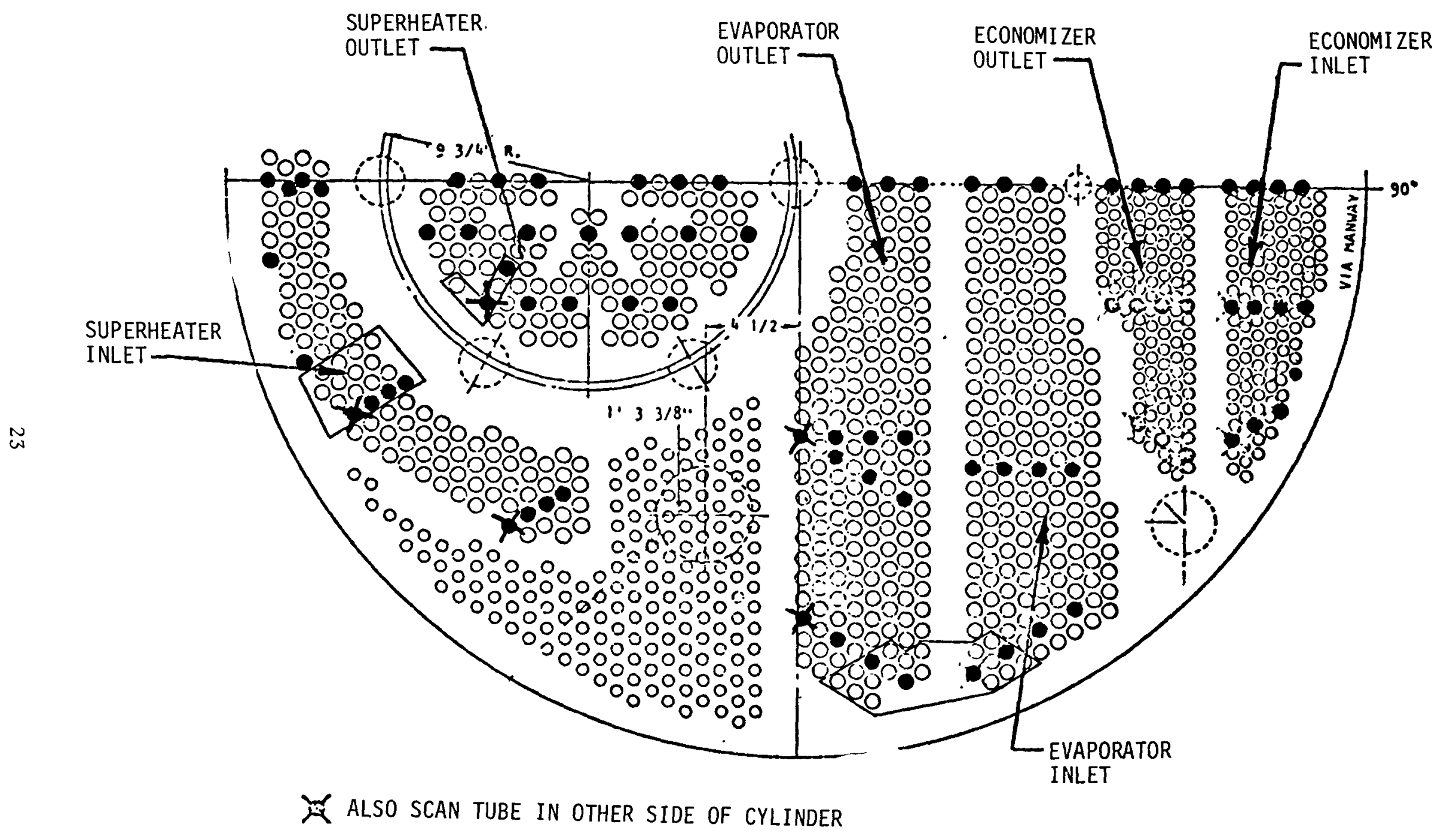

Figure 11. $\gamma$-scan of 79 tubes from water side 


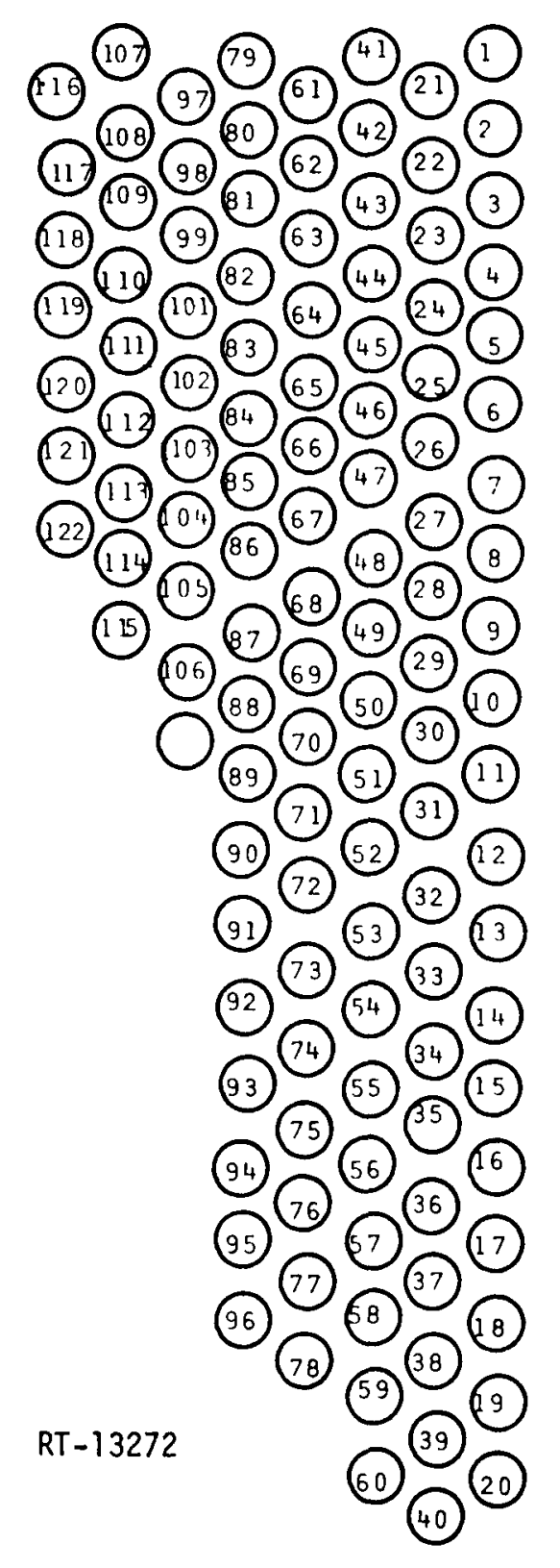

OUTLET

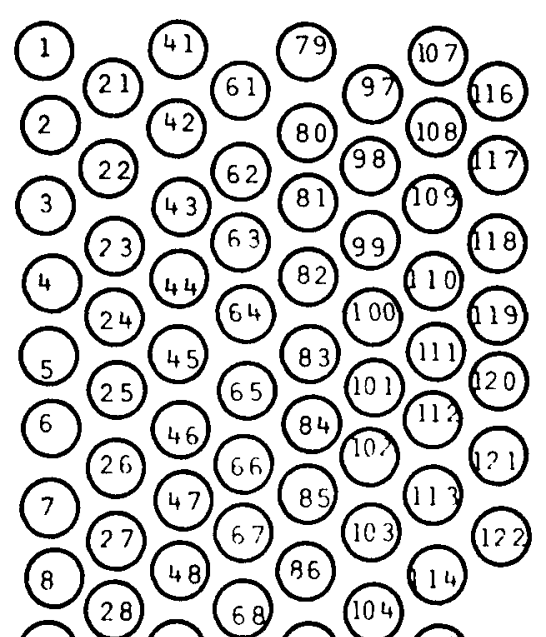

(9) (29) (49) (69) (10) (10) (10) (30) (5) (30) (10) (11) (31) (51) (72) (19) (20) (13) (33) (53) (13) (19) (29)<smiles></smiles>

INLET

Figure 12a. Tube numbering scheme for economizer section of Peach Bottom I steam generator 

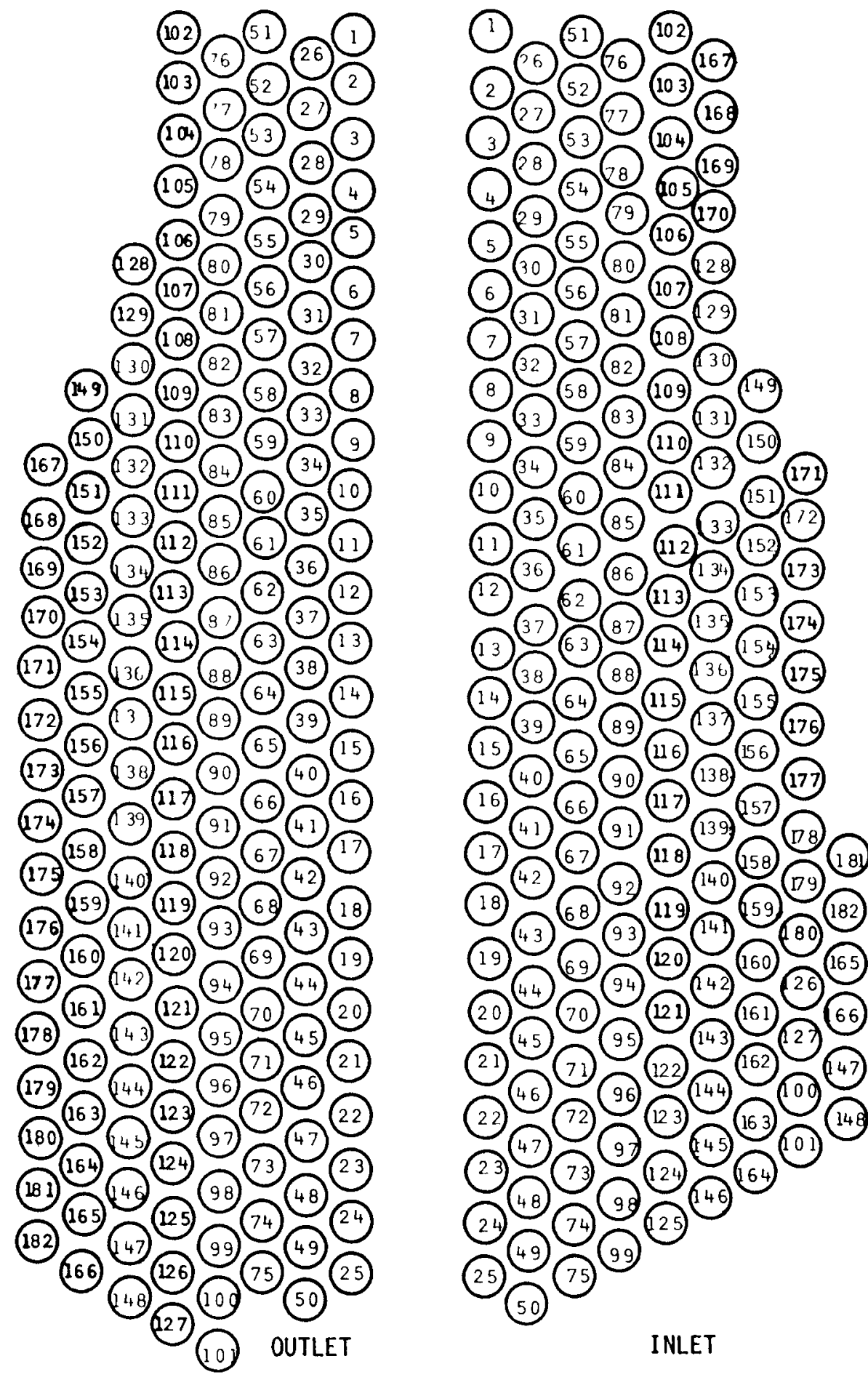

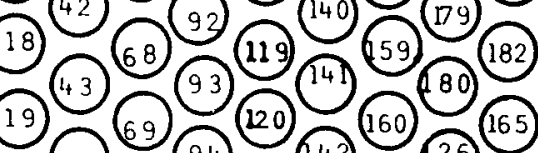

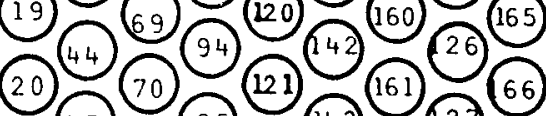

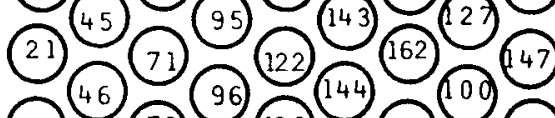

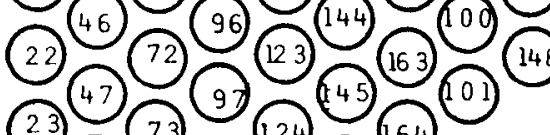

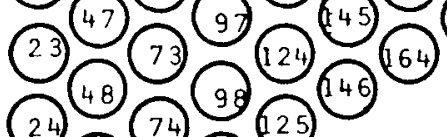

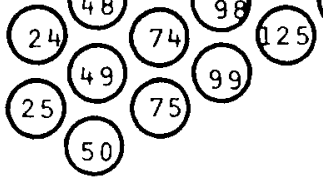

INLET

RT -13273

Figure 12b. Tube numbering scheme for evaporator section of Peach Bottom I steam generator 


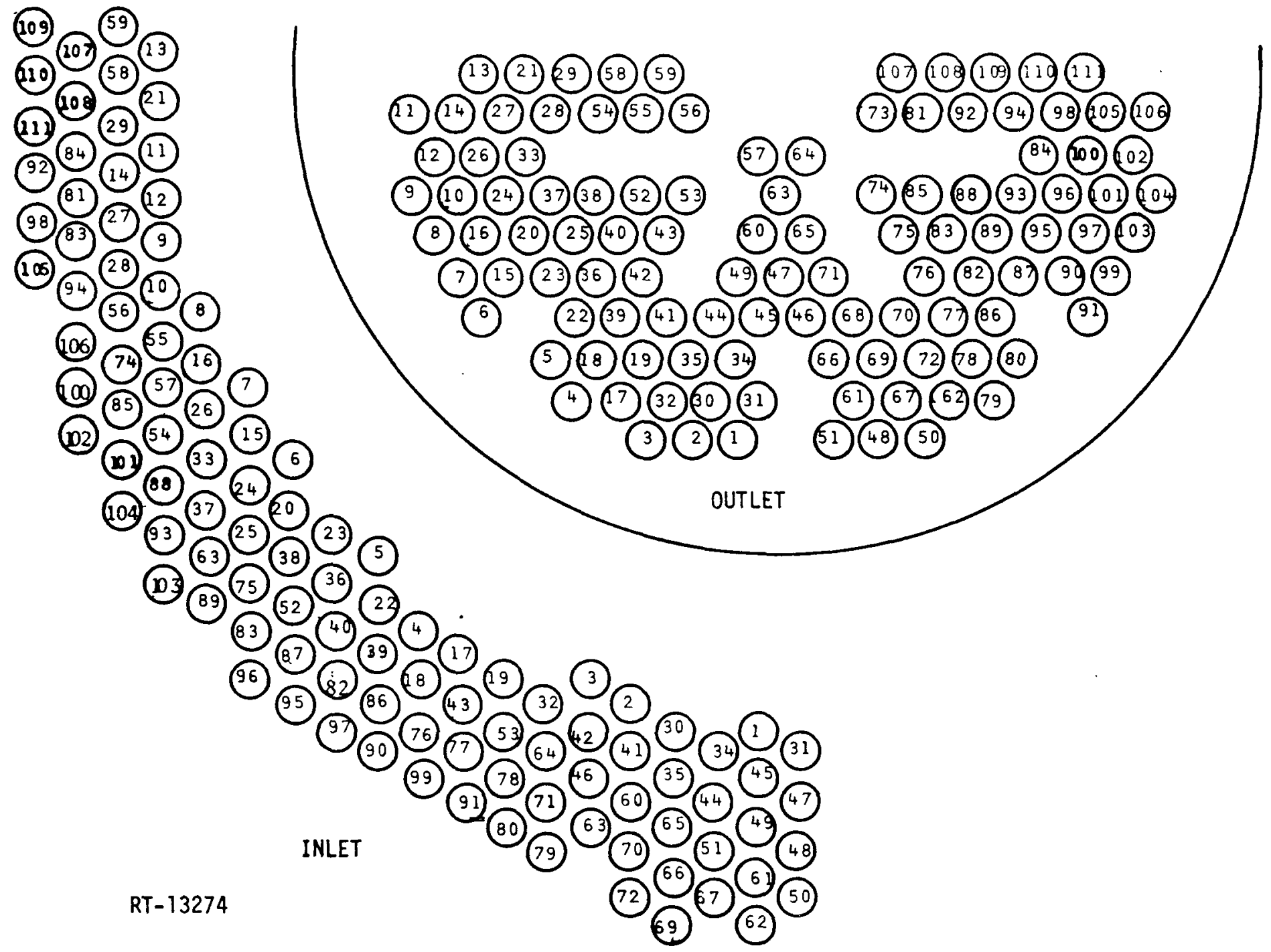

Figure 12c. Tube numbering scheme for superheater section of Peach Bottom I steam generator 
Table 4

CHARACTERISTICS OF PEACH BOTTOM STEAM GENERATOR TUBES

\begin{tabular}{lcccc}
\hline & & \multicolumn{3}{c}{ Dimensions } \\
\cline { 4 - 5 } Section & Material & $\begin{array}{c}\text { o.d. } \\
\text { (inches) }\end{array}$ & $\begin{array}{c}\text { Wall } \\
\text { (inches) }\end{array}$ & $\begin{array}{c}\text { i.d. } \\
\text { (inches) }\end{array}$ \\
\hline Superheater & Incoloy 800 & 0.750 & 0.120 & 0.510 \\
Evaporator & Carbon Steel & 0.750 & 0.078 & 0.594 \\
Economizer & Carbon Steel & 0.500 & 0.062 & 0.376 \\
\hline
\end{tabular}

\subsection{DETECTOR DESCRIPTION AND CALIBRATION}

\subsubsection{CdTe Detector Description}

A variety of detector types were evaluated to determine their potential for being miniaturized and still yielding line spectra for the cesium isotopes. Cryogenically cooled detectors were ruled out by the requirement that the detector fit inside the 0.376-inch-diameter tube and send a signal at least the $20-\mathrm{ft}$ length of the tube. There was insufficient space for storing coolant within the tube, or for flowing it past the electrical leads within the tube. Also, crystalline scintillators were ruled out because of the unavailability of miniaturized photomultiplier tubes.

The detector selected was a small CdTe semiconductor detector. Two sma11 CdTe detectors were purchased. The detectors and associated preamplifiers were packaged so that they would fit inside the smallest diameter tubes.

Some of the characteristics of the two detectors are listed below.

\begin{tabular}{cccc}
\hline Detector & Crystal Size & $\begin{array}{c}\text { Operating } \\
\text { Voltage }\end{array}$ & $\begin{array}{c}\text { Resolution for }{ }^{137 \mathrm{Cs}} \\
\text { (FWHM) }\end{array}$ \\
\hline 1 & $5.5 \times 5.5 \times 2 \mathrm{~mm}$ & 1000 & $7.0 \%$ \\
2 & $4.1 \times 4.1 \times 1.9 \mathrm{~mm}$ & 1000 & $6.5 \%$ \\
\hline
\end{tabular}


The relatively high photopeak efficiency of this detector is due in part to the high effective atomic number.

Measurements made in the laboratory using isotopic sources indicated that these detectors adequately bracketed the expected flux in the heat exchanger tubes. Examples of spectra obtained are shown in Figure 13 and 14 .

The first measurements within the heat exchanger tubes yielded spectra similar to that shown in Figure 15. Resolving the peaks from this spectrum is impossible to do without huge uncertainties. As a result of these first trials, a number of changes were made. A tantalum shield was fabricated to reduce the low-energy gamma background, the preamplifier was modified to give a faster rise time on the output pulses, and the fast-pulse analysis scheme was modified, as explained in Section 3.4. With these modifications the peaks became resolvable.

The diameter of the shielded detector was too great to be used in the economizer tubes, and the unshielded detector would not yield usable spectra. Reliance thus had to be placed on the backup GM tube detector for scanning the economizer tubes.

\subsubsection{CdTe Detector Calibration}

Extensive calibration data were required for the CdTe detectors in order to be able to reduce the counts obtained at any point in a steam generator tube to the local plateout density on the tubes. The approach to these calibrations was to determine the detector response in a given tube due to uniform plateout on the tube and all surrounding tubes.

A tube array mockup was constructed which duplicated the tube physical dimensions and relative positions for all three tube types. A photograph of the tube array is shown in Figure 16. Since it was impractical to plate these tubes with radioactive cesium, sealed foil sources with an active area of $2 \times 2 \mathrm{~cm}$ were wrapped around the tube to provide a uniform band of source $2 \mathrm{~cm}$ in height. This band could be placed at varying distances from a plane normal to the tubes centered on the detector to determine detector response for both the tube housing the detector, as well as 


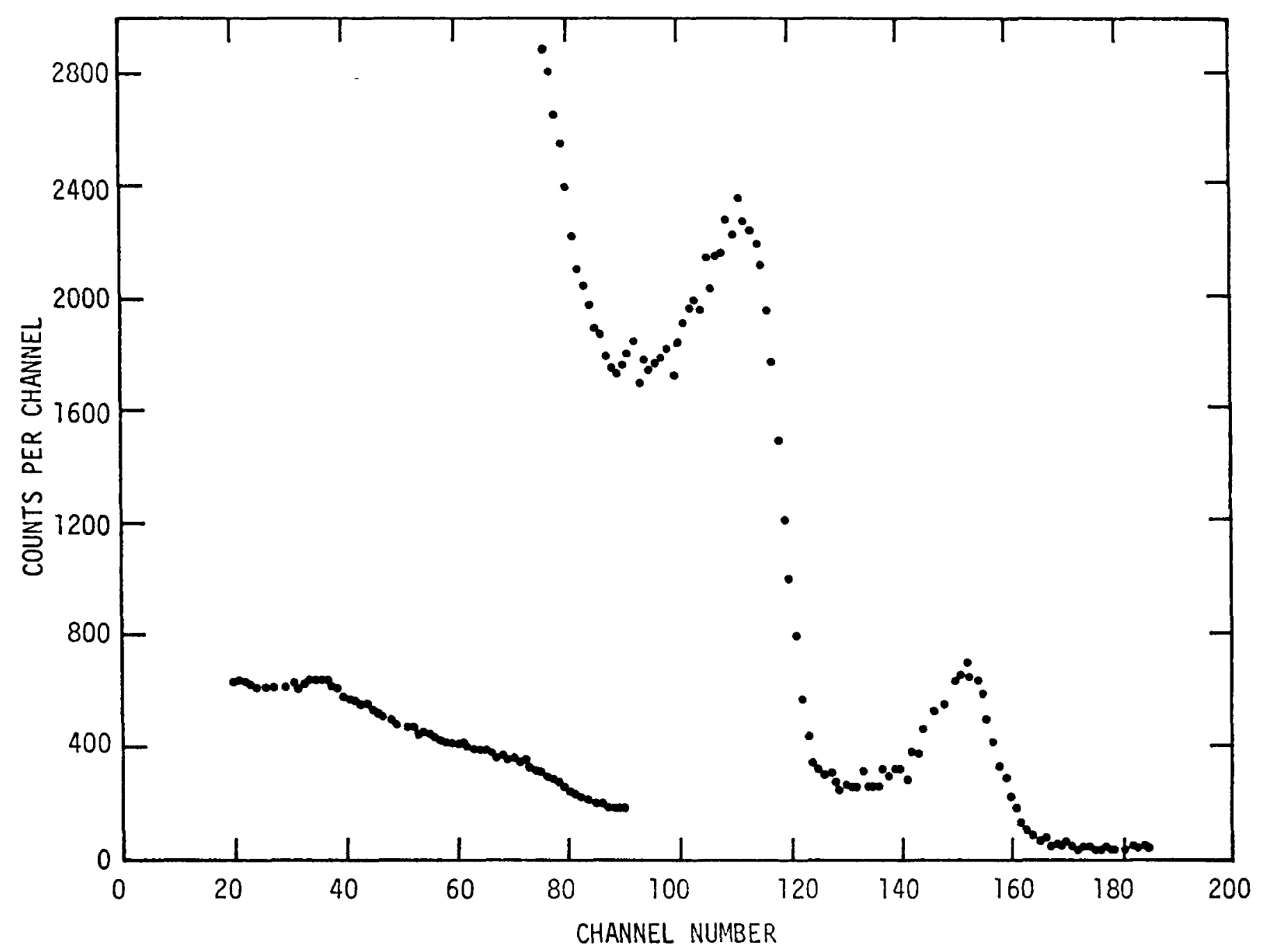

RT -13255

Figure 13. Typical ${ }^{134} \mathrm{Cs}$ spectrum with CdTe detector with Ta shield. 


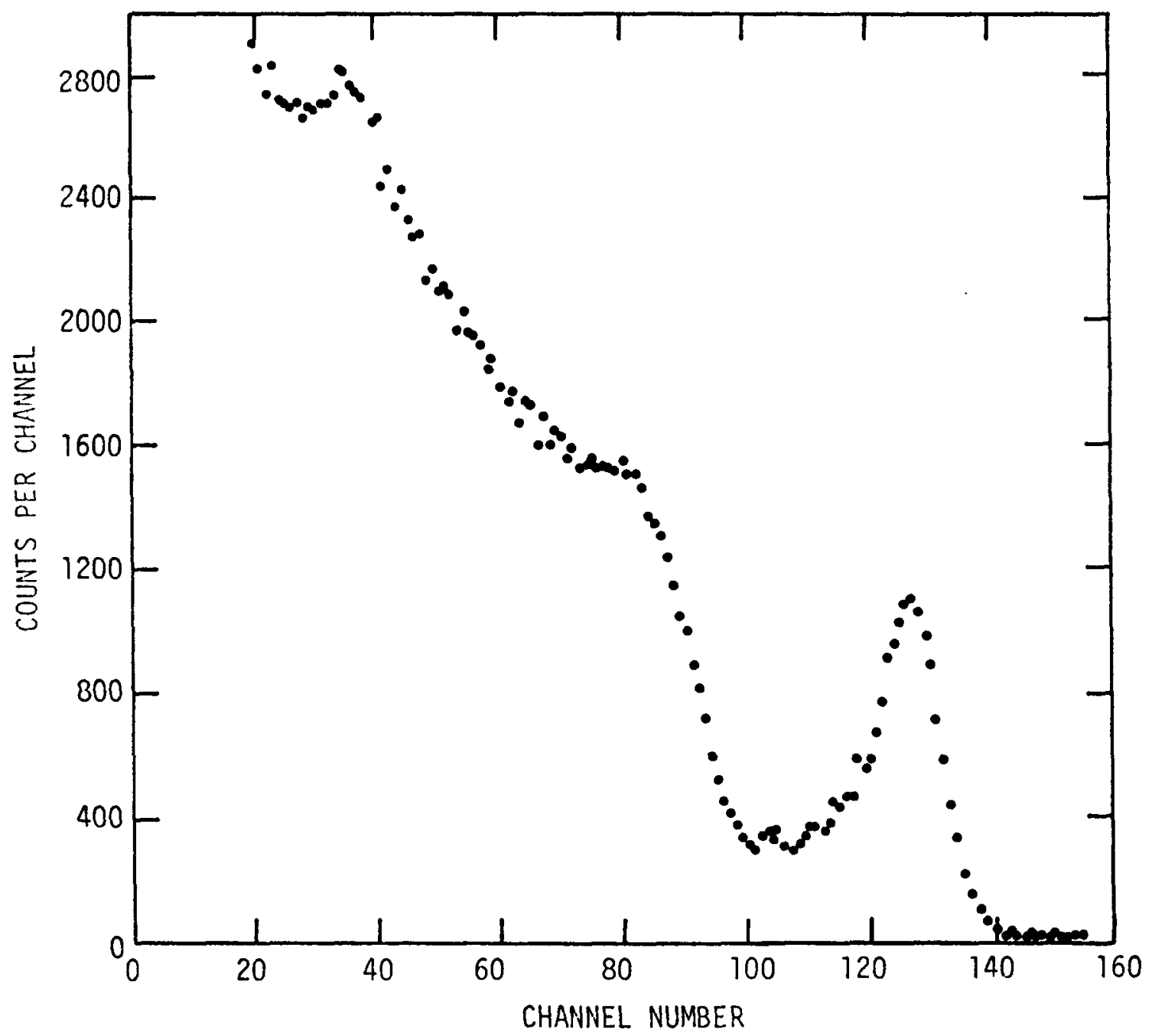

RT - 13256

Figure 14. Typical ${ }^{137} \mathrm{Cs}$ spectrum with CdTe detector with Ta shield. 


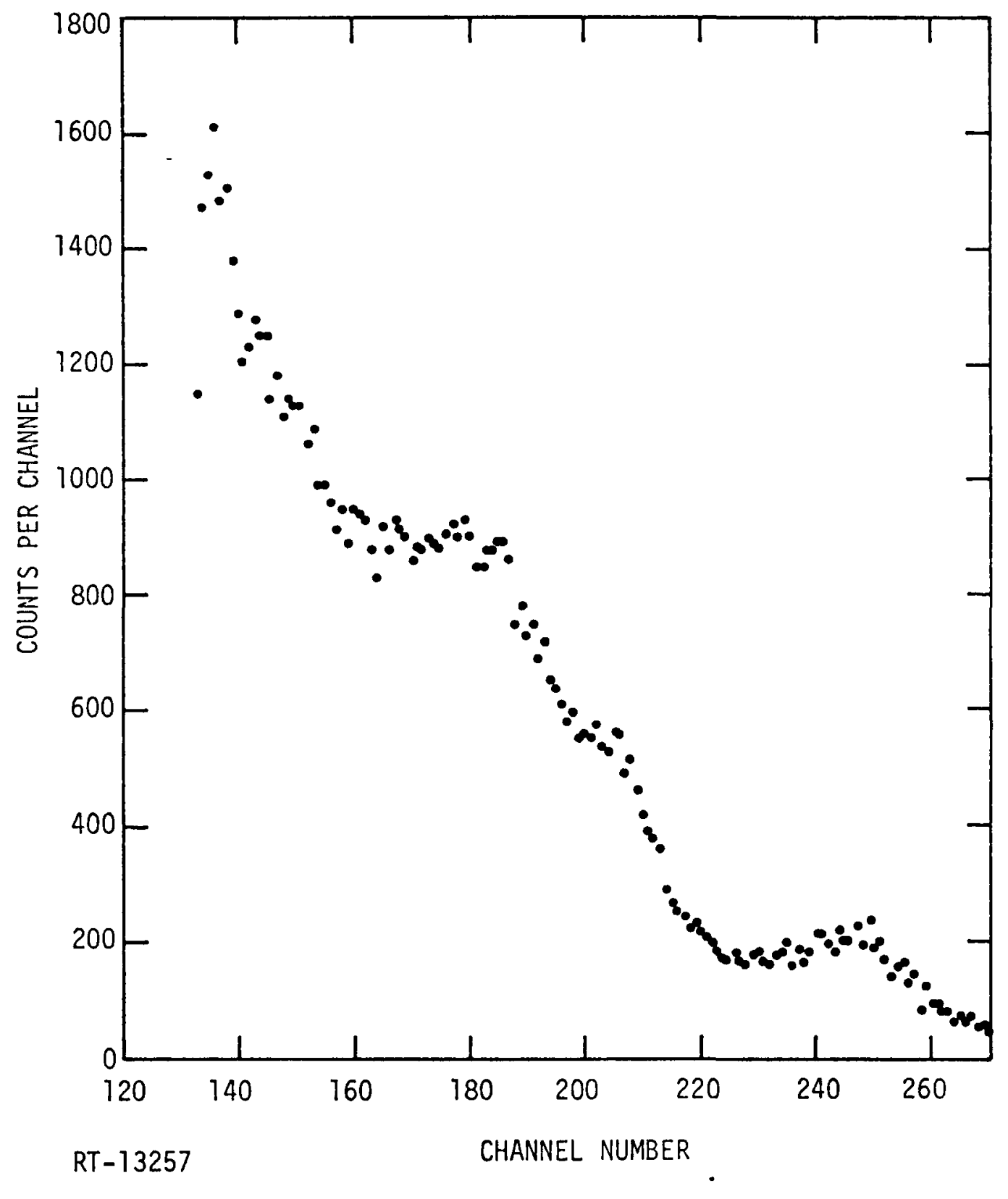

Figure 15. Early CdTe measurement of economizer tube 102 

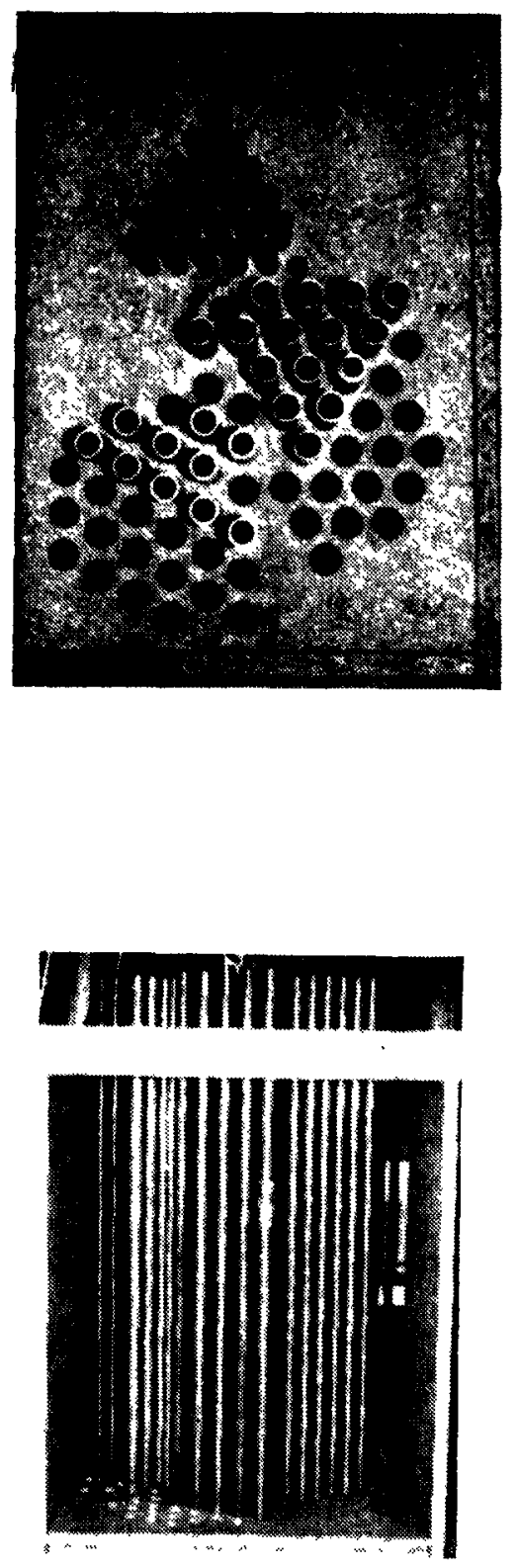

Figure 16. Steam generator mockup 
for neighboring tubes. Figure 17 defines nine classes of tubes with varying numbers of symmetrically equivalent tubes in each class. Differential detector response data as described above were obtained for one tube of each class out to distances of about $15 \mathrm{~cm}$ from the detector plane. Both separation distance and attenuation of intervening tubes made it unnecessary to go beyond the outer edge of these arrays, or beyond the $15-\mathrm{cm}$ height on individual tubes. Examples of the differential data obtained in this manner are shown in Figures 18 through 21 . These data are for the shielded detector as used in the measurements.

In arriving at a total detector response, integrals were performed over the tube length to determine

$$
R_{i}=\frac{2 \pi D}{S} \int_{0}^{\ell} \max r(\ell) d \ell,
$$

where

$$
\begin{aligned}
R_{i}= & \text { integral response for tube } i\left(\mathrm{CPM} / \mu \mathrm{Ci} / \mathrm{cm}^{2}\right) ; \\
r(\ell)= & \text { differential detector response; } \\
\mathrm{S}= & \text { total source strength of the band source used in } \\
& \text { the calibration; and } \\
\pi D= & \text { the surface area of a band around the tube of } 1-\mathrm{cm} \\
& \text { length. }
\end{aligned}
$$

The factor of 2 in the above equation accounts for the response from either side of the detector plane.

To reduce the data from a particular tube, one must determine the number of tubes of each class which influence the detector response and sum these to obtain the total detector response per unit activity plated out on the tubes. In using this approach, the assumption is made that the deposition is locally uniform on all tube surfaces. The fact that a gradient exists across the steam generator and would invalidate this calibration, so long as the gradient is constant and the array is symmetrical for the first few rows of surrounding tubes. 


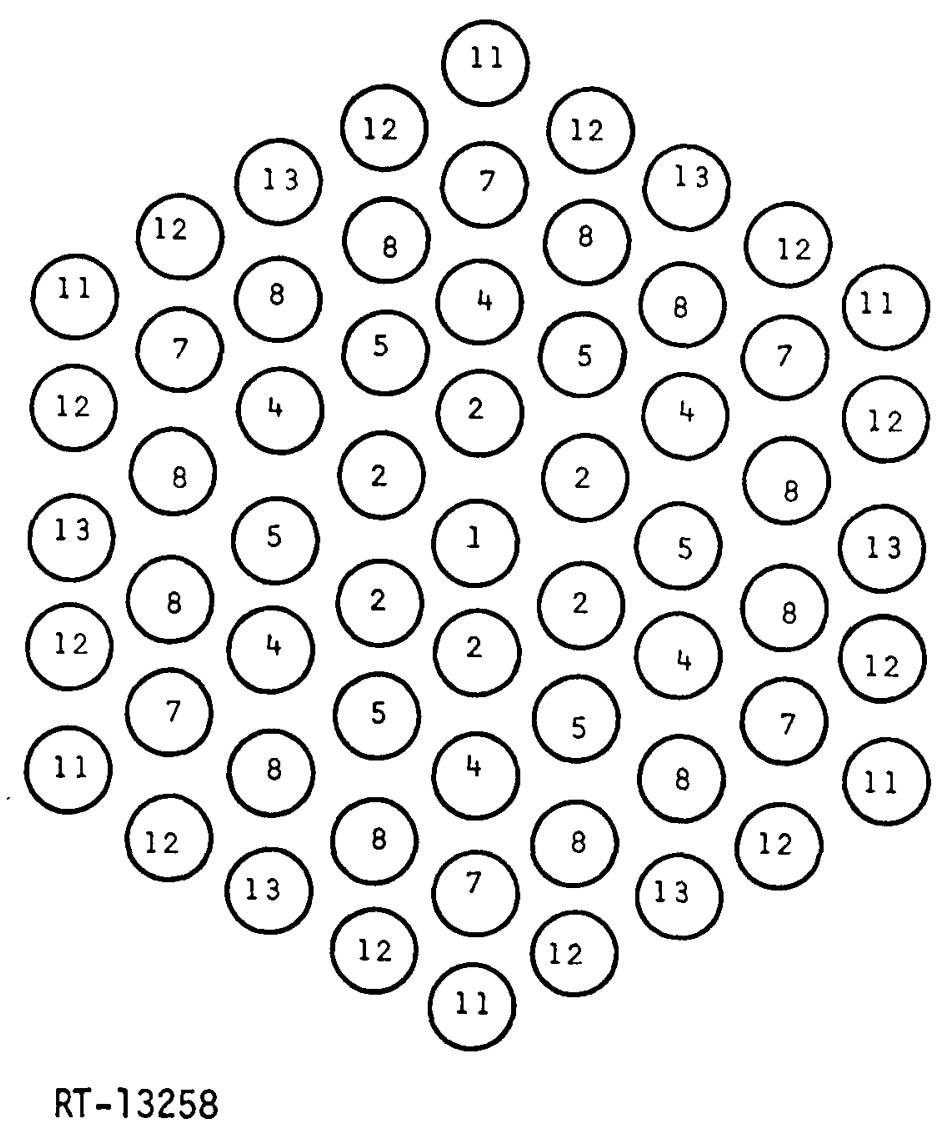

Figure 17. Location of each class of steam generator tube relative to tube being measured (tube 1). 


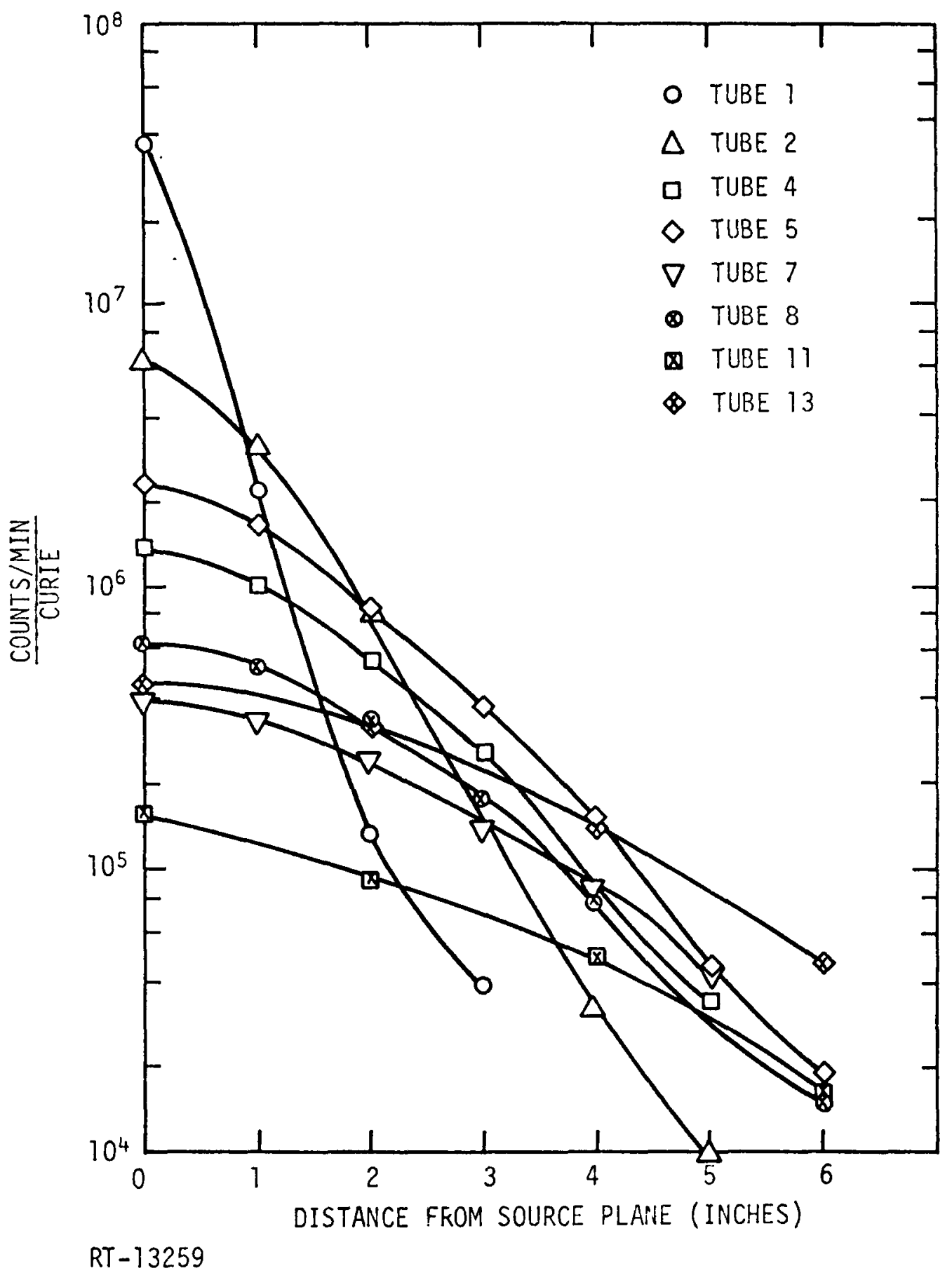

Figure 18. CdTe detector calibration for $0.796 \mathrm{MeV}$ gamma ray of $13{ }^{4} \mathrm{Cs}$ in superheater tubes. 


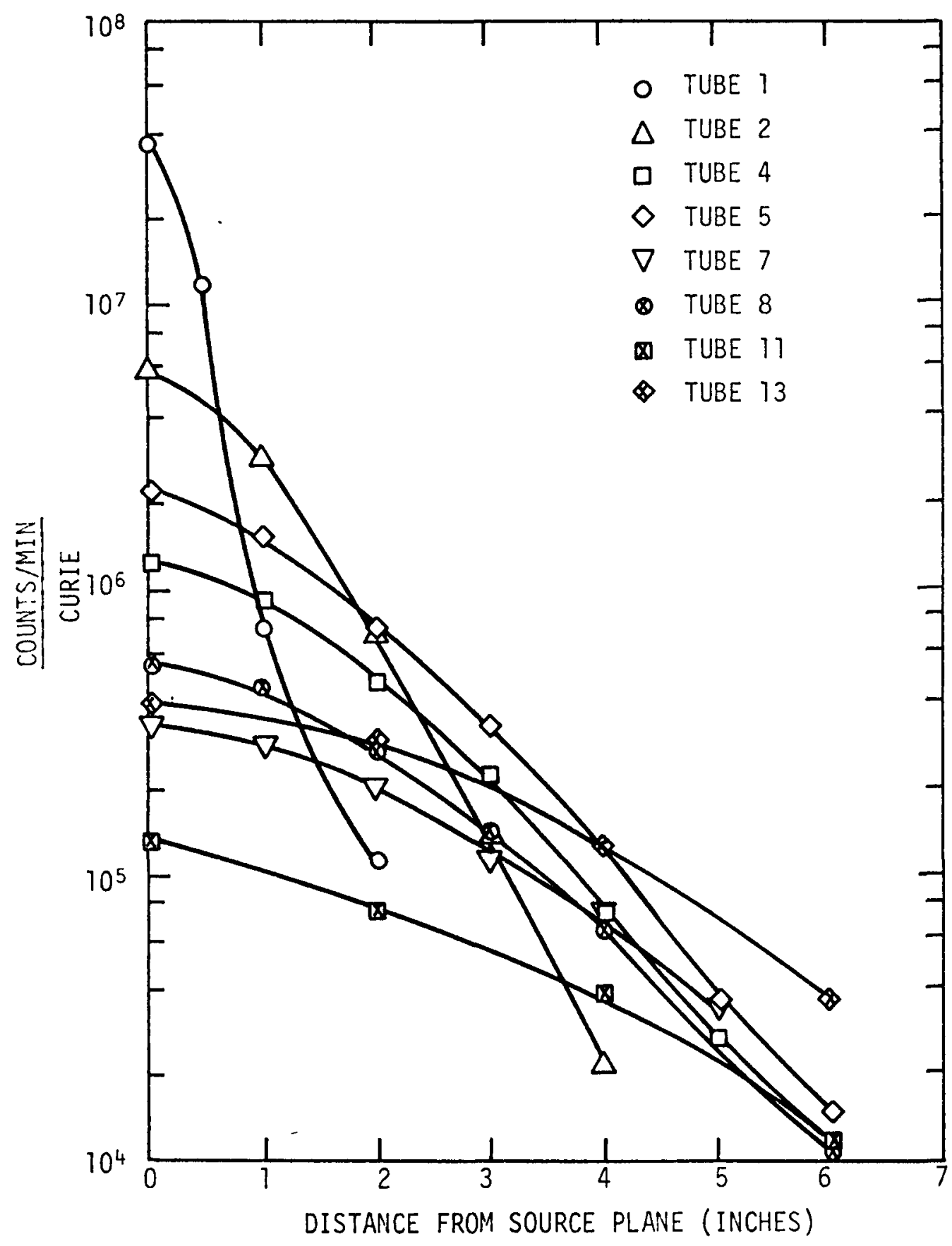

RT -13260

Figure 19. CdTe detector calibration for $0.662 \mathrm{MeV}$ gamma ray of ${ }^{13}$ ? Cs in superheater tubes. 


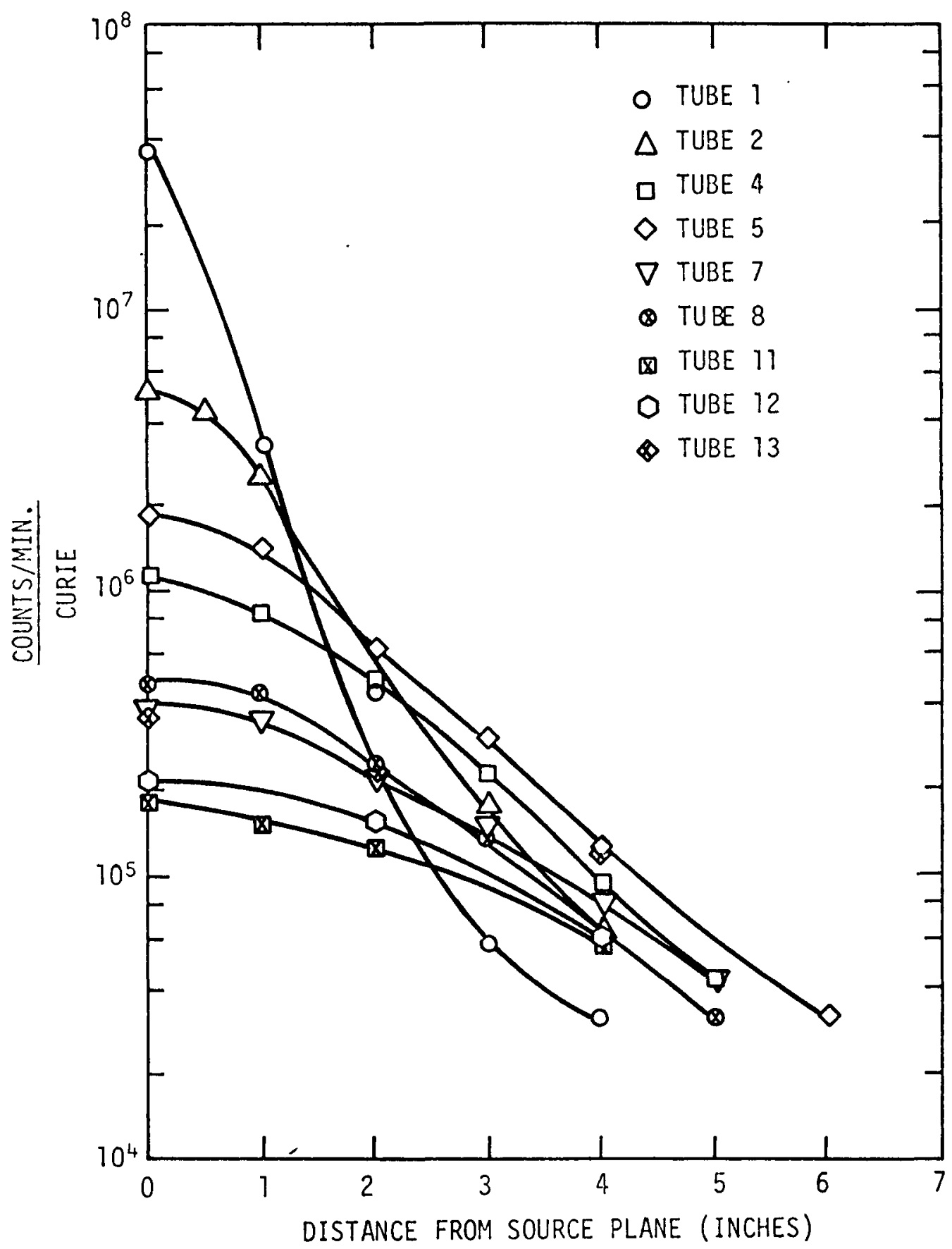

RT -13262

Figure 20. CdTe detector calibration for $0.796 \mathrm{MeV}$ gamma ray of ${ }^{134} \mathrm{Cs}$ in evaporator tubes 


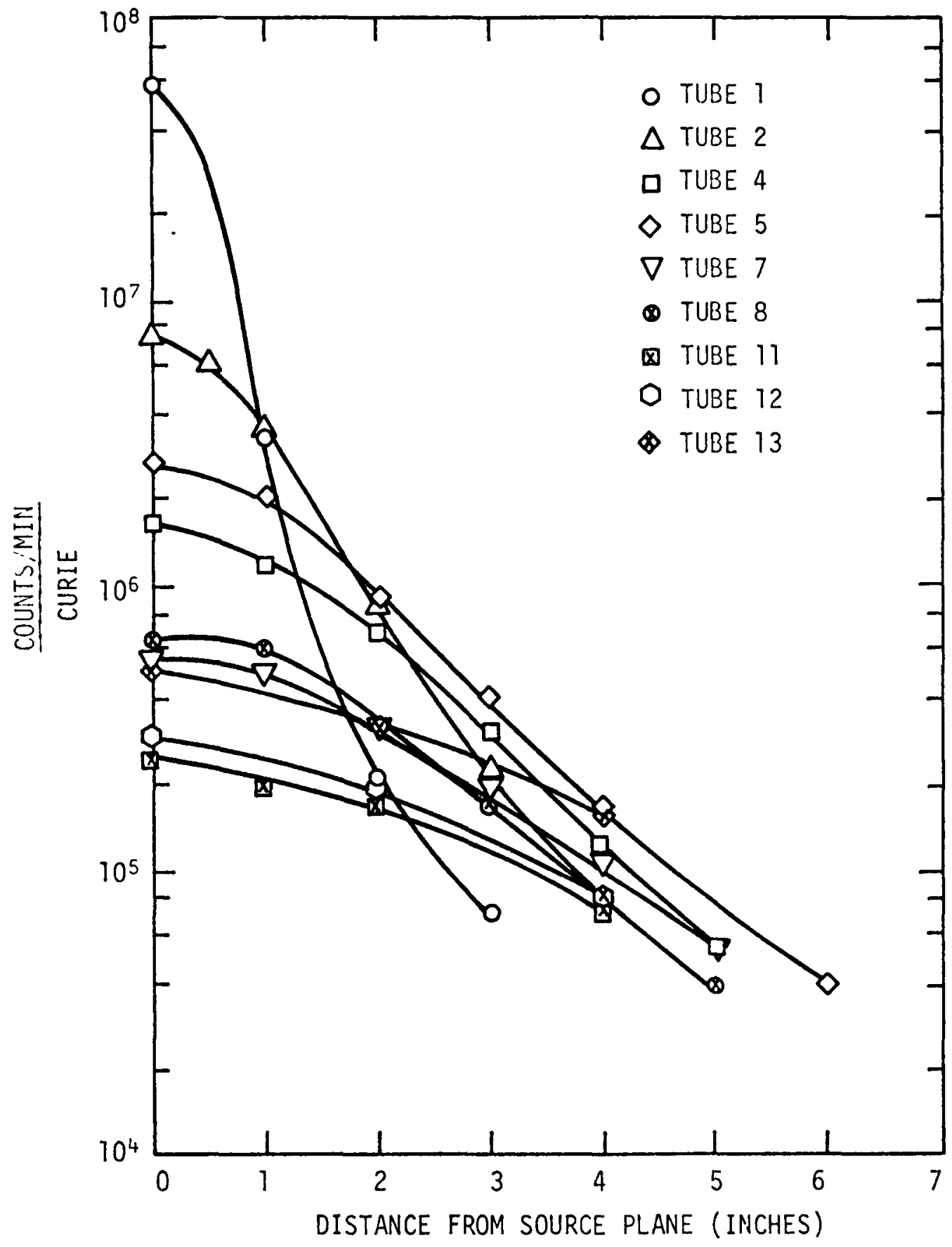

RT -13263

Figure 21. CdTe detector calibration for $0.662 \mathrm{MeV}$ gamma ray of ${ }^{137} \mathrm{Cs}$ in evaporator tubes 


\subsubsection{GM Counter Description}

The GM tube employed in this case was an LND Model 716 with dimensions of 0.2 inch o.d. by 0.75 inch long, and wall thickness of 90 mils of 446 stainless steel. Effective length was 0.125 inch, filled with neon plus halogen.

Sensitivity is indicated by the fact that it yielded 1320 CPS at $10 \mathrm{~cm}$ from a $10-\mu \mathrm{Ci}$ source.

The counting plateau for this detector occurred at 550 to 700 volts; it was operated at 550 volts.

\subsubsection{GM Tube Calibration}

The GM tube was calibrated using the same tube array mockup used in the calibrations of the CdTe detector. The ratio of the ${ }^{137} \mathrm{Cs}$ to ${ }^{134} \mathrm{Cs}$ calibration standards used approximated the ratio expected in the economizer tubes.

Since the GM tube measured total gamma-ray counts, it was impossible to resolve the isotopic contributions solely from the GM data. An independent measurement of the ${ }^{137} \mathrm{Cs}$ and ${ }^{134} \mathrm{Cs}$ activities was necessary. Evaporator tube 102 outlet was counted using both the GM tube and an unshielded $\mathrm{CdTe}$ detector. The ratio of ${ }^{137} \mathrm{Cs}$ to ${ }^{134} \mathrm{Cs}$ was determined from the CdTe data. It was assumed that this ratio was constant for all economizer tubes. The plateout activity of these isotopes on the other tubes is then proportional to the GM counts obtained. The data reduction factors were $2.727 \times 10^{-5} \mu \mathrm{Ci}{ }^{137} \mathrm{Cs} / \mathrm{cm}^{2} / \mathrm{CPM}$ and $2.674 \times 10^{-5} \mu \mathrm{Ci}{ }^{134} \mathrm{Cs} / \mathrm{cm}^{2} / \mathrm{CPM}$, where the CPM values are the gross GM tube count rates.

\subsection{DETECTOR POSITIONING}

The power supply and signal leads to the CdTe detector and preamp were used to properly position the detector in the tubes. For each series of measurements, the detector was lowered to a depth of $18 \mathrm{ft}$ into the tube, as indicated by a marker on the cable bundle. The cable was then placed in a cable drive/measurement apparatus, which stepped the detector in 6-inch increments between measurement points. 
A sketch of the apparatus is shown in Figure 22. It was placed so as to span the opening above the steam generator. The sliding adjustments allowed positioning of the take-up pulley over the tube being measured. The take-up pulley has attached to it a cam which interrupts the drive motor at the end of six inches of travel. A spectrum is obtained, and the drive motor is again actuated by the operator. The line is marked at various lengths as a check against the accuracy of the positioner.

This same technique was employed with the GM tube measurements.

\subsection{ELECTRONICS AND DATA RECORDING}

The high background of low-energy gamma rays encountered in the steam generator prompted the adoption of special signal-processing techniques, as well as detector shielding. The fast-pulse analysis scheme shown in Figure 23 was used to provide time-of-rise selection and pulse pileup rejection. In this arrangement, pulses are delayed enroute to the analyzer until they can be analyzed to determine their acceptability. If they are found acceptable, a time window is generated to allow their acceptance by the analyzer. The criteria for acceptability is that the pulses begin from a quiet baseline and have a rapid rise. In this manner, pulses are rejected (a) if they begin from other than a quiet background, or (b) if their pulse rise time exceeds the acceptable limit. Within the detector crystal the hole mobility is much slower than the electron mobility. Consequently, events occurring near the negative pole are faster, cleaner pulses and provide better spectral resolution than those occurring in regions where the hole mobility dominates the pulse width. By accepting only the fastrise-time pulses, better spectral definition is obtained.

The GM tube electronic setup was as sketched below.

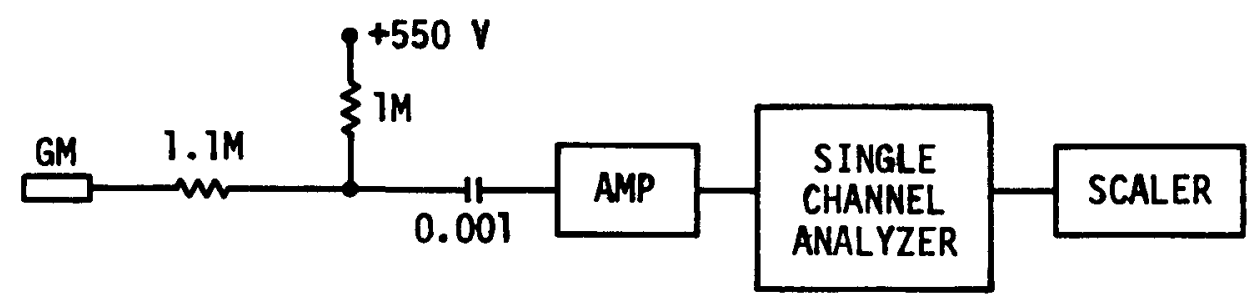



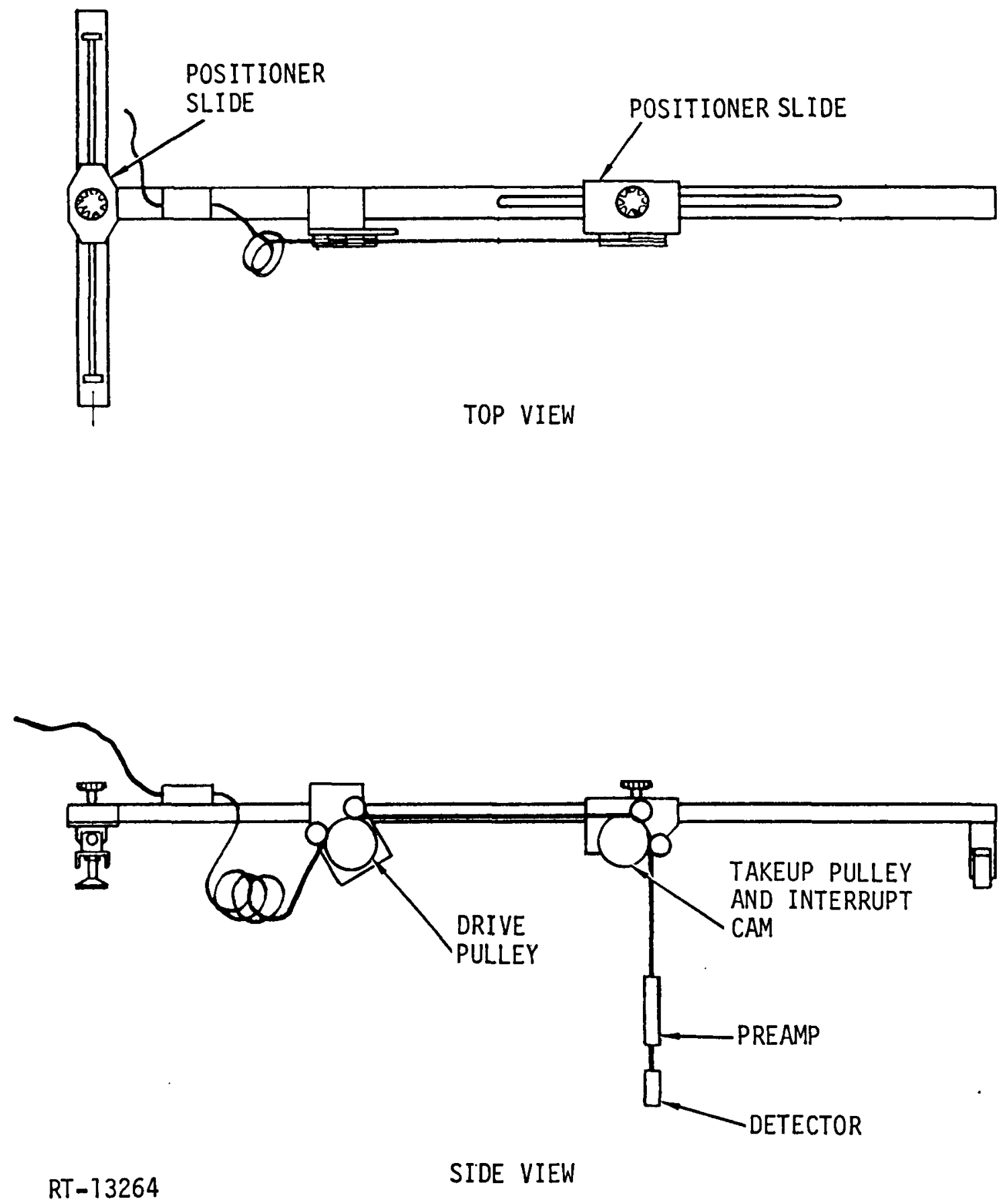

Figure 22. CdTe detector positioning apparatus 


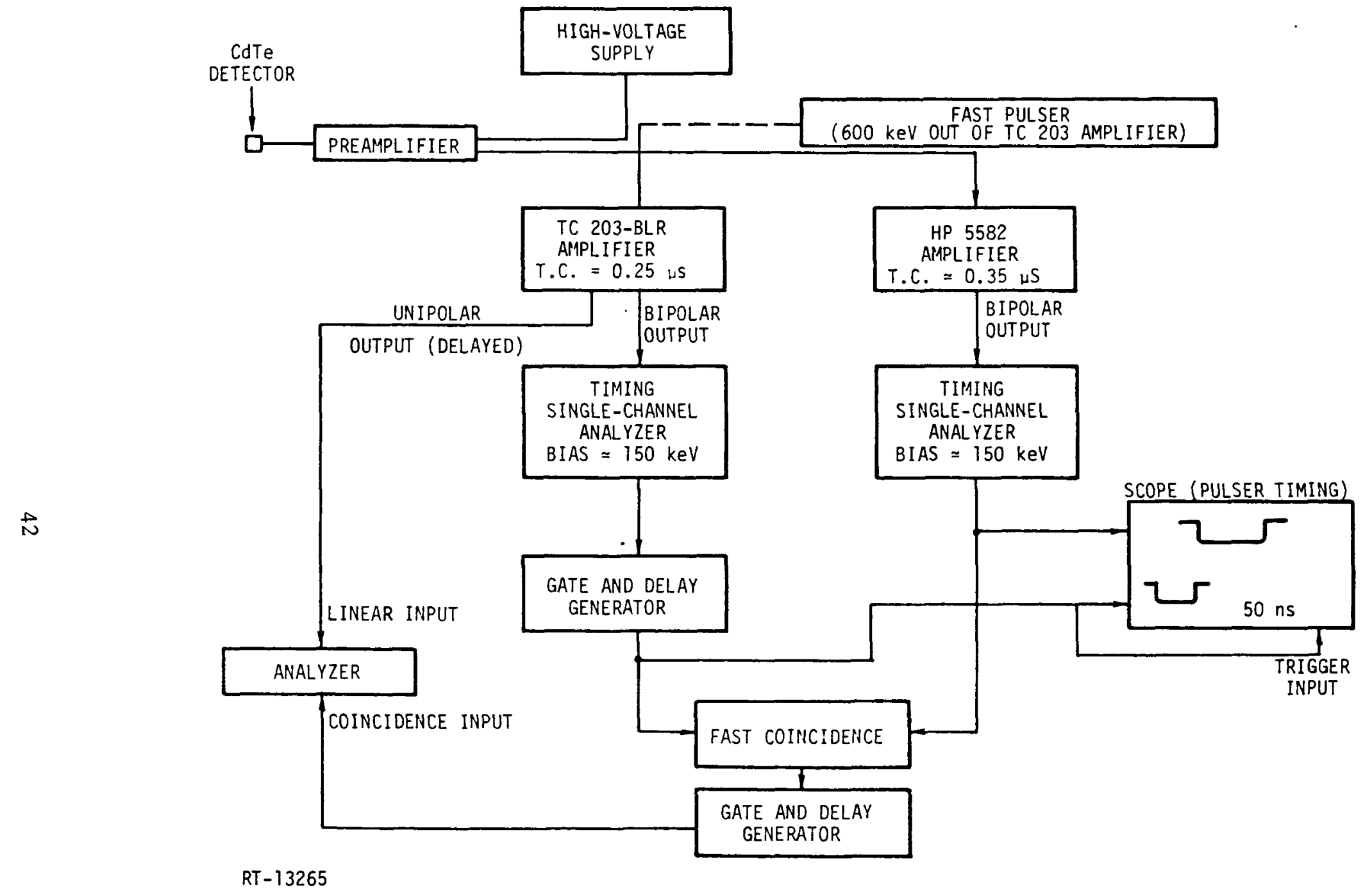

Figure 23. Equipment configuration for steam generator scans 
The pulses were amplified, shaped by a single-channel analyzer, and accumulated in a scaler. Data recording was by manual logging.

\subsection{REDUCTION OF STEAM GENERATOR GAMMA SCAN DATA}

The spectra obtained with the CdTe detector presented some unique data reduction problems. The small size of the detector resulted in a low-peakto-Compton ratio. This, plus the scattering from the large number of closely packed steel tubes, gave a spectrum dominated by a low-energy continuum. Typical spectra taken with an unshielded and a tantalum shielded detector are shown in Figures 24 and 25 , respectively.

Cesium-134 has two prominent gamma rays at 0.605 and $0.796 \mathrm{MeV}$. The $0.605-\mathrm{MeV}$ photopeak is the larger of the two in the spectrum. This is partly due to the better detector efficiency at the lower energy, but also because the peak is on top of the Compton edge from the 0.796-MeV gamma ray. As a result, the peak is very poorly shaped, and it would be very difficult to define the background. In addition, this peak is not resolved from the $0.662-\mathrm{MeV}$ photopeak of ${ }^{137} \mathrm{Cs}$, which is also present in the spectrum. Therefore, it would be extremely difficult, if not impossible, to determine an accurate peak area for the $0.605-\mathrm{MeV}$ peak. By contrast, the $0.796-\mathrm{MeV}$ photopeak of ${ }^{134} \mathrm{Cs}$, although smaller, is free from interference and is easily integrated. This gamma ray was used to calculate the ${ }^{134} \mathrm{Cs}$ activity.

Cesium-137 has only one gamma ray at $0.662 \mathrm{MeV}$. This photopeak is not resolved from the $0.605-\mathrm{MeV}$ peak of ${ }^{134} \mathrm{Cs}$, but appears as a bulge on the high-energy side of the peak. To calculate the ${ }^{137} \mathrm{Cs}$ activity, this interference from ${ }^{134} \mathrm{Cs}$ must be removed. Because of the large number of spectra involved, and the need to maintain good amplifier gain stability, manual spectrum stripping was not a practical method to remove the interference. Several computer fitting schemes were tried to resolve these peaks, but none were successful. The method which was used as an extension of a method described by Lukens (Ref. 9). Figure 26 shows the ${ }^{137} \mathrm{Cs}$ photopeak superimposed onto the equivalent portion of the ${ }^{134} \mathrm{Cs}$ spectrum. As can be seen in the figure, the right, or high-energy side, of the $0.662-\mathrm{MeV}{ }^{137} \mathrm{Cs}$ peak overlaps a flat portion of the ${ }^{134} \mathrm{Cs}$ spectrum. As a result, the net 


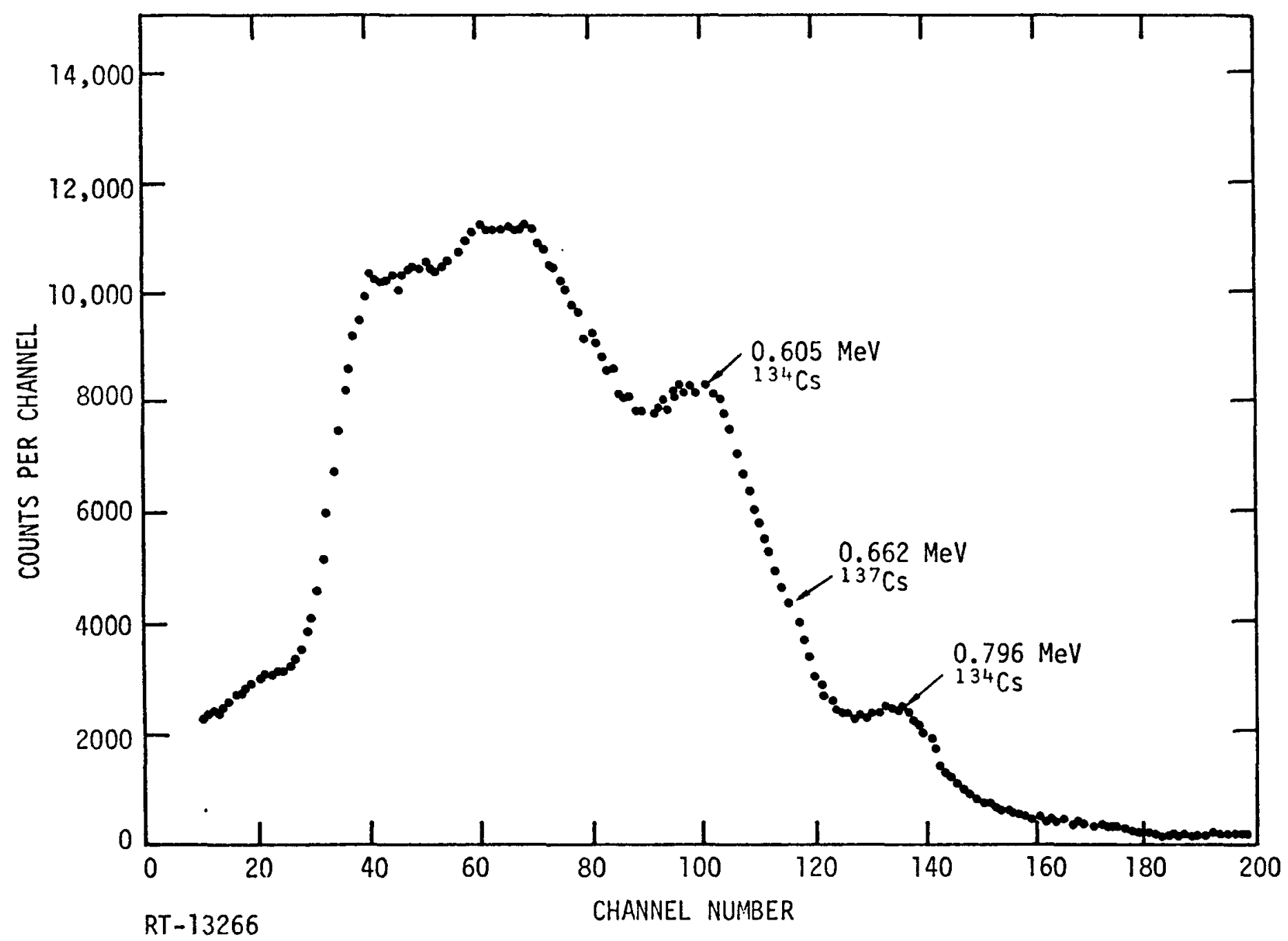

Figure 24. Typical spectrum of a steam generator tube taken with an unshielded CdTe detector 


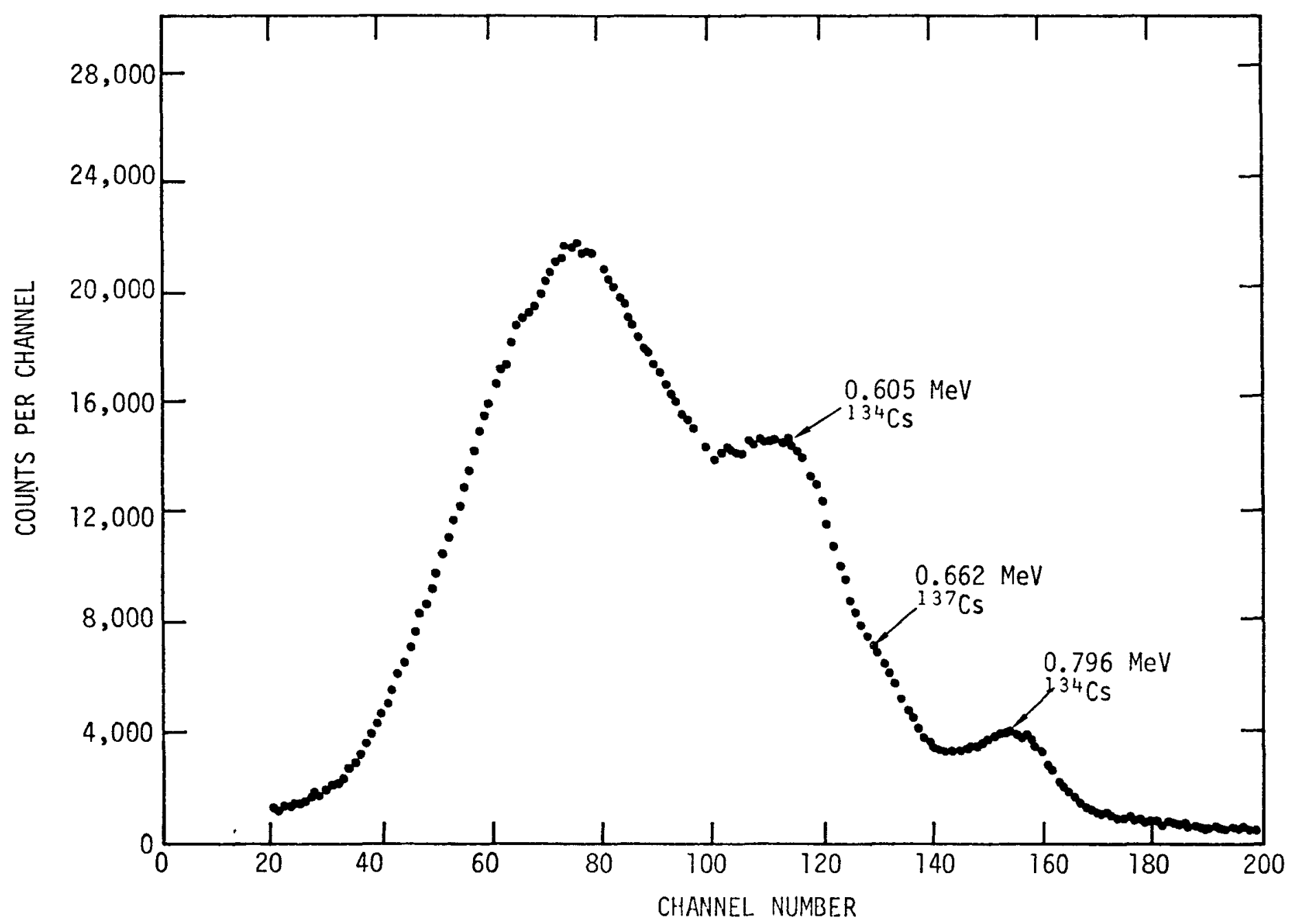

RT $\cdot 13267$

Figure 25. Typical spectrum of a steam generator tube taken with a shie1ded CdTe detector 


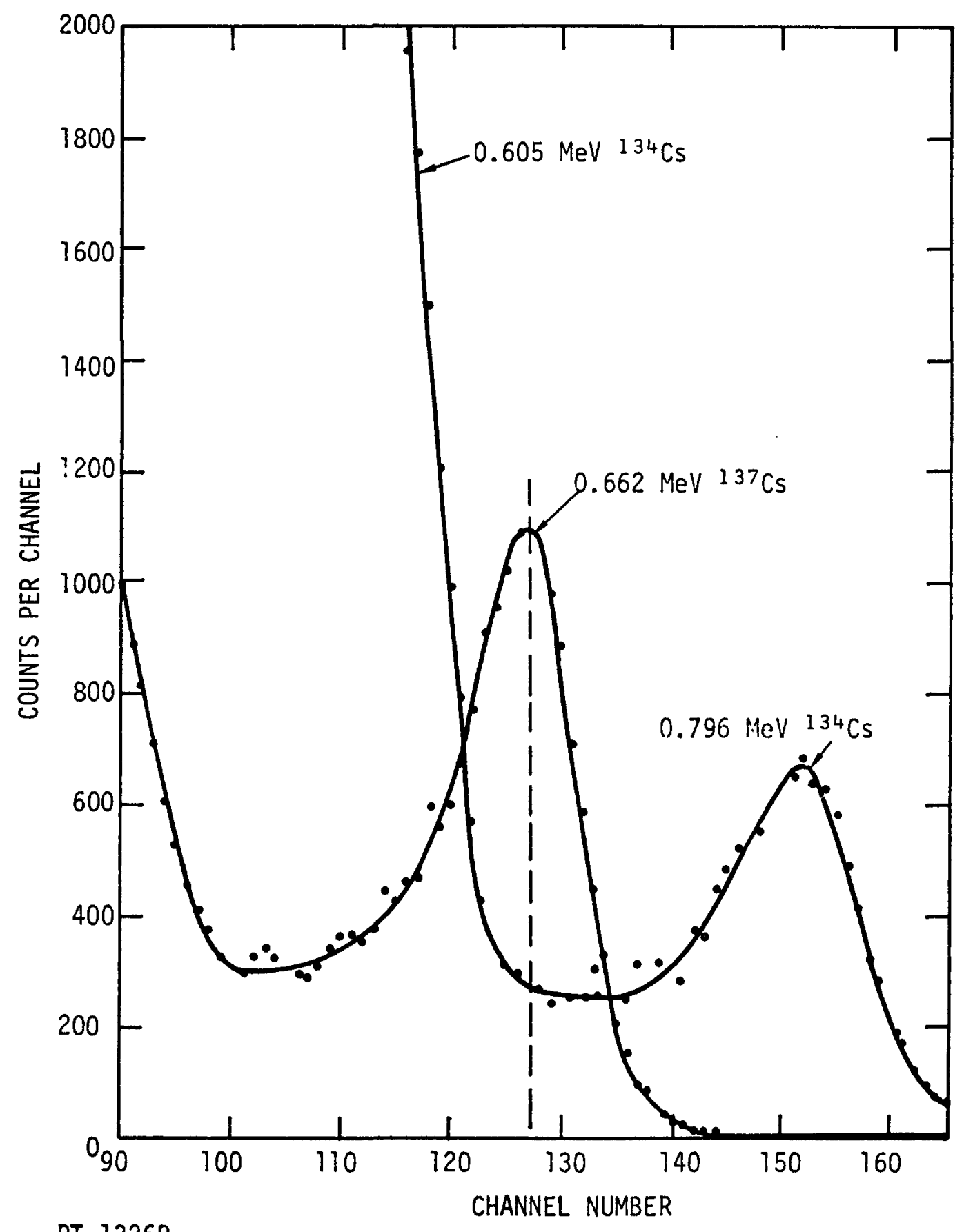

RT -13268

Figure 26. Superimposed spectra of ${ }^{134} \mathrm{Cs}$ and ${ }^{137} \mathrm{Cs}$ taken with a shielded CdTe detector 
area of the high-energy side of the ${ }^{137} \mathrm{Cs}$ peak in a composite spectrum is independent of the amount of ${ }^{134} \mathrm{Cs}$ present. To determine the ${ }^{137} \mathrm{Cs}$ peak area, it is only necessary to define the location of the peak maximum and the peak boundary on the high-energy side. The background is then defined by a zero slope line extrapolated from the peak boundary to the maximum.

The exact location of the ${ }^{137} \mathrm{Cs}$ peak is not easily determined directly from the composite spectrum. The peak location was therefore determined from the several ${ }^{137} \mathrm{Cs}$ energy calibration checks which were made. The calibration spectra were processed with the "RYE" computer code. RYE smooths the data, locates the peaks, makes a least-squares fit to calculate the exact peak channel (which may lie between integral channels), and determines the peak boundaries. The ${ }^{137} \mathrm{Cs}$ peak location in any set of steam generator spectra was the average of the peak channel for the two ${ }^{137} \mathrm{Cs}$ calibration spectra which bracket the spectra.

All of the steam generator spectra were also processed with RYE to determine the peak boundaries of the $0.796-\mathrm{MeV}$ peak of ${ }^{134} \mathrm{Cs}$, as well as the high-energy boundary of the $0.662-\mathrm{MeV}$ peak of ${ }^{137} \mathrm{Cs}$. Because the two $\mathrm{Cs}$ peaks are not resolved, the high-energy boundary calculated for the $0.605-$

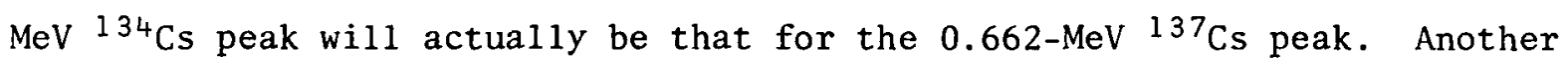
code, "PEACH", was written to use the peak location data to integrate the $0.796-\mathrm{MeV}$ peak of ${ }^{134} \mathrm{Cs}$ and the high-energy side of the $0.662-\mathrm{MeV}{ }^{137} \mathrm{Cs}$ peak. The high-energy side of the ${ }^{137} \mathrm{Cs}$ peak in the calibration spectra was also calculated using this code and the ratio of the partial peak area to the total area was determined. The data from the calibrations described in Section 3.2.2 are based on the total peak area of the ${ }^{137} \mathrm{Cs}$ peak. These data were used to calculate $\mathrm{Ci} / \mathrm{cm}^{2}$ for the two isotopes. The standard deviation based on counting statistics only is also calculated. No estimate is made of systematic errors which may contribute to overall uncertainty.

Most of the steam generator tubes have a unique environment, resulting in a constant to convert counts per minute to $\mu \mathrm{Ci} / \mathrm{cm}^{2}$, which is specific for each tube. These constants, calculated from the calibration data, are given for each tube in Table 5. Included in each is a correction for radioactive decay from October $31,1974$. 
Table 5

CONVERSION CONSTANTS FOR CDTE STEAM GENERATOR DATA

\begin{tabular}{|c|c|c|}
\hline Tube & $\begin{array}{c}{ }^{134} \mathrm{Cs} \\
\times 10^{-10} \frac{\mathrm{Ci} / \mathrm{cm}^{2}}{\mathrm{CPM}} \\
\end{array}$ & $\begin{array}{l}{ }^{137} \mathrm{Cs} \\
\times 10^{-10} \frac{\mathrm{Ci} / \mathrm{cm}^{2}}{\mathrm{CPM}} \\
\end{array}$ \\
\hline SHI 110 & 3.9606 & 3.6354 \\
\hline SHI 58 & 3.2041 & 2.9038 \\
\hline SHI 108 & 3.2262 & 2.9252 \\
\hline SHI 21 & 3.7428 & 3.4235 \\
\hline SHI 105 & 4.4640 & 4.1246 \\
\hline SHI 104 & 4.2196 & 3.8869 \\
\hline SHI 83 & 3.4879 & 3.1808 \\
\hline SHI 52 & 3.0179 & 2.7309 \\
\hline SHI 36 & 3.2073 & 2.9122 \\
\hline SHI 5 & 3.9031 & 3.5840 \\
\hline SHI 72 & 4.2276 & 3.8941 \\
\hline SHI 66 & 3.2930 & 2.9989 \\
\hline SHI 51 & 3.1496 & 2.8464 \\
\hline SHI 49 & 3.4053 & 3.0857 \\
\hline SHO 13 & 3.1340 & 2.8450 \\
\hline SHO 29 & 2.8972 & 2.6335 \\
\hline SHO 59 & 3.2906 & 2.9978 \\
\hline SHO 107 & 3.2906 & 2.9978 \\
\hline SHO 109 & 2.8972 & 2.6335 \\
\hline SHO 9 & 3.8639 & 3.5274 \\
\hline SHO 24 & 2.9611 & 2.6845 \\
\hline SHO 52 & 3.1390 & 2.8700 \\
\hline SHO 63 & 3.5424 & 3.2385 \\
\hline SHO 74 & 3.4150 & 3.1245 \\
\hline SHO 93 & 2.7924 & 2.5315 \\
\hline SHO 36 & 2.8728 & 2.6060 \\
\hline SHO 19 & 3.0236 & 3.7369 \\
\hline SHO 34 & 3.0396 & 2.7586 \\
\hline SHO 69 & 3.0316 & 2.7510 \\
\hline SHO 111 & 3.0687 & 2.7771 \\
\hline SHO 104 & 4.1084 & 3.4145 \\
\hline SHO 78 & 3.6365 & 3.0127 \\
\hline EVO 102 & 3.8849 & 2.2533 \\
\hline EVO 51 & 3.1553 & 1.7783 \\
\hline EVO 1 & 3.4562 & 1.9045 \\
\hline EVI 1 & 3.4562 & 1.9045 \\
\hline EVI 51 & 3.0088 & 1.6994 \\
\hline EVI 102 & 2.8669 & 1.5707 \\
\hline EVO 171 & 4.1950 & 2.3712 \\
\hline EVI 136 & 2.9767 & 1.6862 \\
\hline EVO 137 & 2.9767 & 1.6862 \\
\hline
\end{tabular}


Table 5 (Continued)

\begin{tabular}{|c|c|c|}
\hline Tube & $\begin{array}{c}134 \mathrm{Cs} \\
\times 10^{-10} \frac{\mathrm{Ci} / \mathrm{cm}^{2}}{\mathrm{CPM}}\end{array}$ & $\begin{array}{c}137 \mathrm{Cs} \\
\times 10^{-10} \frac{\mathrm{Ci} / \mathrm{cm}^{2}}{\mathrm{CPM}} \\
\end{array}$ \\
\hline EVO 88 & 2.8459 & 1.6150 \\
\hline EVO 90 & 2.8459 & 1.6150 \\
\hline EVO 38 & 3.0873 & 1.7302 \\
\hline EVO 41 & 3.0873 & 1.7302 \\
\hline EVO 180 & 3.9751 & 2.2431 \\
\hline EVO 146 & 3.1535 & 1.7821 \\
\hline EVO 99 & 3.3001 & 1.8646 \\
\hline EVO 50 & 4.8901 & 2.7266 \\
\hline EVI 51 & 4.1950 & 2.3712 \\
\hline EVI 65 & 2.9253 & 1.6541 \\
\hline EVI 116 & 2.8337 & 1.6085 \\
\hline EVI 156 & 3.0028 & 1.6695 \\
\hline EVI 25 & 4.9182 & 2.6997 \\
\hline EVI 74 & 3.4621 & 1.9494 \\
\hline EVI 124 & 3.3158 & 1.8760 \\
\hline EVI 163 & 3.4412 & 1.9435 \\
\hline EVI 15 & 3.4562 & 1.9045 \\
\hline
\end{tabular}




\subsection{DATA PRESENTATION}

Tabular and geographical data are presented in Appendix A for each of the 79 steam generator tubes scanned. The first 63 tables are the $\mathrm{CdTe}$ data for the superheater and evaporator sections. The remaining 16 report the scaled GM data for the Economizer. The tables present pointby-point values of counts, curies $/ \mathrm{cm}^{2}$, and the statistical standard deviation. * The curves show activity versus depth, with four to six tubes per graph.

It will be noted that variations with depth within the tube are small for depths below three feet. For each tube an average value was computed for depths greater than three feet. Figure 27 is a plot of the average activity for tubes along the axis of symmetry of the steam generator. Figures 28 through 32 show the radial profile at depths of $4,7.5,11,15$, and 18 feet below the main tubesheet. The tube position is plotted in terms of the cumulative surface area to which the main coolant stream has been exposed up to that point.

\footnotetext{
* The standard deviation $\sigma_{p}$ of the integral counts in a peak is calculated by $\sigma_{p}=\sqrt{\sigma_{g}^{2}+\sigma_{b}^{2}} ; \sigma_{g}$ is the standard deviation of the gross counts between the peak boundaries and is defined by $\sigma_{g}=\sqrt{N_{g}}$ where $N_{g}$ is the total cross counts; $\sigma_{b}$ is the standard deviation of the background counts between the peak boundaries and is defined by $\sigma_{b}=\sqrt{N_{b}}$ where $N_{b}$ is total background counts. Strictly speaking, $\mathrm{N}_{b}$ is not directly determined. If $A+B$ are the counts at the left and right thresholds of the pulse, then $\sigma_{b}=\sqrt{A+B /(2)} \times n$, where $n$ is the number of channels between $A$ and $B$. It is recognized that there are other systematic and random errors associated with the measurements. It is impossible to accurately express these errors numerically, and are therefore not included in the calculation.
} 


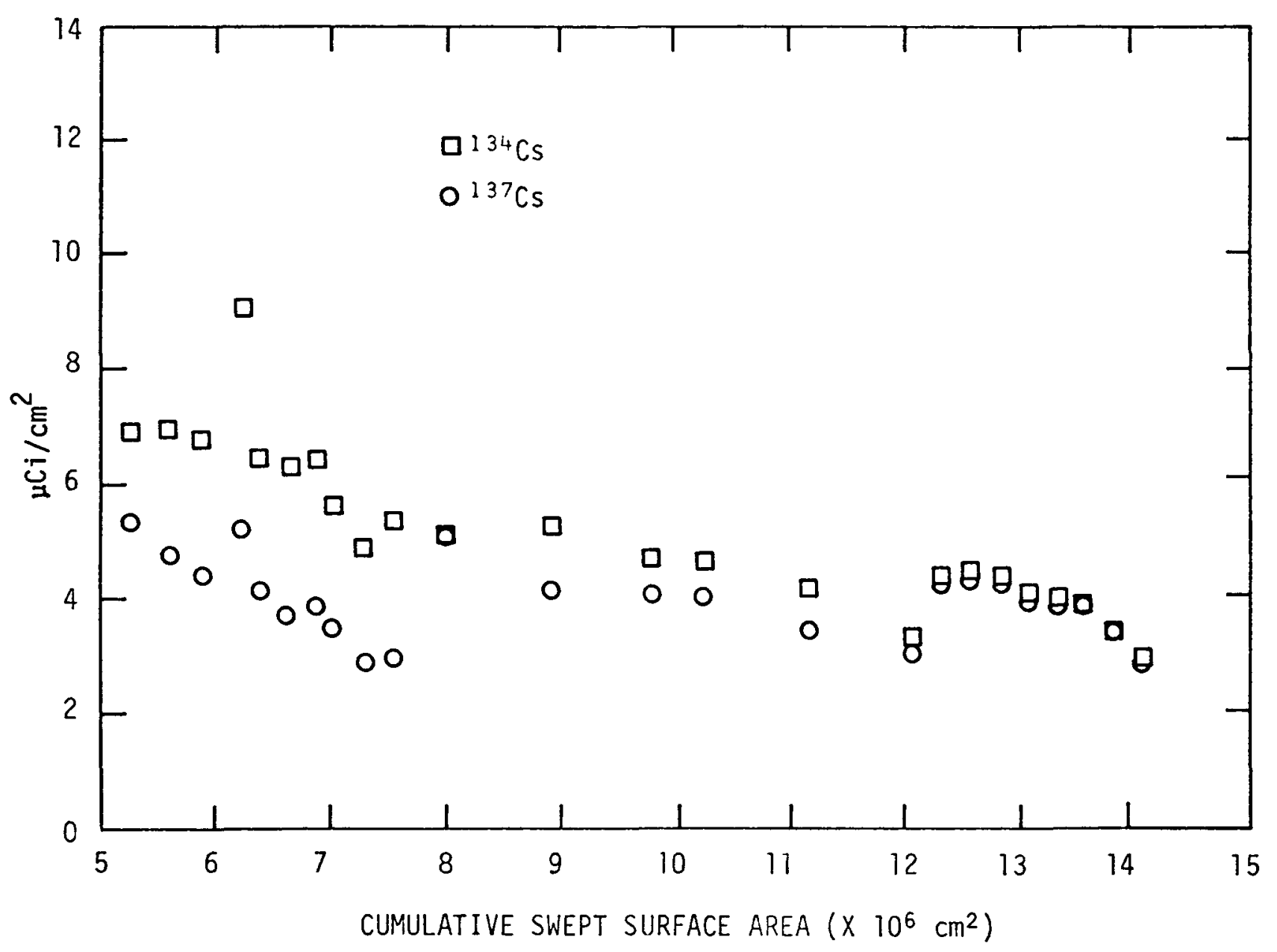

RT -13463

Figure 27. Radial profile of average activity across steam generator tube sheet bundle on axis of symmetry 


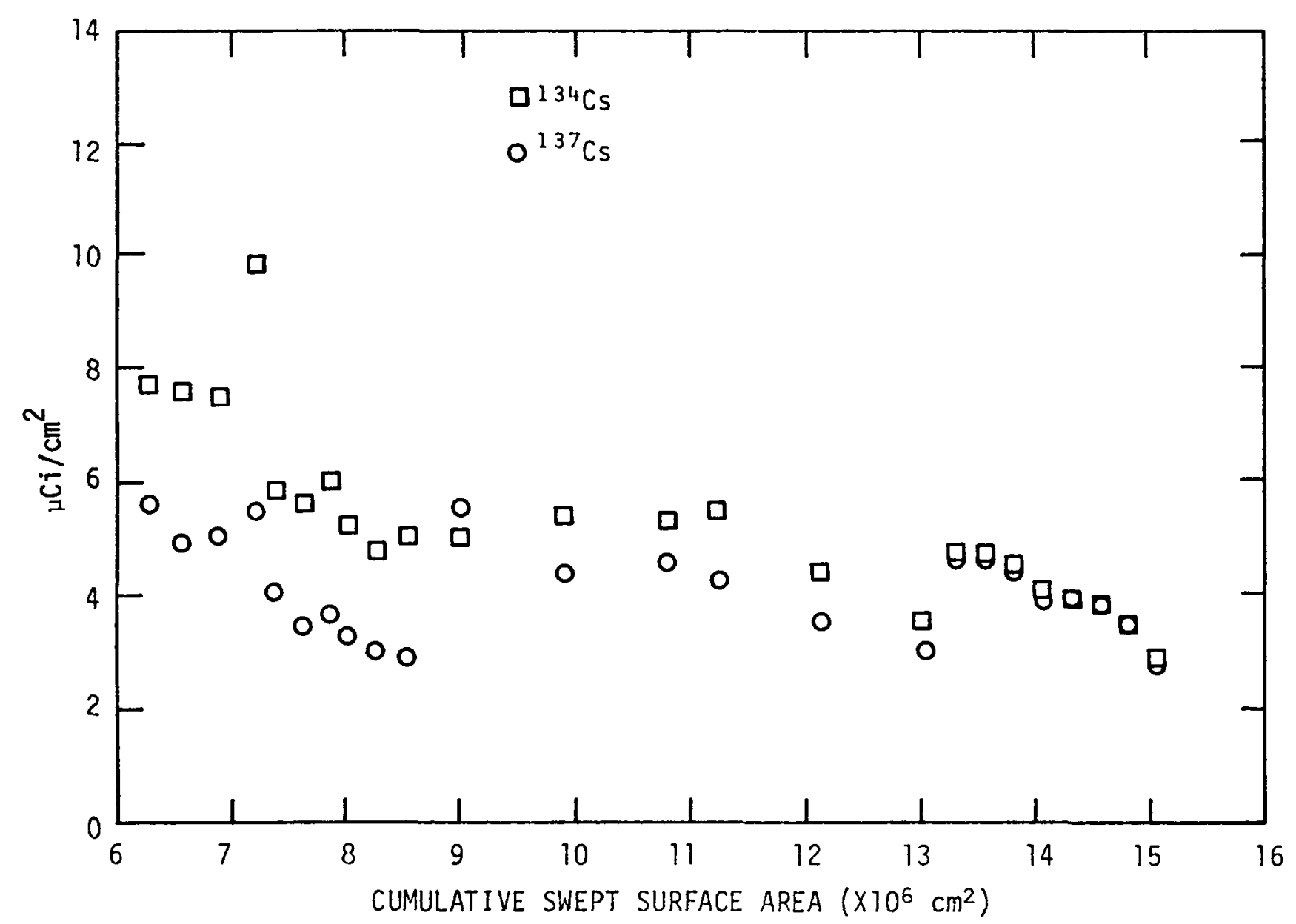

RT -13462

Figure 28. Radial profile of activity across steam generator tube sheet bundle at 4 foot depth. 


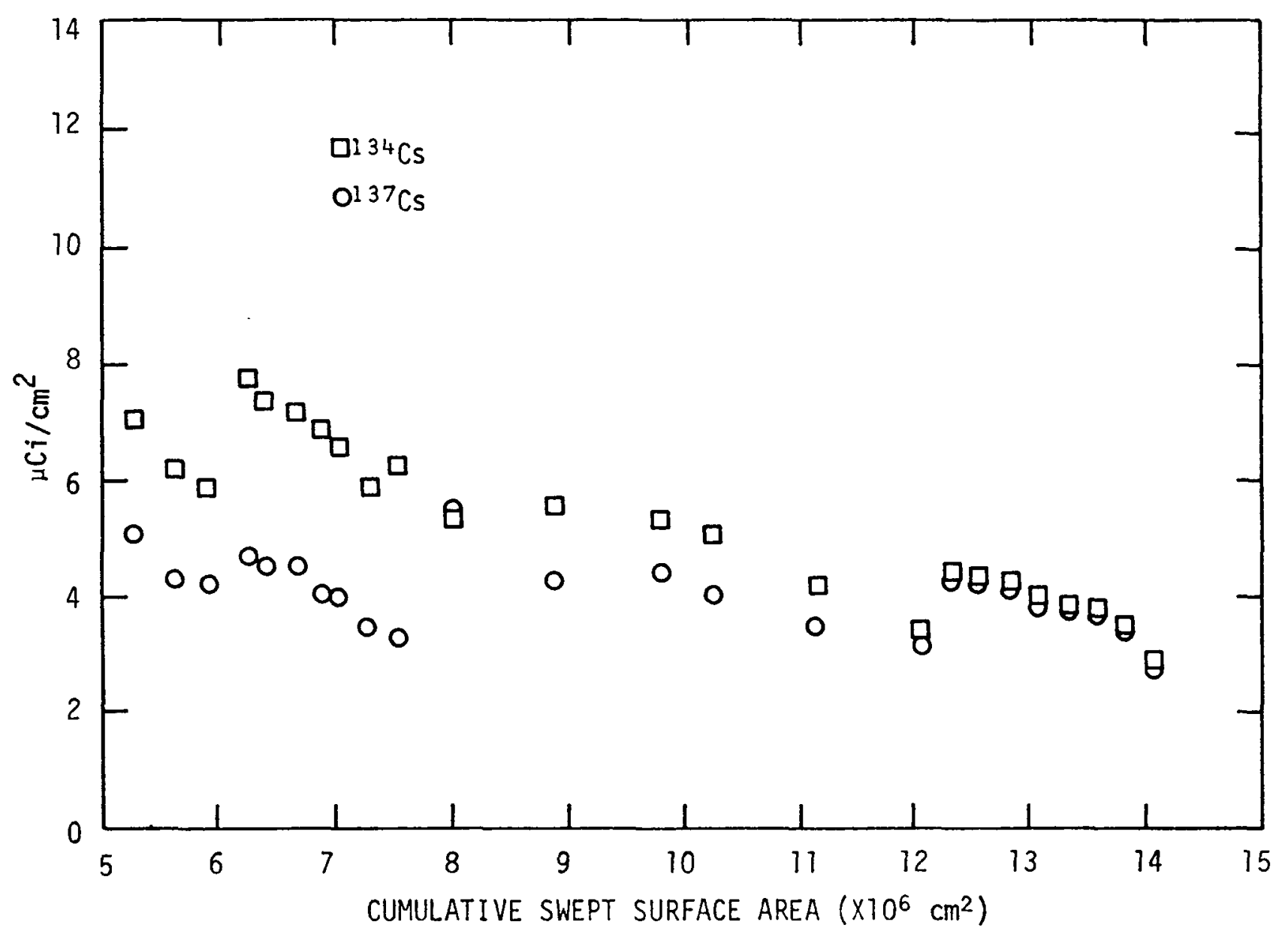

RT -13461

Figure 29. Radial profile of activity across steam generator tube sheet bundle at 7.5 foot depth. 


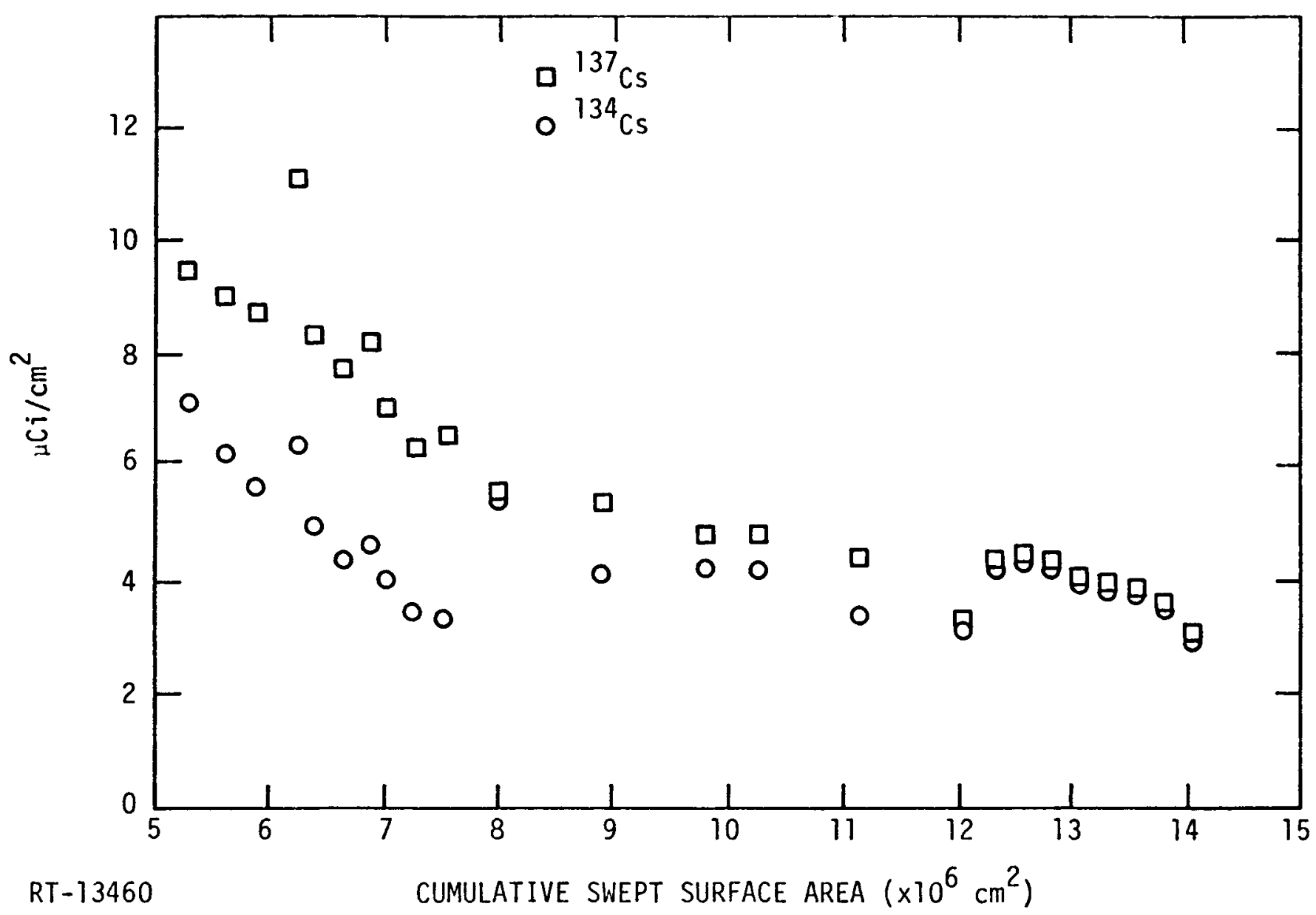

Figure 30. Radial profile of activity across steam generator tube sheet at $11-\mathrm{ft}$ depth 


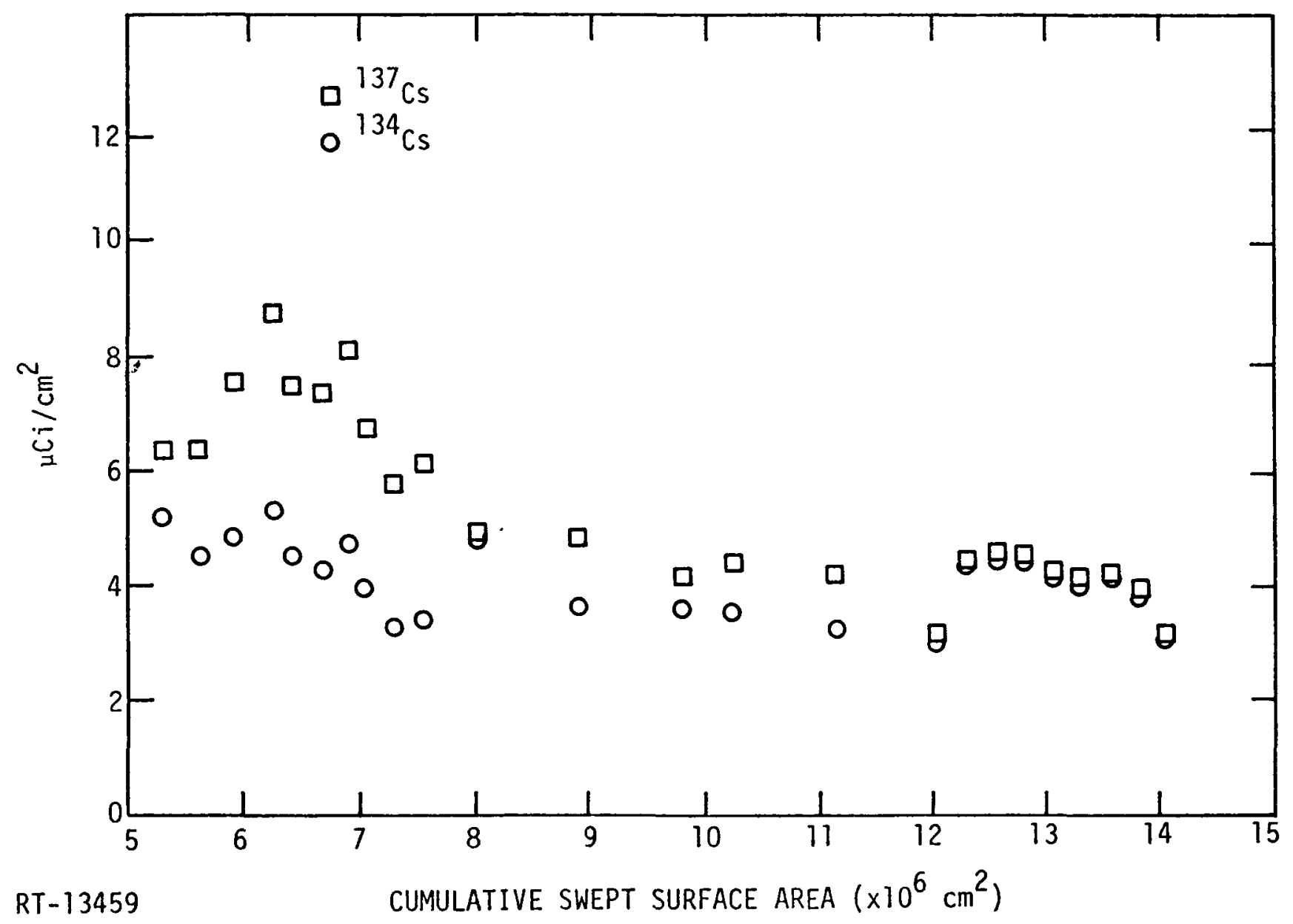

Figure 31. Radial profile of activity across steam generator tube sheet bundle at $15-\mathrm{ft}$ depth 


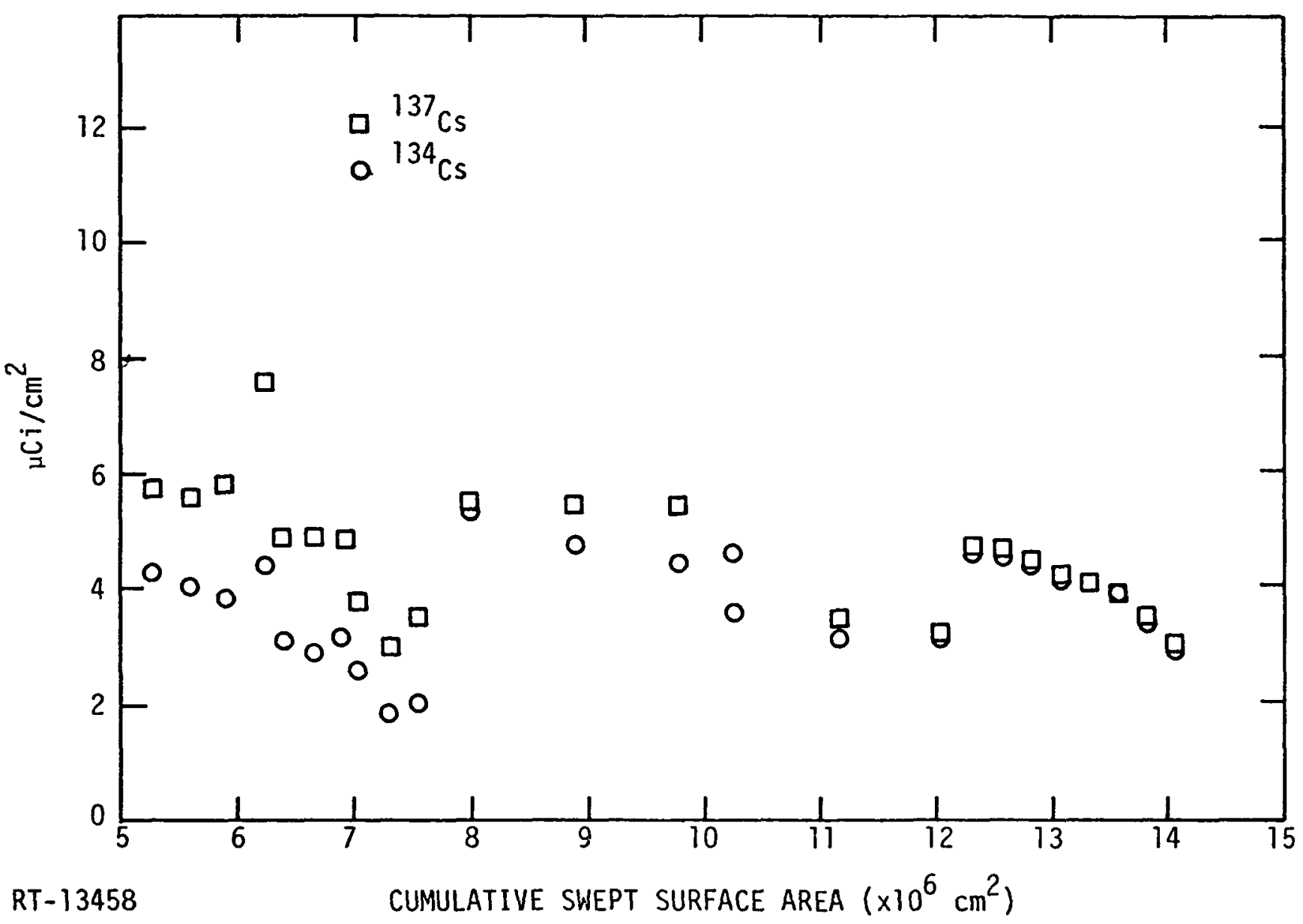

Figure 32. Radial profile of activity across steam generator tube sheet bundle at $18-\mathrm{ft}$ depth 


\subsection{ERROR ANALYSIS}

In performing a task such as these measurements there are many opportunities for error. While due diligence has been applied to limit the source of error, it must be recognized that uncertainties in various aspects of the work can compound in the final result. Errors will be examined in the categories of: (1) calibration; (2) data taking; and (3) data reduction.

\subsubsection{Calibration Errors}

Uncertainties in calibration of the detector can exist due to the use of a laboratory scale model of the tube bundles, counting statistics, or errors in positioning the detector or the isotopes which simulate the plateout and errors in source strength.

Some of the errors due to use of a laboratory scale model can result from the finite length of the tubes. Estimates were made of the effect on the integral detector response of the radiations coming from greater distances on the tubes than the length of the model tubes. This was done by extrapolating the curves in Figure 21 to twice the length at which the curve terminates using the terminal slope. The results indicate a $-1.2 \%$ influence on the value of the integral. In that the curves for other tube types and other isotopes are quite similar in nature, this result is considered typical. Other aspects of the model, such as tube thickness and tube material, were copied with great precision and could not be the source of significant uncertainty. Counting statistics on the calibrations were quite good. Total counts on the order of 20,000 per position were obtained which would give a standard deviation of $0.7 \%$. Detector and isotope positioning were accurate to within $\pm 1 \mathrm{~mm}$. The impact of $\pm 1 \mathrm{~mm}$ would have a negligible effect on the integrals of the calibration curves. Due to the fact that the source band was $2 \mathrm{~cm}$ in width, each data point on the curves averages over that source region and a $1 \mathrm{~mm}$ variation would not change the value of the data points measurably. It is estimated that the maximum uncertainty on source strength calibration is on the order of $5 \%$. This is based on past experience in calibrating against standards with similar counting geometry and equipment. 


\subsubsection{Data-Taking Errors}

At the measurement site frequent measurements were made of standard sources to detect any shifts in the detector electronics. Uncertainties are induced by the assumption that changes in peak channels between the beginning and the end of a run occur linearly in time. Shifts were normally in the one-channel-or-less category, but occasionally were as great as four channels. If in the data reduction the assumption of linearity is made when the shift actually occurred precipitously, it is estimated that an uncertainty as high as $20 \%$ could occur. However, by virtue of the fact that such a data point would stand out as a maverick, shifts are ordinarily much less, and tend to occur linearly, a variability factor of $3 \%$ would seem a reasonable upper bound.

\subsubsection{Data Reduction}

Uncertainties which could be introduced in the data reduction would arise from (1) errors in spectrum stripping, and (2) errors in applying the calibration model to the heat exchanger geometry.

Since the integration of the ${ }^{137} \mathrm{Cs}$ peak depends on the location of the peak channel, which cannot be determined from each individual spectrum, any error in the peak channel value input to the PEACH code will cause the peak area determined to be in error. The greatest change in the peak channel in any two consecutive ${ }^{137} \mathrm{Cs}$ calibration spectra was about one channel. Most variations were less than this, however. It is estimated that the maximum error in the input channel number would be 0.5 channels. PEACH runs were made on typical spectra, wherein 0.5 channel and 1 channel variations in peak location were made in either direction. These runs showed that an error of 0.5 channel in either direction will cause a $10 \%$ change in the ${ }^{137} \mathrm{Cs}$ peak area. This uncertainty does not exist for ${ }^{134} \mathrm{Cs}$ where the peak stands alone.

For heat exchanger tubes buried within a grouping of tubes of the same type, uncertainties are minimized for extrapolating from the calibration model. The uncertainties are greatest when the tube is at the edge of tubes of the same type and looks at tubes of another type across an air gap, or looks at the heat exchanger pressure vessel across an air gap. 
The number of contingencies involved in accounting for these vertical surfaces was simply too large to permit individual calibrations for each one. Instead, estimates of the effects of these vertical surfaces were made based on selected calibrations across air gaps. The level of uncertainty thus induced is limited by dilution. In every case the most adjacent sources, the ones having the greatest impact on the integral detector signal, were correctly accounted for. There was much less influence of the more remote surfaces on the integral counts. In order to bracket this uncertainty, a worst-case tube (evaporator inlet 25), was considered. The integral response of a detector in this tube would be influenced by tubes across an air gap and by the nearby pressure vessel. The only problem with including the tubes of the same type which are across the air gap, is their slight displacement laterally from what a continuation of an orderly pattern would predict. It is believed that the normal calibration would adequately represent these tubes, because the lateral displacement will have a negligible effect on total separation distance. To estimate the effect of the pressure vessel wall, a point kernel integration was performed over the surface for a point on the tube. The flux was attenuated through the tube wall and the resultant count rate (after applying the detector efficiency) was compared to the total count rate for that position. The maximum influence of the wall under these conditions was on the order of $\pm 1.5 \%$.

\subsubsection{Composite Uncertainty}

Combining uncertainties for components of a problem to arrive at a total uncertainty on an experimental value requires defining the functional relationship between the final answer and the components. If we have a function

$$
y=f(x, t, z)
$$

where uncertainties $\Delta x, \Delta t$, and $\Delta z$ exist in the independent variables, then a maximum uncertainty for $y$ can be defined as

$$
\Delta y=\frac{\partial f}{\partial x} \Delta x+\frac{\partial f}{\partial t} \Delta t+\frac{\partial f}{\partial z} \Delta z
$$


Where error function distributions are known, alternate statistical techniques can be used. It was, however, impossible to define such functions for this case.

In our case the final answer is linear, with most of the quantities being considered, such as:

1. integral area under the calibration curves $(-1.2 \%)$;

2. integral effect of electronic drift $( \pm 3 \%)$;

3. effect on total peak area of peak center definition $( \pm 10 \%)$;

4. effect of vessel wall on counts in certain tubes $(-1.5 \%)$; and

5. source strength calibration $( \pm 5 \%)$.

The worst-case composite error for an edge tube for the ${ }^{137} \mathrm{Cs}$ plateout intensity would then be $\pm 20.7 \%$.

For ${ }^{134} \mathrm{Cs}$ the corresponding error would be $\pm 10.7 \%$. 


\section{INTERNAL DUCT SCANS}

This section reports the second phase of the fission-product monitoring activity carried out by IRT Corporation under subcontract to the General Atomic Company. The purpose of Phase 2 was to determine whether local structure exists in the plateout along the coolant ducts, and if so, the nature and magnitude of the variations. To answer this question, a traveling detector was placed inside two long vertical runs of ducting, and readings were taken at closely spaced intervals along these runs. A conclusion which can be drawn from the data presented in Section 4.4 is that there is apparently no significant degree of structure in the fission-product plateout.

This work was performed in accordance with References 7 and 8 .

\subsection{DUCT SCAN LOCATIONS}

Two ducts were scanned internally to determine the fission-product plateout at closely spaced intervals. These two were the ducts with the trepan locations marked 1-4 and 1-10 in Figure 1. They are in the loop 1 cavity of the Peach Bottom I reactor. Entry to the two ducts was obtained through $1 \times 2 \mathrm{ft}$ ports cut at the level of the trepan samples 1-4 and 1-10. Scans were made between that level and a point $20 \mathrm{ft}$ below that level. At the entry point level, there are four parallel ducts centered at the corner of a 5 -ft square.

\subsection{DETECTOR/COLLIMATOR DESCRIPTION AND CALIBRATION}

The principal detector used in the internal scans was an intrinsic germanium detector built by Applied Detector Corporation. The active crystal is $30 \mathrm{~mm}$ front face and $4 \mathrm{~mm}$ in depth. The entire detector consists of a $9.25 \times 3$ inch cylindrical dewar, with a $3.9 \times 1.5$ inch 
housing for the crystal mounted at one end coaxially. The center of the crystal lies 0.344 inch from the end of the housing. The detector has an optimum resolution of about $0.5 \%$ for ${ }^{137} \mathrm{Cs}$ gamma rays. A photograph of the detector housed in the collimator/carriage is shown in Figure 33. The preamplifier is attached to the dewar housing at the opposite end to the detector. The lead collimator fits as a collar around the crystal housing, limiting the "viewing" angle of the detector to approximately a $32-\mathrm{cm}$ band on the inner surface of the duct. The carriage is configured to hold the detector on the duct axis while suspended inside the duct. The spacer arms which provide this function can be collapsed inward while inserting the apparatus into the ducts, and then unfolded and locked into position for the traverse.

Figure 33 also shows the setup used to calibrate the detector. Calibrated sources of both ${ }^{137} \mathrm{Cs}$ and ${ }^{134} \mathrm{Cs}$ are placed at a point on a 1 ine parallel to the detector axia and offset at a distance of 13.69 inches, which is the inner radius of the duct. Counts in the photopeaks are obtained for various source positions along this line. The data obtained in this manner are plotted in Figure 34. The detector response

$$
\mathrm{R}_{\mathrm{d}} \frac{\text { counts/minute }}{\mu \mathrm{Ci} / \mathrm{cm}^{2}}
$$

is related to raw counts $C$ counts/minute by

$$
R_{\mathrm{d}}=\frac{\mathrm{C} \Delta \mathrm{A}}{\mathrm{S}}
$$

where $S$ is the source strength in $\mu \mathrm{Ci}$, and $\Delta \mathrm{A}$ is the area of a $1-\mathrm{cm}$ band on the inner surface of the duct. The use of these data to reduce the data from the Peach Bottom measurements is explained in Section 4.5.

Although not used in the measurements, calibration data were obtained for the NaI (Tl) backup detector. This detector was a 2 inch diameter $\times 1 / 4$ inch long cylindrical detector which fits within the collimator using a special adaptor. The calibration data are shown in Figure 35. These data correspond to those in Figure 34 for the Ge detector, and were obtained in the same manner. 


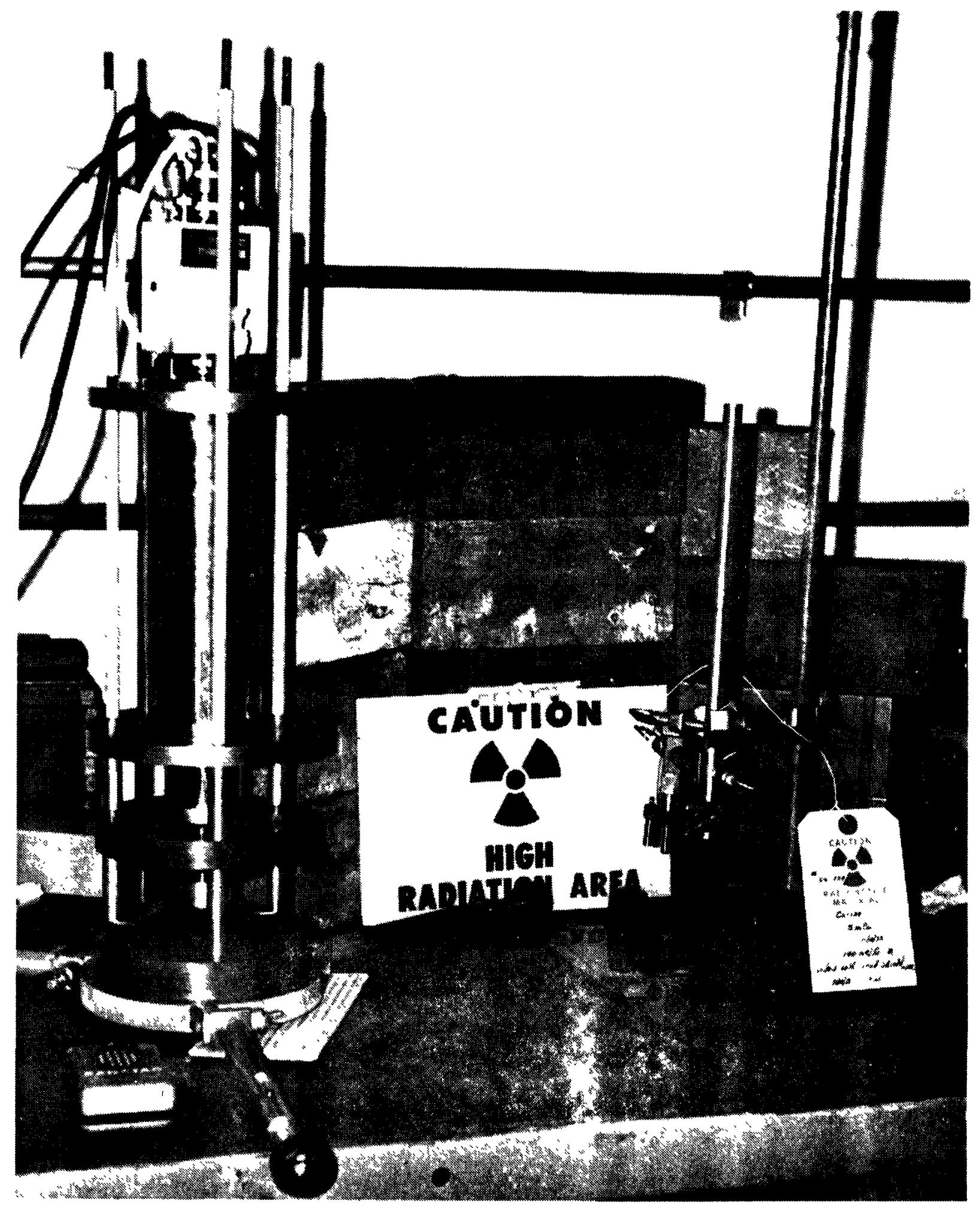

Figure 33. Ge(Li) detector, preamplifier, collimator, and carriage 


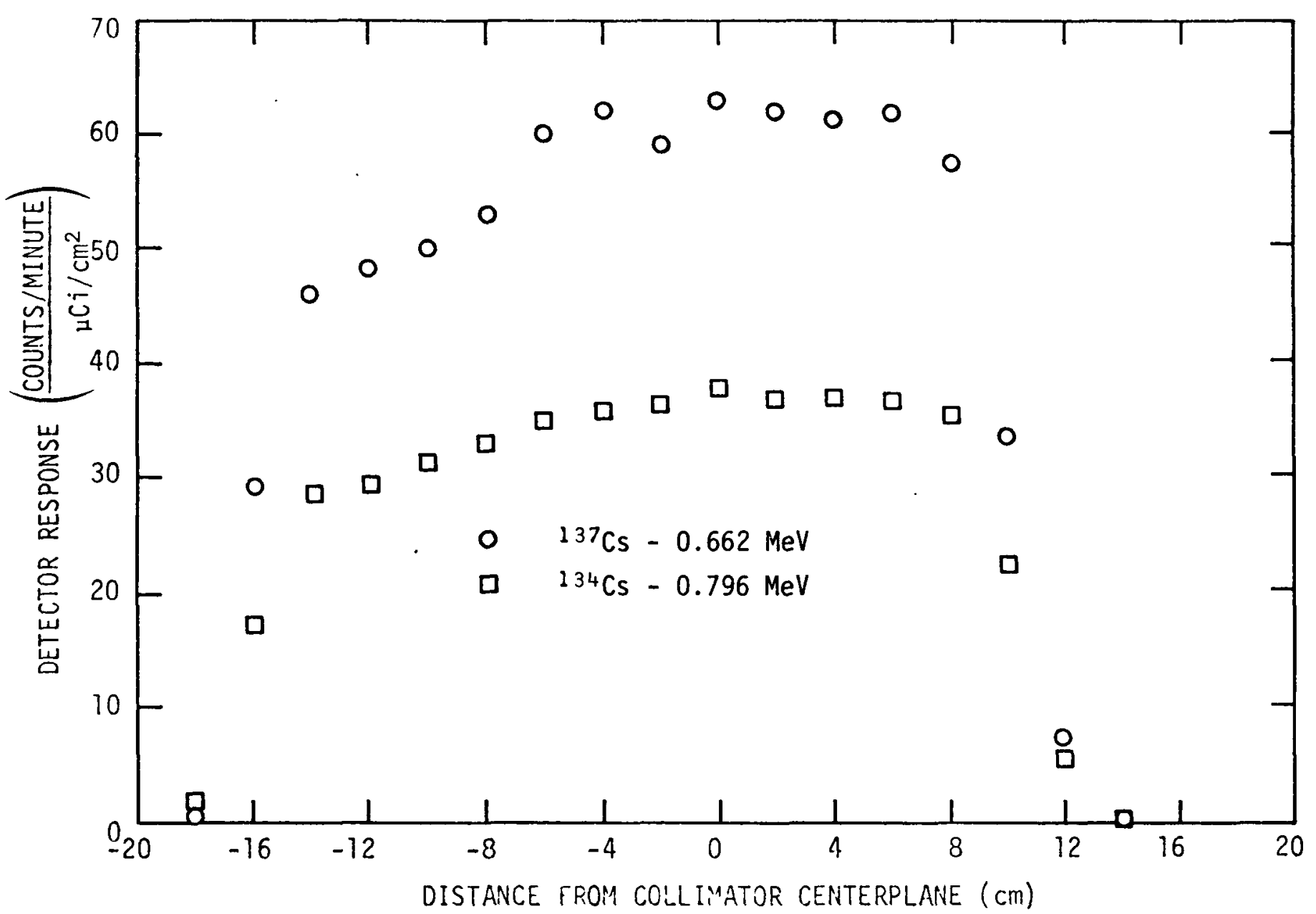

RT -13269

Figure 34. Efficiency for the collimated intrinsic Ge detector for counting activity on the inner surface of the 13-9/16inch inner radius duct 


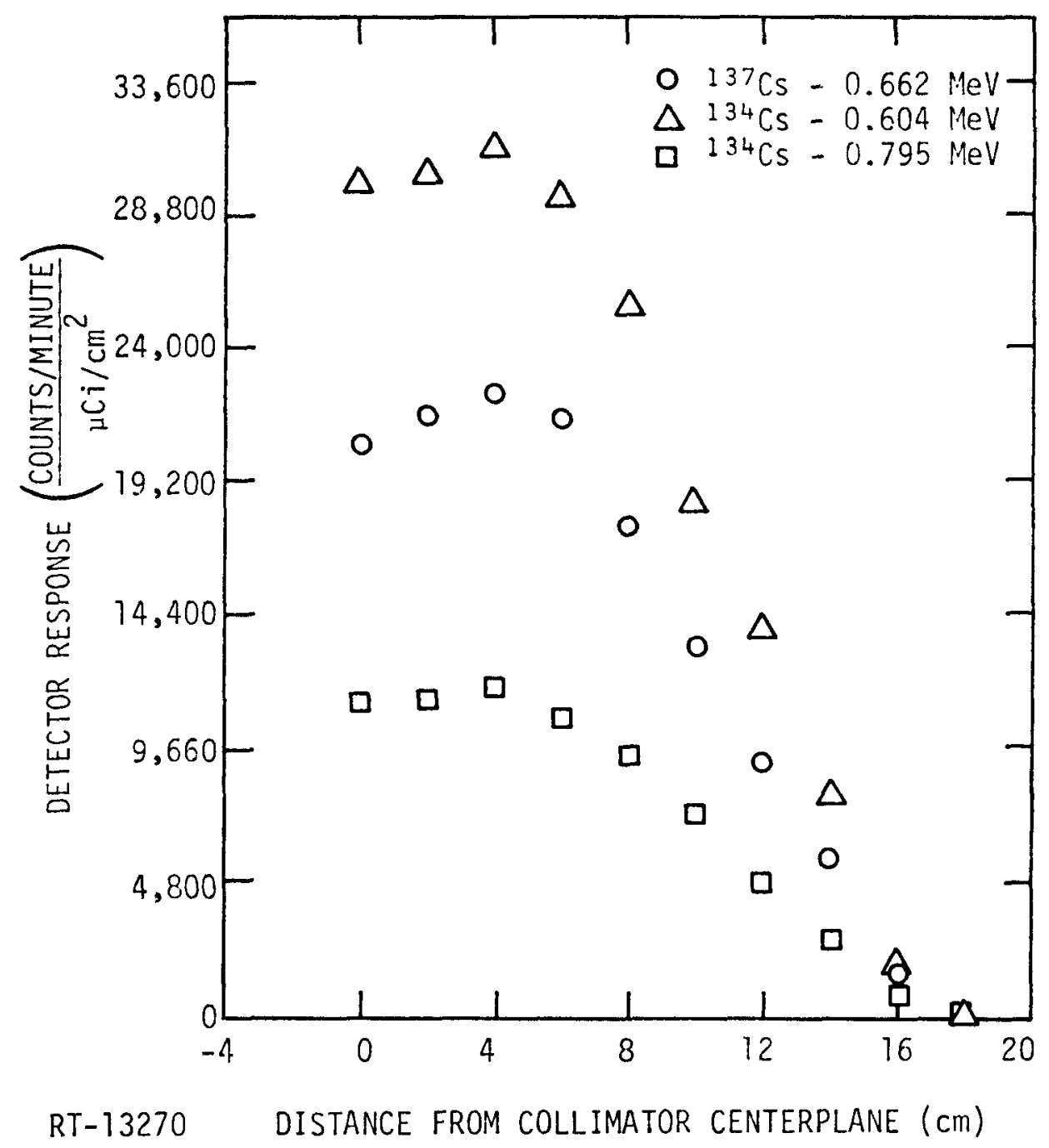

Figure 35. Efficiency for the collimated NaI(Tl) detector for counting activity on the inner surface of the 13-9/16inch inner radius duct 
In addition to these calibrations, there were measurements made using a small isotopic source in the laboratory and on site. The purpose of these measurements was to check on the constancy of the detector and electronics. Count rates were obtained in a fixed geometry before each series of measurements, and at the end. Small variations in the count rate for these calibrations were assumed to have occurred linearly in time for purposes of data reduction.

\subsection{DETECTOR TRANSPORT MECHAN ISM}

The same pulley-cam-relay electrical drive system was used in stepping the detector carriage between counting positions, as was employed to scan the steam generator tubes. Alterations were made to provide a more powerful drive motor and an automatic clutch/brake to hoist and hold the heavier detector carriage and collimator. Control was provided at the counting station on the refueling floor, and at the duct opening in the loop 1 cavity. The control circuitry is shown schematically in Figure 36.

A photograph of the handling mechanism attached to a mockup of the duct entry is shown in Figure 37. Attachment to the duct was provided by bolting a vertical structural member to the duct above the center of the opening. The detector assembly was then placed inside the duct. A steel cable connected the carriage to a motor-driven spool, which could be operated by the experimenter, either continuously or in 6-inch, camcontrolled steps. The detector was lowered to the bottom measurement position and stepped upward following each period of data accumulation. Count times were in the 5 to 10 minute range.

\subsection{ELECTRONICS AND DATA RECORDING}

The suite of electronic equipment used to analyze and record the data from the internal scans differed in only minor respects from that used for the external scans. Figure 38 shows a block diagram of the equipment.

The pulse output from gamma interaction with the detector is conditioned, shaped, and amplified in the preamplifier attached to the detector. 


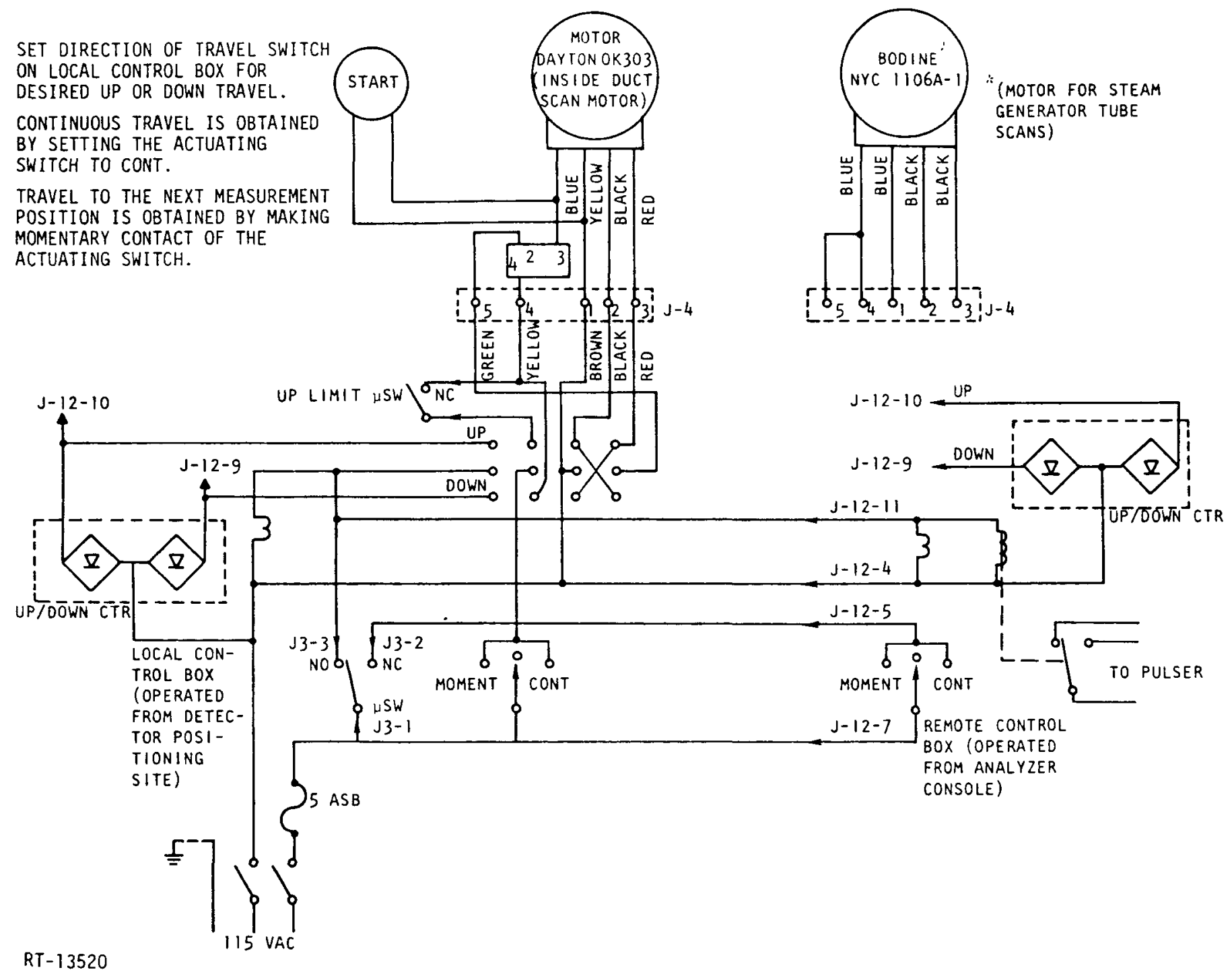

Figure 36. Detector location control circuitry 


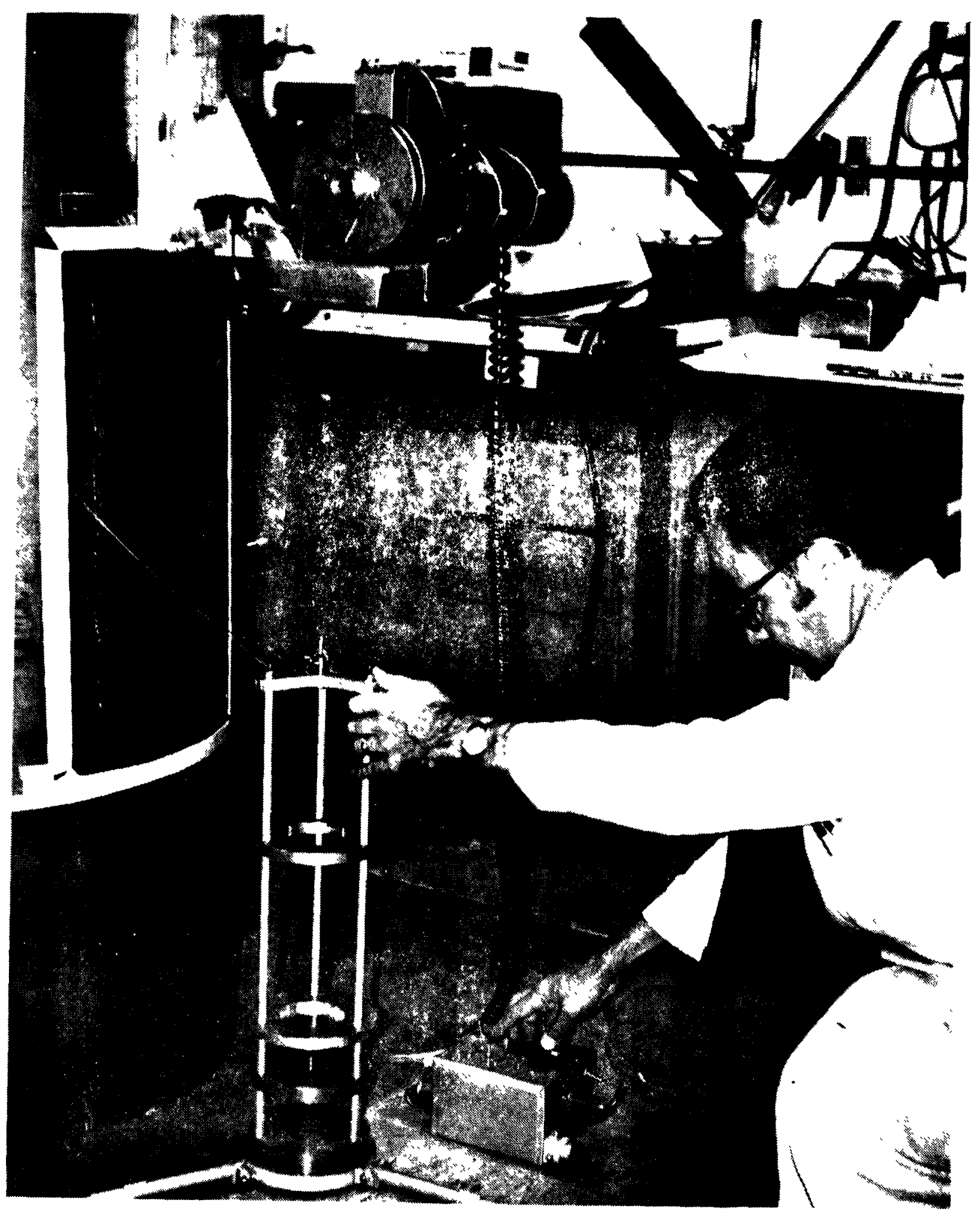

Figure 37. Electromechanical positioner for internal scans 


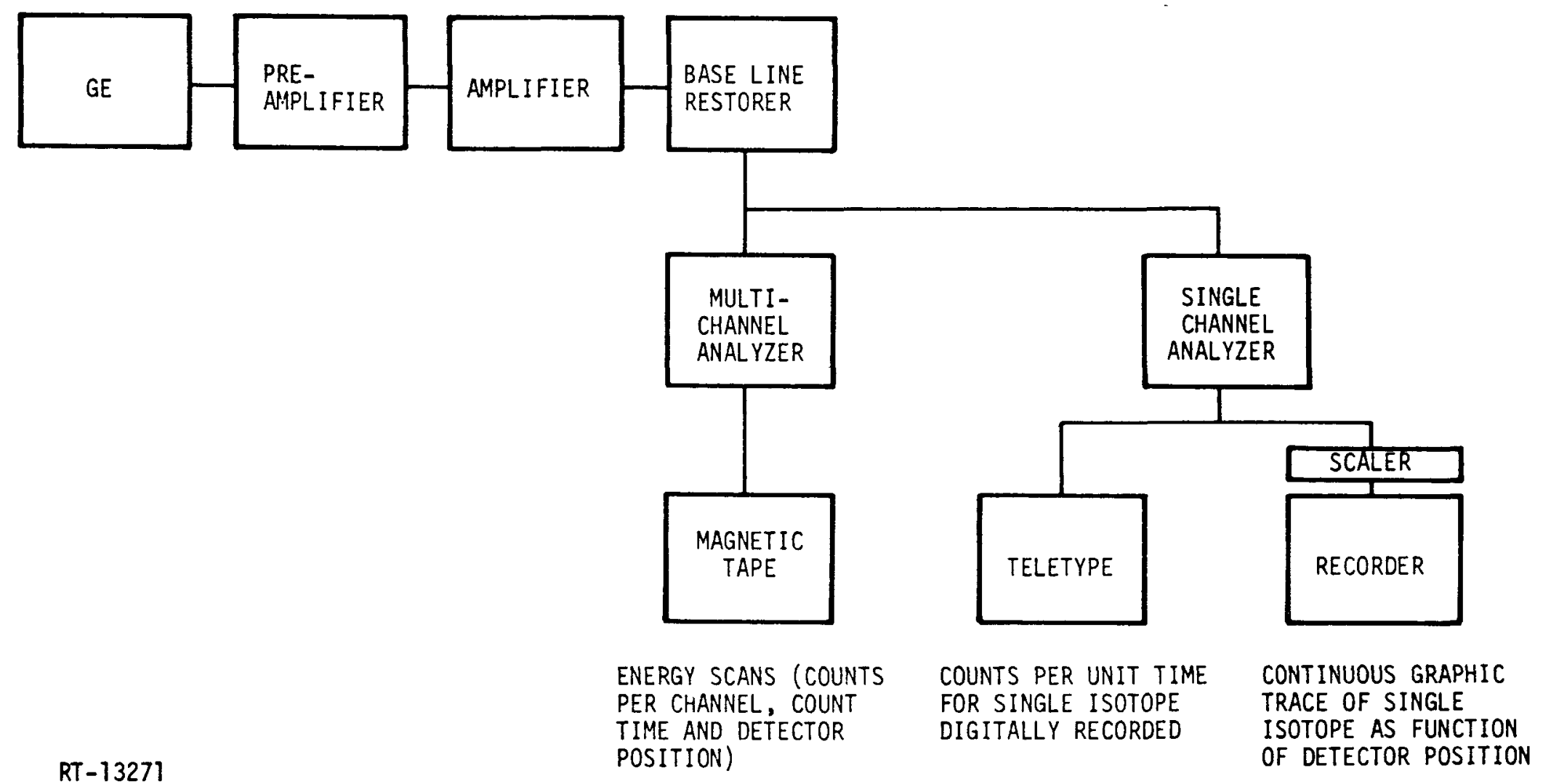

Figure 38. Block diagram for internal duct scanning 
The output pulse from the preamplifier is transmitted to the amplifier. The amplifier further shapes and amplifies the signal to condition it for the 4096-channel multichannel analyzer (MCA). A baseline restorer (BLR) positioned between the amplifier and MCA provide a final shaping of the signal to reduce undershoot of the amplifier signal, and provide an optimized signal to the MCA, which converts the incoming analog signal to a digital count proportional to the energy of the gamma ray striking the detector.

The signal from the amplifier is also transmitted to a single-channel analyzer (SCA) set to monitor the ${ }^{134} \mathrm{Cs}$ activity. After a significant number of counts have been accumulated in the MCA, the data, along with the counting time and identification information, is stored on magnetic tape. The scaler rate data are printed out on a teletype, displayed on a strip chart recorder, and recorded in the $\log$ book.

\subsection{DATA REDUCTIONS}

In order to translate count-rate data from the internal scans into plateout intensity $\left(\mu \mathrm{Ci} / \mathrm{cm}^{2}\right)$, two things were necessary:

- application of the collimated detector calibration data; and

- correction for interference from adjacent ducts.

These items are explained in order below.

\subsubsection{Application of Calibration Data}

In Section 4.2 the method of calibrating the collimated detector is explained. The data in Figure 34 define a detector response $R_{d}$ (counts/ $\mu \mathrm{Ci}$ /area increment), where the area increment is a $1-\mathrm{cm}$ band around the inside of the duct. The count rate for $1 \mu \mathrm{Ci} / \mathrm{cm}^{2}$ uniform deposition within the duct is given by

$$
\mathrm{C}_{1, \mathrm{i}}=\int \mathrm{R}_{\mathrm{d}, \mathrm{i}} \mathrm{d} \ell \text {, }
$$


where $i$ denotes the particular photopeak, the integral is performed over the length for which $\mathrm{R}_{\mathrm{d}}$ is defined $(-18$ to $+14 \mathrm{~cm}$ from detector centerplane).

In the Peach Bottom measurements a total count rate, $\mathrm{C}_{\mathrm{T}}$, is obtained within a photopeak which is then reduced to $\mu \mathrm{Ci} / \mathrm{cm}^{2}$ by

$$
\mathrm{S}_{\mathrm{A}}\left(\frac{\mu \mathrm{C} i}{\mathrm{~cm}^{2}}\right)=\frac{\mathrm{C}_{\mathrm{T}, \mathrm{i}}}{\mathrm{C}_{1, \mathrm{i}}}
$$

\subsubsection{Correction for Interference from Adjacent Ducts}

A computer routine was written to perform a point kernel calculation of the detector response due to activity inside an adjacent duct. Since the detector is analyzing line spectra, it is possible to perform such a calculation on a line-of-sight basis without consideration of photon scattering.

The geometry of the problem is similar to that sketched below.

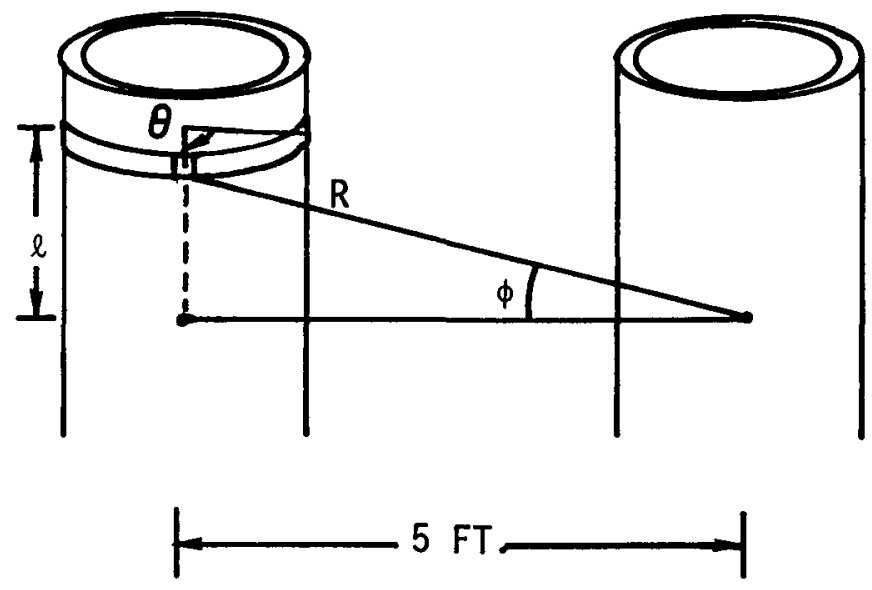

The surface inside the duct was divided into a large number of increments of $\theta$ and $l$. The source associated with each increment is $S_{A} \Delta A$, where $\Delta A$ is the area associated with the increment, and $S_{A}$ is the plateout intensity in the adjacent pipe. The detector response due to this source increment is 


$$
R(c / s e c)=\frac{\Delta A S_{A} 3.7 \times 10^{10} B r}{4 \pi R^{2}} e^{-\sum \mu_{i} t_{i}} E(\phi),
$$

where $\mathrm{Br}$ is the branching ratio, $\mathrm{E}(\phi)$ is the collimated detector efficiency at angle $\phi$, and $e^{-\sum \mu_{i} t_{i}}$ is the total attenuation along the ray for the photon energy of interest. Integration over $\theta$ and $\ell$ gives a total response due to the adjacent duct.

The code is constructed such that integrations are also performed over the inside of the duct containing the detector, and the ratio of the two contributions is calculated. A typical value for the ratio of (counts due to adjacent:total counts) is 0.0428 for the $0.662-\mathrm{MeV} 1$ ine of ${ }^{137} \mathrm{Cs}$, or slightly over $4 \%$ of the counts are due to one adjacent duct if the plateout intensities are the same in both ducts.

In applying these analytical data to reduction of the scan data, a first-order estimate is made of the plateout intensity with no correction, and the correction is then applied. This allows scaling of the adjacent duct contribution in calculating a total correction. There are four ducts in the well, whereas scans are performed in only two. The other two ducts are continuations of the ones which are scanned. Each is assumed to have the same activity throughout that portion of its length which is in the well as the average determined from the scan.

The final corrections applied in this manner are all on the order of $10 \%$. Listed below are values of the ratio of counts due to the duct being measured to total counts.

\begin{tabular}{lll}
\hline & \multicolumn{2}{c}{ I sotope } \\
\cline { 2 - 3 } Point & ${ }^{134} \mathrm{Cs}$ & ${ }^{137} \mathrm{Cs}$ \\
\hline $1-4$ & 0.926 & 0.925 \\
$1-10$ & 0.900 & 0.903 \\
\hline
\end{tabular}




\subsection{DATA PRESENTATION}

The data reduction factors explained above were applied to the onsite measurements. The resulting data are presented in Table 6. All of these results have been corrected for radioactive decay to October 31 , 1974, the date of reactor shutdown. Because of the uniformity of the data, readings were taken at $1-\mathrm{ft}$ intervals in some cases. Plots of the data are shown in Figure 39. 
Table 6

INTERNAL DUCT SCANS

$\left(\mu \mathrm{Ci} / \mathrm{cm}^{2}\right)$

\begin{tabular}{|c|c|c|c|c|}
\hline \multirow[b]{2}{*}{ Position } & \multicolumn{2}{|c|}{ Location $1-4$} & \multicolumn{2}{|c|}{ Location $1-10$} \\
\hline & ${ }^{137} \mathrm{Cs}$ & ${ }^{134} \mathrm{Cs}$ & ${ }^{137} \mathrm{Cs}$ & ${ }^{134} \mathrm{Cs}$ \\
\hline Top & -- & -- & 0.85 & 1.17 \\
\hline-0.5 & 1.51 & 1.98 & -- & -- \\
\hline-1.0 & 1.53 & 1.98 & 0.85 & 1.14 \\
\hline-1.5 & 1.45 & 1.93 & -- & -- \\
\hline-2.0 & 1.48 & 1.93 & 0.85 & 1.11 \\
\hline-2.5 & 1.44 & 1.83 & -- & -- \\
\hline-3.0 & 1.44 & 1.98 & 0.86 & 1.11 \\
\hline-3.5 & 1.42 & 1.93 & -- & -- \\
\hline-4.0 & 1.43 & 1.90 & 0.81 & 1.03 \\
\hline-4.5 & 1.45 & 1.89 & -- & -- \\
\hline-5.0 & 1.44 & 1.93 & 0.82 & 1.08 \\
\hline-5.5 & 1.50 & 1.92 & -- & -- \\
\hline-6.0 & 1.50 & 1.98 & 0.82 & 1.09 \\
\hline-6.5 & 1.45 & 1.93 & -- & -- \\
\hline-7.0 & 1.45 & 1.90 & 0.81 & 1.11 \\
\hline-7.5 & 1.47 & 1.93 & -- & -- \\
\hline-8.0 & 1.44 & 1.95 & 0.80 & 1.08 \\
\hline-8.5 & 1.42 & 1.95 & -- & -- \\
\hline-9.0 & 1.41 & 1.87 & 0.79 & 1.06 \\
\hline-9.5 & 1.43 & 1.90 & -- & -- \\
\hline-10.0 & 1.39 & 1.86 & 0.78 & 1.09 \\
\hline-10.5 & 1.40 & 1.92 & -- & -- \\
\hline-11.0 & 1.38 & 1.93 & 0.80 & 1.09 \\
\hline-11.5 & 1.39 & 1.84 & -- & -- \\
\hline-12.0 & 1.41 & 1.92 & 0.80 & 1.08 \\
\hline-12.5 & 1.38 & 1.90 & -- & -- \\
\hline-13.0 & -- & -- & 0.80 & 1.08 \\
\hline-13.5 & 1.39 & 1.84 & -- & -- \\
\hline-14.0 & -- & -- & 0.82 & 1.11 \\
\hline-15.0 & 1.36 & 1.83 & 0.81 & 1.09 \\
\hline-16.0 & 1.33 & 1.90 & 0.83 & 1.12 \\
\hline-17.0 & 1.37 & 1.89 & 0.85 & 1.09 \\
\hline-18.0 & -- & -- & 0.85 & 1.17 \\
\hline-18.5 & 1.37 & 1.90 & -- & -- \\
\hline-19.0 & -- & -- & 0.87 & 1.15 \\
\hline-20.0 & 1.38 & 1.87 & 0.86 & 1.17 \\
\hline
\end{tabular}




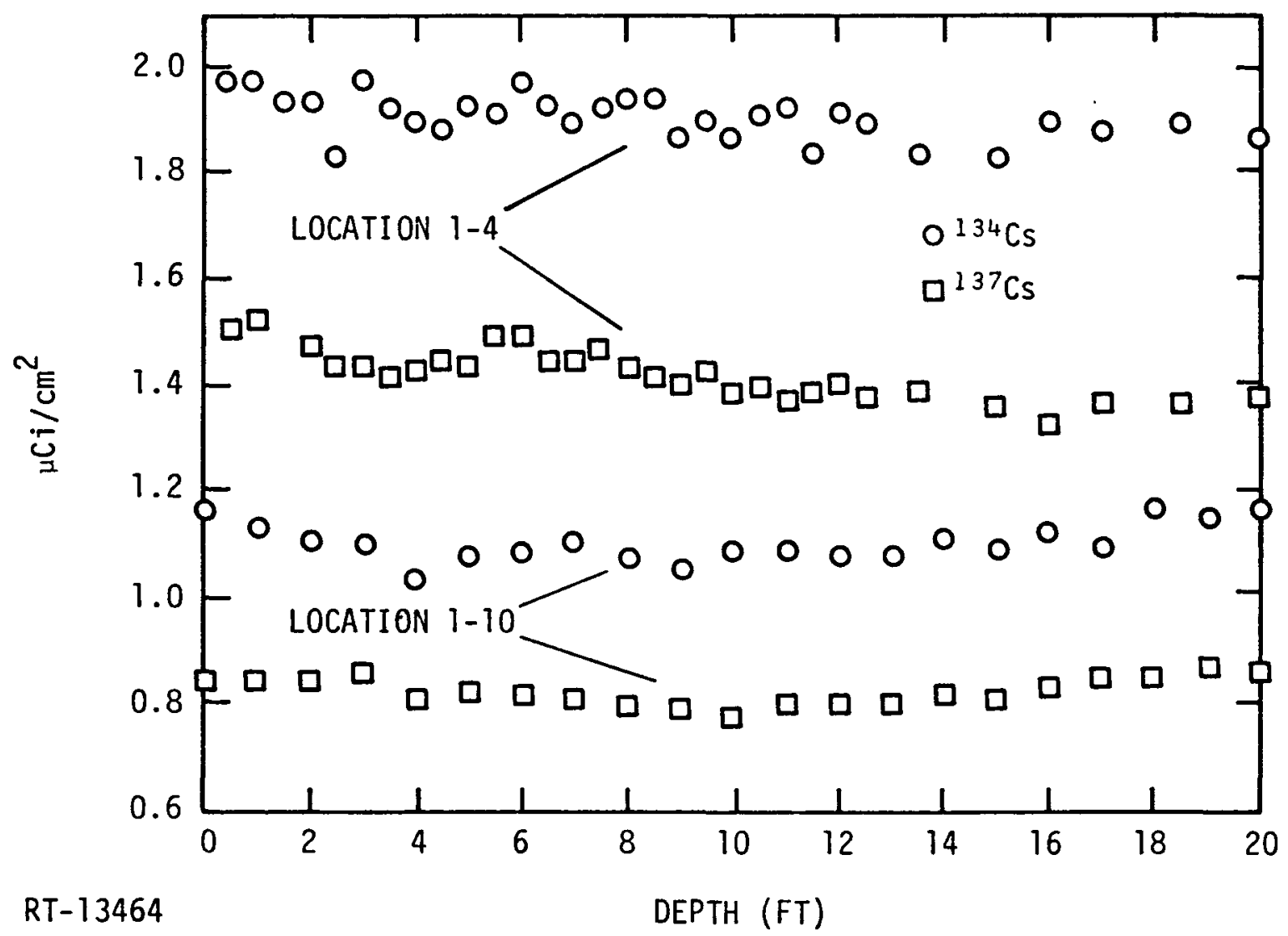

Figure 39. Internal duct scans specific activity vs depth 


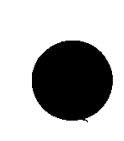

This page intentionally left blank. 
REFERENCES

1. "Peach Bottom End-of-Life Research Program," General Atomic Proposal AP 42-939, December 1974.

2. M. J. Haire, D. W. McEachern, "Gassious Radioactivity Levels in the Primary Coolant of an HTGR," General Atomic Report GA-A-12946, October 1974.

3. D. Alberstein, P. D. Smith, M. J. Haire, "Metallic Fission Product Release from the HTGR," General Atomic Report GA-A-13258, May 15, 1975 .

4. F. E. Vanslager, L. D. Mears, "PAD: A Computer Code for Calculating the Plateout Activity Distribution in a Reactor Circuit," General Atomic Report GA-10460, January 1971.

5. General Atomic Company Test Specification 167-56-2 issued May 1975.

6. IRT Corporation Test Procedure Document 167-56-9 issued June 1975.

7. General Atomic Test Specification 167-56-6, "Internal Gamma Scanning of Peach Bottom Primary Circuit," October 1975.

8. IRT Corporation Test Procedures Document 167-56-10, Test Procedure for Gamma Scanning the Peach Bottom Primary Circuit," November 1975.

9. Modern Trends in Activation Analysis, p. 1250, NBS Special Publication 312, J. R. Devoe (Ed.), 1969. 
This page intentionally left blank. 


\section{APPENDIX A}

PEACH BOTTOM STEAM GENERATOR TUBE FISSION PRODUCT PLATEOUT VALUES 
This page intentionally left blank. 


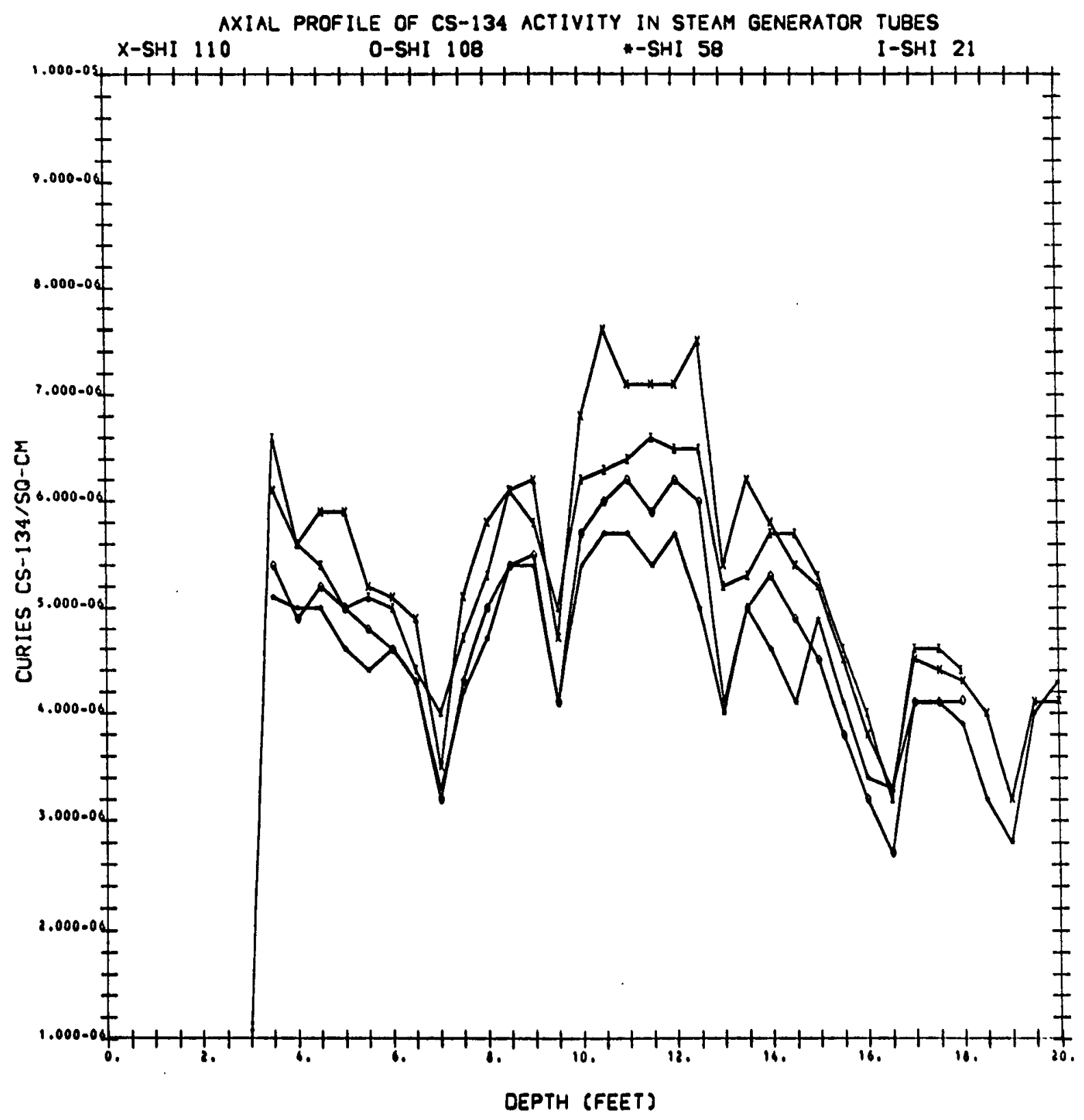




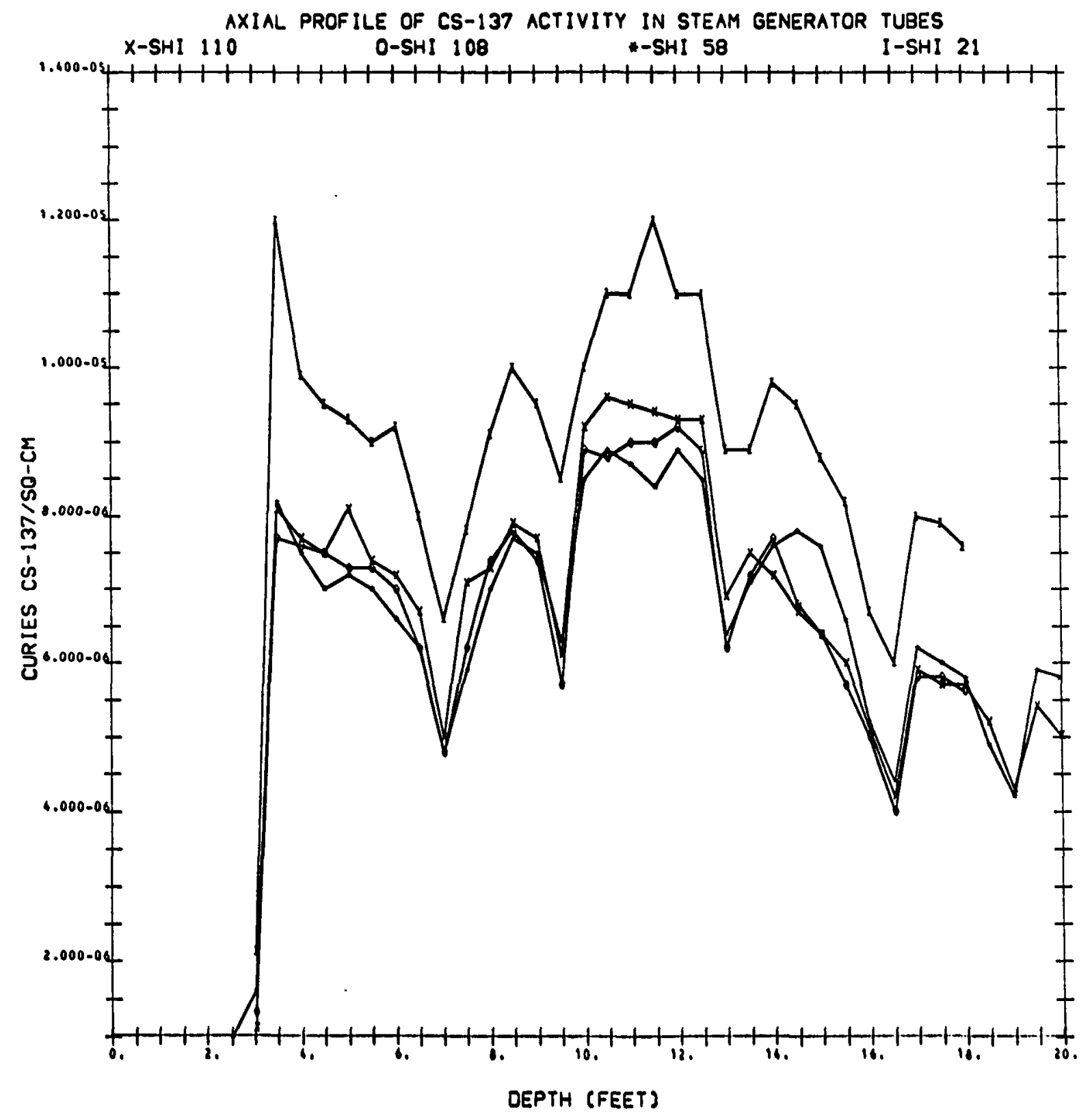




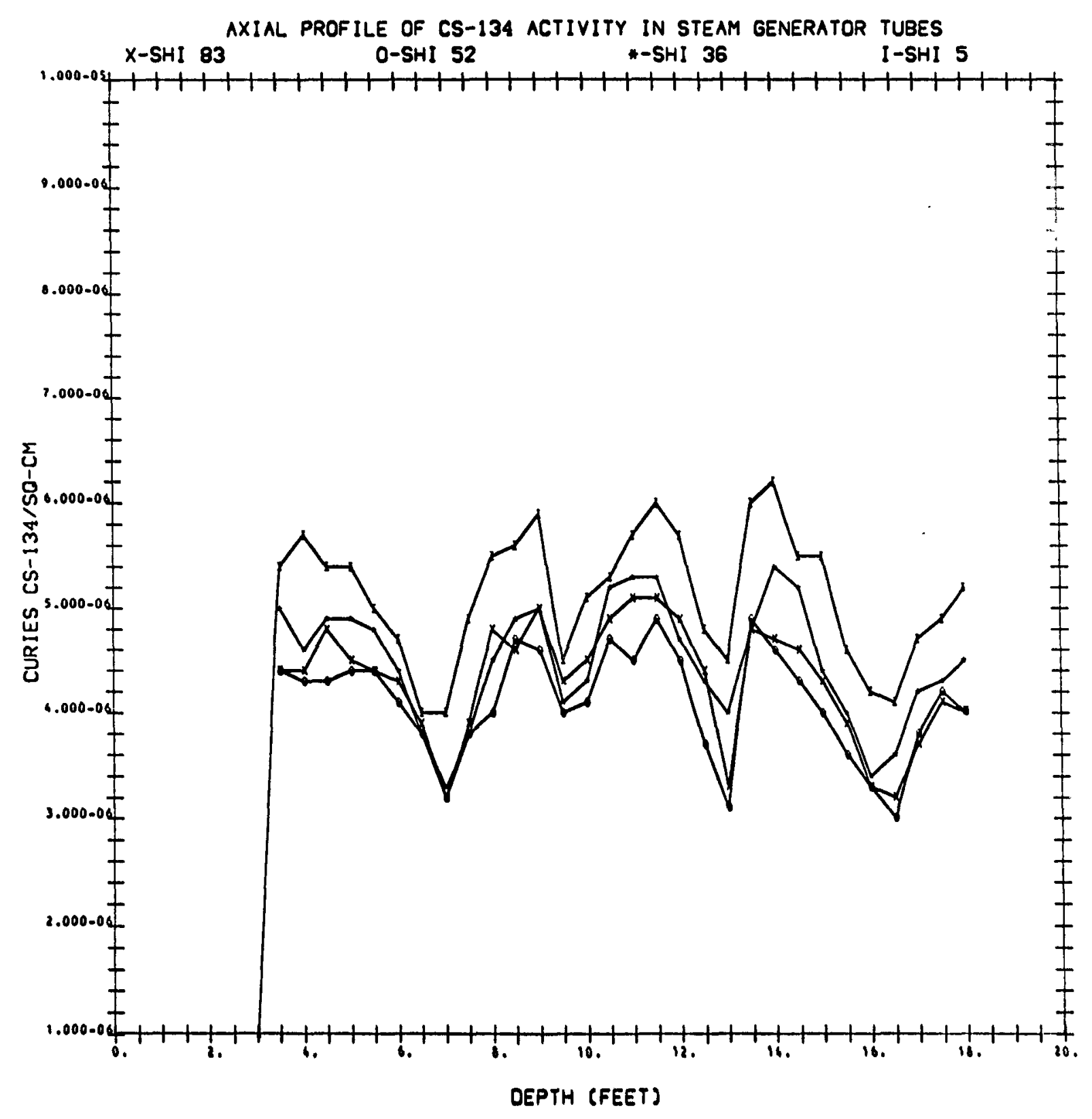




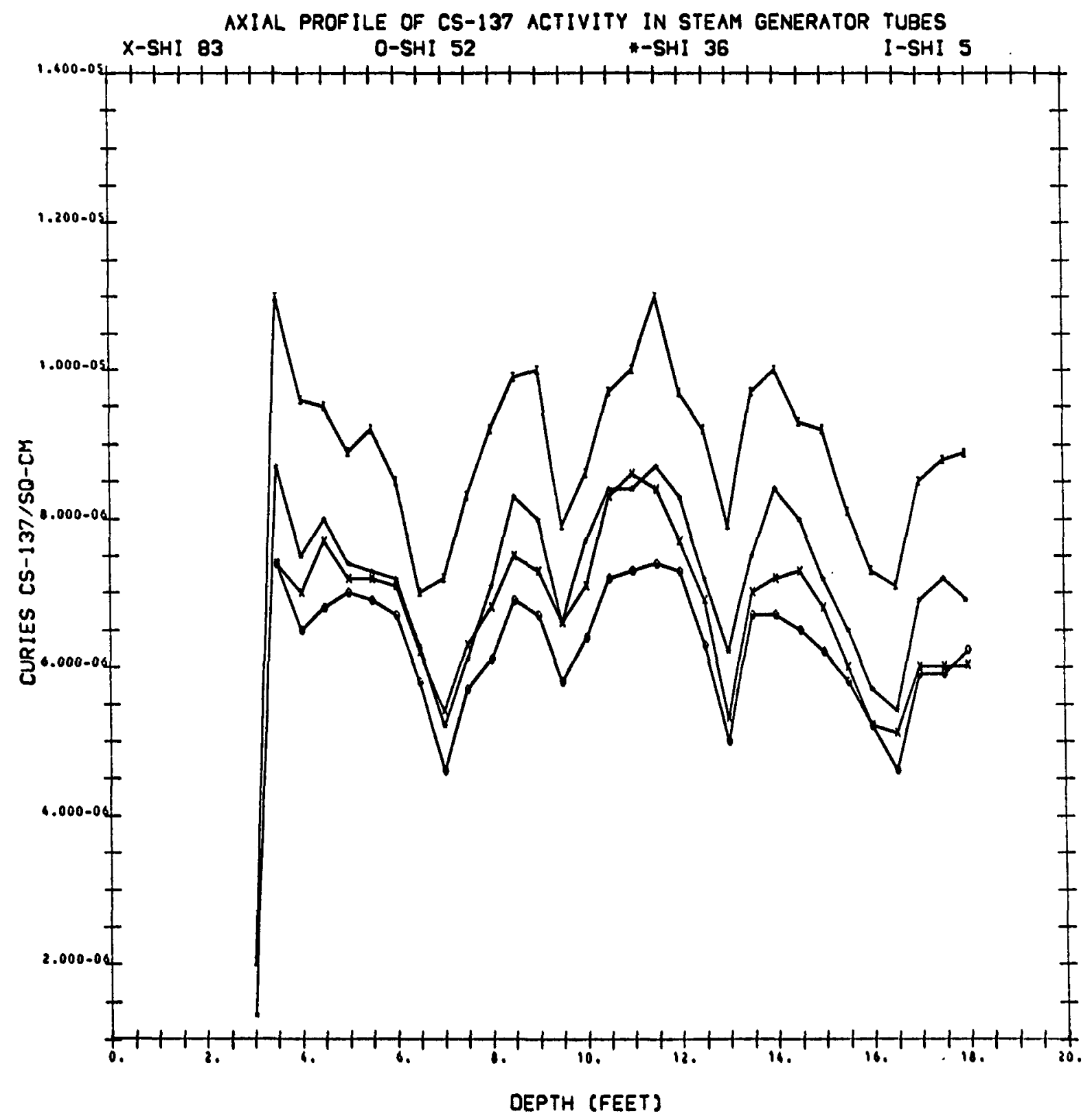




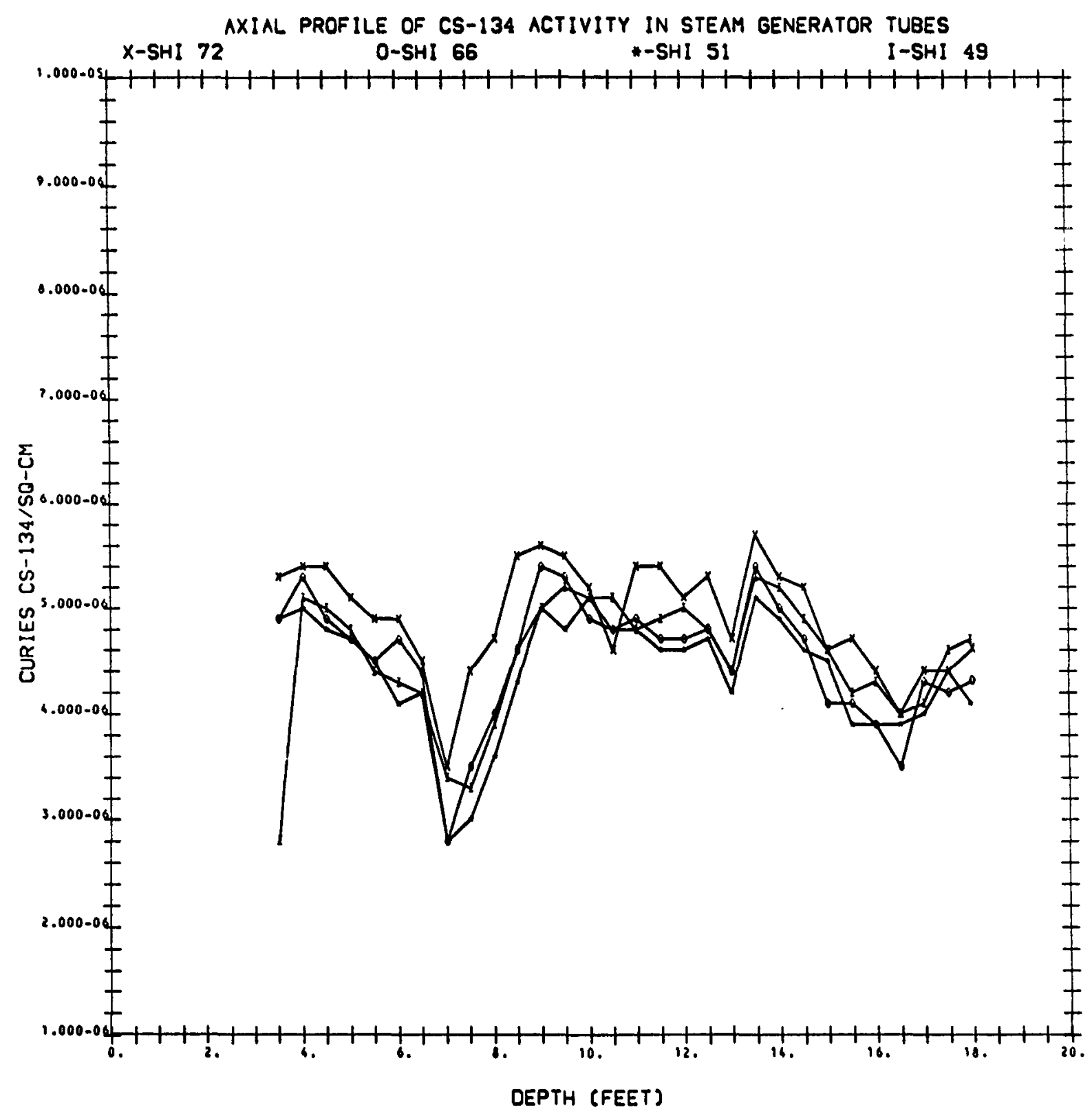




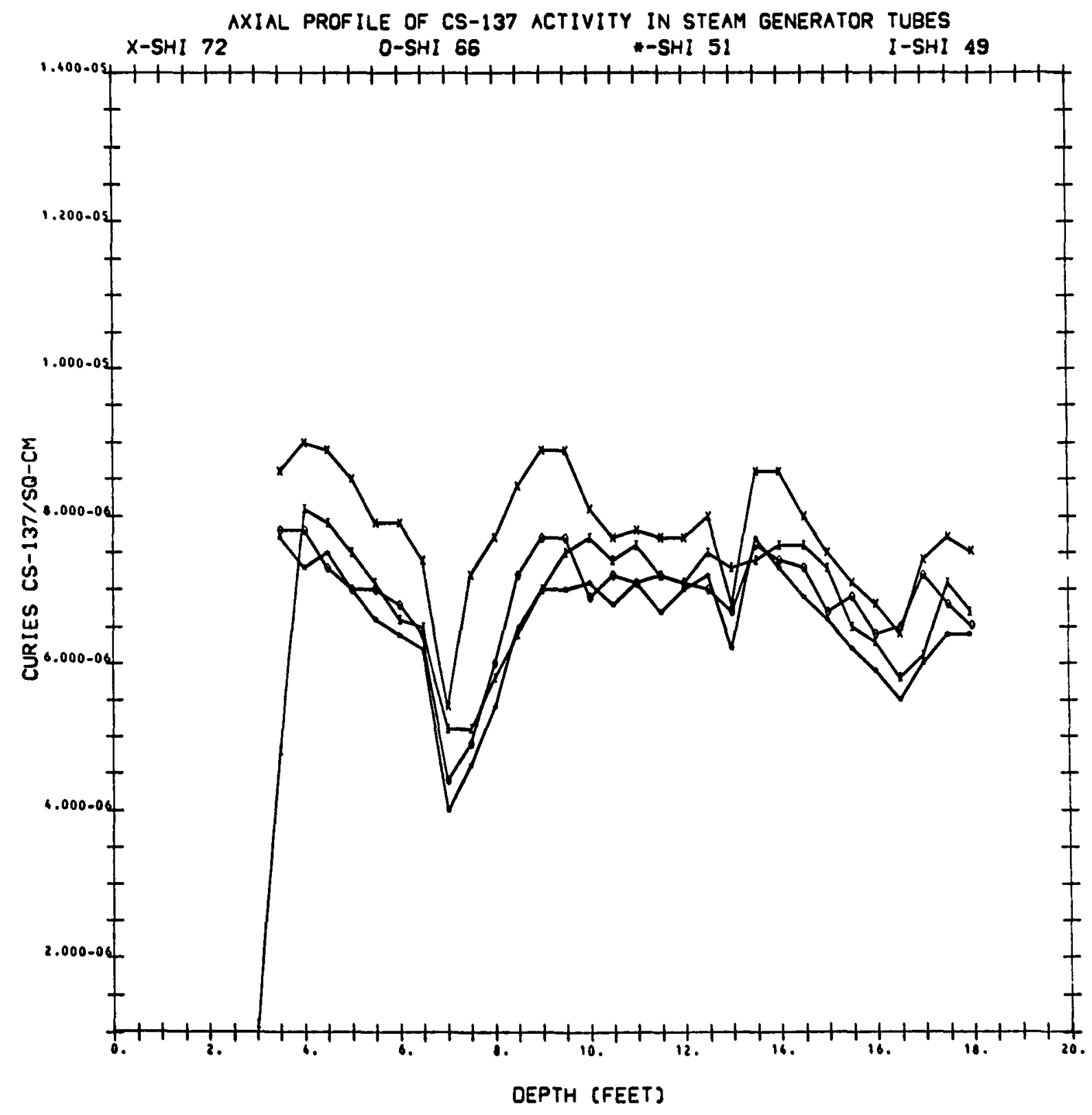




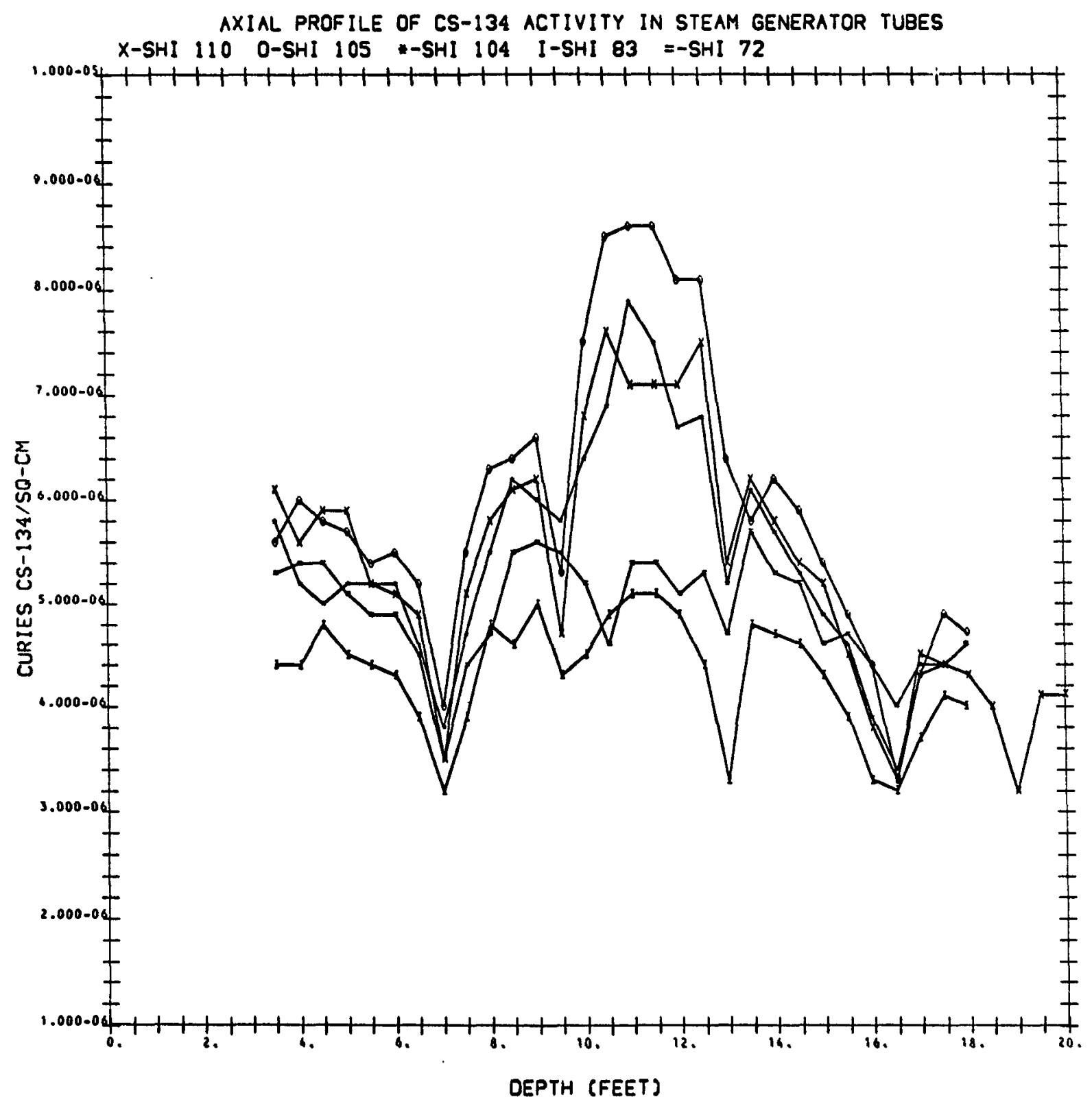




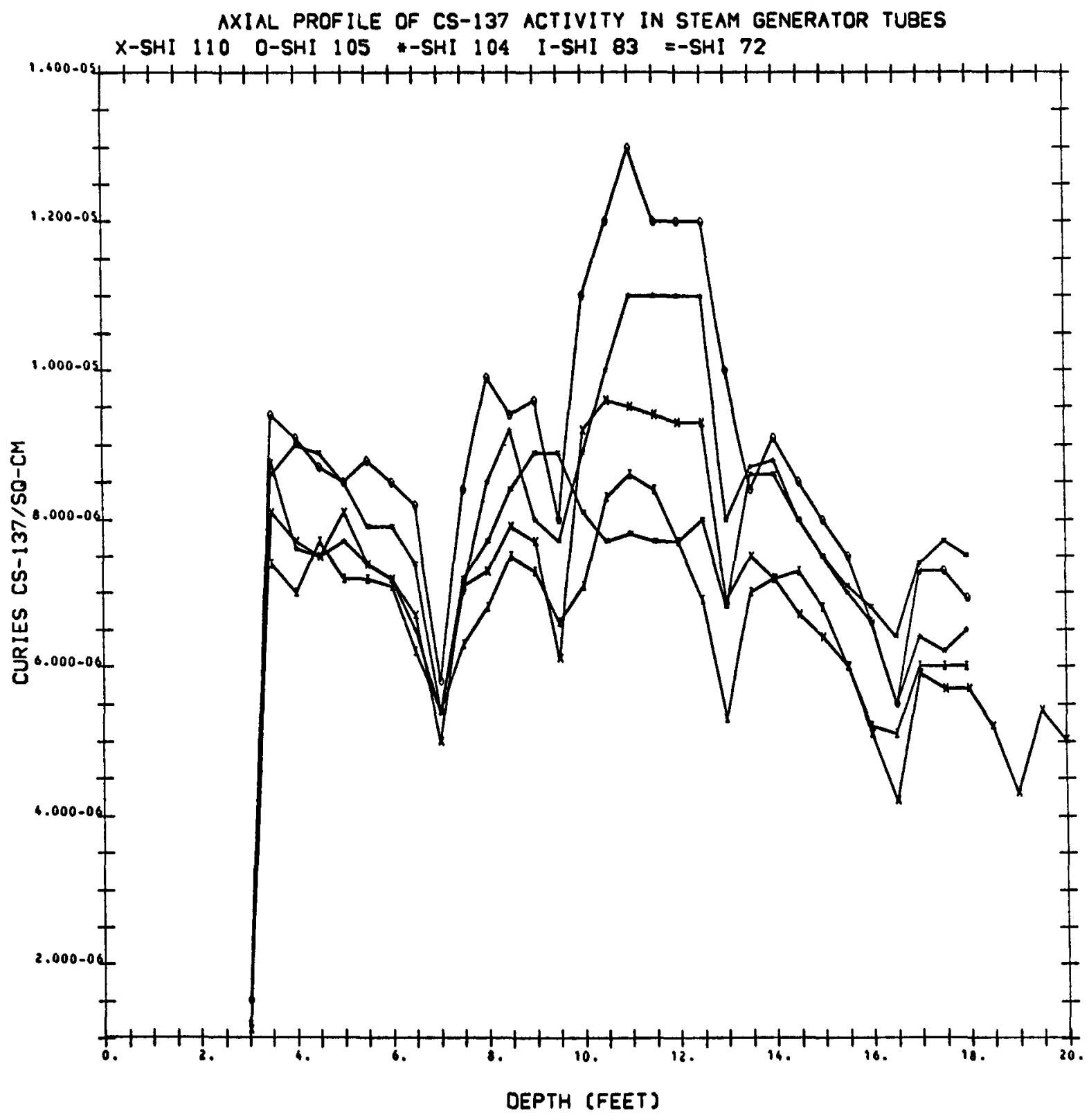




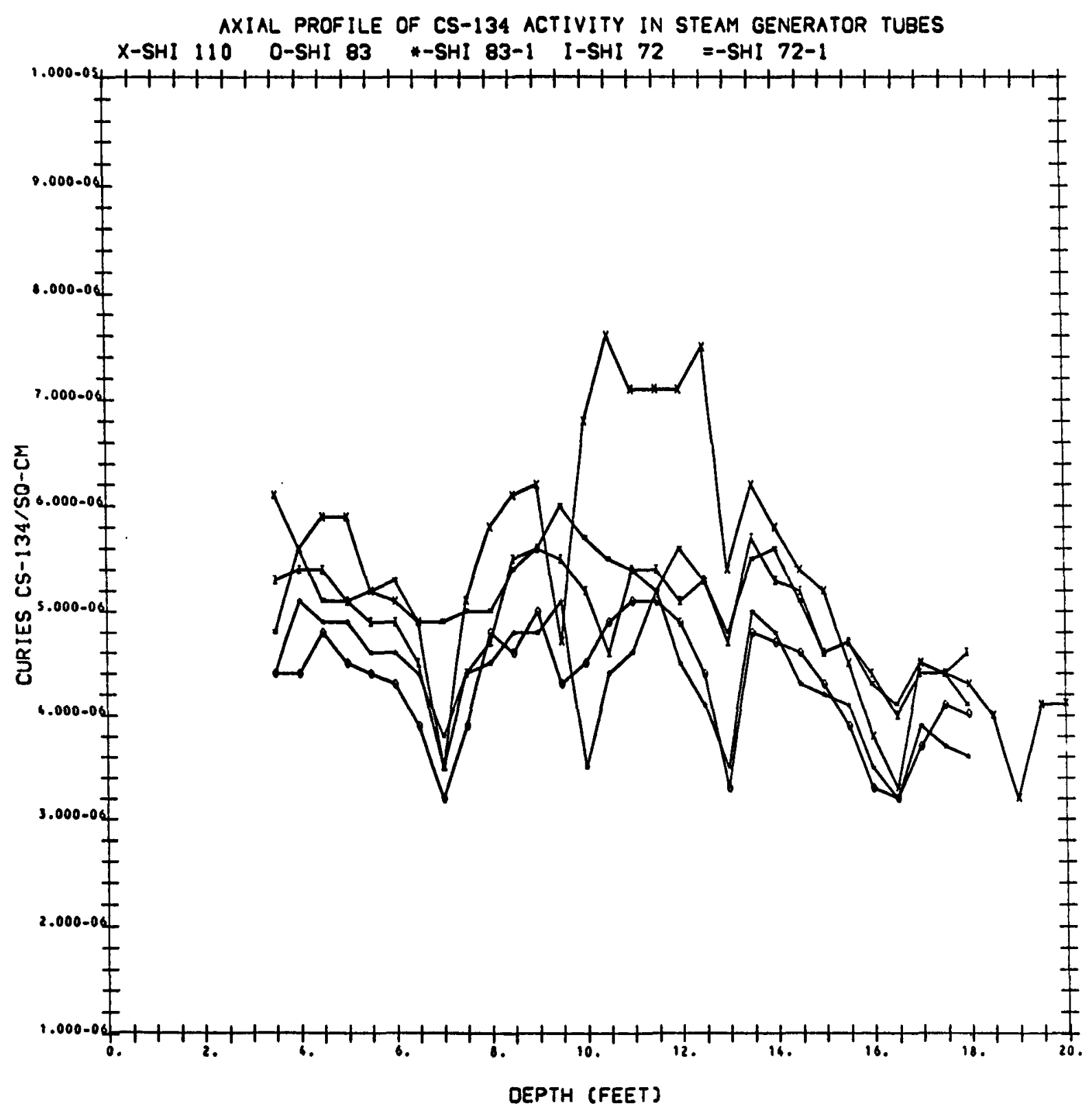




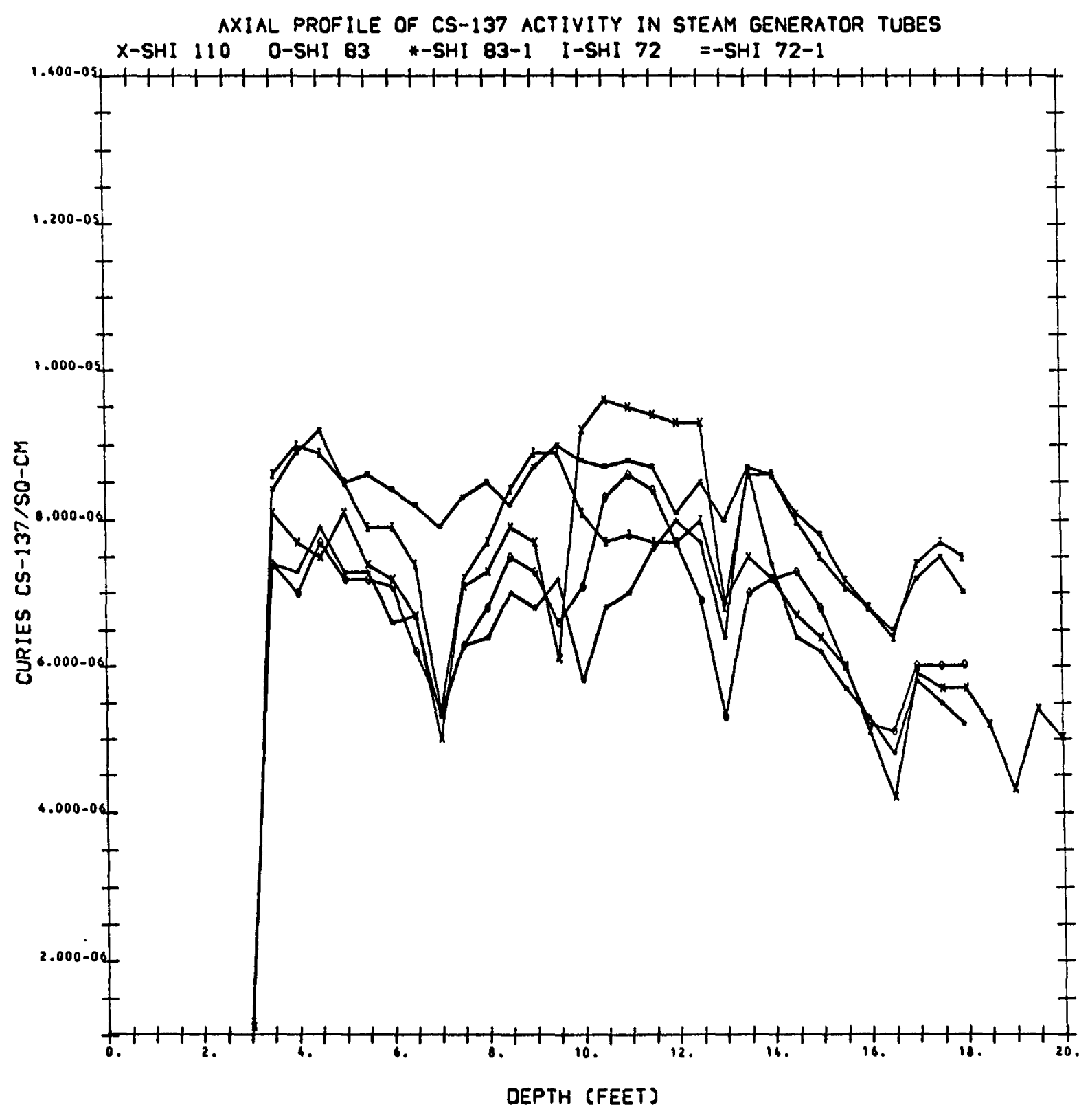




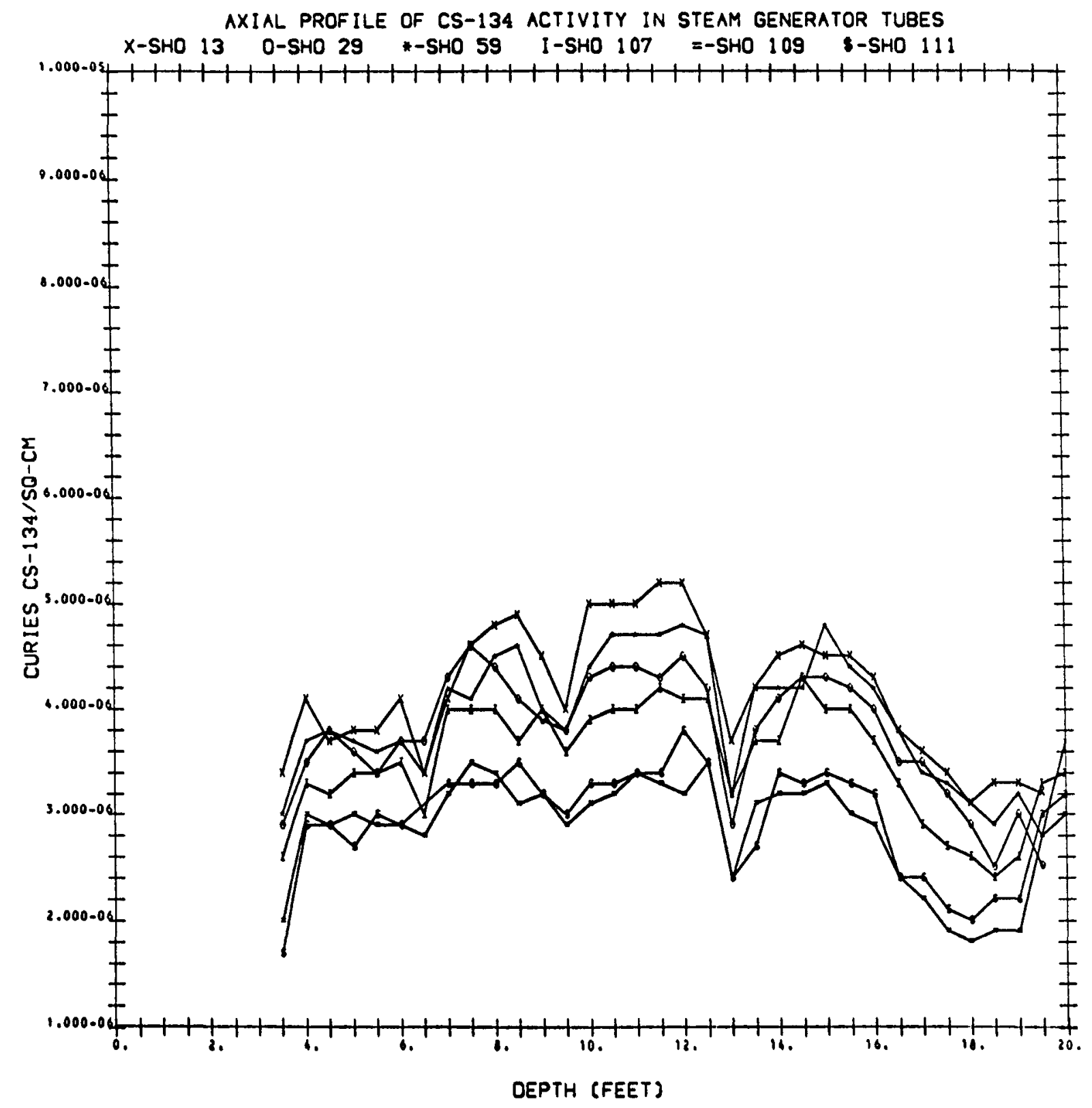




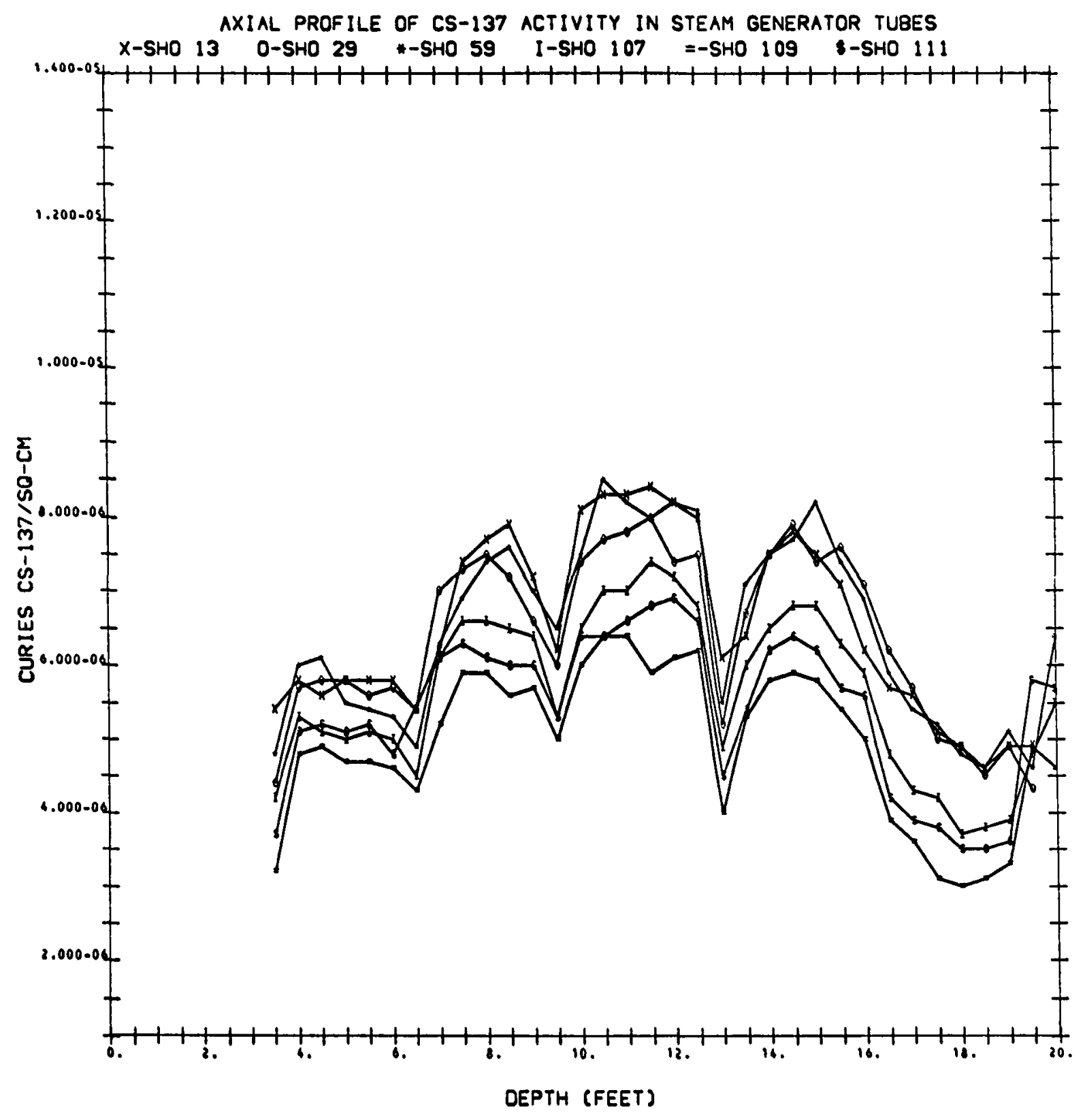




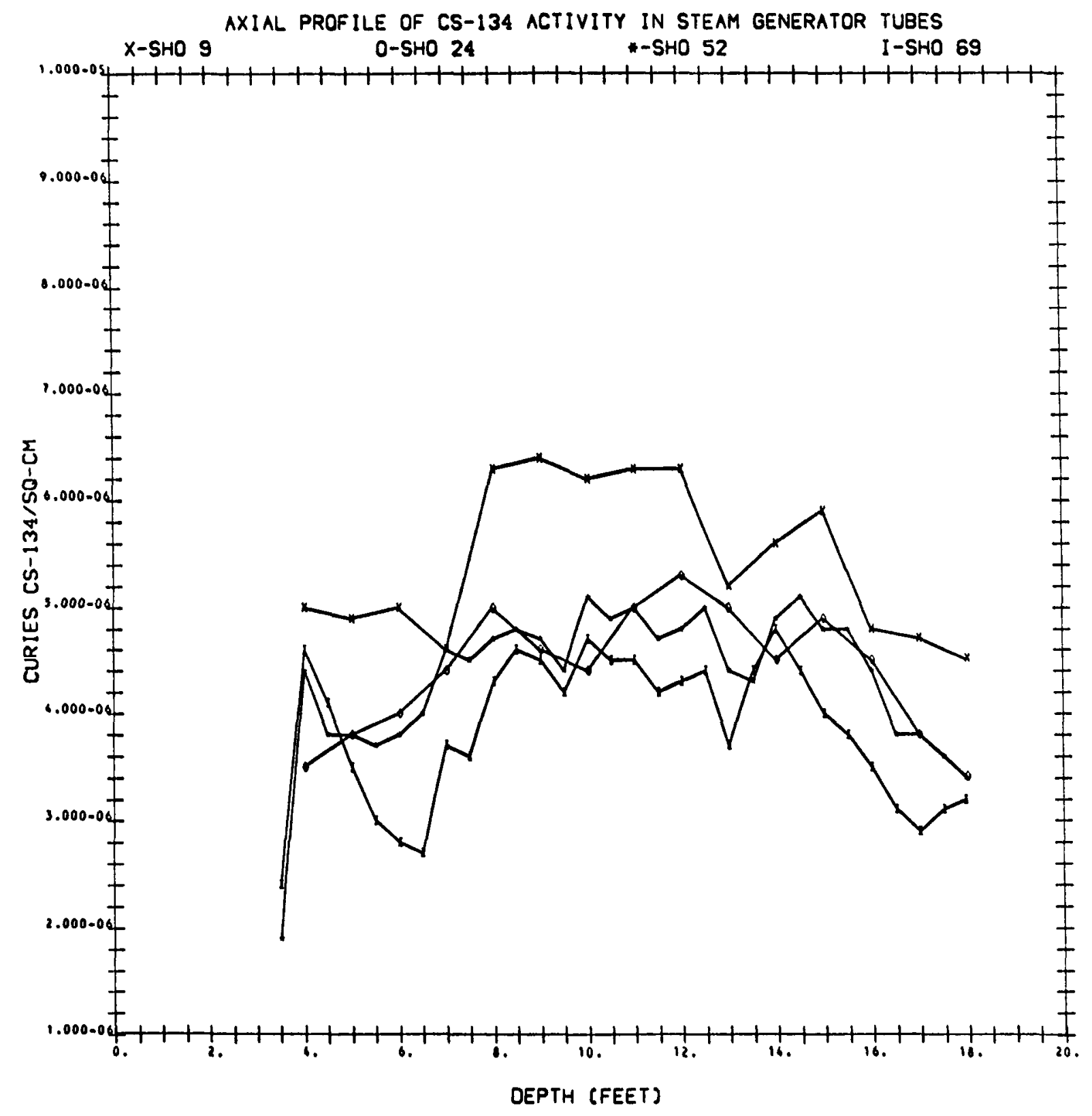




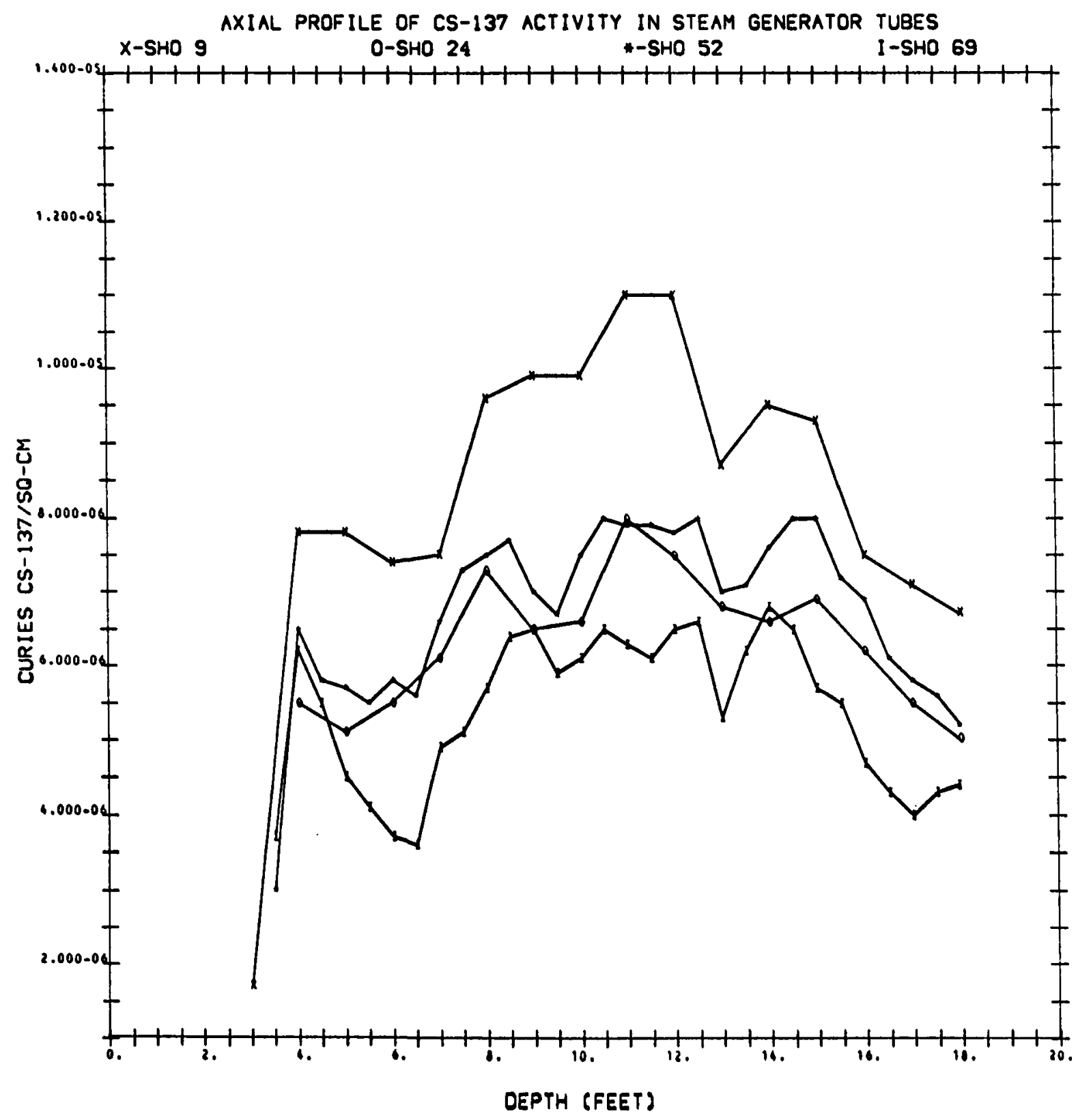




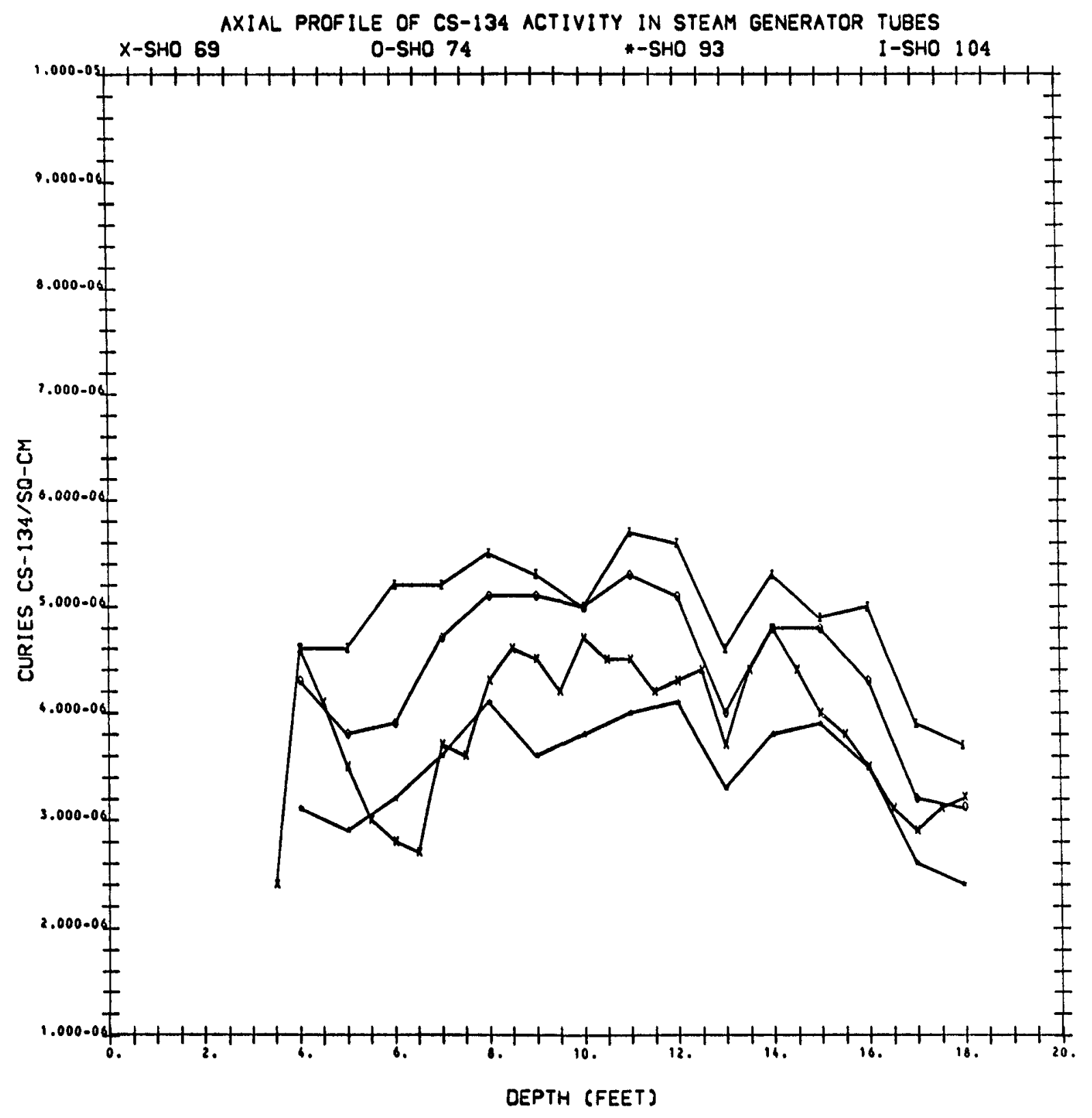




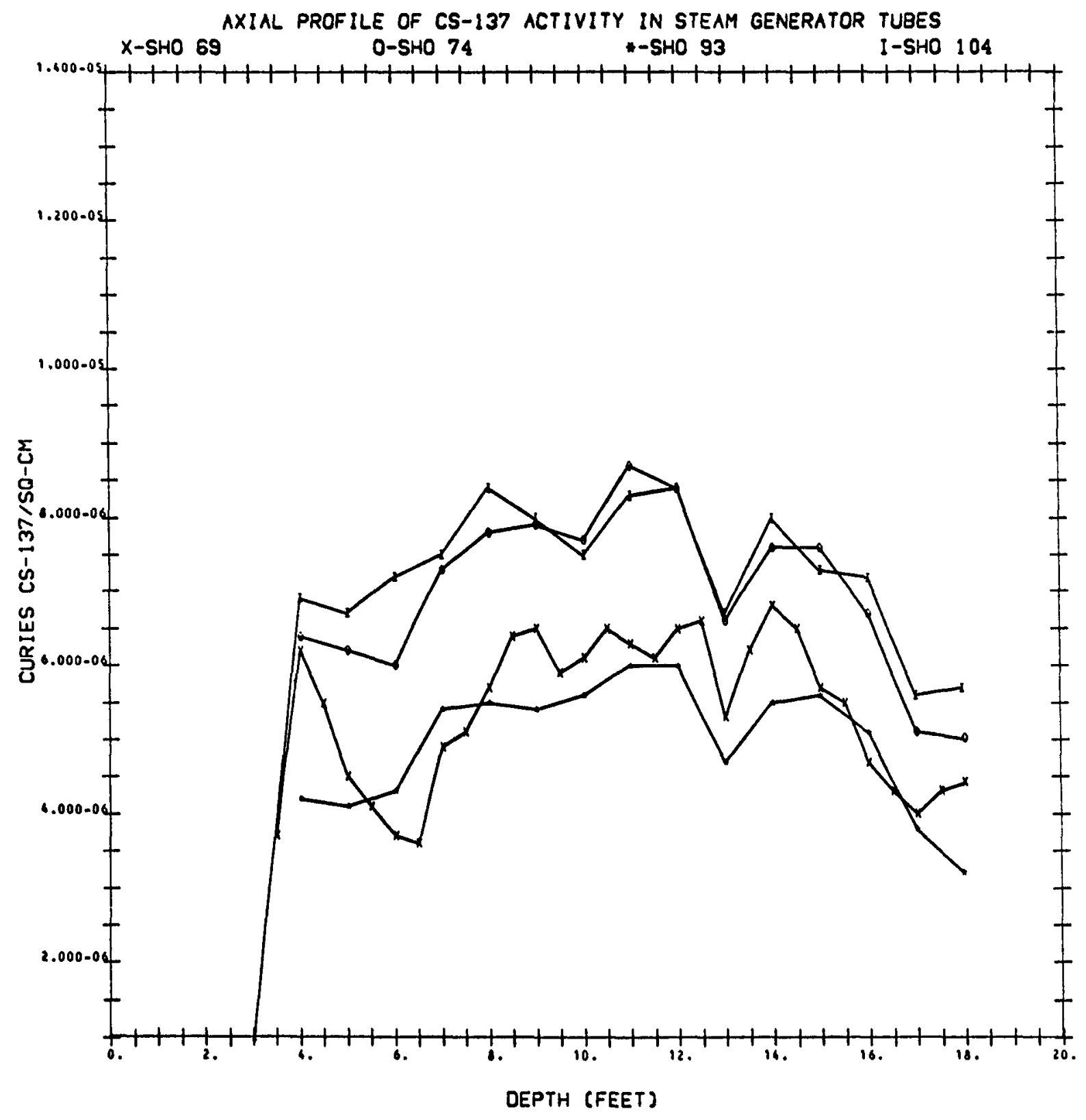




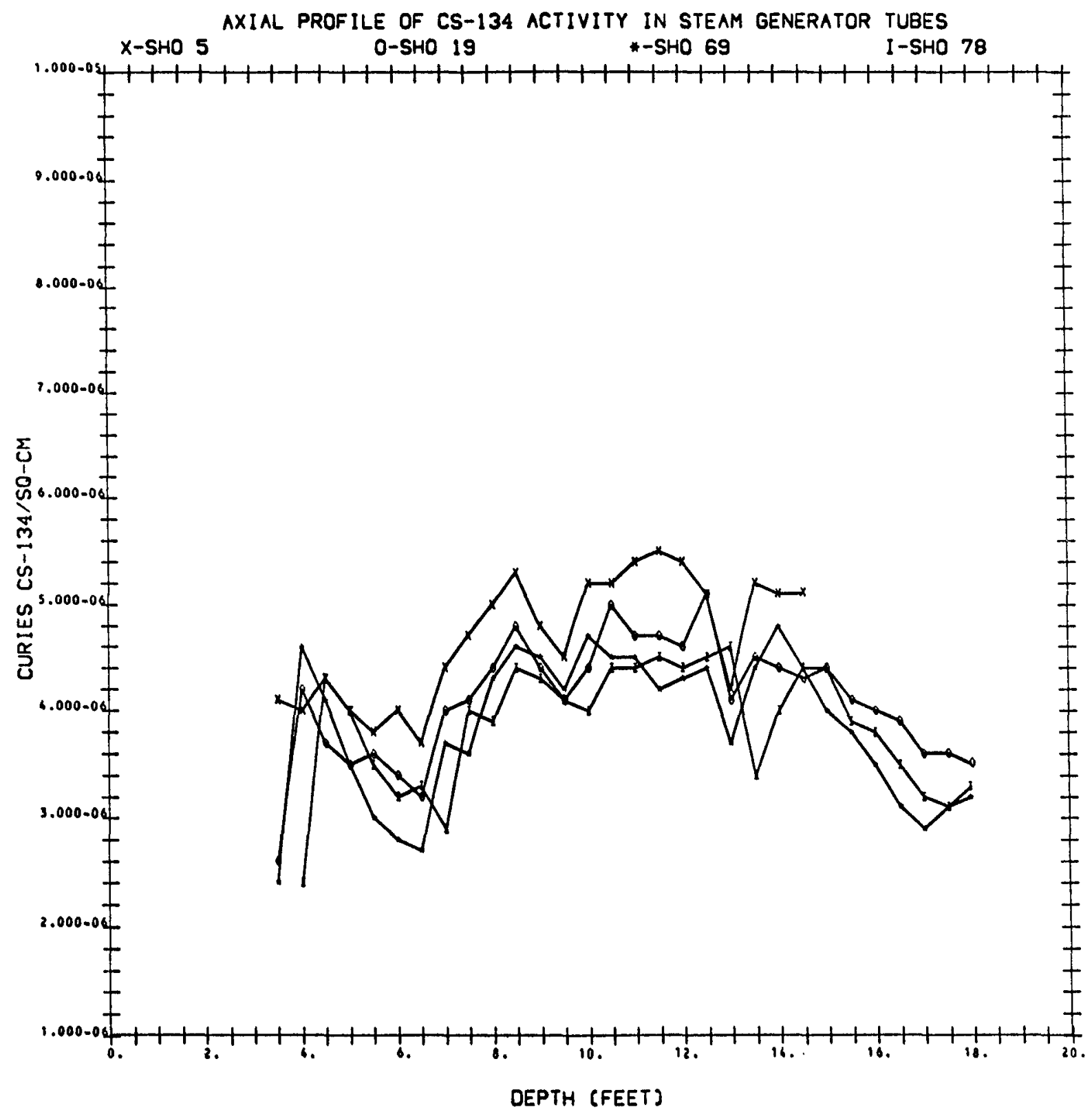




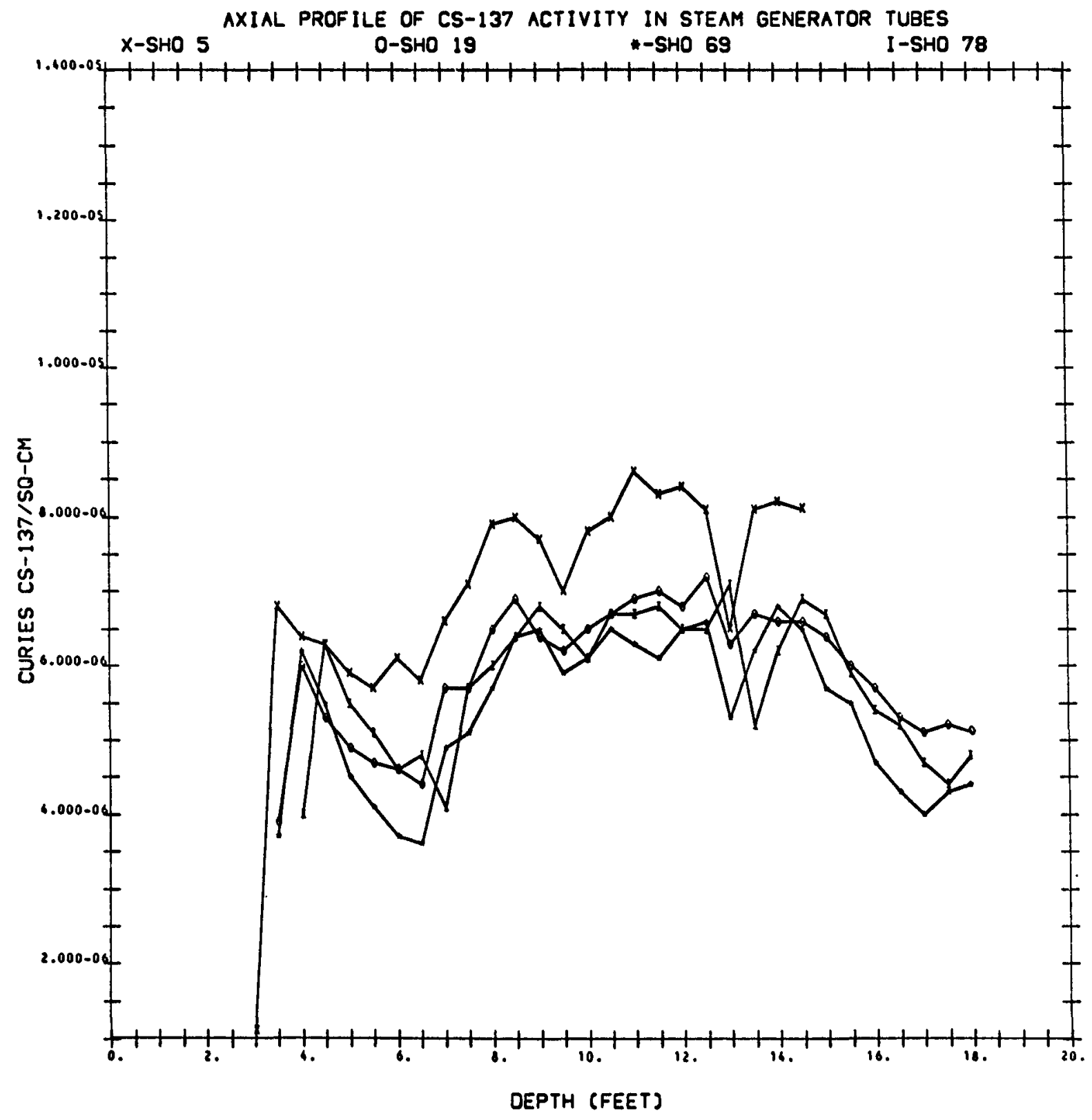




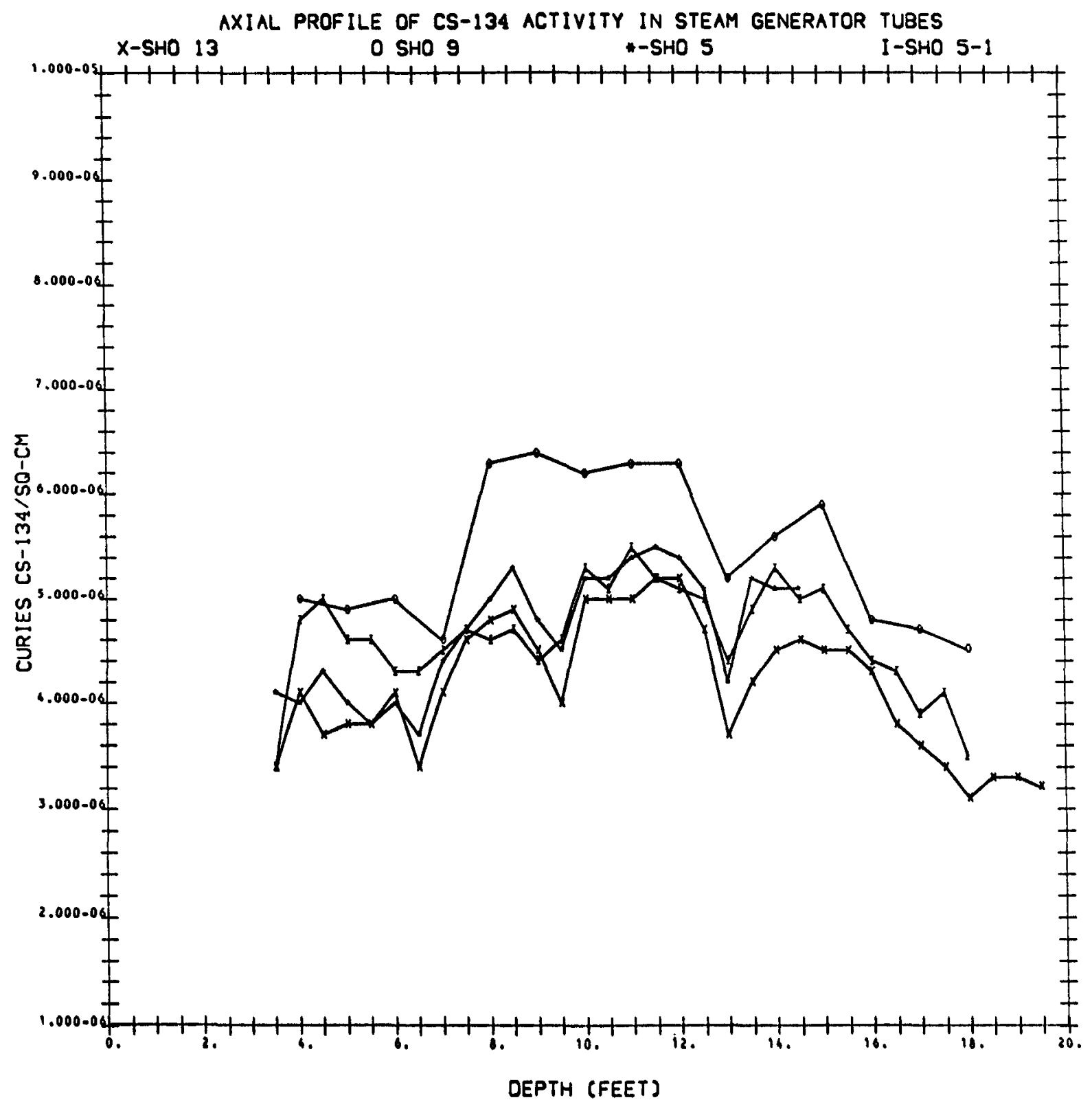




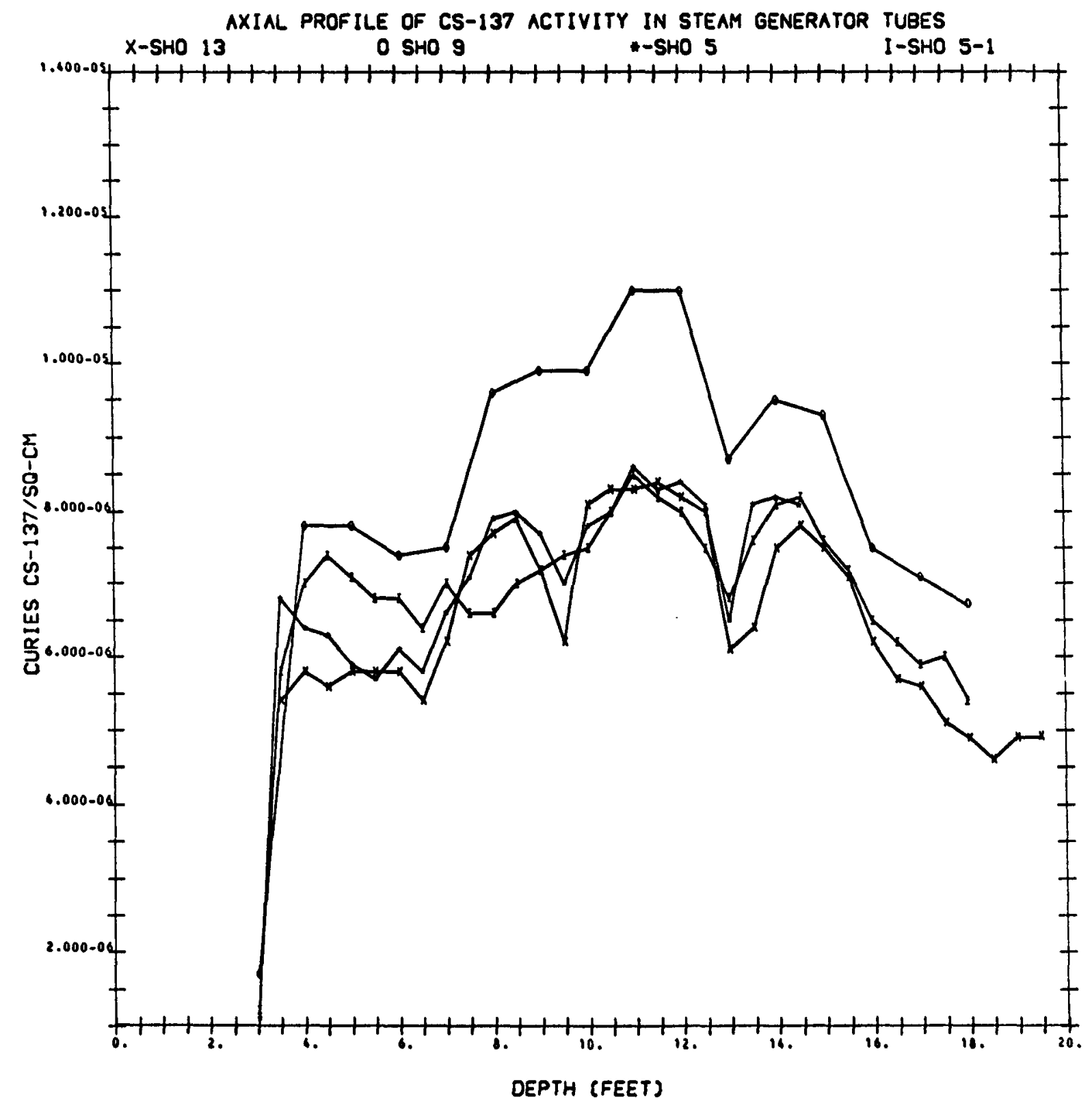




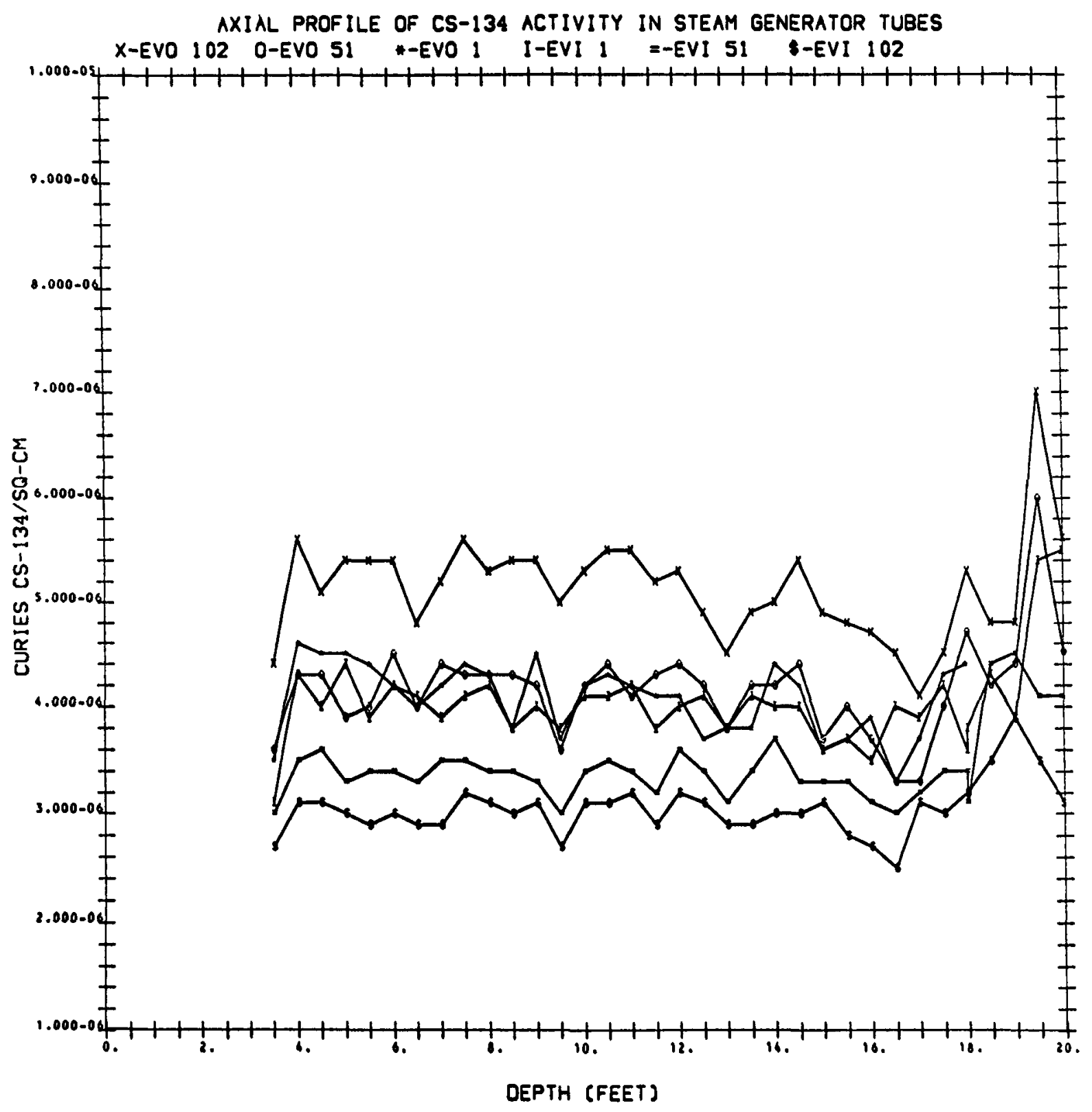




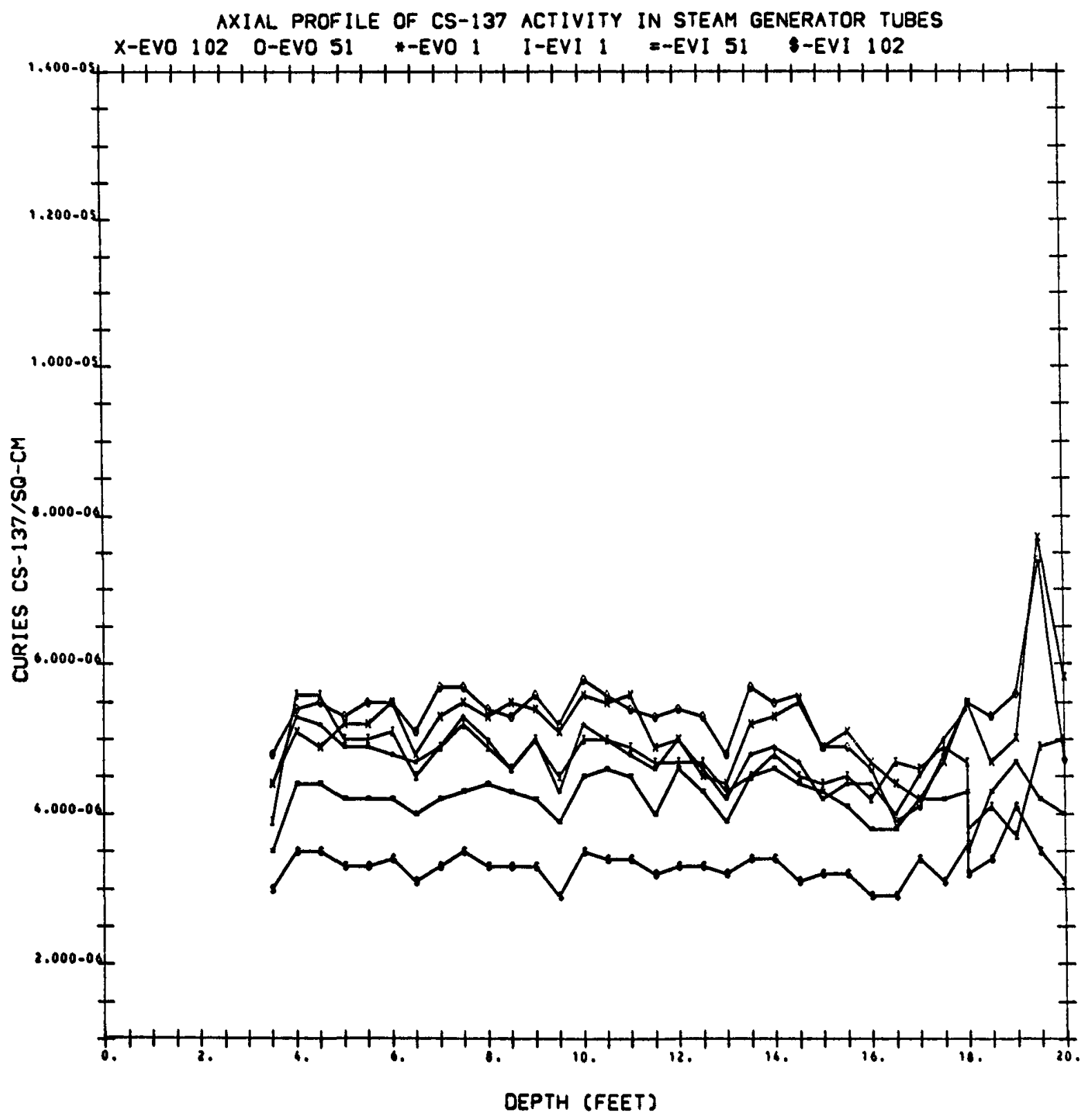




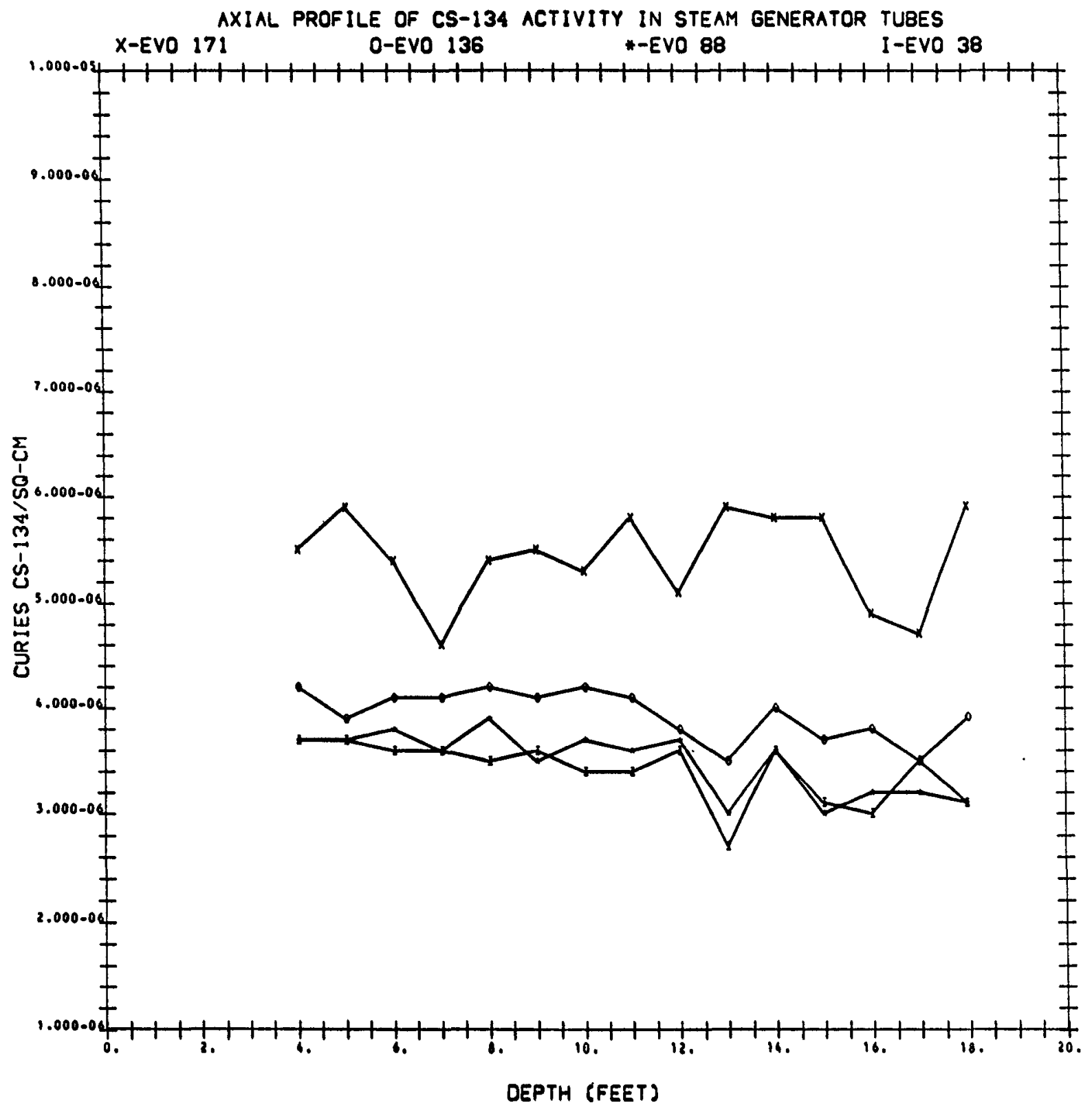




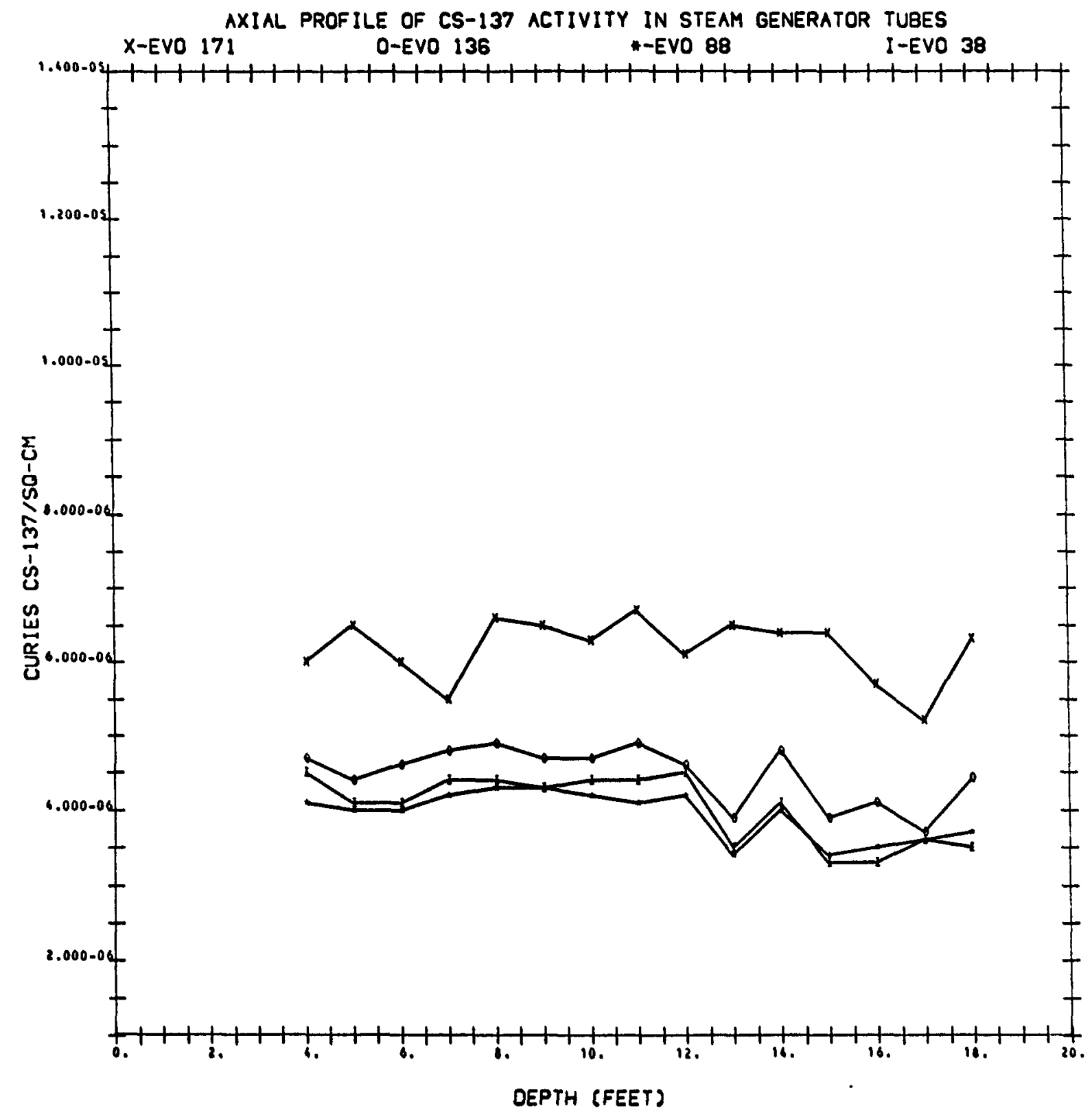




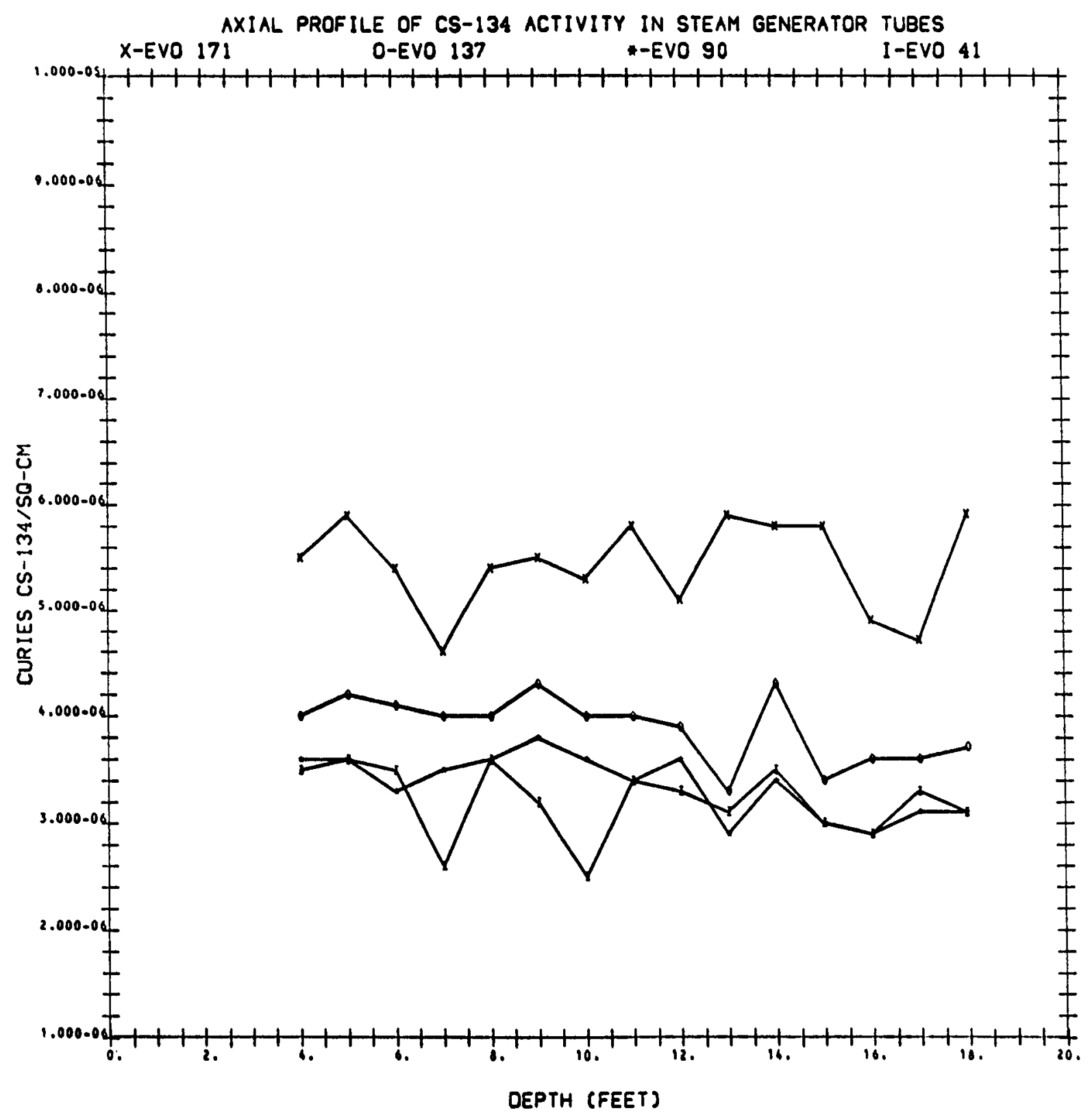




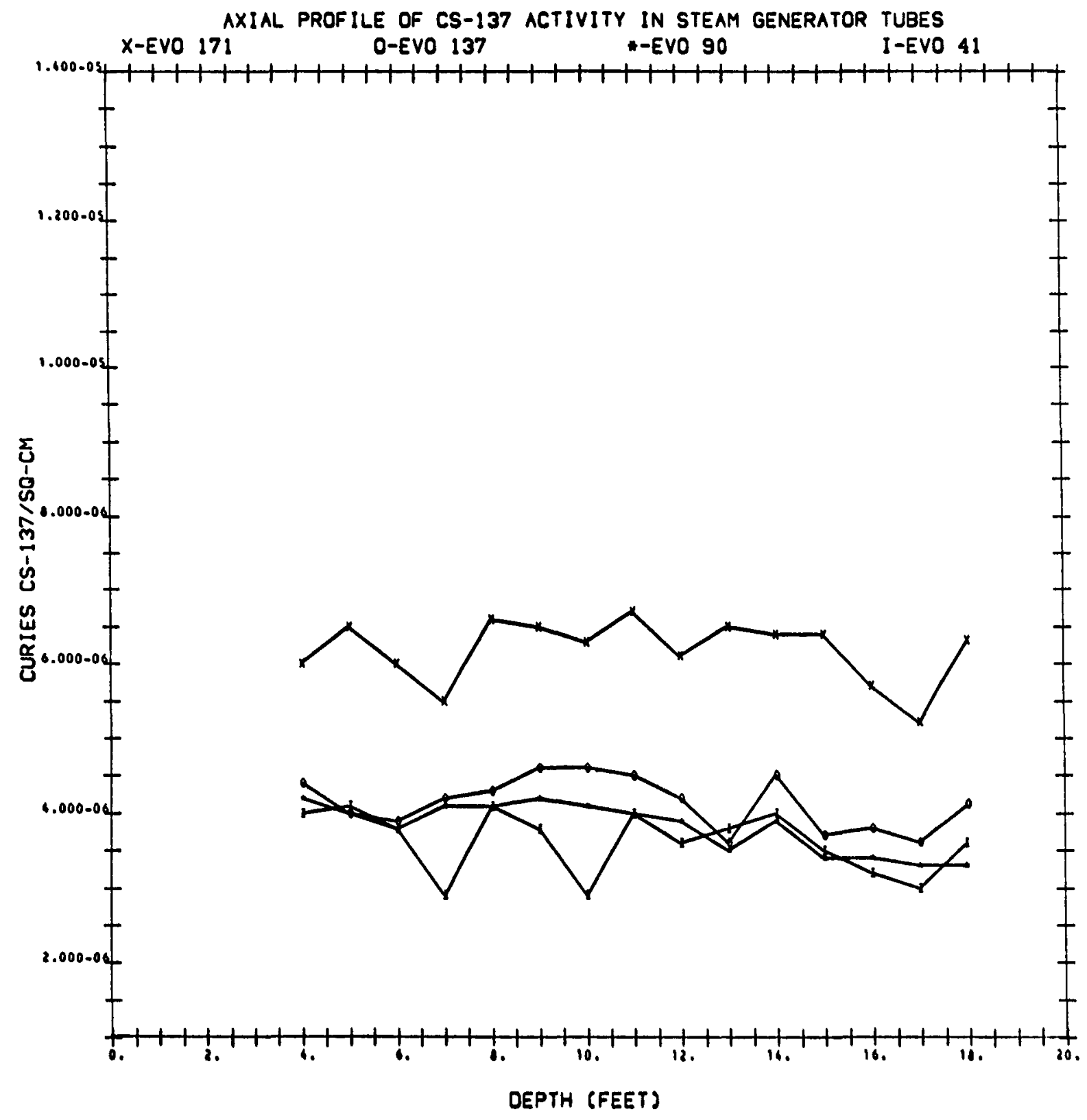




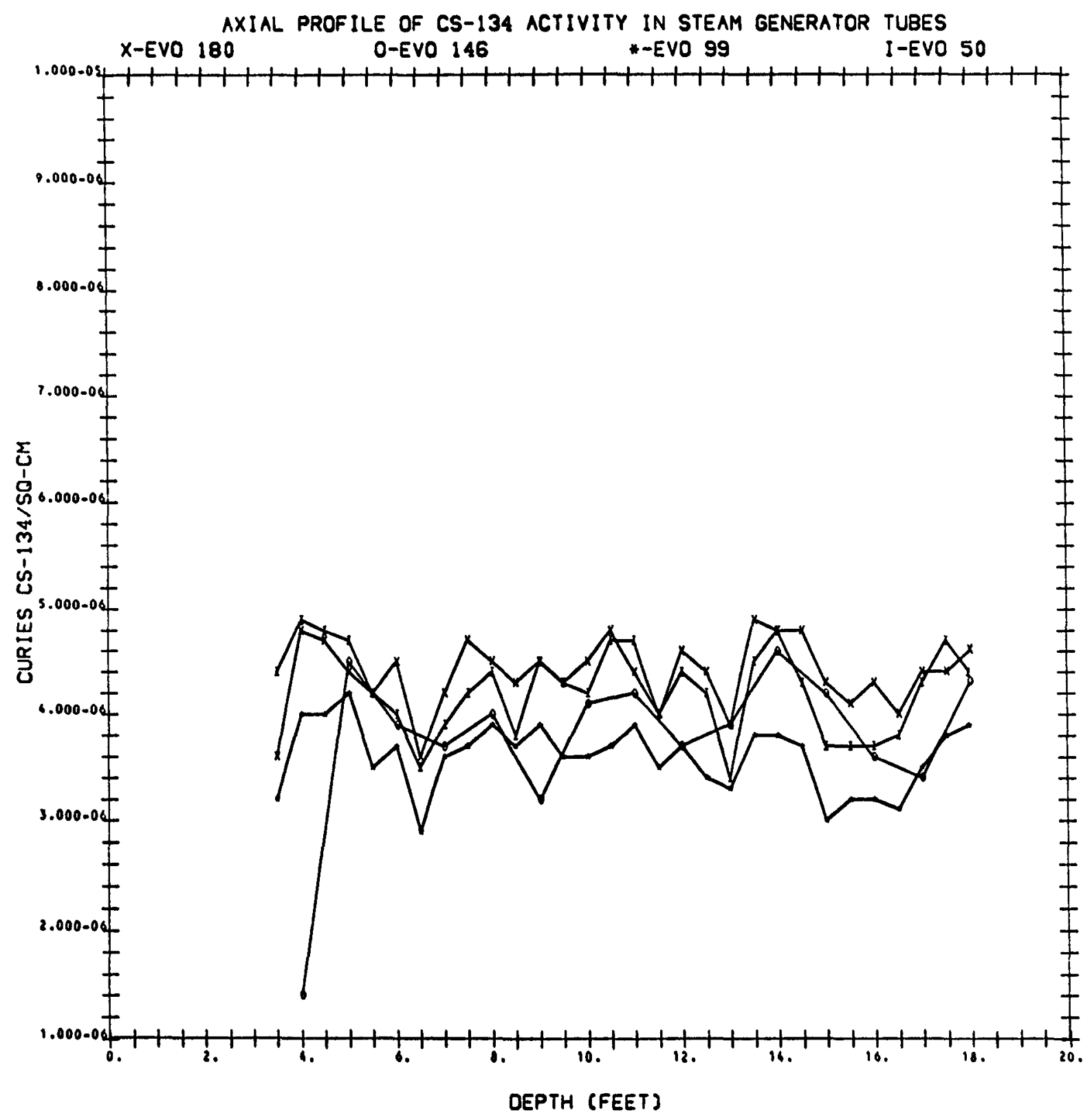




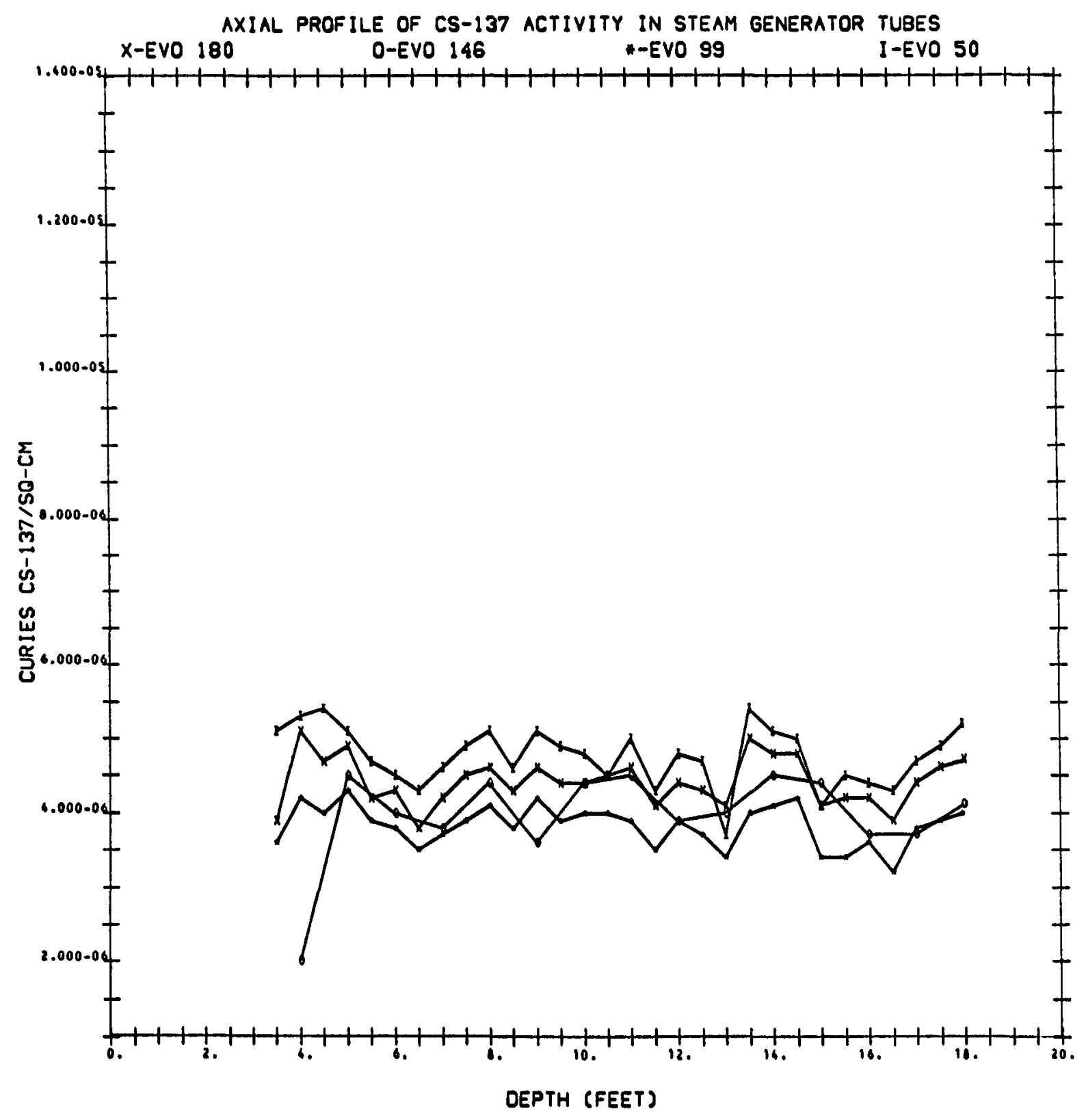




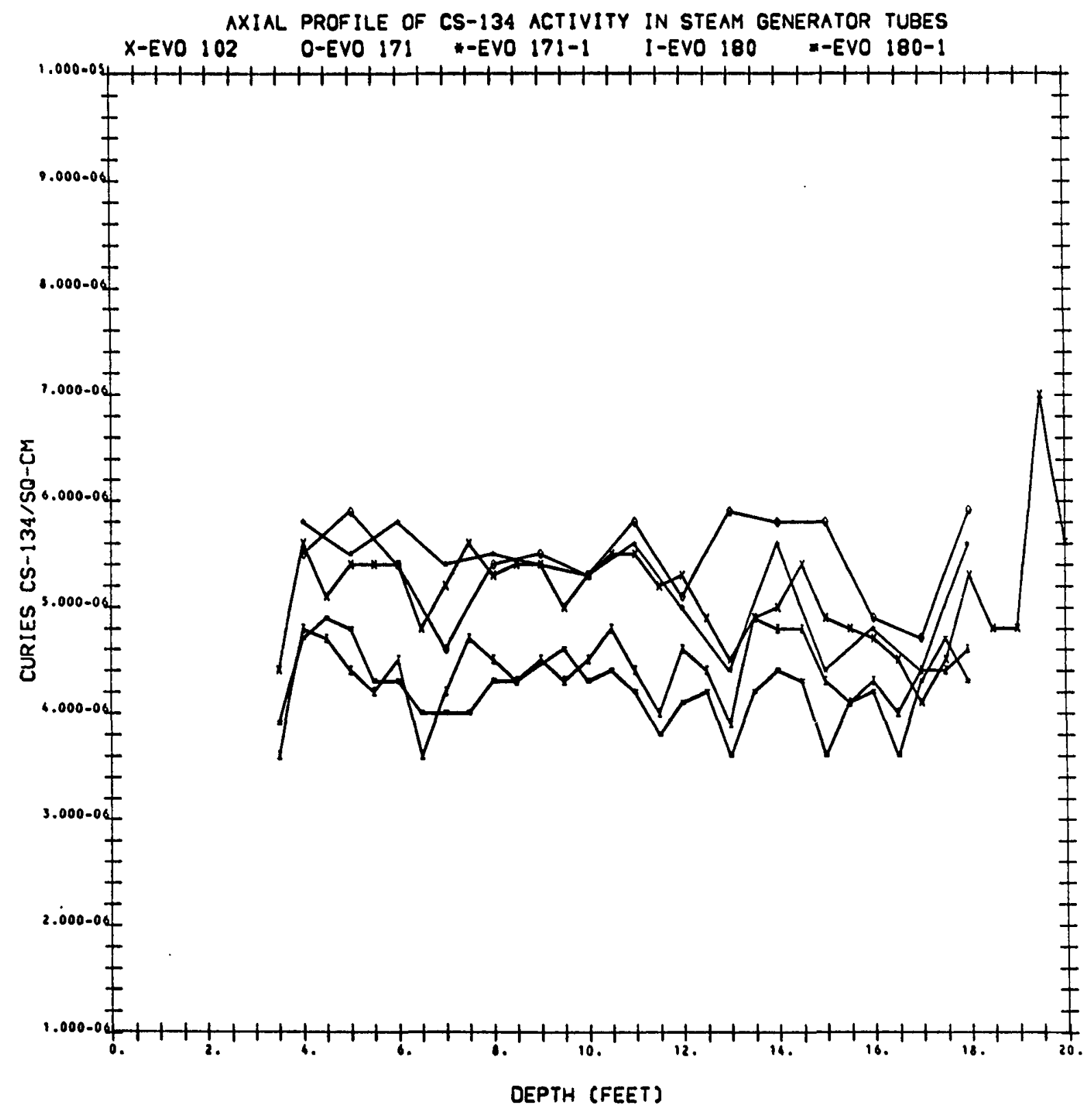




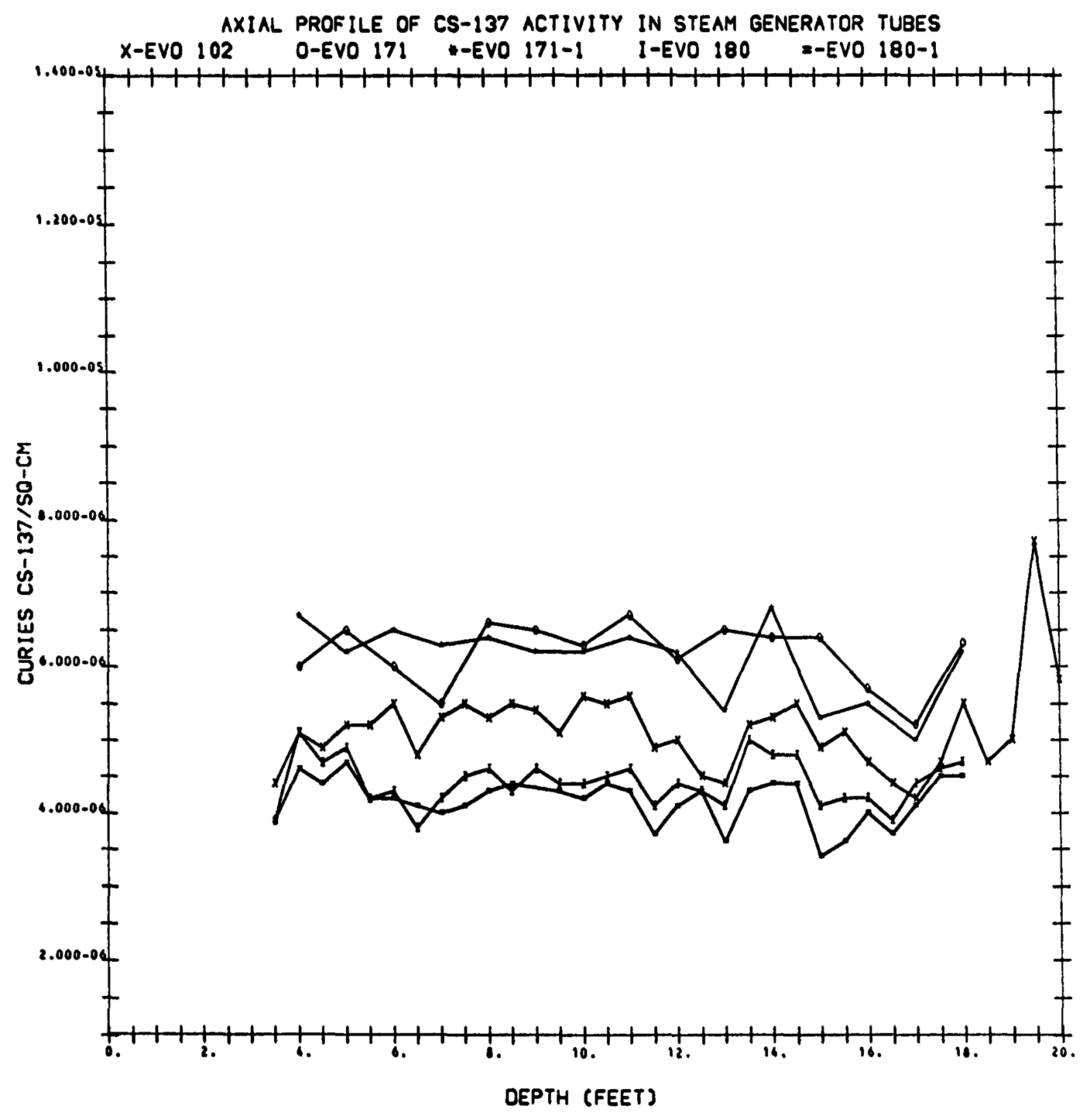




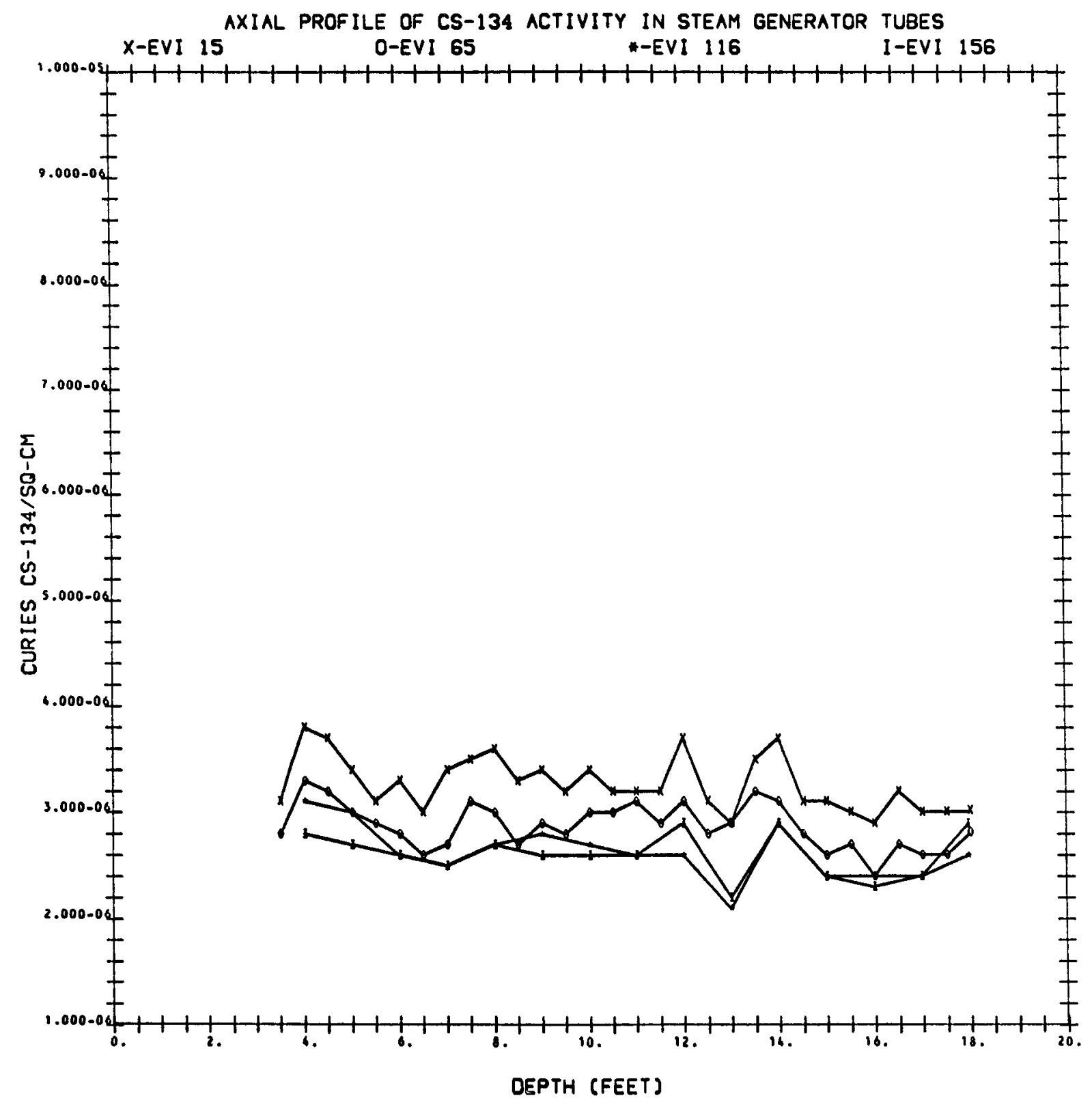




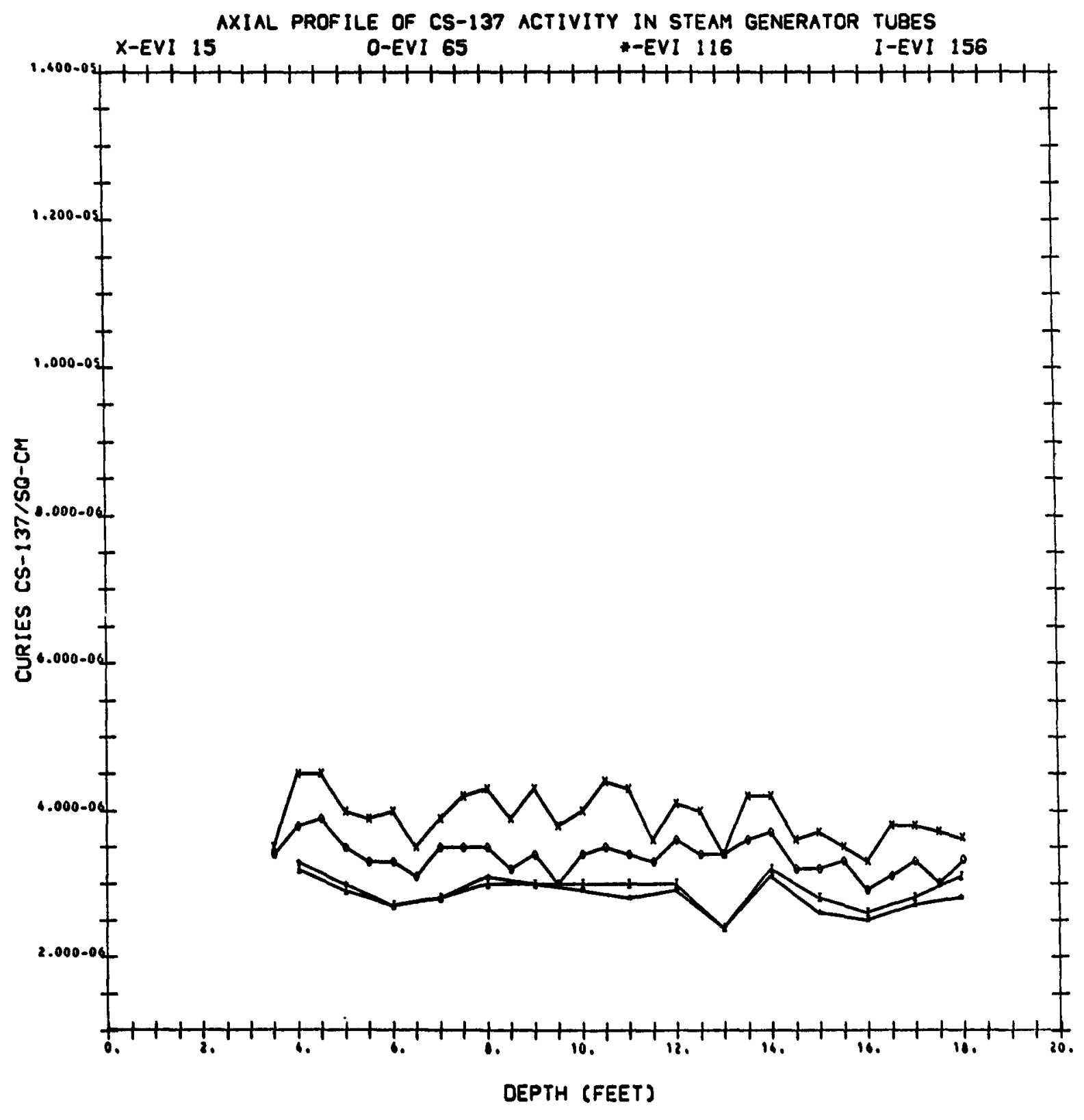




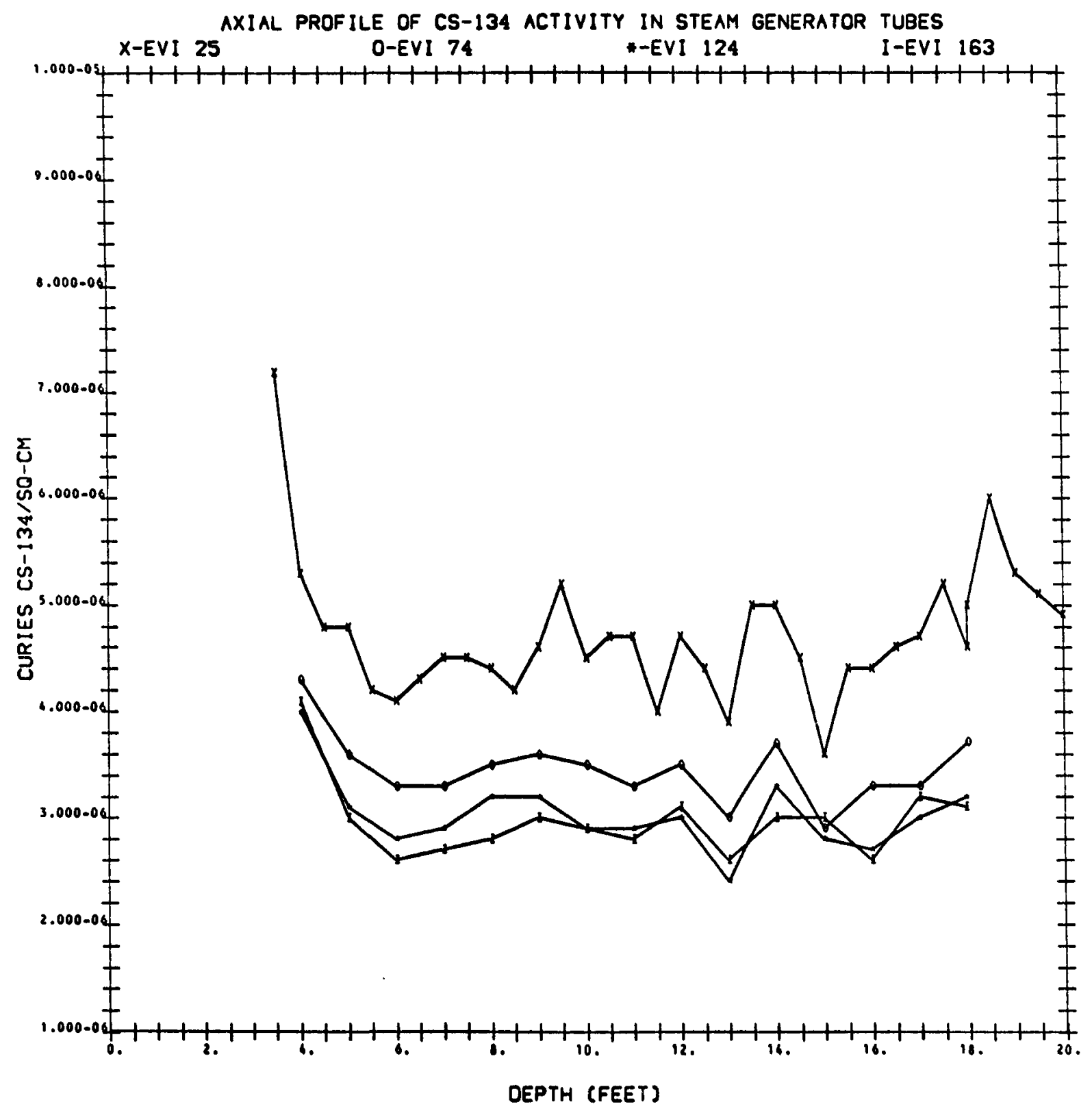




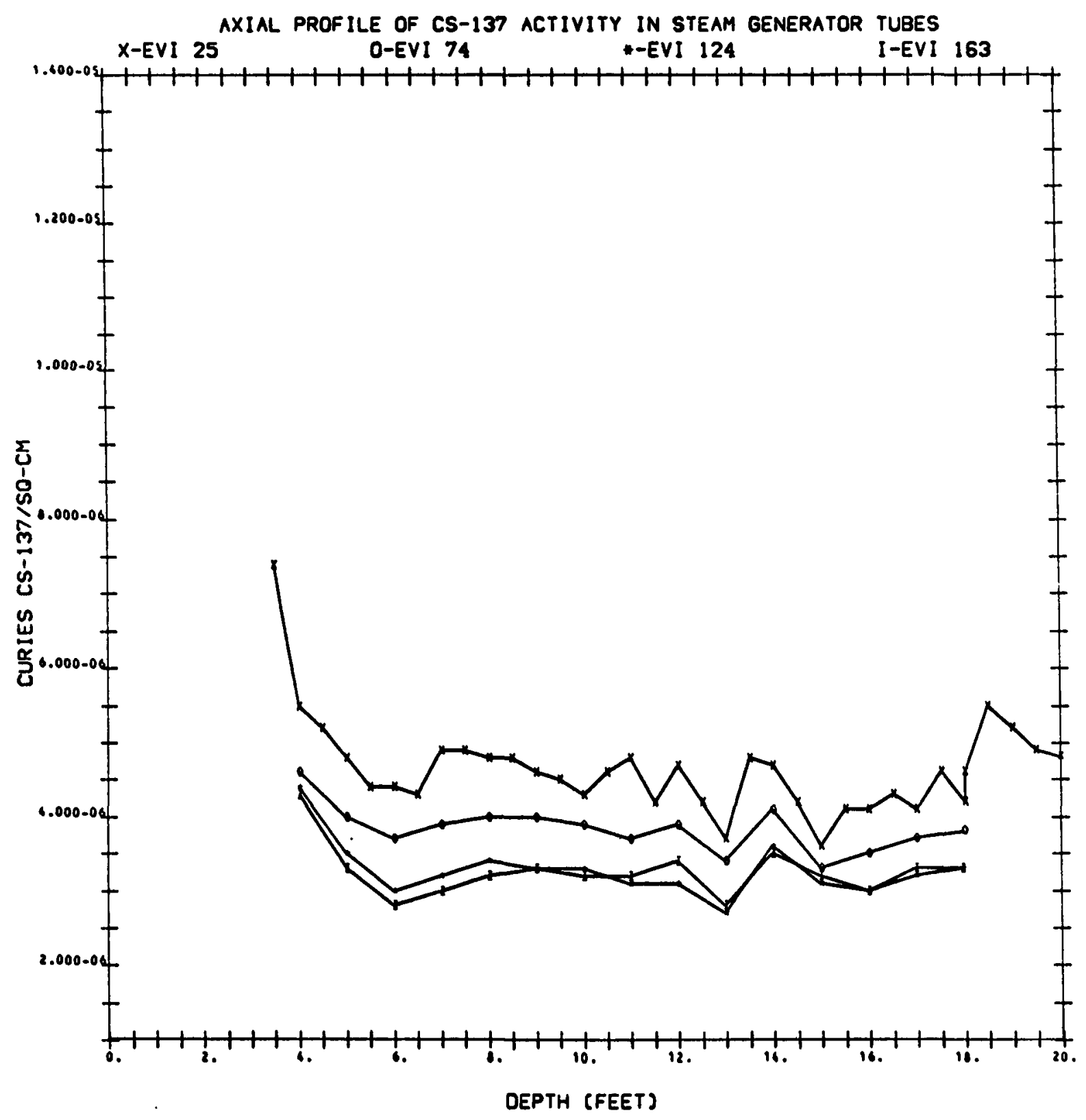




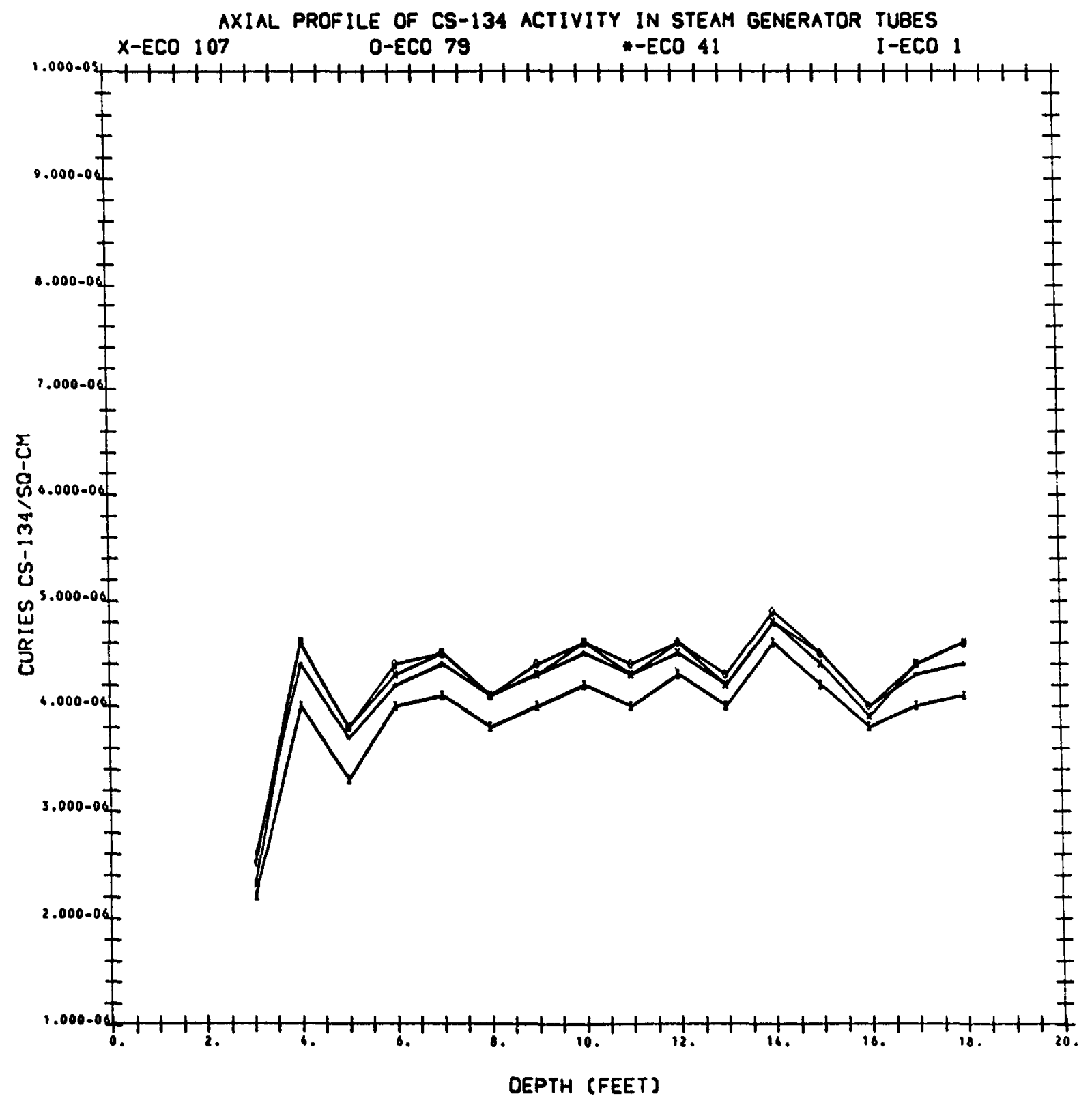




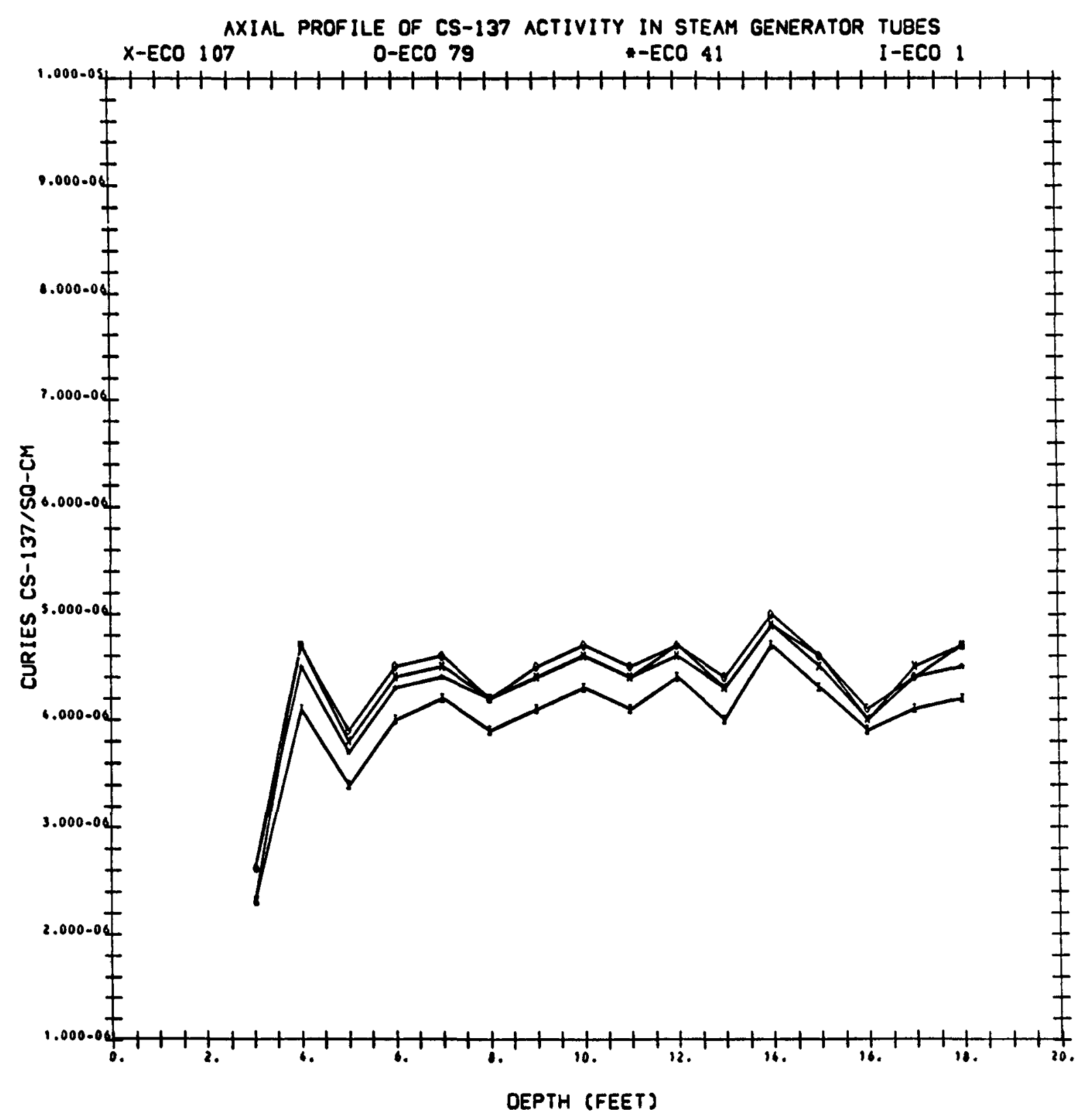




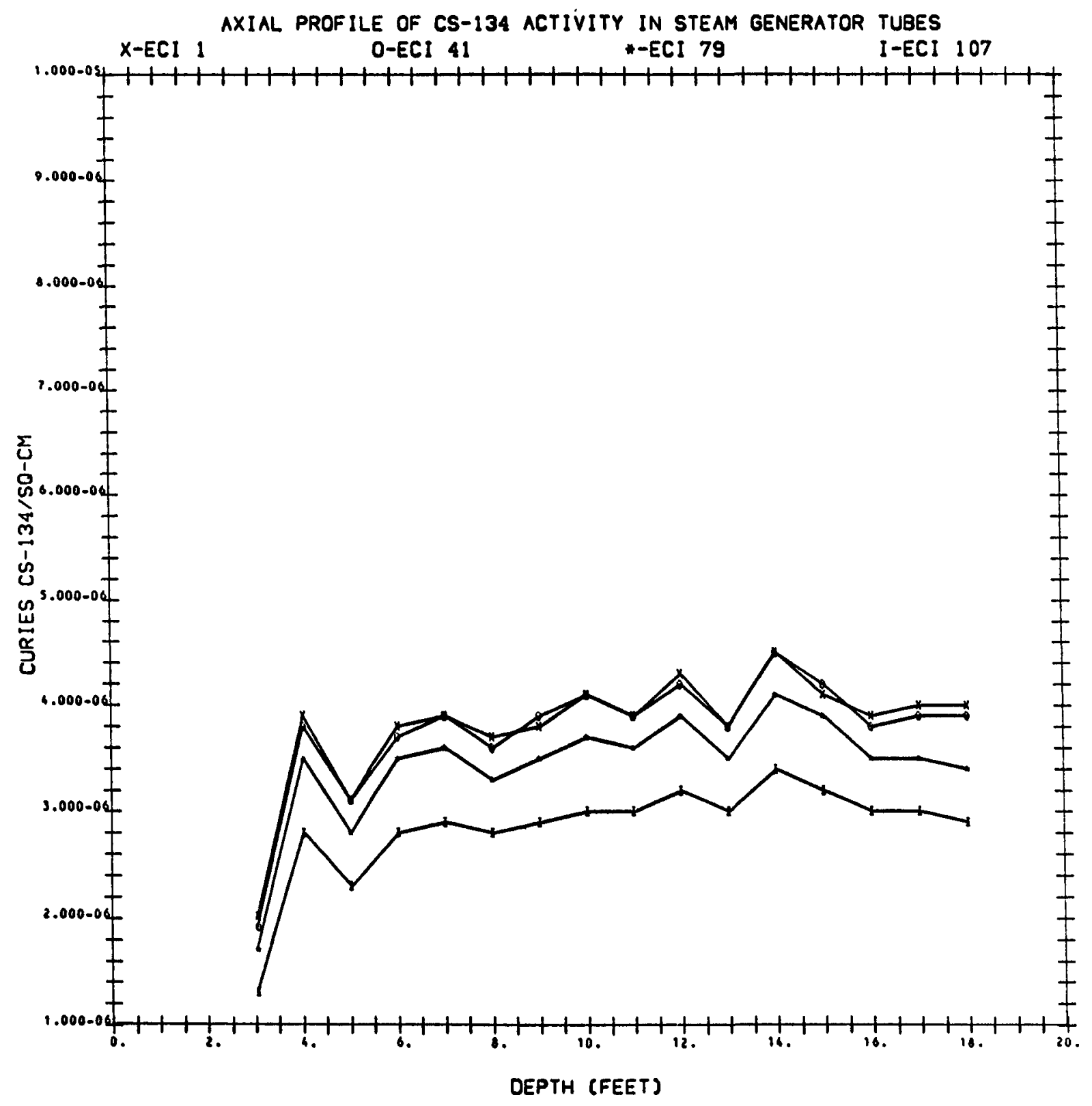




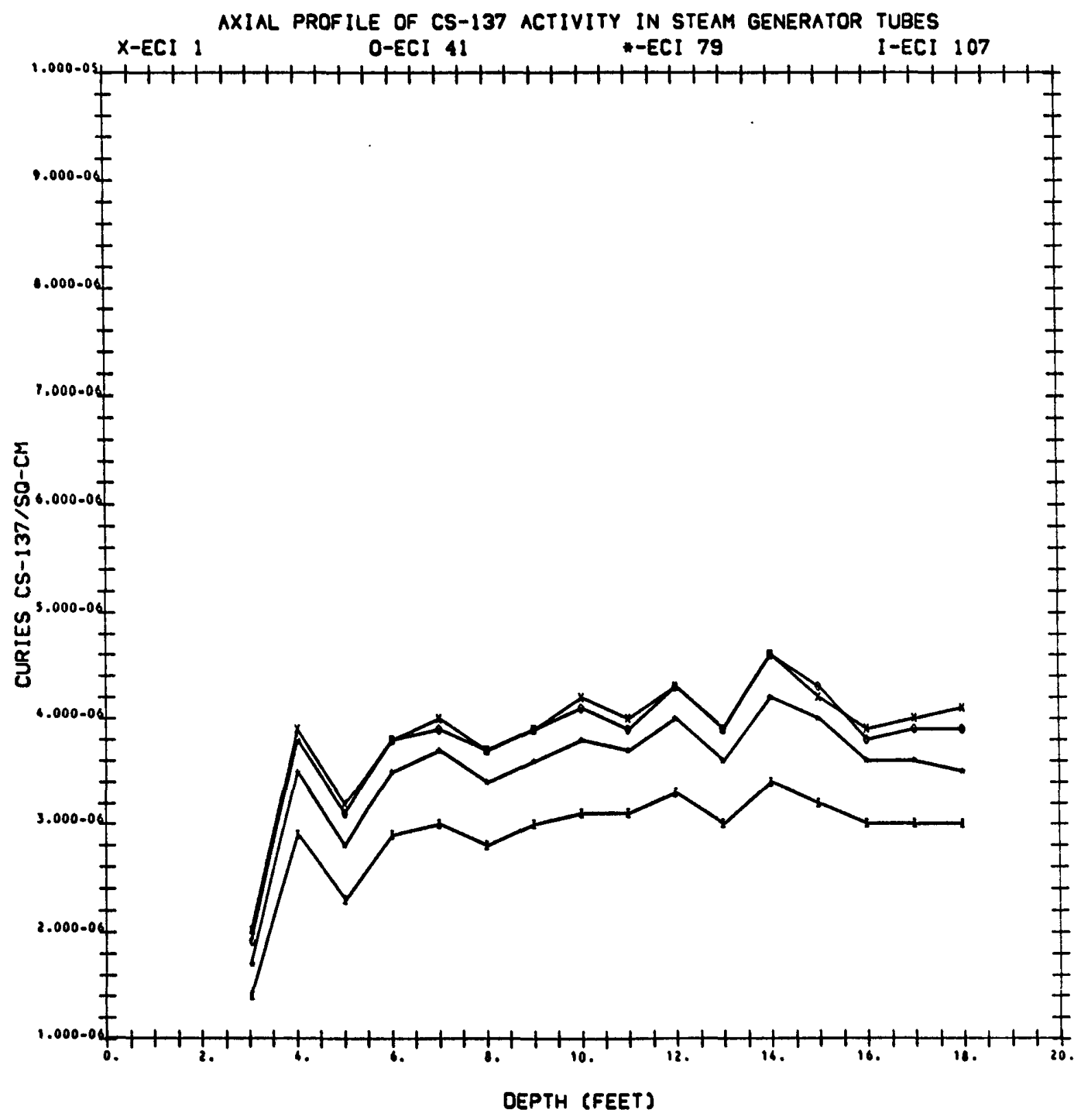




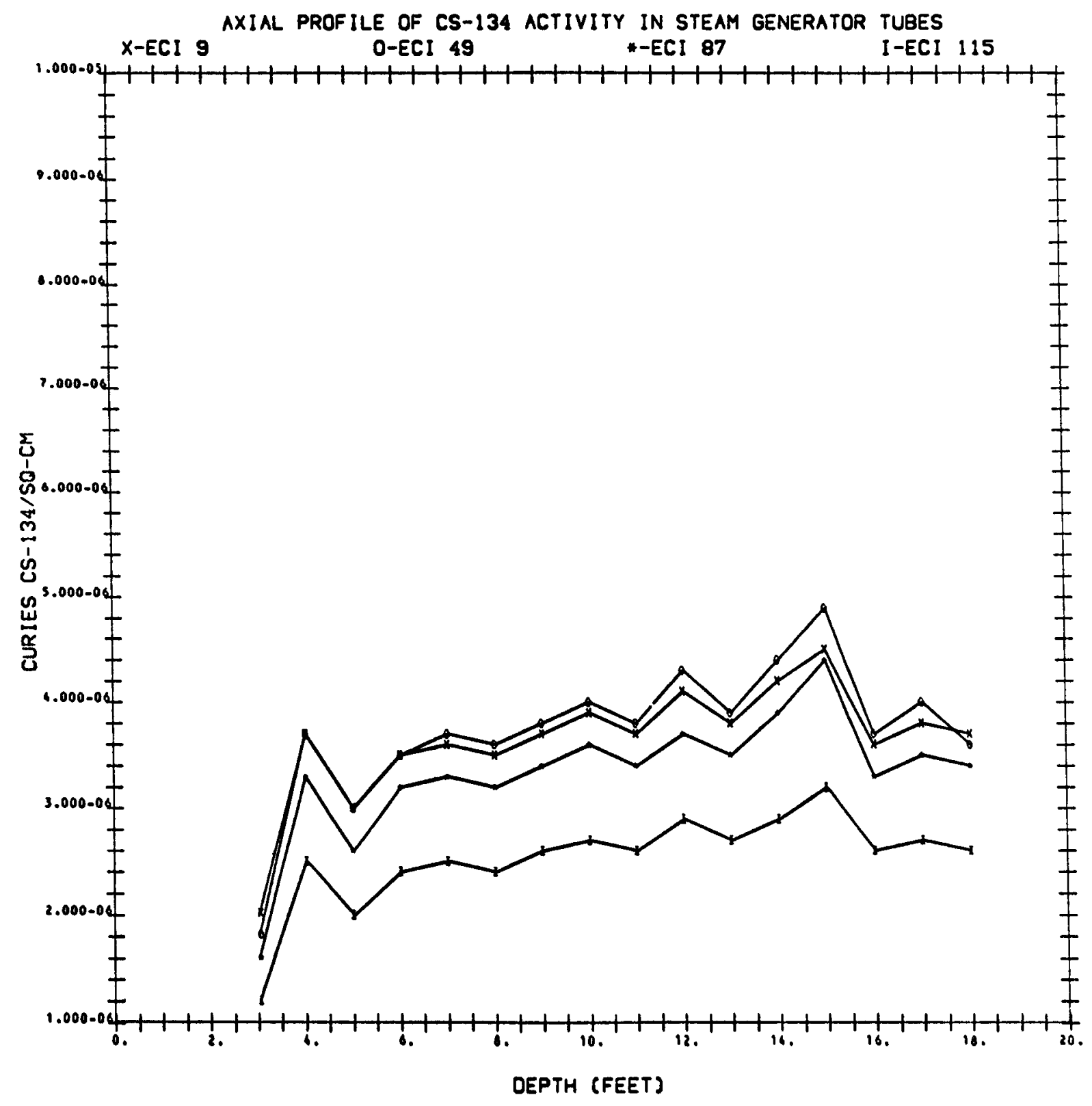




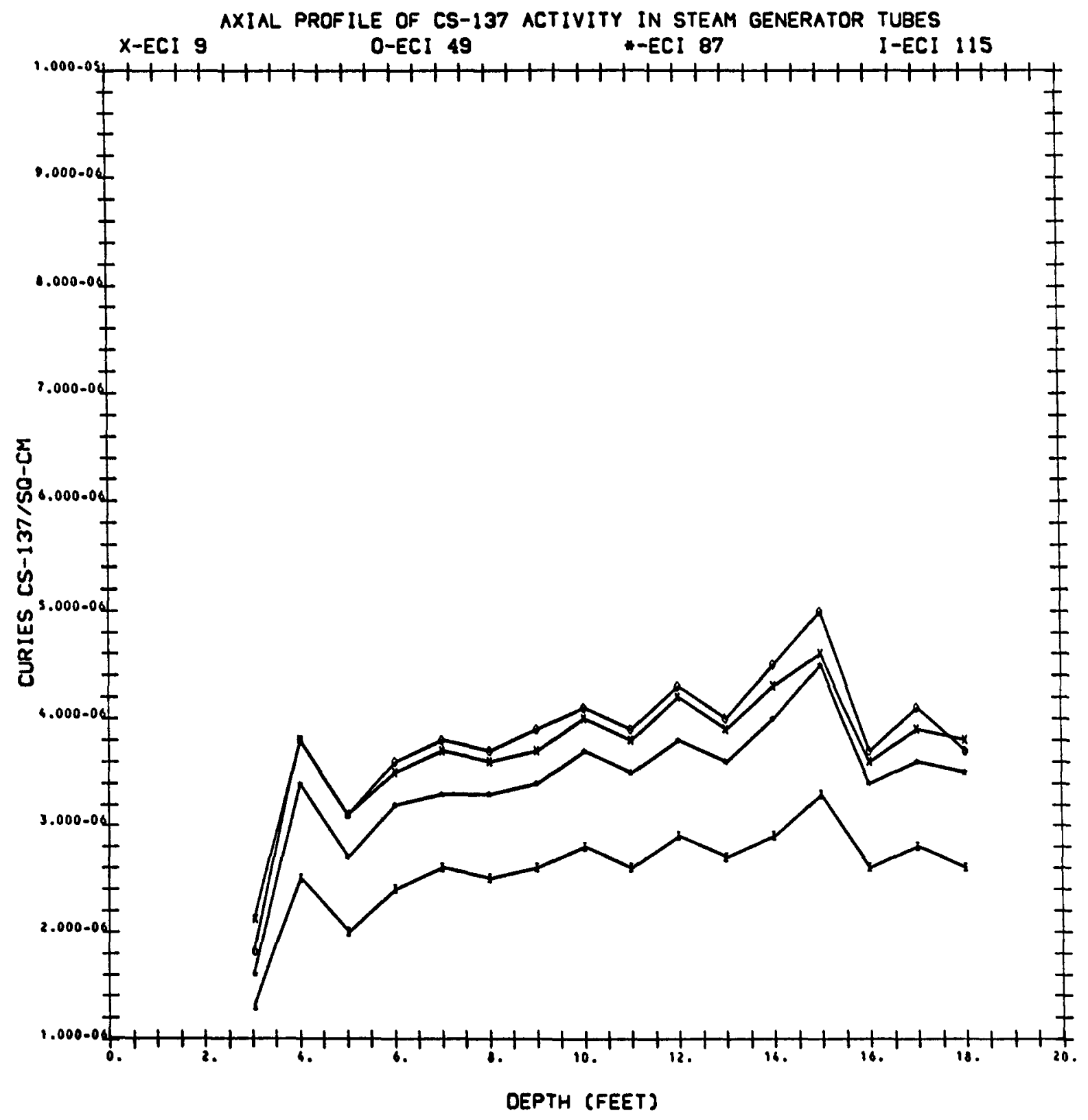




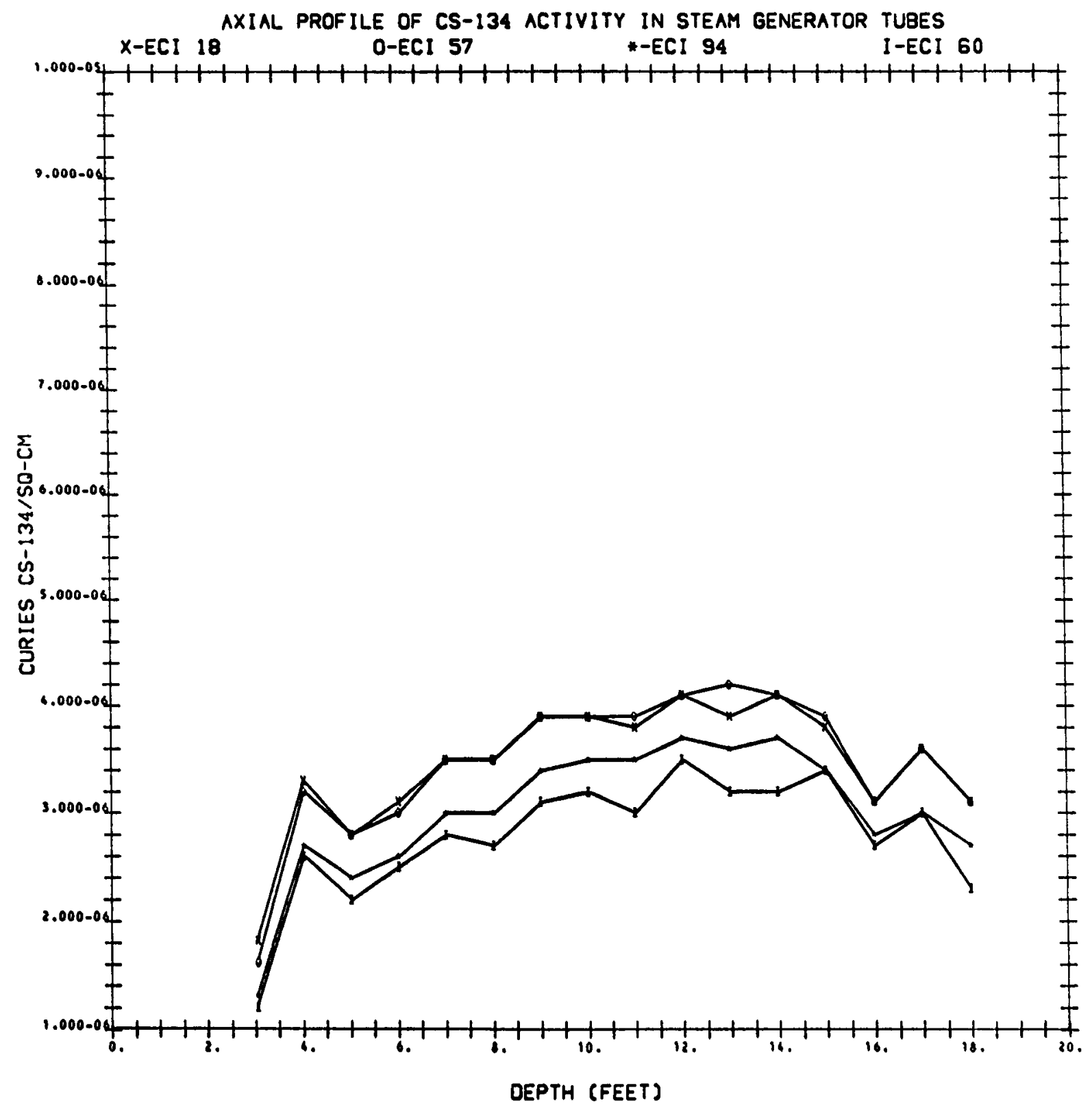




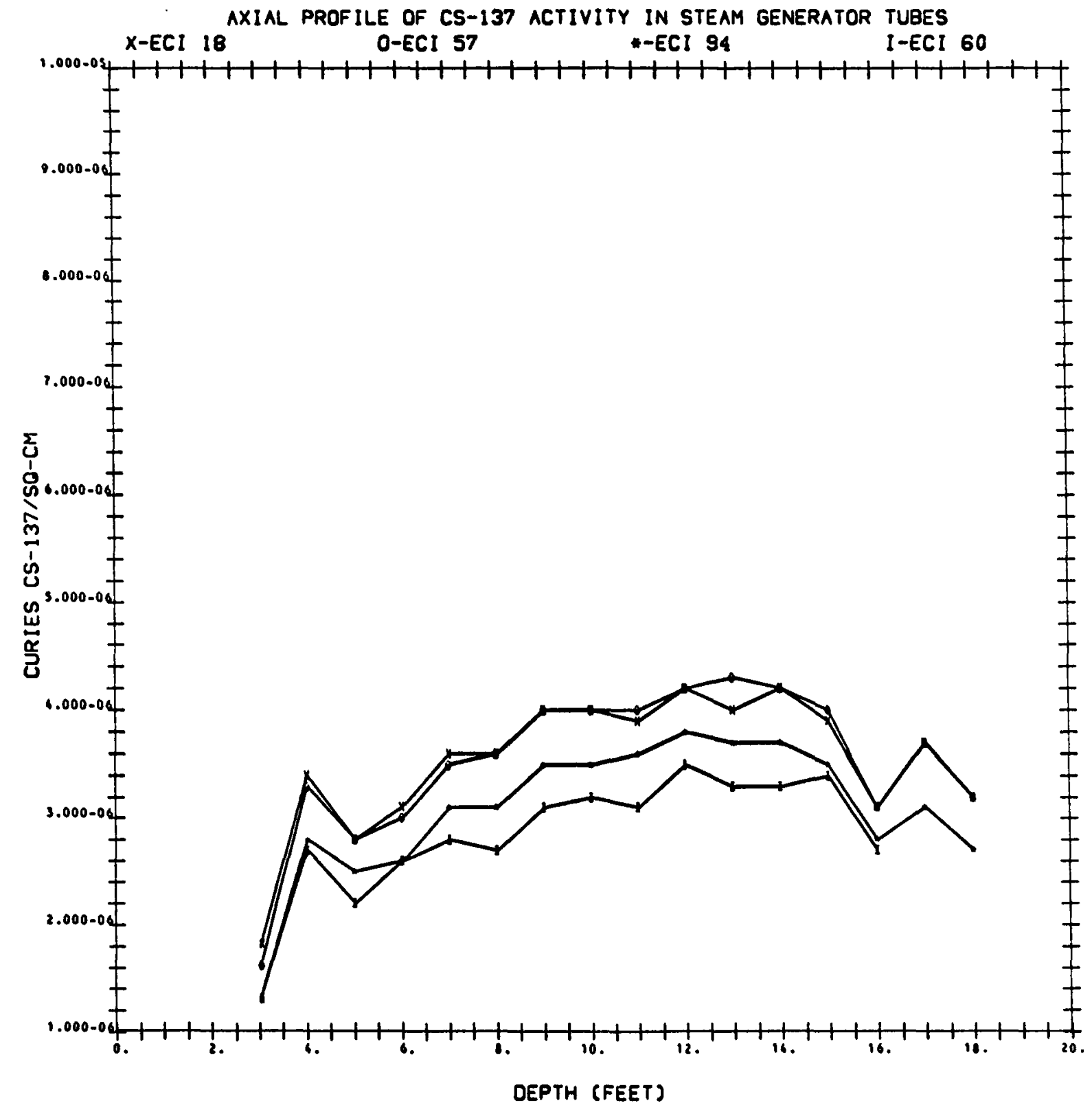




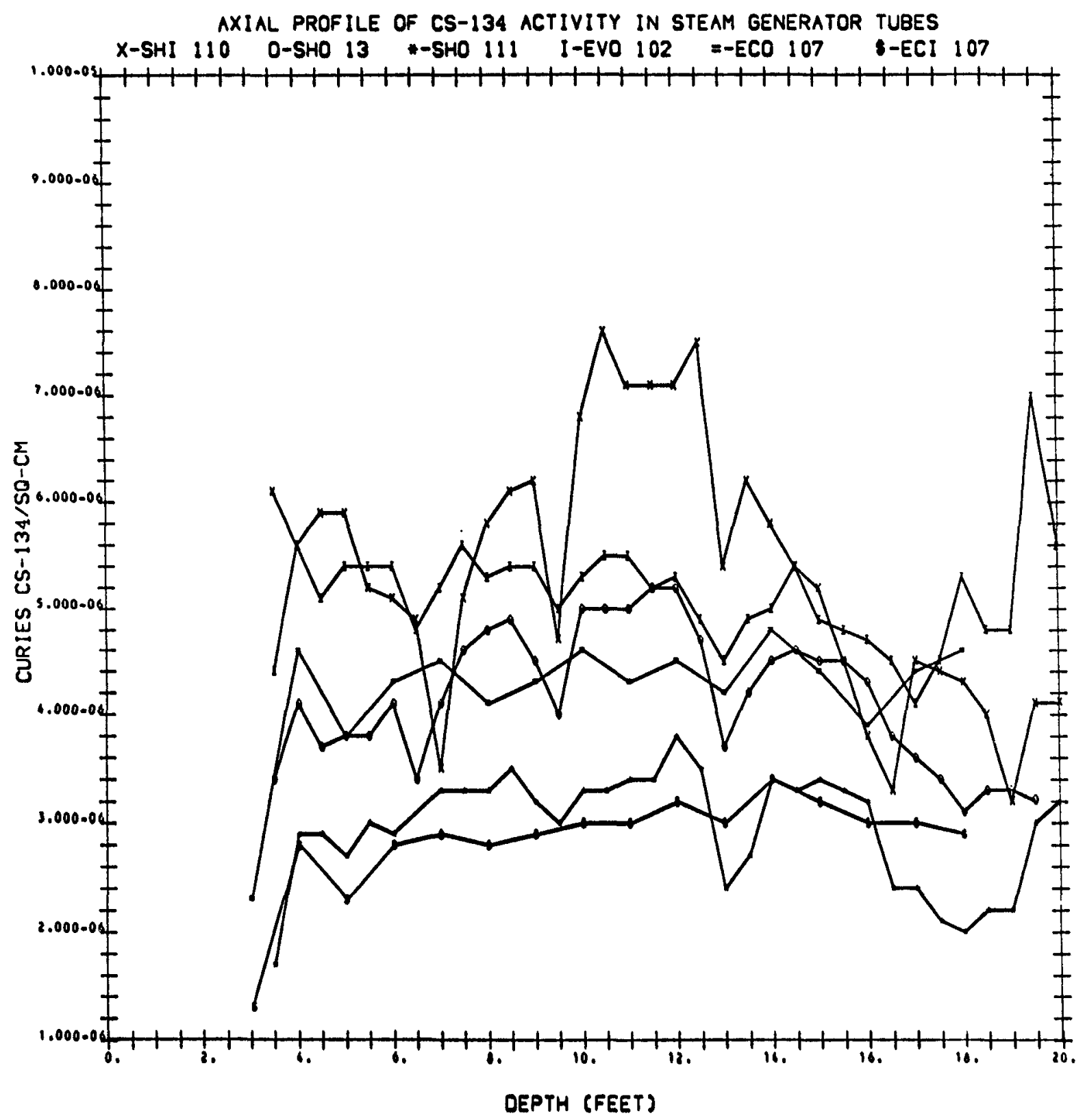




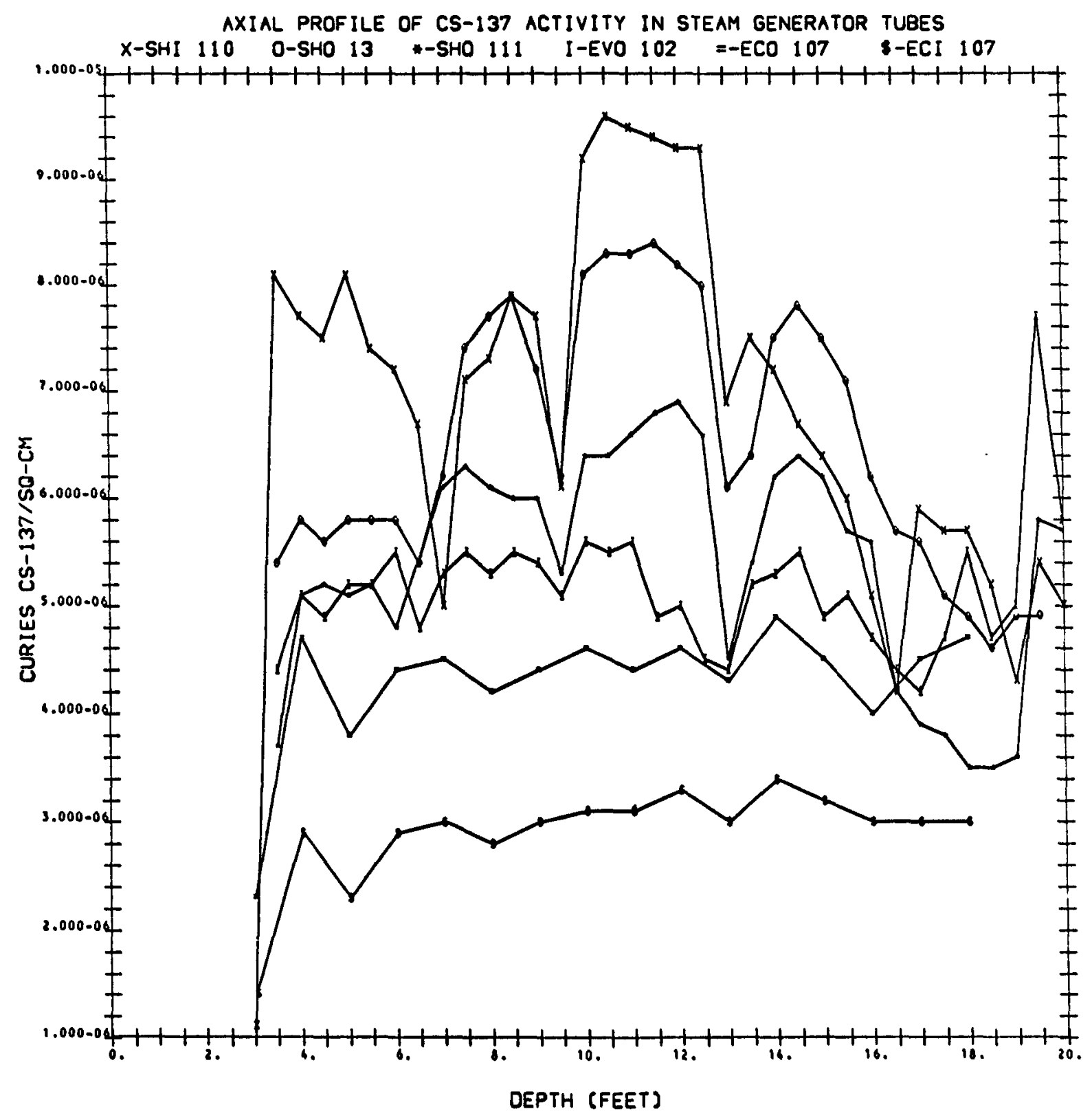




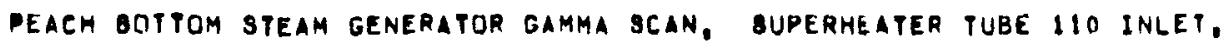

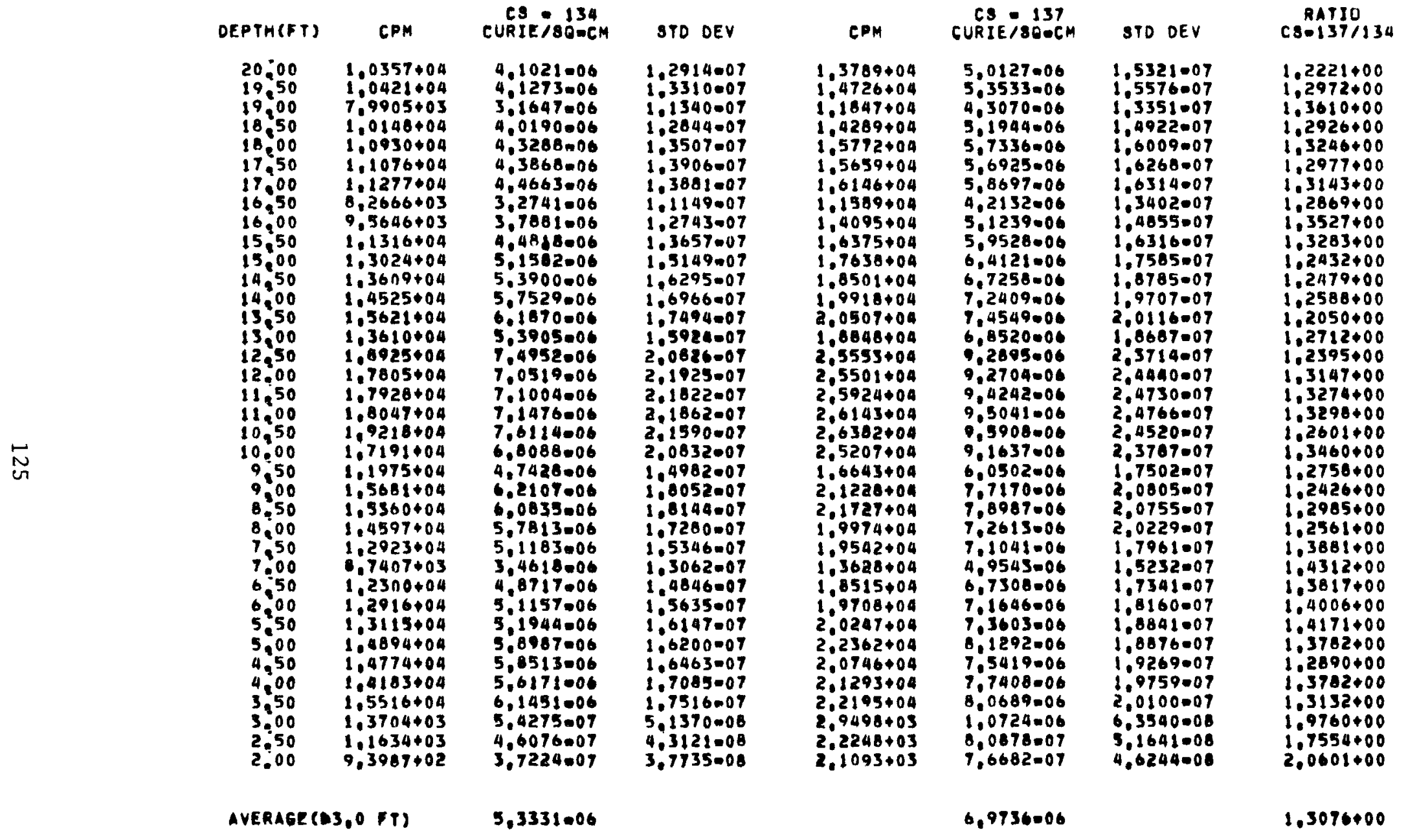

Standard deviation shown is that associated with counting statistics only. 
- Peach bottom stean generator gamma scan, evaporator tube 102 outle

\begin{tabular}{|c|c|c|c|c|c|c|c|c|}
\hline & DEPTH(FT) & CPM & $\begin{array}{c}\text { CS } 134 \\
\text { CURIE/SOOCM }\end{array}$ & STD DEV & CPM & $\begin{array}{c}\text { CS } 137 \\
\text { CURIE } 1800 \mathrm{CM}\end{array}$ & STO OEV & $\begin{array}{c}\text { RATIO } \\
\text { Cs-1371134 }\end{array}$ \\
\hline 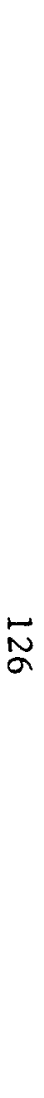 & 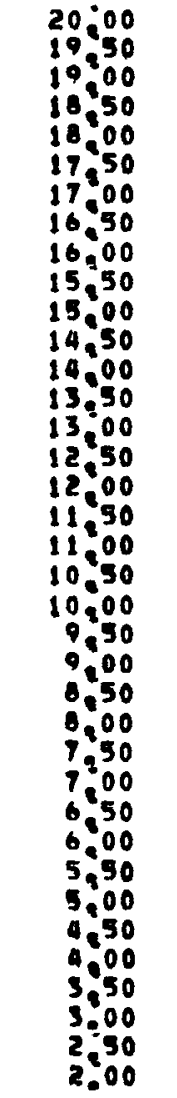 & 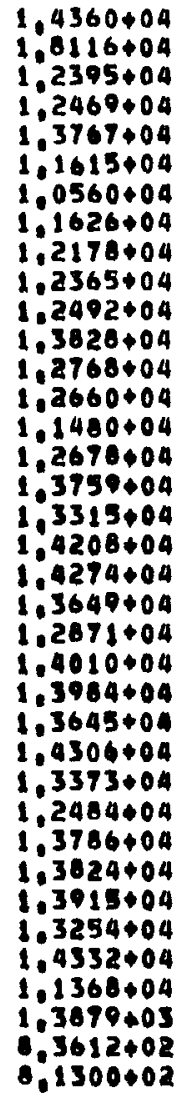 & 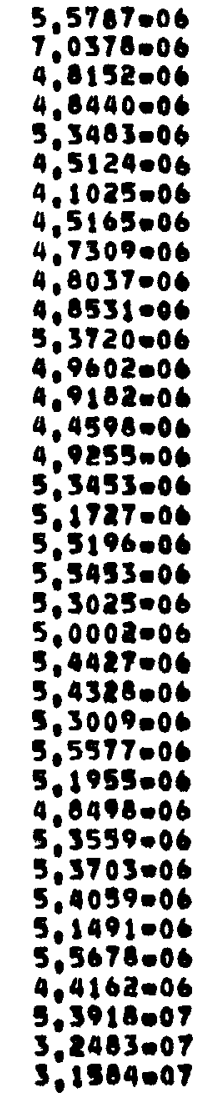 & 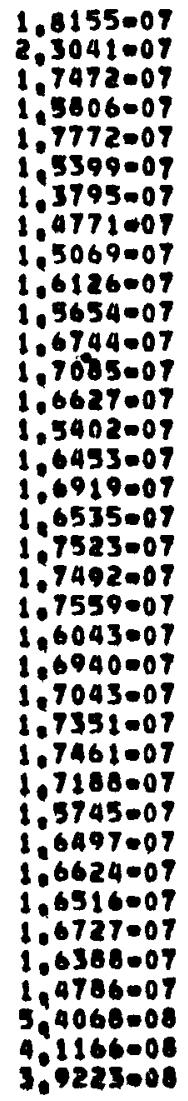 & $\begin{array}{l}2,5647+04 \\
3,3993+04 \\
2,2386+04 \\
2,0925+04 \\
2,4428+04 \\
2,0990+04 \\
1,0975+04 \\
1,9431+04 \\
2,0685+04 \\
2,2413+04 \\
2,1941+04 \\
2,4231+04 \\
2,3354+04 \\
2,3201+04 \\
1,9407+04 \\
2,0162+04 \\
2,2290+04 \\
2,1872+04 \\
2,5042+04 \\
2,4485+04 \\
2,4924+04 \\
2,2419+04 \\
2,4085+04 \\
2,4602+04 \\
2,3665+04 \\
2,4254+04 \\
2,3376+04 \\
2,1455+04 \\
2,4192+04 \\
2,2990+04 \\
2,3197+04 \\
2,1579+04 \\
2,2460+04 \\
1,9563+04 \\
3,7754+03 \\
2,4020+03 \\
2,4196+03\end{array}$ & 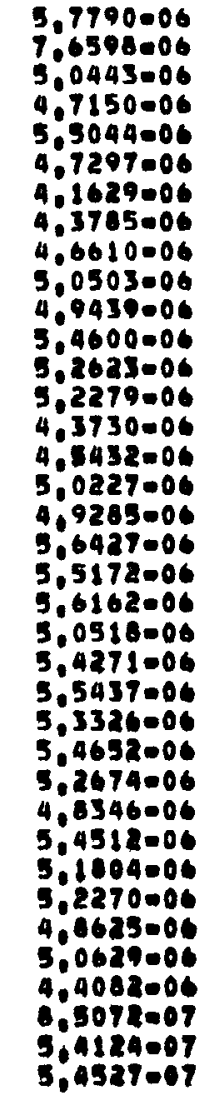 & 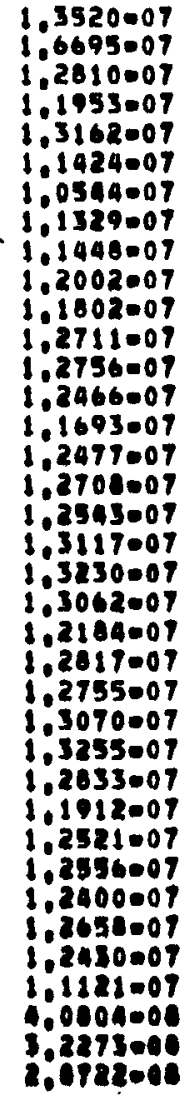 & 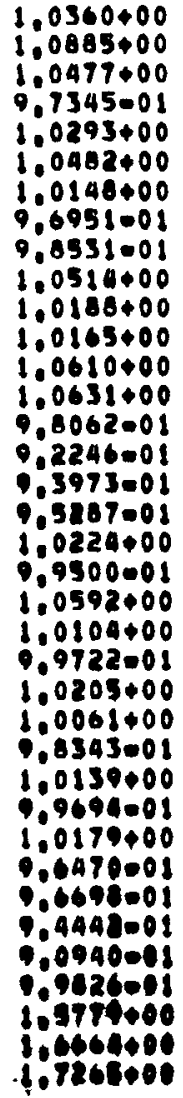 \\
\hline & AVERAGEl & $13.0(7)$ & 5.1305006 & & & $5.1570-06$ & & 1.0036400 \\
\hline
\end{tabular}

Standard deviation shown is that associated with counting statistics only. 
PEACH BOTTOM STEAM GENERATOR GAMMA SCAN, SUPERHEATER TUBE 56 IMLET.

\begin{tabular}{|c|c|c|c|c|c|c|c|}
\hline DEPTH(FT) & CPM & CS 134 & STD DEV & CPM & $\begin{array}{l}\text { C8 } 137 \\
\text { CURIE/SO-CM }\end{array}$ & STD DEV & $\begin{array}{c}\text { RATIR } \\
\operatorname{cs}=137 / 134\end{array}$ \\
\hline 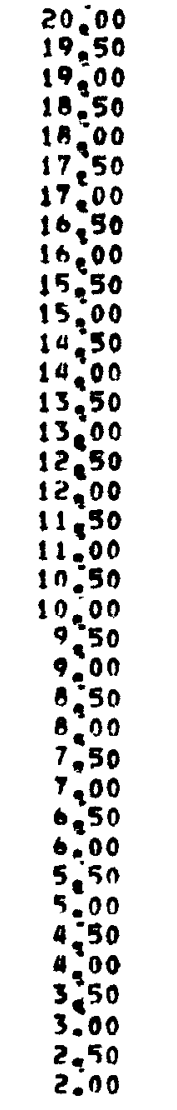 & 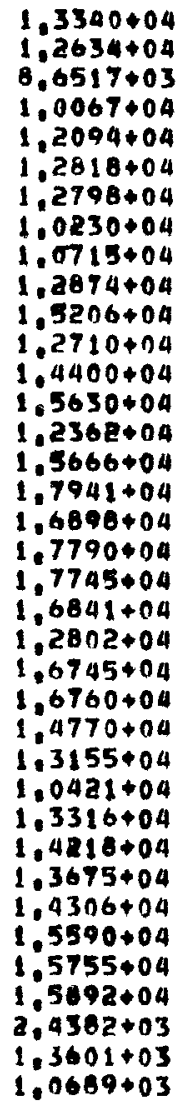 & 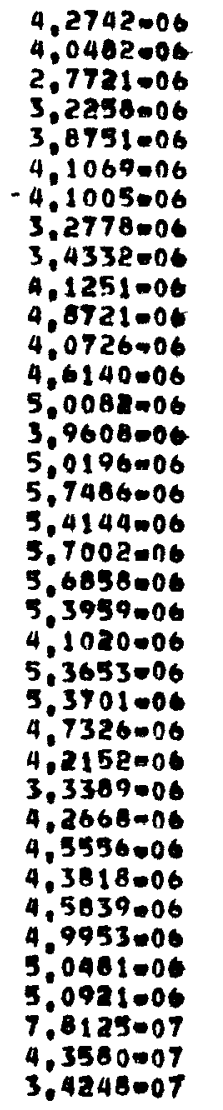 & 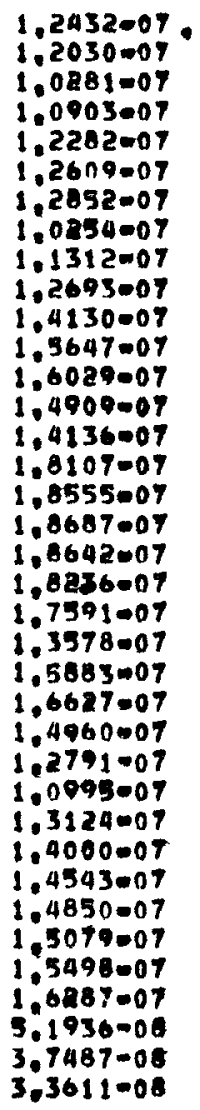 & 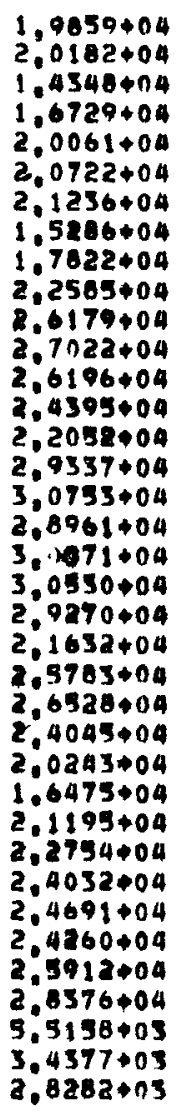 & 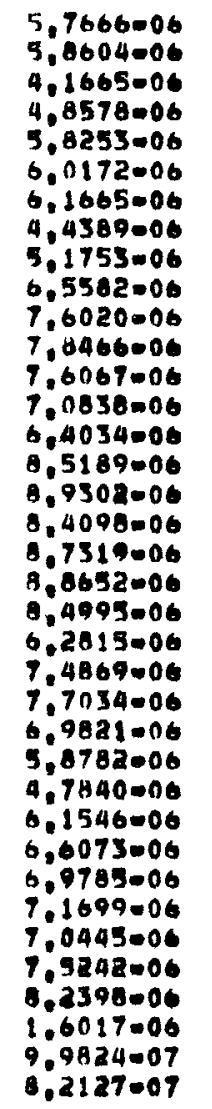 & 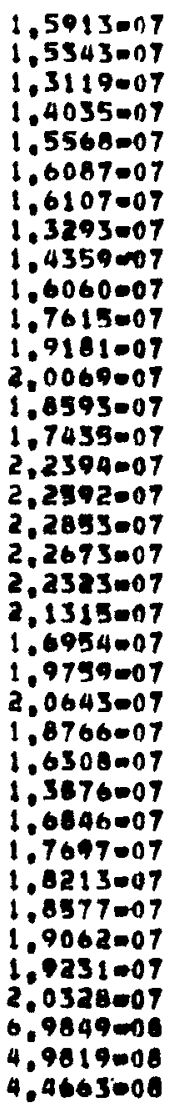 & $\begin{array}{l}1.3493+00 \\
1.4478+00 \\
1.5031+00 \\
1.5061+00 \\
1.5034+00 \\
1.4653+00 \\
1.5040+00 \\
1.3543+00 \\
1.5075 * 00 \\
1.5900+00 \\
1.9604+00 \\
1.9264+00 \\
1.6487+00 \\
1.4146+00 \\
1.6168+00 \\
1.6973+00 \\
1.5536+00 \\
1.5534+00 \\
1.5320+00 \\
1.5593+00 \\
1.5753+00 \\
1.5315+00 \\
1.3955+00 \\
1.4346+00 \\
1.4754+00 \\
1.3946+00 \\
1.4329+00 \\
1.0426+00 \\
1.4505+00 \\
1.5928+00 \\
1.5643+00 \\
1.4103+00 \\
1.4904+00 \\
1.6183+00 \\
2.0903+00 \\
2.2908+00 \\
2.3982+00\end{array}$ \\
\hline \multicolumn{2}{|c|}{ A VenaEe $(23,0 \mathrm{mT})$} & 7. & & & $6.0284-06$ & & 1.515000 \\
\hline
\end{tabular}

Standard deviation shown is that associated with counting statistics only. 
PEACH BotTOM STEAM genERATOR gamMa SCAN, SUPERHEATER TUBE 13 QUTLET,

\begin{tabular}{|c|c|c|c|c|c|c|c|c|}
\hline & DEPTH(FT) & CPM & $\begin{array}{c}\text { CS } \\
\text { CURIE } 134 \\
\text { SO }\end{array}$ & STO DEV & CPM & $\begin{array}{c}\text { CS } 137 \\
\text { CURIE/SOCCM }\end{array}$ & STD OEV & $\begin{array}{c}\text { RAT10 } \\
\operatorname{cs} 1137 / 134\end{array}$ \\
\hline$\infty$ & 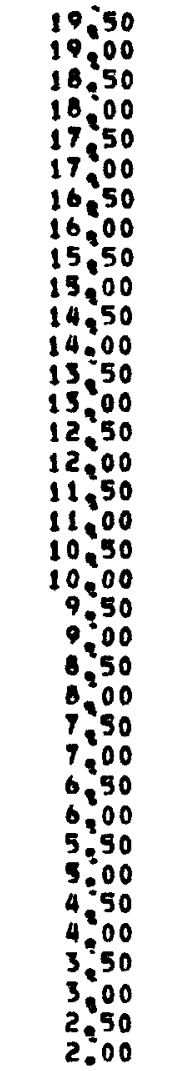 & 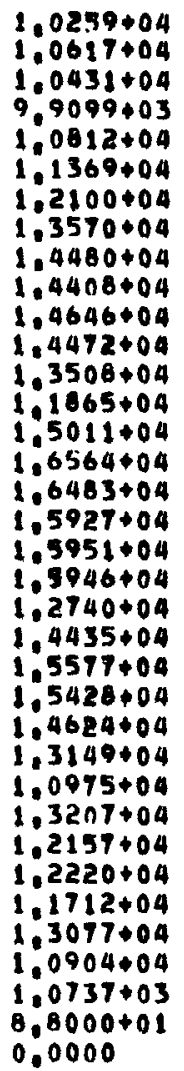 & 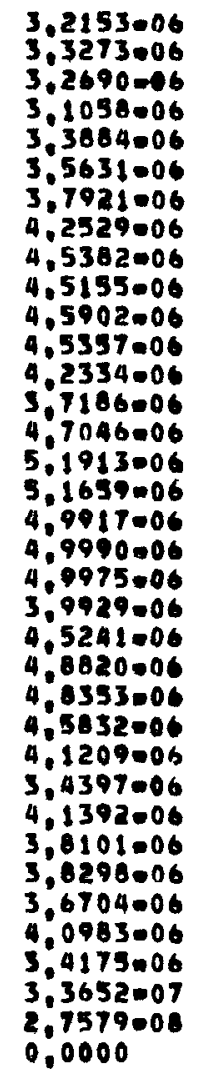 & 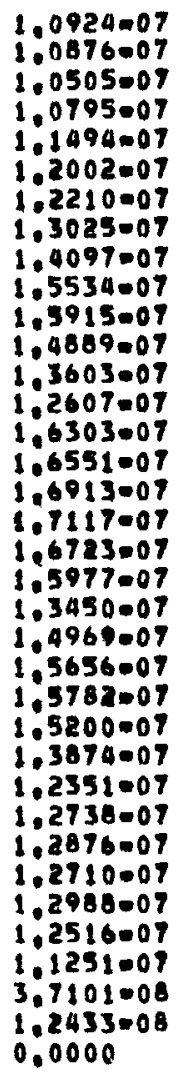 & 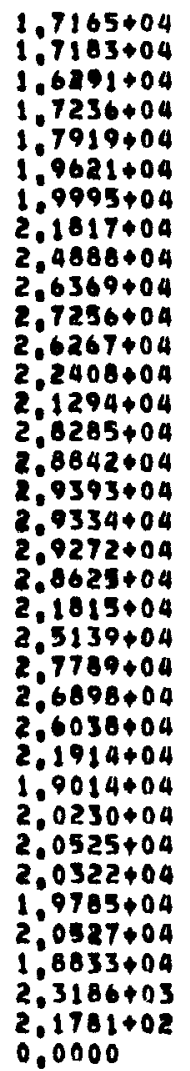 & 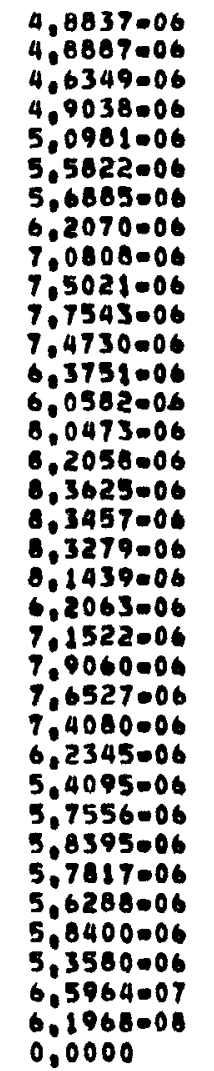 & 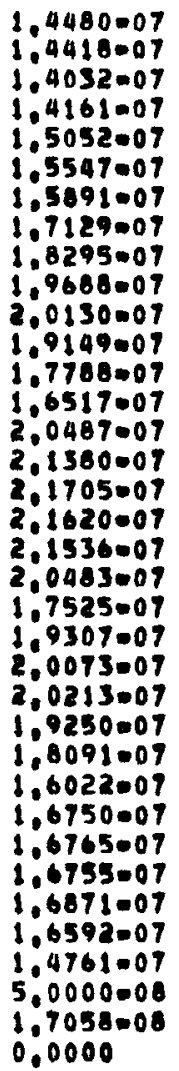 & $\begin{array}{l}1.5190+00 \\
1.4694+00 \\
1.4179+00 \\
1.5790+00 \\
1.5047+00 \\
1.5668+00 \\
1.5002+00 \\
1.4596+00 \\
1.5604+00 \\
1.6615+00 \\
1.6895+00 \\
1.6477+00 \\
1.5060+00 \\
1.6293+00 \\
1.7106+00 \\
1.5806+00 \\
1.6109+00 \\
1.6721+00 \\
1.6661+00 \\
1.6297+00 \\
1.5545+00 \\
1.5810+00 \\
1.6195+00 \\
1.5828+00 \\
1.6165+00 \\
1.5130+00 \\
1.5728+00 \\
1.3906+00 \\
1.5328+00 \\
1.5098+00 \\
1.5337+00 \\
1.4251+00 \\
1.5680+00 \\
1.9604+00 \\
2.2471+00 \\
0.0000\end{array}$ \\
\hline & AVERAGECS & $3,0 \mathrm{FT}$ & $4.1648=06$ & & & $6.5375=06$ & & $1.5097+00$ \\
\hline
\end{tabular}

Standard deviation shown is that associated with counting statistics only. 
PEACH BOITOM STEAM GENERATOR GAMMA SCAN, SUPERHEATER TUBE 29 OUTLET.

\begin{tabular}{|c|c|c|c|c|c|c|c|c|}
\hline & DEPTH(FT) & CPM & $\begin{array}{c}C \$=134 \\
\text { CURIE/SOAM }\end{array}$ & ETD DEV & CPM & $\begin{array}{l}\text { CS }=137 \\
\text { CURIE/SO-CM }\end{array}$ & STO DEV & $\begin{array}{c}R 4750 \\
\cos -137 / 134\end{array}$ \\
\hline 1 & 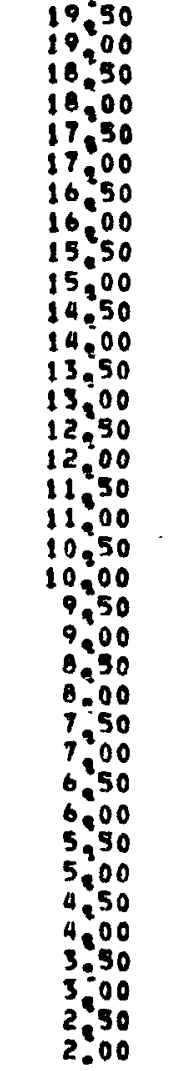 & $\begin{array}{l}8,7951+03 \\
1,0459+04 \\
8,7699+03 \\
1,0092+04 \\
1,1050+04 \\
1,2154+04 \\
1,1923+04 \\
1,3678+04 \\
1,4616+04 \\
1,4836+04 \\
1,4961+04 \\
1,4083+04 \\
1,3007+04 \\
1,0111+04 \\
1,4490+04 \\
1,5422+04 \\
1,4813+04 \\
1,5228+04 \\
1,3160+04 \\
1,4919+04 \\
1,3272+04 \\
1,3575+04 \\
1,4319+04 \\
1,5228+04 \\
1,5781+04 \\
1,4896+04 \\
1,2678+04 \\
1,2771+04 \\
1,1803+04 \\
1.2341+04 \\
1,3105+04 \\
1.1924+04 \\
9,9452+03 \\
6,8775+02 \\
6,7750+01 \\
7,0000+00\end{array}$ & 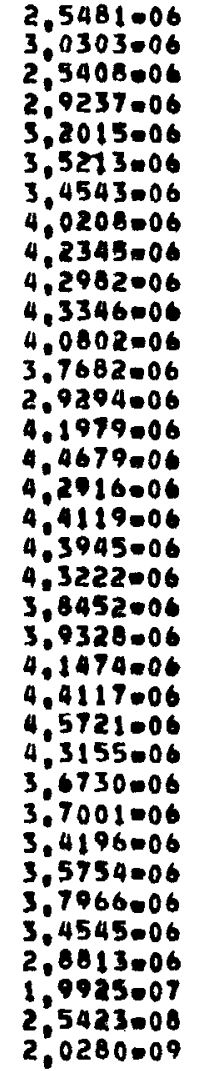 & 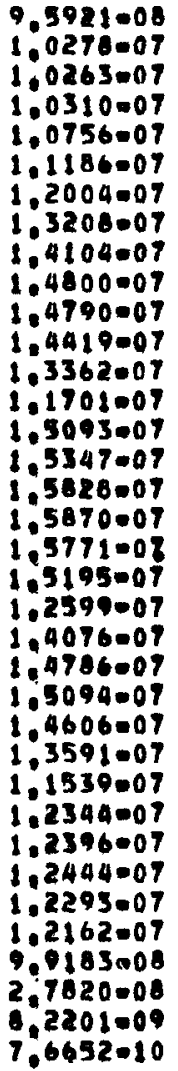 & 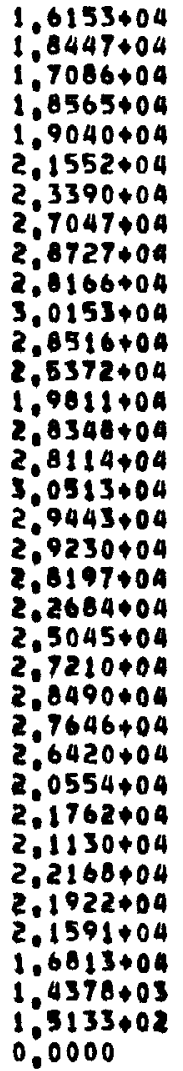 & 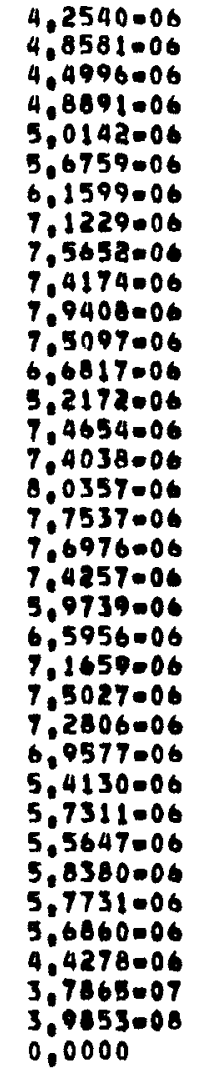 & 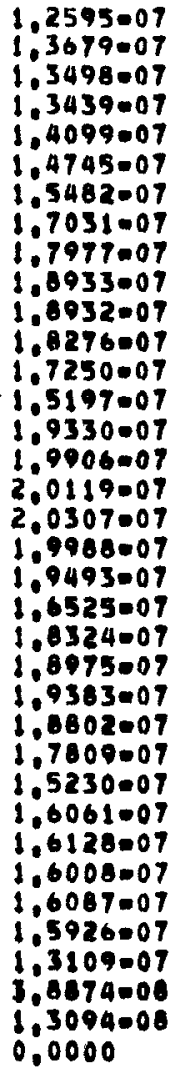 & $\begin{array}{l}1.6696+00 \\
1.6033+00 \\
1.7711+00 \\
1.6723+00 \\
1.5663+00 \\
1.6120+00 \\
1.7834+00 \\
1.7717+00 \\
1.7867+00 \\
1.7258+00 \\
1.8321+00 \\
1.8407+00 \\
1.7733+00 \\
1.7611+00 \\
1.7785+00 \\
1.6572+00 \\
1.8726+00 \\
1.7576+00 \\
1.7518+00 \\
1.7182+00 \\
1.5537+00 \\
1.6772+00 \\
1.7200+00 \\
1.7008+00 \\
1.5925+00 \\
1.6124+00 \\
1.479+400 \\
1.5490+00 \\
1.6274+00 \\
1.6329+00 \\
1.5207+00 \\
1.6461+00 \\
1.5369+00 \\
1.9005+00 \\
1.5677+00 \\
0,0000\end{array}$ \\
\hline & AVERAGE & $3.0 \mathrm{FT}$ & $3,7787.06$ & & & $3787=06$ & & $1,6881+00$ \\
\hline
\end{tabular}

Standard deviation shown is that associated with counting statistics only. 
PEACH BotTOM STEAM GENERATOR GAMMA sGaN, SUPERHEATER TUBE 59 OUTLET,

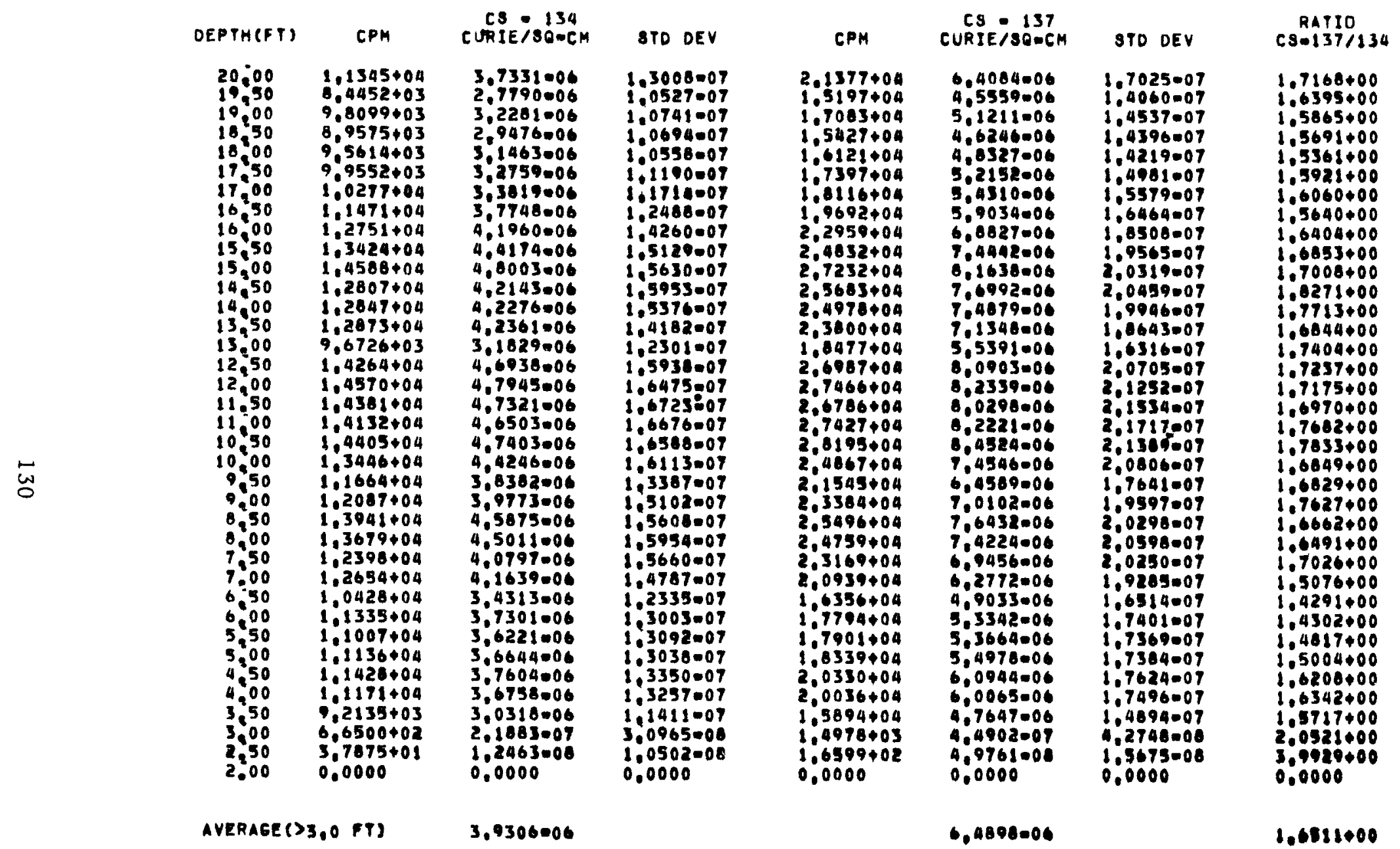

Standard deviation shown is that associated withcounting statistics only. 
PEACH BOTTOM STEAM GENERATOR GAMMA BCAN, SUPERHEATEA TUBE 107 DUTLET,

\begin{tabular}{|c|c|c|c|c|c|c|c|c|}
\hline & DEPTH(FT) & CPM & $\begin{array}{l}\text { CS } \\
\text { CURIE/SOOCM }\end{array}$ & STO DEV & CPM & $\begin{array}{l}\text { CS } 137 \\
\text { CURIE/80 CM }\end{array}$ & STO OEV & $\begin{array}{c}\text { RAT10 } \\
\operatorname{cse} 137 / 134\end{array}$ \\
\hline$\stackrel{\omega}{\bullet}$ & 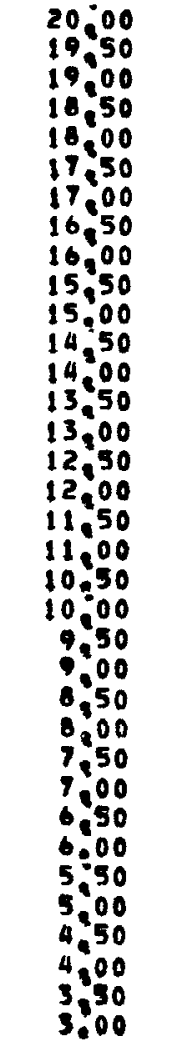 & 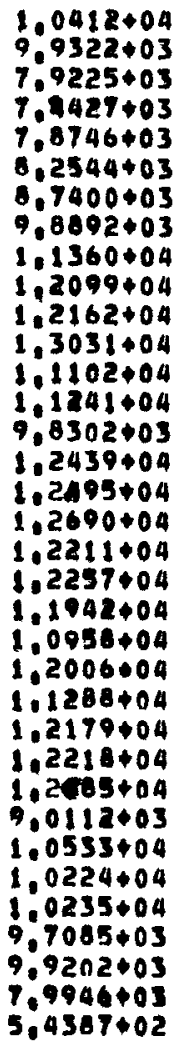 & 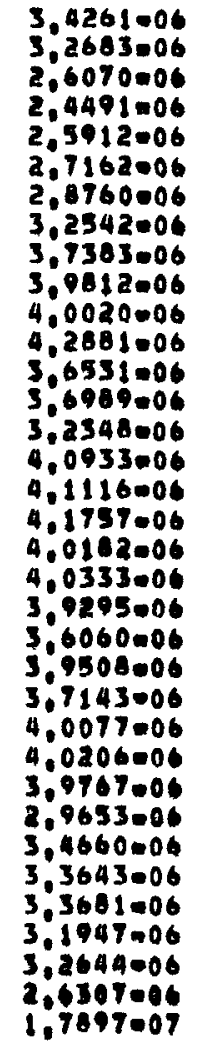 & 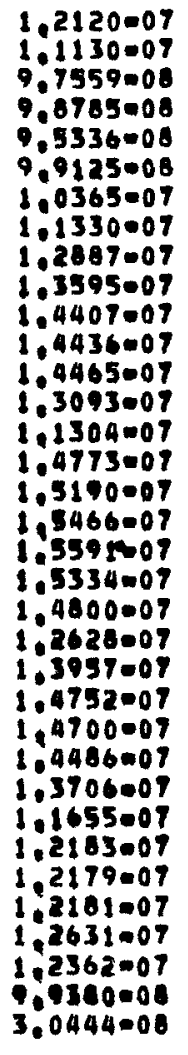 & 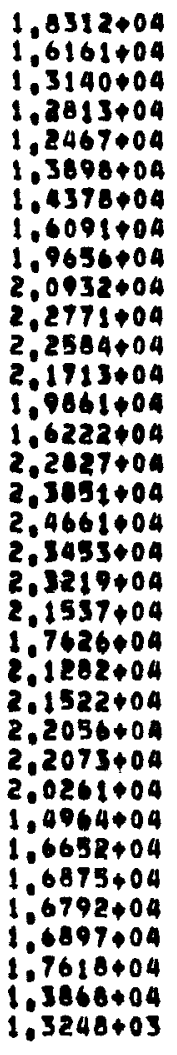 & 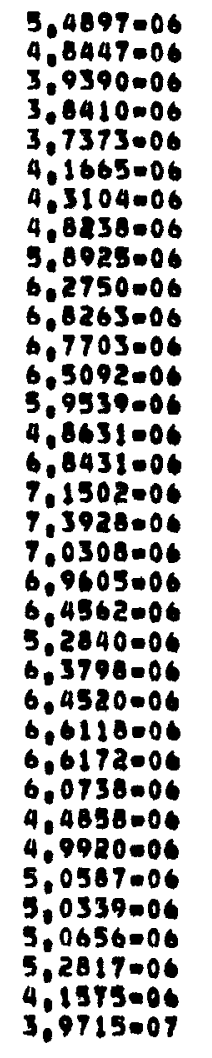 & 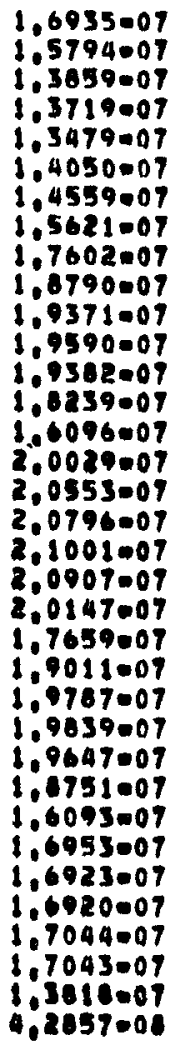 & 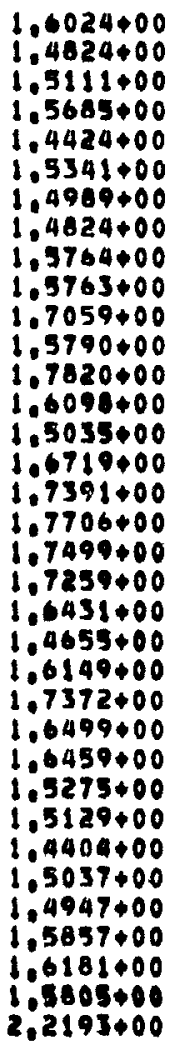 \\
\hline & AVERAGE & $0 \mathrm{FIJ}$ & 3.5199006 & & & $5.6344=06$ & & $1,6007+00$ \\
\hline
\end{tabular}




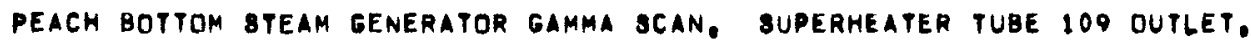

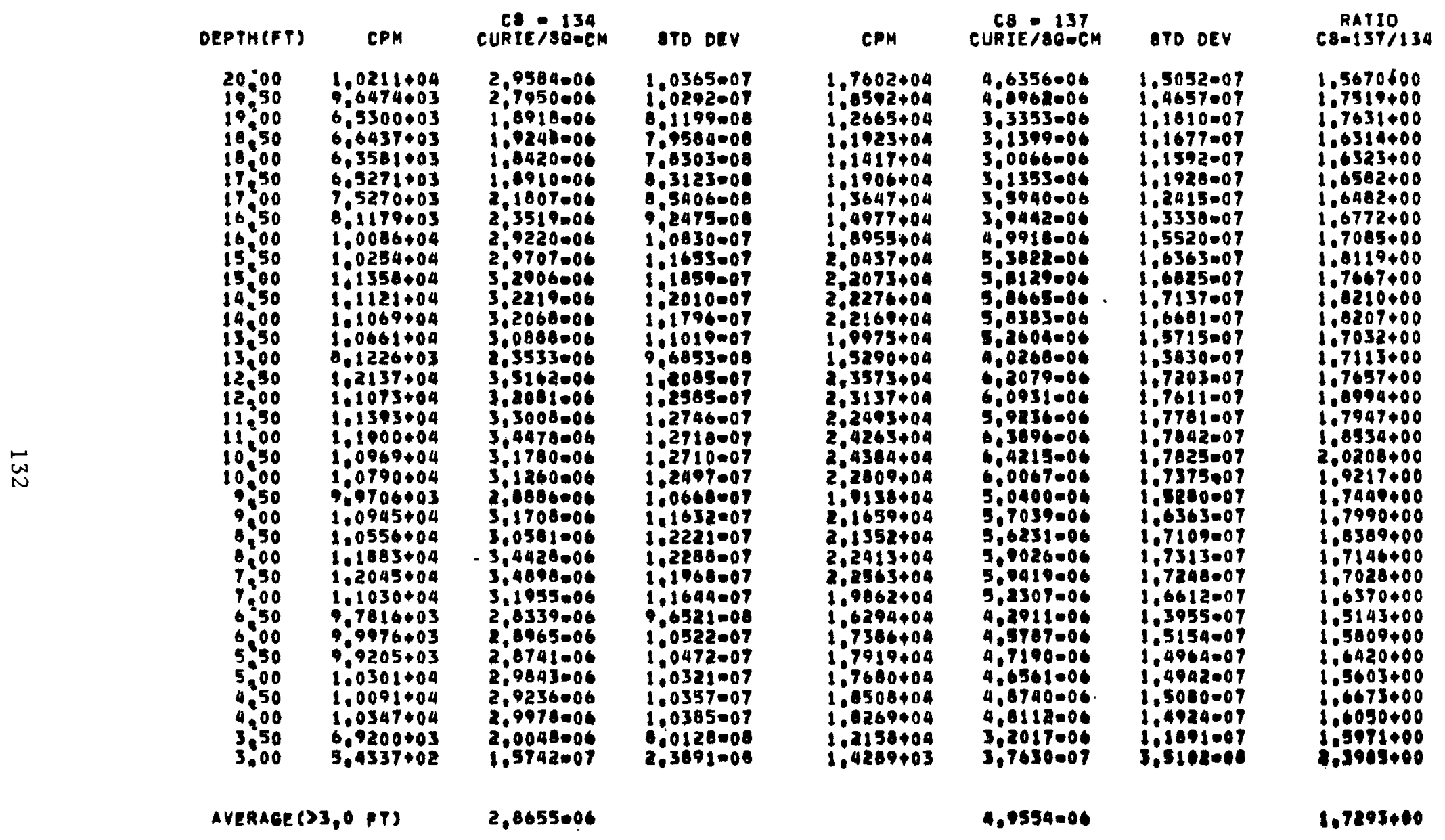

Standard deviation shown is that associated with counting statistics only. 
PEACH BOTTOM SPEAM gENERATOR OAHMA BCAM, SUPERHEATER tUBE 111 OUTLET.

\begin{tabular}{|c|c|c|c|c|c|c|c|c|}
\hline & DEPTHEFT) & CPM & $\begin{array}{c}\text { CS } \\
\text { CURIEISOSCH }\end{array}$ & OTD DEV & CPM & $\begin{array}{c}\text { CS } \\
\text { CURIE } 137 \\
\text { COSOCM }\end{array}$ & STO DEV & $\begin{array}{c}\text { RAT30 } \\
\text { C8-137/134 }\end{array}$ \\
\hline$\omega_{\omega}^{\omega}$ & 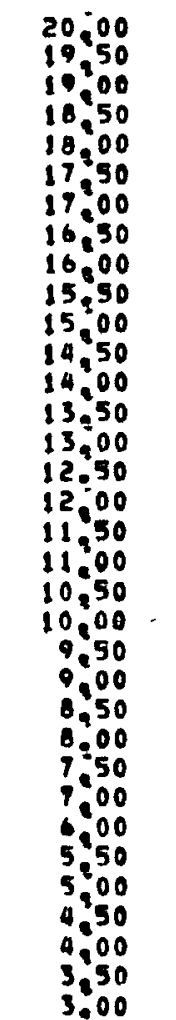 & 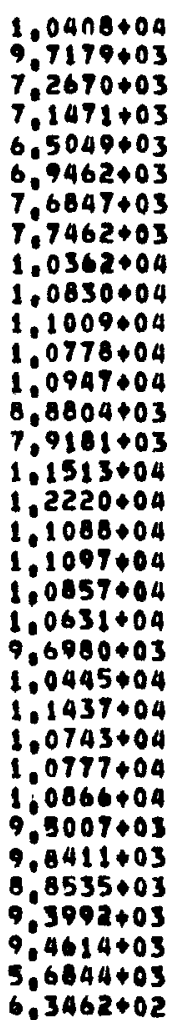 & 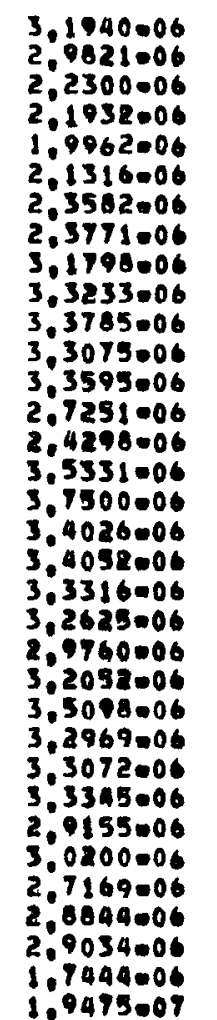 & 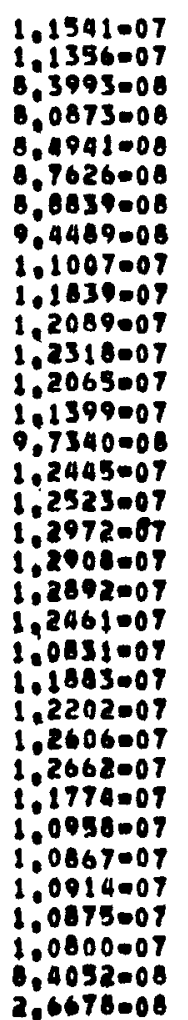 & 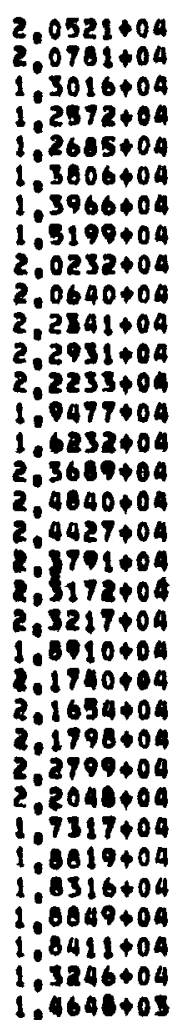 & 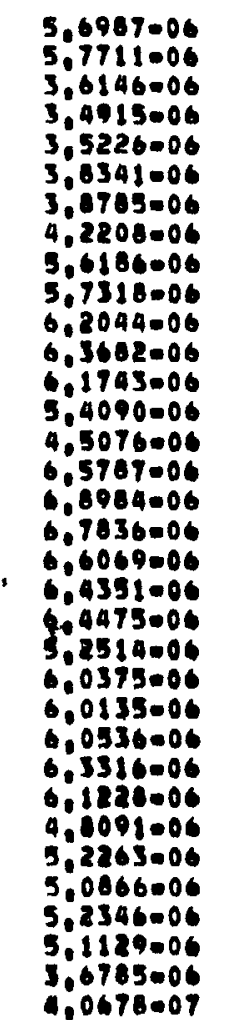 & 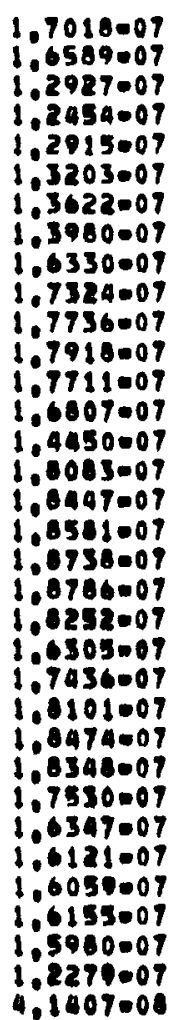 & 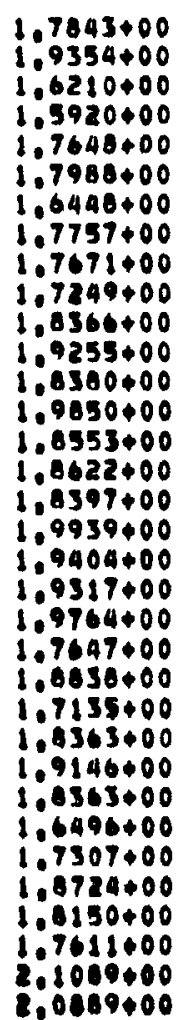 \\
\hline & AVERAOE () & $(.0 \mathrm{FT}$ & 2,9596006 & & & 5.4168006 & & $1.030 \$ 400$ \\
\hline
\end{tabular}


PEACH BotTom steam generator gamma scan, eVAPORATOR tUBe 5 \& OUTLET.

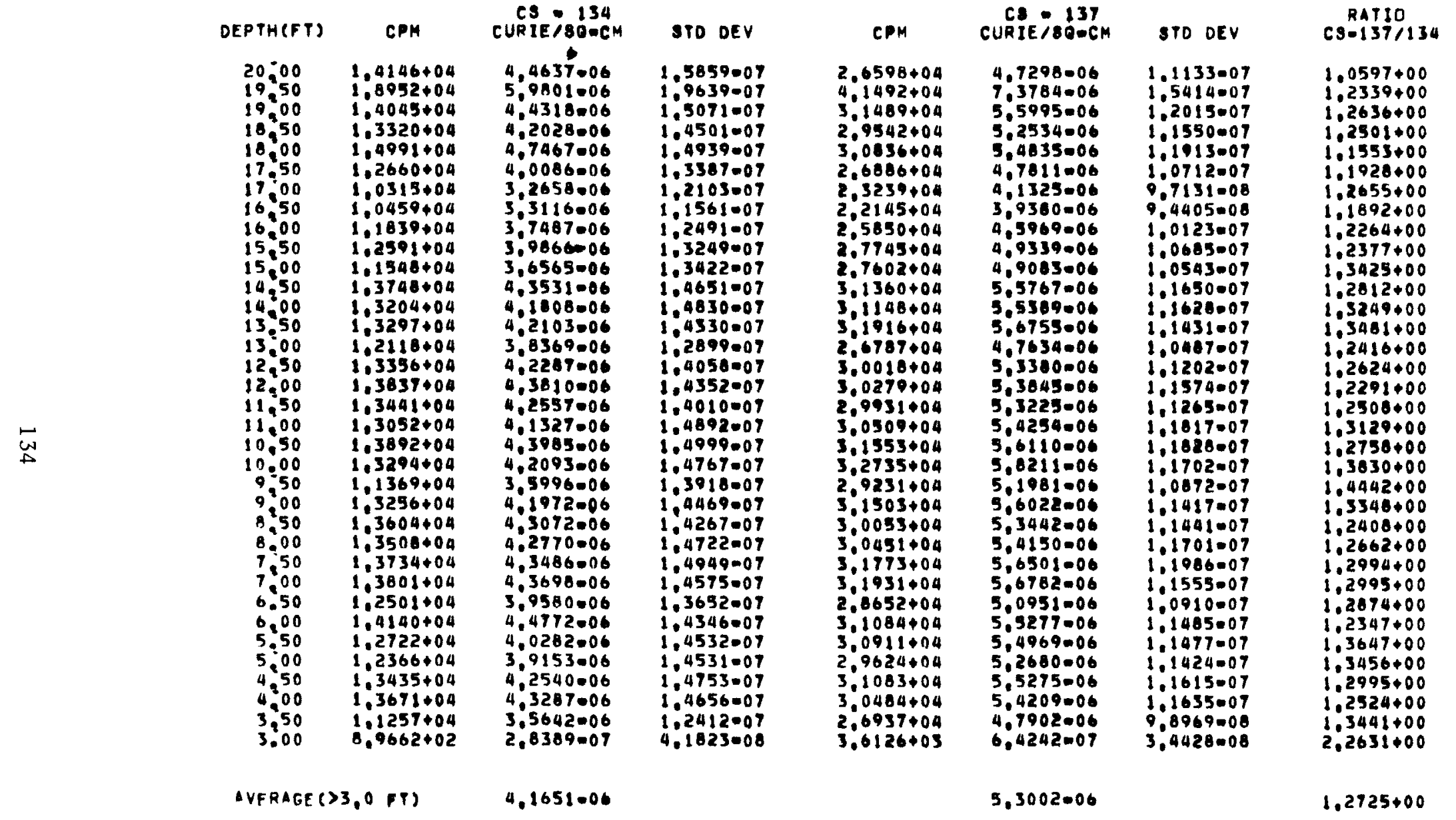

Standard deviation shown is that associated with counting statistics only. 
peach bottom steam genenator gamma scan, eVAPORator tube I outLet.

\begin{tabular}{|c|c|c|c|c|c|c|c|c|}
\hline & DEPTH(FT) & CPM & $\begin{array}{c}C 8134 \\
\text { CURIEISO-CM }\end{array}$ & BTO DEV & CPM & $\begin{array}{c}C S 137 \\
\text { CURIEISOACM }\end{array}$ & STD DEY & $\begin{array}{c}\text { RATI0 } \\
\operatorname{cs}=137 / 134\end{array}$ \\
\hline - & 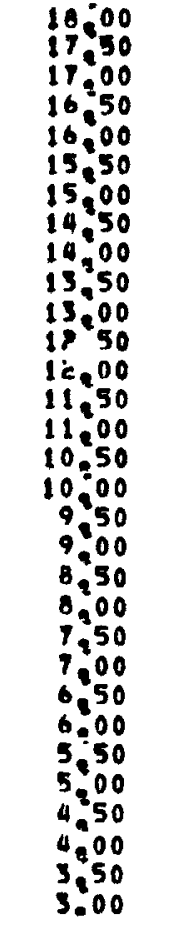 & $\begin{array}{l}1.2615+04 \\
1.2437+04 \\
1.0636+04 \\
9.4202+03 \\
1.1261+04 \\
1.0654+04 \\
1.0401+04 \\
1.2069+04 \\
1.2656+04 \\
1.0867+04 \\
1.0861+04 \\
1.0794+04 \\
1.1033+04 \\
1.1742+04 \\
1.2237+04 \\
1.2523+04 \\
1.2166+04 \\
1.0608+04 \\
1.2867+04 \\
1.0890+04 \\
1.2339+04 \\
1.2780+04 \\
1.2290+04 \\
1.1516+04 \\
1.2158+04 \\
1.2666+04 \\
1.2934+04 \\
1.3094+04 \\
1.3431+04 \\
1.0144+04 \\
1.0012+03\end{array}$ & 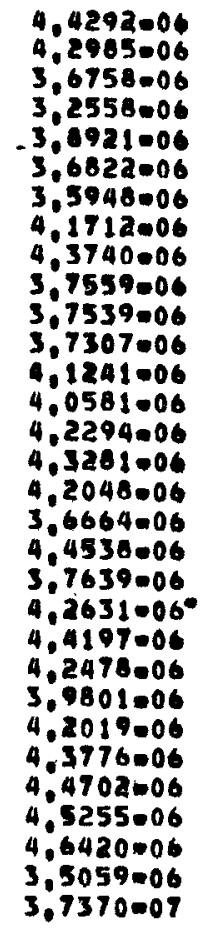 & 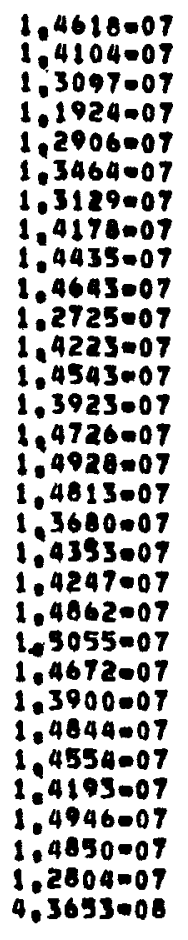 & $\begin{array}{l}2,8435+04 \\
2,6319+04 \\
2,3671+04 \\
2,11155+04 \\
2,2075+04 \\
2,3354+04 \\
2,2135+04 \\
2,4894+04 \\
2,5033+04 \\
2,5353+04 \\
2,2072+04 \\
2,4221+04 \\
2,6359+04 \\
2,4048+04 \\
2,5427+04 \\
2,6499+04 \\
2,7405+04 \\
2,2406+04 \\
2,6102+04 \\
2,4377+04 \\
2,6245+04 \\
2,8086+04 \\
2,5524+04 \\
2,4478+04 \\
2,5335+04 \\
2,5501+04 \\
2,5735+04 \\
2,7053+04 \\
2,8005+04 \\
2,2965+04 \\
3,4194+03\end{array}$ & 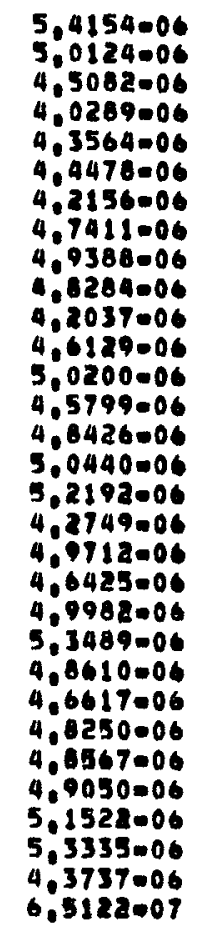 & 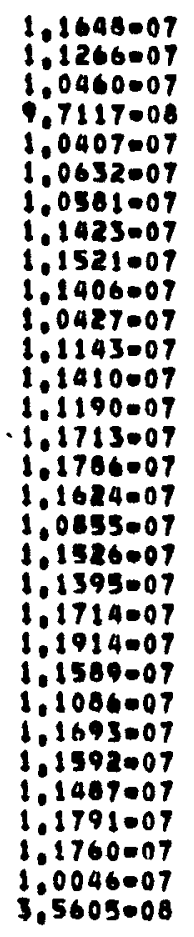 & $\begin{array}{l}1.2227+00 \\
1.1662+00 \\
1.2265+00 \\
1.2375+00 \\
1.1194+00 \\
1.2080+00 \\
1.1720+00 \\
1.1367+00 \\
1.1292+00 \\
1.2857+00 \\
1.1199+00 \\
1.2366+00 \\
1.2173+00 \\
1.1287+00 \\
1.1451+00 \\
1.1655+00 \\
1.2414+00 \\
1.1660+00 \\
1.1162+00 \\
1.2335+00 \\
1.1926+00 \\
1.2103+00 \\
1.1444+00 \\
1.1713+00 \\
1.148400 \\
1.1095+00 \\
1.0973+00 \\
1.11386+00 \\
1.1491+00 \\
1.2476+00 \\
1.7426+00\end{array}$ \\
\hline & A VERAGE & $3.0 \mathrm{FT}$ & 4.0692 .06 & & & 4.7740006 & & 1.1732 .00 \\
\hline
\end{tabular}

Standard deviation shown is that associated with counting statistics only. 
PEACH BOTTOM STEAM GENERATOR gAMMA SCAN, EVAPORATOR TUBE I INLET,

\begin{tabular}{|c|c|c|c|c|c|c|c|c|}
\hline & DEPTH (FT) & $C P M$ & $\begin{array}{l}\text { CS } \$ 34 \\
\text { CURIE/SO-CM }\end{array}$ & STD DEV & CPM & $\begin{array}{c}C B-137 \\
\text { CURIE } 130=C M\end{array}$ & STO DEV & $\begin{array}{c}\text { RAT10 } \\
\text { C8-137/134 }\end{array}$ \\
\hline$\tilde{\omega}$ & 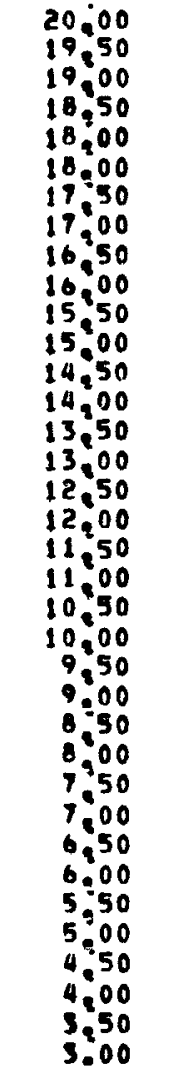 & 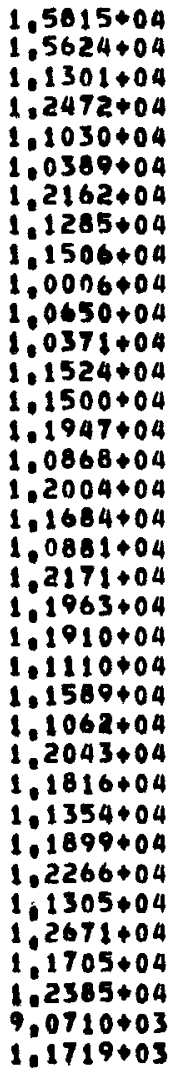 & 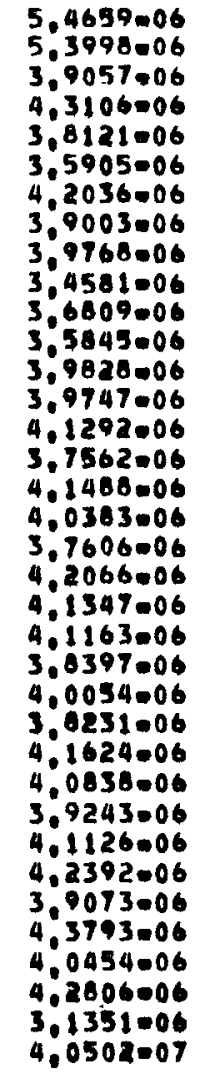 & 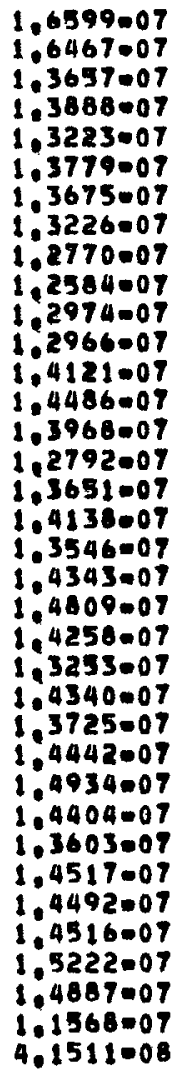 & $\begin{array}{l}2,6071+04 \\
2,5593+04 \\
1,9652+04 \\
2,1804+04 \\
2,0015+04 \\
2,4451+04 \\
2,5678+04 \\
2,4086+04 \\
2,4667+04 \\
2,2040+04 \\
2,3519+04 \\
2,3287+04 \\
2,3462+04 \\
2,5078+04 \\
2,3843+04 \\
2,2391+04 \\
2,4699+04 \\
2,4750+04 \\
2,4447+04 \\
2,556+04 \\
2,6227+04 \\
2,6271+04 \\
2,3681+04 \\
2,6211+04 \\
2,3939+04 \\
2,5697+04 \\
2,7427+04 \\
2,5805+04 \\
2,3629+04 \\
2,6632+04 \\
2,6359+04 \\
2,6516+04 \\
2,9341+04 \\
2,9238+04 \\
2,0620+04 \\
3,0704+03\end{array}$ & 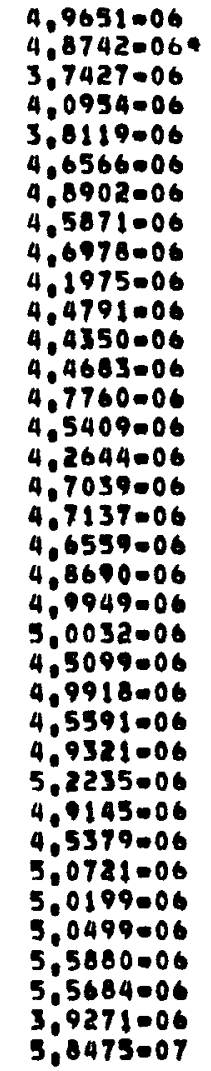 & 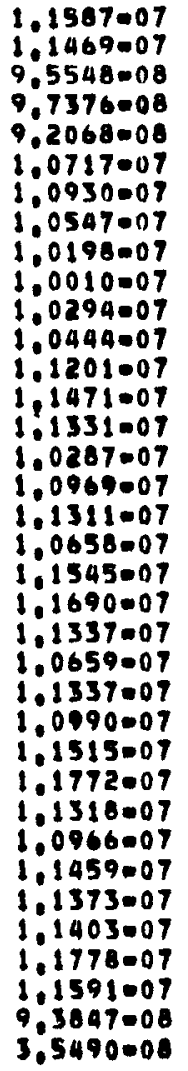 & $\begin{array}{l}9.0845001 \\
9.0273001 \\
9.5833-01 \\
9.5015001 \\
1.0000+00 \\
1.2970+00 \\
1.1635+00 \\
1.1762+00 \\
1.1814+00 \\
1.2139+00 \\
1.2169+00 \\
1.2374+00 \\
1.1220+00 \\
1.2017+00 \\
1.0996+00 \\
1.1354+00 \\
1.1339+00 \\
1.1673+00 \\
1.2382+00 \\
1.1576+00 \\
1.2081+00 \\
1.2156+00 \\
1.1747+00 \\
1.2464+00 \\
1.1926+00 \\
1.1850+00 \\
1.2792+00 \\
1.2524+00 \\
1.1035+00 \\
1.1966+00 \\
1.2849+00 \\
1.1532+00 \\
1.3614+00 \\
1.3009+00 \\
1.2327+00 \\
1.4439+00\end{array}$ \\
\hline & AVERAGE ( & $.0 F T$ & $4.0421=06$ & & & $4.6948-06$ & & $1,1615+00$ \\
\hline
\end{tabular}

Standard deviation shown is that associated with counting statistics only. 
PEACH BOTTOM STEAM GENERATOR GAMMA SCAN, EVAPORATOR TUBE 51 DUTLET.

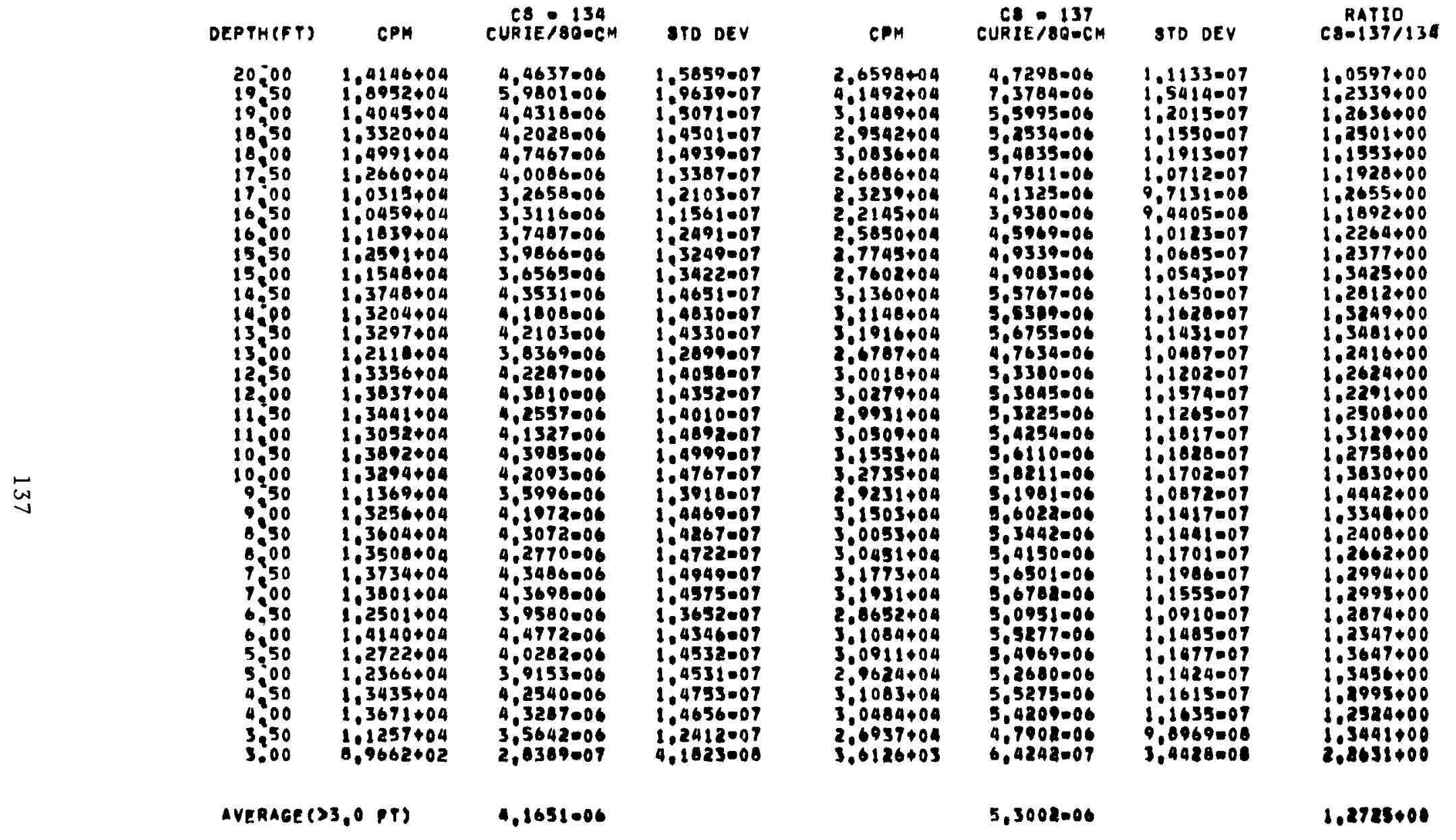

Standard deviation shown is that associated with counting statistics only. 
PEACH BOTYOM STEAM GENERATOR GAMMA SCAN. EVAPORATOR TUGE 102 INLET.

\begin{tabular}{|c|c|c|c|c|c|c|c|c|}
\hline & DEPTH(FT) & $C P M$ & $\begin{array}{c}\text { CS } 134 \\
\text { CURIE/SO-CM }\end{array}$ & STO DEV & CPM & $\begin{array}{l}\text { CS } 137 \\
\text { CURIE/SO-CM }\end{array}$ & BTD DEV & $\begin{array}{c}\text { RATIO } \\
\operatorname{csel} 137 / 134\end{array}$ \\
\hline w & 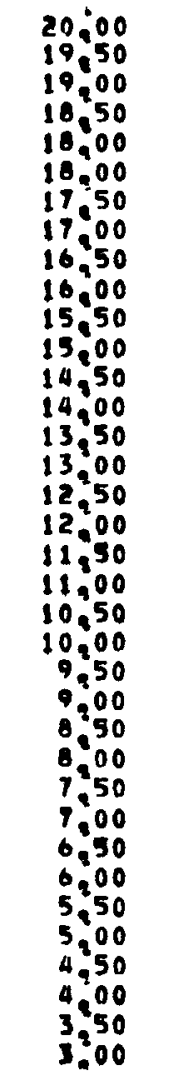 & 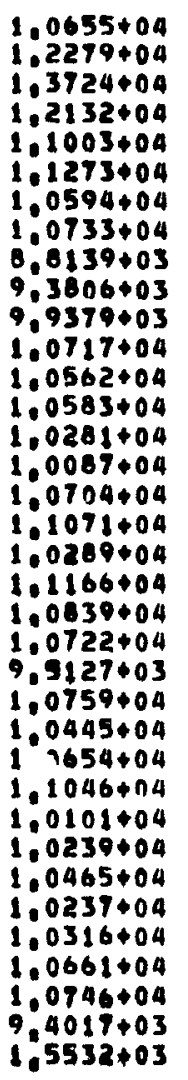 & 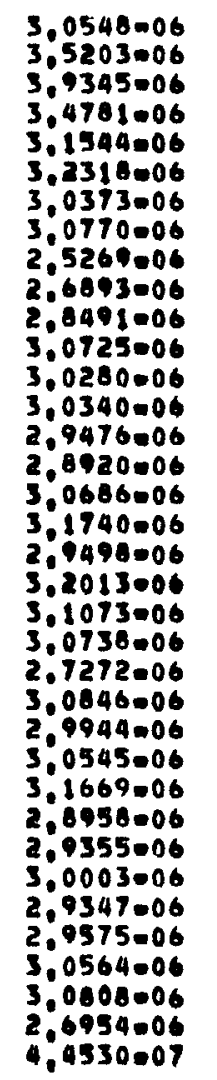 & 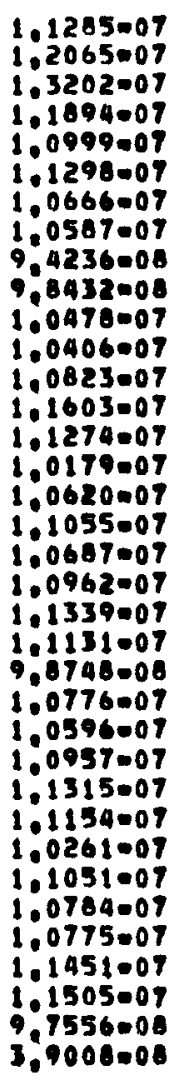 & 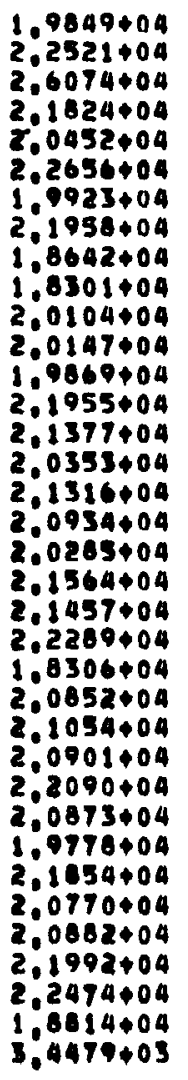 & 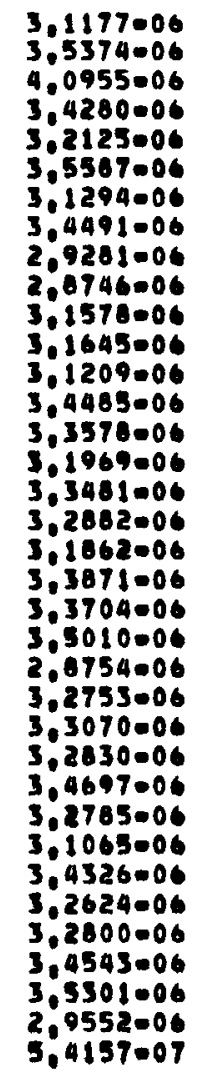 & 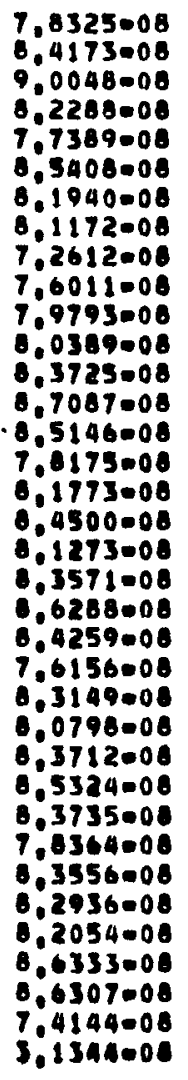 & $\begin{array}{l}1.0207+00 \\
1.0049+00 \\
1.0410+00 \\
9.0567+01 \\
1.0185+00 \\
1.1012+00 \\
1.0304+00 \\
1.1210+00 \\
1.1589+00 \\
1.0690+00 \\
1.1084+00 \\
1.0300+00 \\
1.0308+00 \\
1.1367+00 \\
1.1393+00 \\
1.1055+00 \\
1.0912+00 \\
1.0361+00 \\
1.0002+00 \\
1.0581+00 \\
1.0847+00 \\
1.1391+00 \\
1.0544+00 \\
1.0619+00 \\
1.1045+00 \\
1.0749+00 \\
1.0957+00 \\
1.1323+00 \\
1.0583+00 \\
1.1442+00 \\
1.1117+00 \\
1.1091+00 \\
1.1303+00 \\
1.1459+00 \\
1.0965+00 \\
1.2163+00\end{array}$ \\
\hline & AVERAGE () & $3.0 \mathrm{F1}$ & $3,0482-06$ & & & $3,2963-06$ & & $1.0814 \bullet 00$ \\
\hline
\end{tabular}

Standard deviation shown is that associated with counting statistics only. 
PEACH botTom steam generator bamma scan, superheater tube a3 INLET,

\begin{tabular}{|c|c|c|c|c|c|c|c|c|}
\hline & DEPTH(FT) & CPM & $\begin{array}{c}\text { CS } \\
\text { CURIE } 134 \\
\end{array}$ & STO OEV - & CPM & $\begin{array}{c}\text { CSE } 137 \\
\text { CURIE/SO-CM }\end{array}$ & STO DEV & $\begin{array}{c}\text { RATIO } \\
\text { C8- } 137 / 134\end{array}$ \\
\hline & 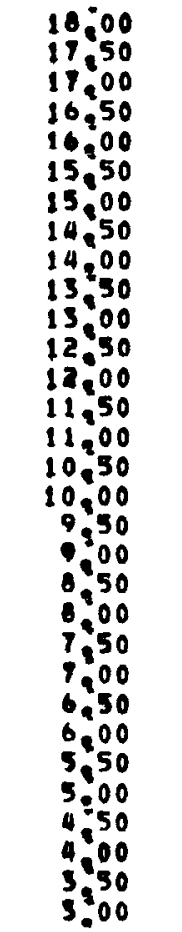 & $\begin{array}{l}1,1485+04 \\
1,1774+04 \\
1,0523+04 \\
9,0525+03 \\
9,5610+03 \\
1,1164+04 \\
1,2216+04 \\
1,3073+04 \\
1,3425+04 \\
1,3749+04 \\
9,3402+03 \\
1,2624+04 \\
1,3922+04 \\
1,4660+04 \\
1,4594+04 \\
1,4160+04 \\
1,2829+04 \\
1,2394+04 \\
1,4378004 \\
1,3305+04 \\
1,3647+04 \\
1,1111+04 \\
9,3076+03 \\
1,1120+04 \\
1,2289+04 \\
1,2665+04 \\
1,2978+04 \\
1,3627+04 \\
1,2613+04 \\
1,2510004 \\
1,2005+03\end{array}$ & 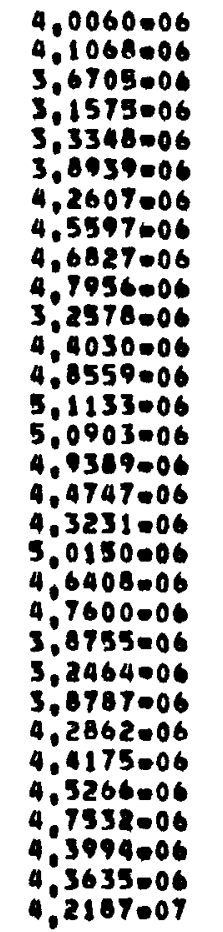 & 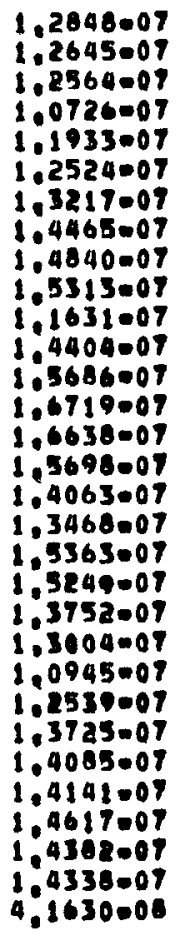 & 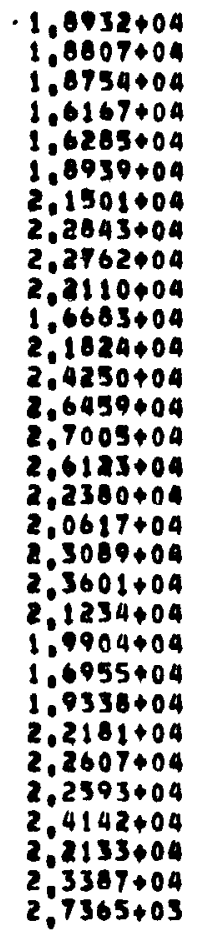 & 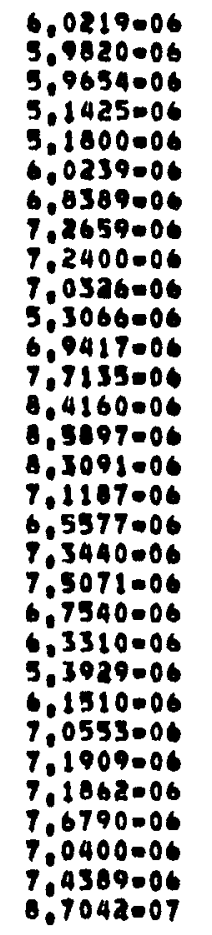 & 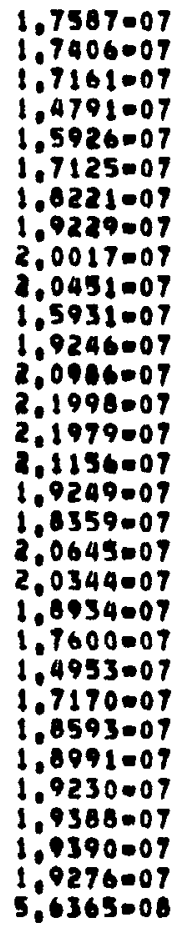 & 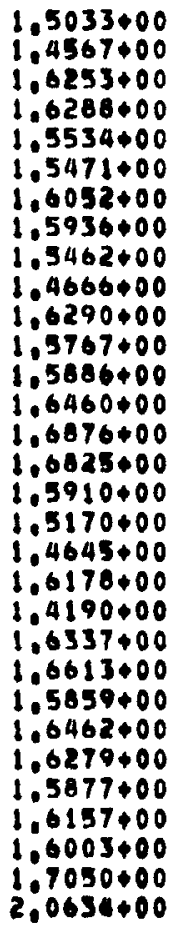 \\
\hline & AVERAGECS & $3.0 \mathrm{FT}$ & 9.3029006 & & & 6,8239000 & & $1,8059+00$ \\
\hline
\end{tabular}


PEACH DOTTOM STEAM GENERATOR GAMMA SCAN, SUPERHEATER TUBE 83-1 INLET.

\begin{tabular}{|c|c|c|c|c|c|c|c|c|}
\hline & DEPTH(FT) & CPM & $\begin{array}{c}\text { CS } 134 \\
\text { CURIE/SO-CM }\end{array}$ & STD DEY & CPM & $\begin{array}{c}\text { CS } 137 \\
\text { CUAIE } 180=\mathrm{CM}\end{array}$ & STD DEV & $\begin{array}{c}\text { RATIO } \\
\text { C8-1371134 }\end{array}$ \\
\hline 苾 & 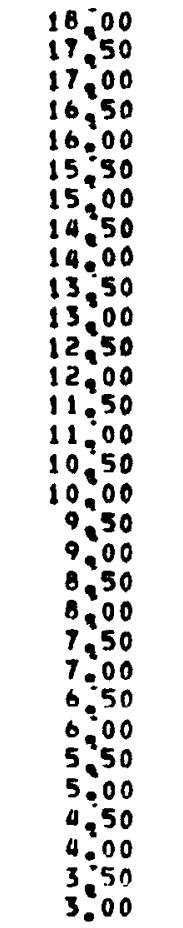 & $\begin{array}{l}1,0197+04 \\
1,0678+04 \\
1,1040+04 \\
9,2212+03 \\
9,9770+03 \\
1,1745+04 \\
1,2060+04 \\
1,2439+04 \\
1,3647+04 \\
1,4193+04 \\
1,0173+04 \\
1,1733+04 \\
1,3016+04 \\
1,4799+04 \\
1,3320+04 \\
1,2581+04 \\
9,9682+03 \\
1,4527+04 \\
1,3694+04 \\
1,3636+04 \\
1,2853+04 \\
1,2616+04 \\
1,082+04 \\
1,2674+04 \\
1,3209+04 \\
1,3125+04 \\
1,3911+04 \\
1,4125+04 \\
1,4487+04 \\
1,2520+04 \\
2,2966+03\end{array}$ & 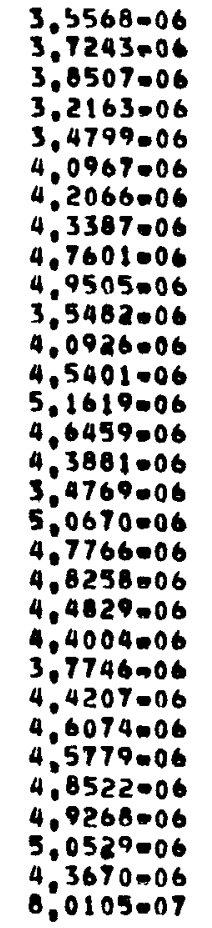 & 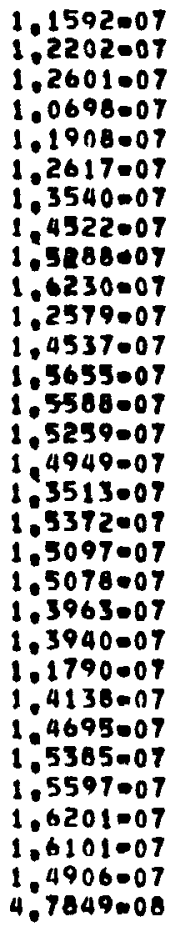 & 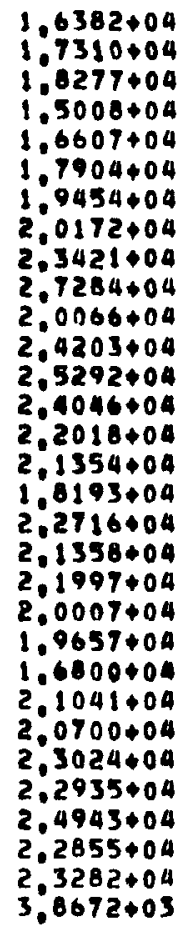 & 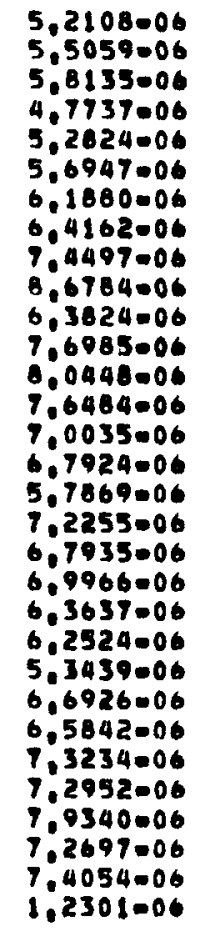 & 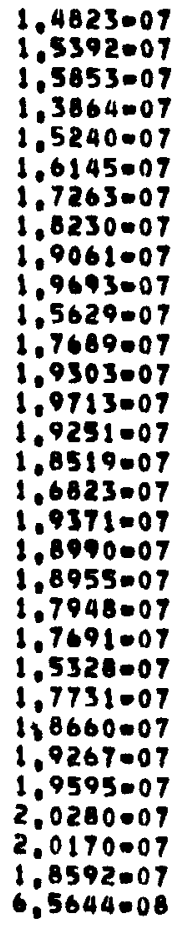 & $\begin{array}{l}1.4651+00 \\
1.4785+00 \\
1.5098+00 \\
1.4843+00 \\
1.5181+00 \\
1.3902+00 \\
1.4711+00 \\
1.4789+00 \\
1.5652+00 \\
1.7932+00 \\
1.7989+00 \\
1.8812+00 \\
1.7721+00 \\
1.4618+00 \\
1.5076+00 \\
1.5480+00 \\
1.6645+00 \\
1.4261+00 \\
1.4224+00 \\
1.4499+00 \\
1.4197+00 \\
1.4210+00 \\
1.4159+00 \\
1.5140+00 \\
1.4292+00 \\
1.5998+00 \\
1.5036+00 \\
1.6105+00 \\
1.4386+00 \\
1.6959+00 \\
1.5357+00\end{array}$ \\
\hline & GE & $0 F T$ & $.3389 \mathrm{~m} 06$ & & & $6.6617=06$ & & $.5353+00$ \\
\hline
\end{tabular}

Standard deviation shown is that associated with counting statistics only. 
PEACH GOTTOM STEAM GENERATOR GAMMA BCAN, SUPERHEATER TUBE 12 INLET.

\begin{tabular}{|c|c|c|c|c|c|c|c|c|}
\hline & DEPTH $(F T)$ & CPM & $\begin{array}{c}\text { C8 } 134 \\
\text { CURIE } 130-6 M\end{array}$ & STO DEV & CPM & $\begin{array}{c}\text { CS } 137 \\
\text { CURIE } 180=\mathrm{CM}\end{array}$ & STO DEY & $\begin{array}{c}\text { RATIO } \\
\cos =137 / 134\end{array}$ \\
\hline 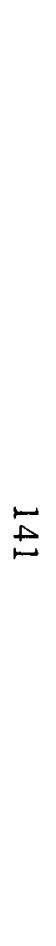 & 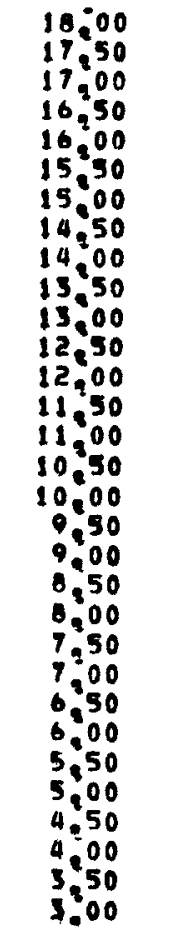 & 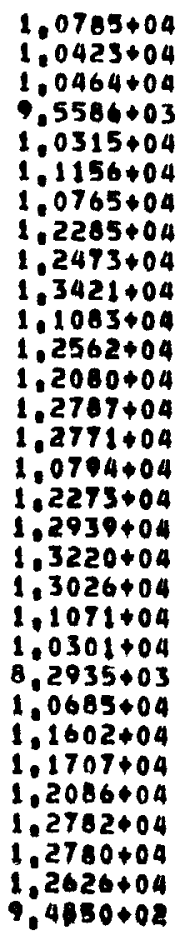 & 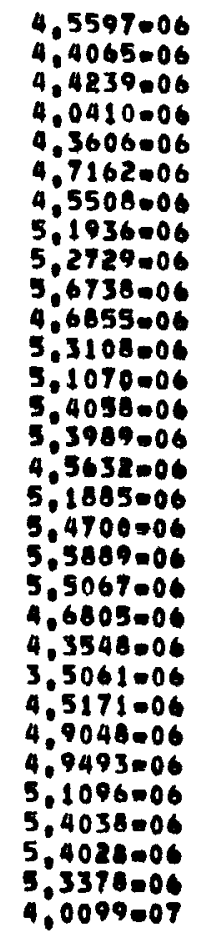 & 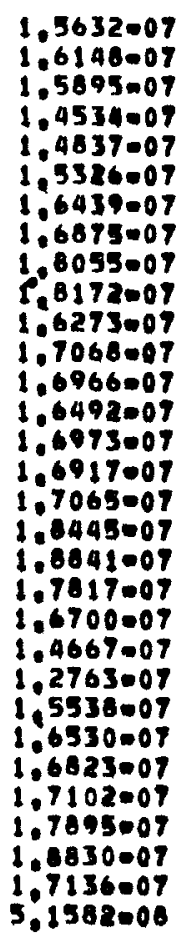 & 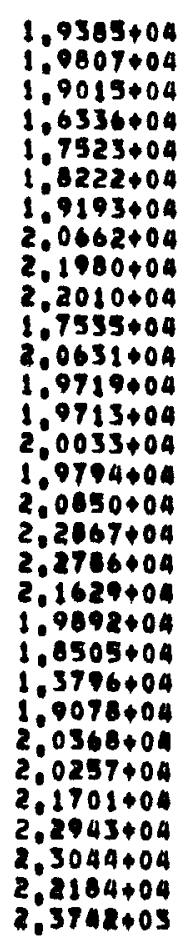 & 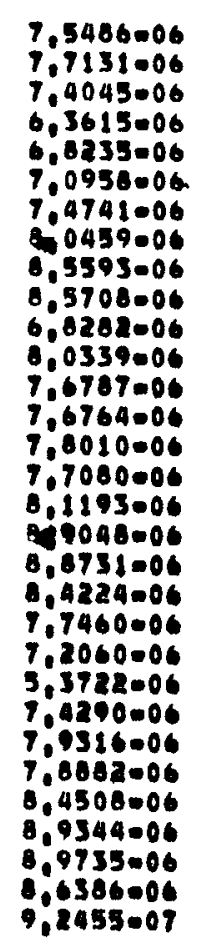 & 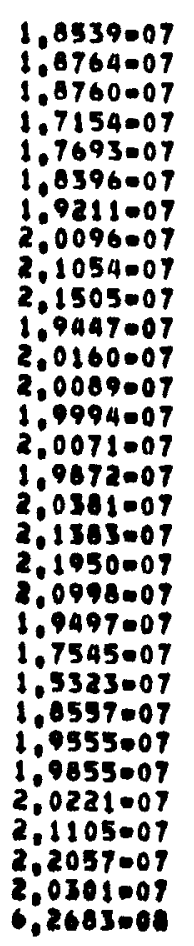 & $\begin{array}{l}1.6556+00 \\
1.7505+00 \\
1.6739+00 \\
1.5944+00 \\
1.5649+00 \\
1.5047+00 \\
1.6425+00 \\
1.5493+00 \\
1.6234+00 \\
1.5109+00 \\
1.4574+00 \\
1.5129+00 \\
1.5037+00 \\
1.4201+00 \\
1.4450+00 \\
1.6893+00 \\
1.5650+00 \\
1.6281+00 \\
1.5976+00 \\
1.5296+00 \\
1.6551+00 \\
1.6549+00 \\
1.5323+00 \\
1.6440+00 \\
1.6172+00 \\
1.5939+00 \\
1.6540+00 \\
1.6535+00 \\
1.6610+00 \\
1.6165+00 \\
2.3059+00\end{array}$ \\
\hline & AVEF & $1.0(1)$ & 4.9197 .06 & & & 7.6071006 & & $5004+00$ \\
\hline
\end{tabular}


PEACH BotTOM STEAM GENERATOR GAMMA SCAN. SUPERMEATER TUBE T2-1 INLET.

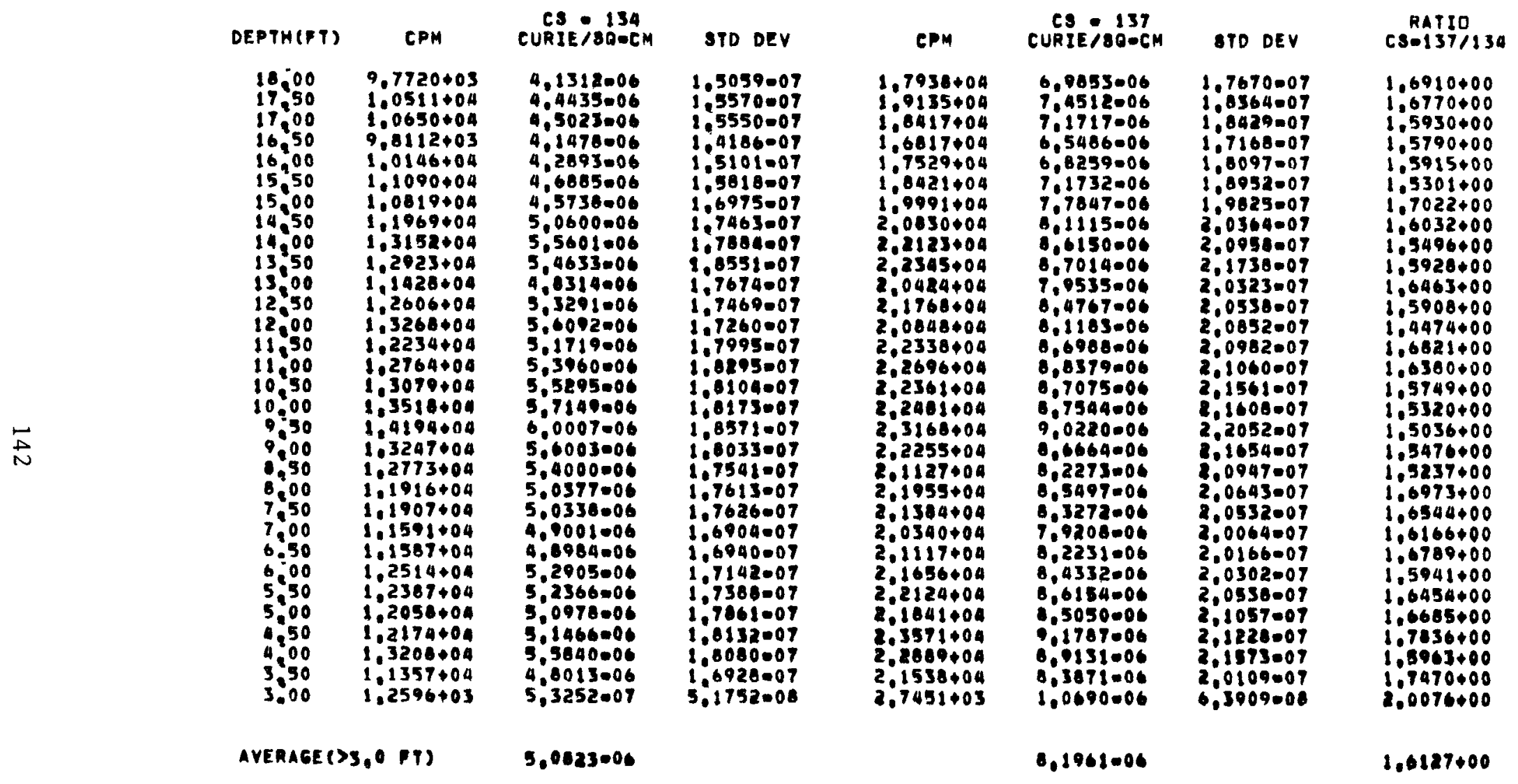

Standard deviation shown is that associated with counting statistics only. 
PEACH BotTom oteam generator gamma sCan, eyapurator tube 180 outLet.

\begin{tabular}{|c|c|c|c|c|c|c|c|c|}
\hline & DEPTH (FT) & CPH & $\begin{array}{c}\text { CS } 134 \\
\text { CURIE/SO-CM }\end{array}$ & $8 T 0$ DEV & EPM & $\begin{array}{c}\text { CSE } 137 \\
\text { CURIE/80-CM }\end{array}$ & STD DEV & $\begin{array}{c}\text { RATIO } \\
\cos 137 / 134\end{array}$ \\
\hline- & 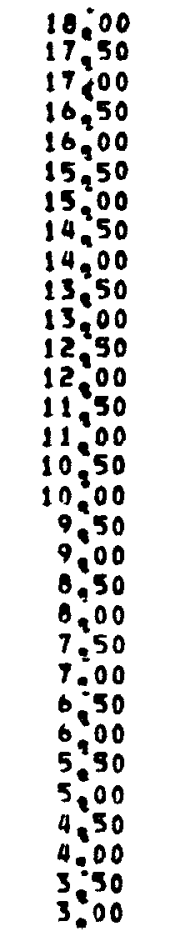 & 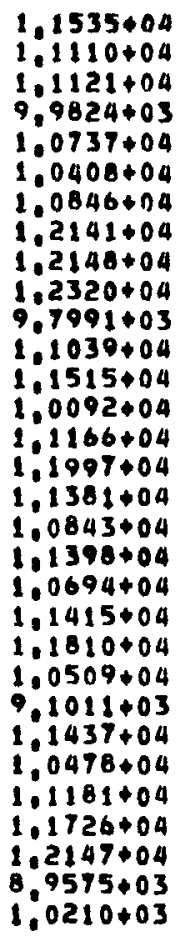 & 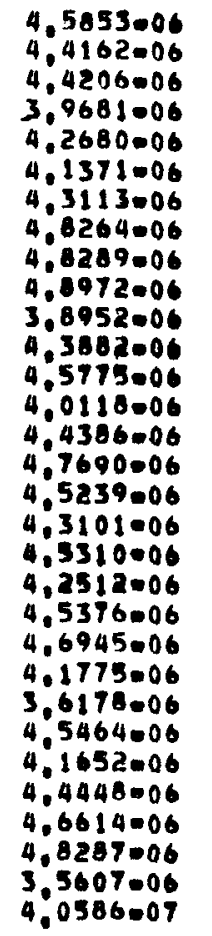 & 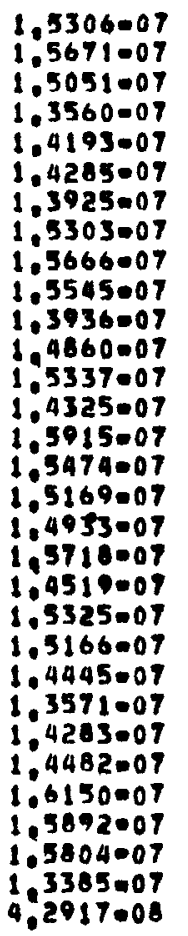 & 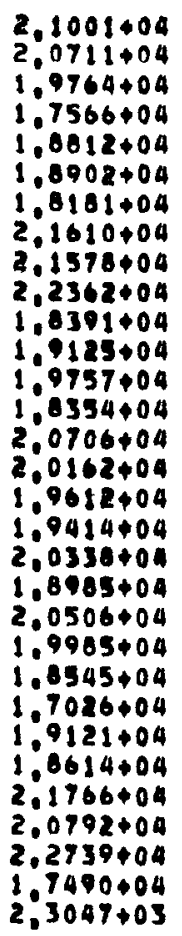 & 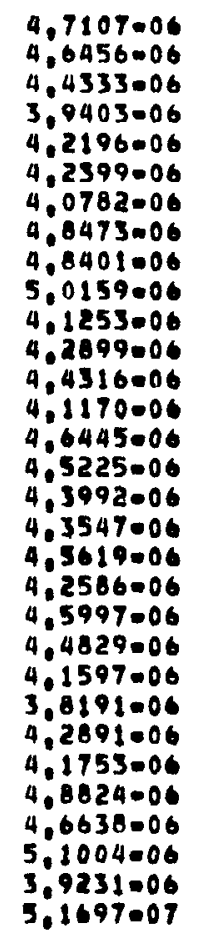 & 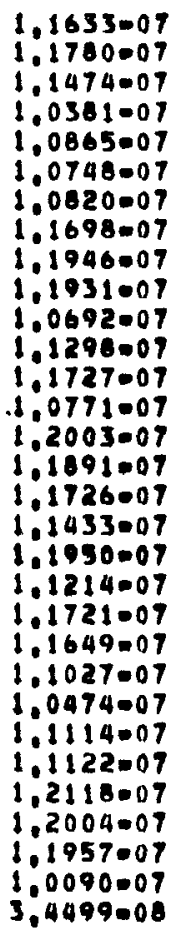 & 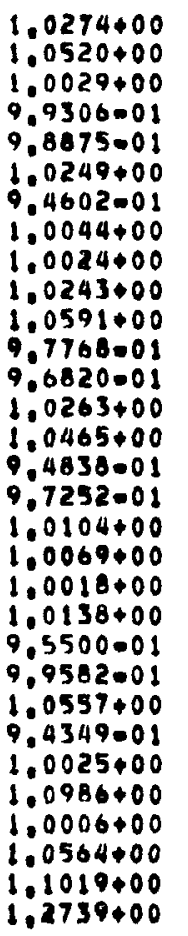 \\
\hline & AVERAGE () & $3.0 \mathrm{TI}$ & 4,3863006 & & & 4.4257 .06 & & $1.0090+00$ \\
\hline
\end{tabular}


PEACH BOTTOM BTEAM GENERATOR GAMMA BCAN, EYAPORATOR TUBE 180-1 RUTLET.

\begin{tabular}{|c|c|c|c|c|c|c|c|c|}
\hline & DEPTH(FT) & CPM & $\begin{array}{c}\text { C8 } 134 \\
\text { CURIE } 130=C M\end{array}$ & STD DEV & CPM & $\begin{array}{c}\text { CS } 137 \\
\text { CURIE/SO-CM }\end{array}$ & BTD DEV & $\begin{array}{c}\text { RATIO } \\
\cos =137 / 136\end{array}$ \\
\hline 1 & 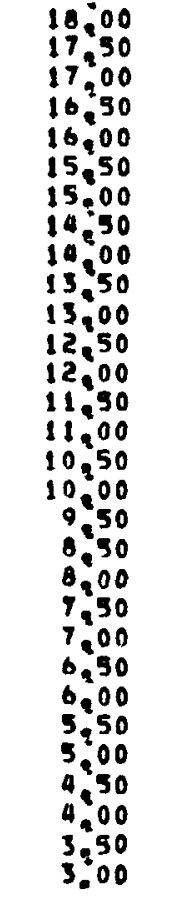 & 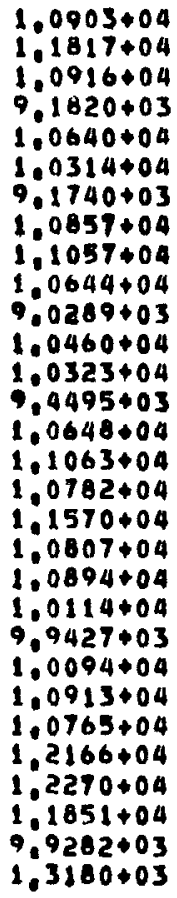 & 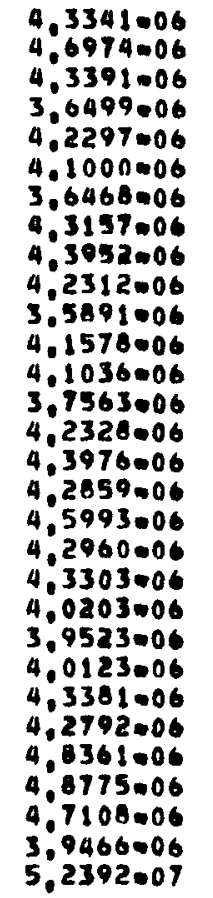 & 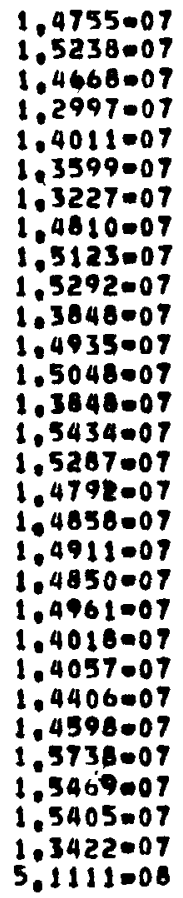 & $\begin{array}{l}2.0129+04 \\
2.0010+04 \\
1.0219+04 \\
1.6377+04 \\
1.7970+04 \\
1.6154+04 \\
1.5363+04 \\
1.9524+04 \\
1.9545+04 \\
1.9284+04 \\
1.5941+04 \\
1.9029+04 \\
1.8494+04 \\
1.6365+04 \\
1.8973+04 \\
1.9696+04 \\
1.8870+04 \\
1.9150+04 \\
1.9558+04 \\
1.9199+04 \\
1.8386+04 \\
1.7714+04 \\
1.8450+04 \\
1.8796+04 \\
1.8709+04 \\
2.0846+04 \\
1.9812+04 \\
2.0705+04 \\
1.7207+04 \\
3,0186+03\end{array}$ & 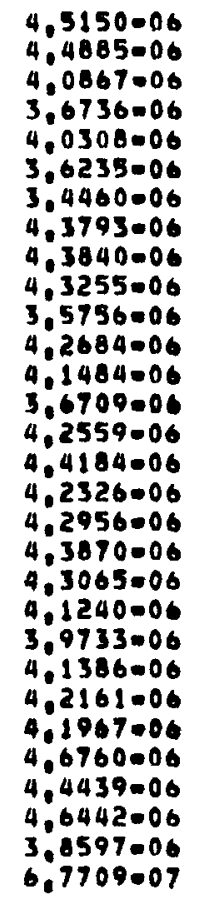 & 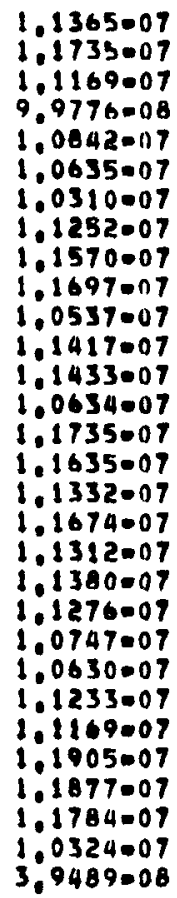 & 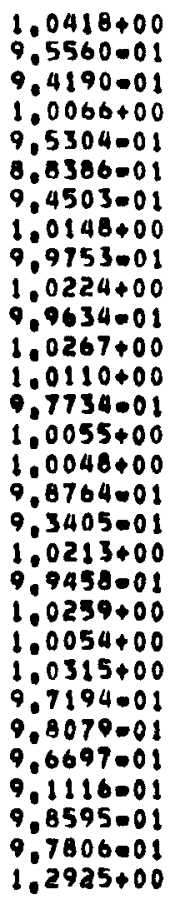 \\
\hline & AVERAGEC & $3.0(T)$ & $4,2297,06$ & & & 4.1650006 & & 0.8470001 \\
\hline
\end{tabular}

Standard deviation shown is that associated with counting statistics only. 
PEACH BotToM steam generator gamma scan, EVAPORATOR tUBE 25 INLET.

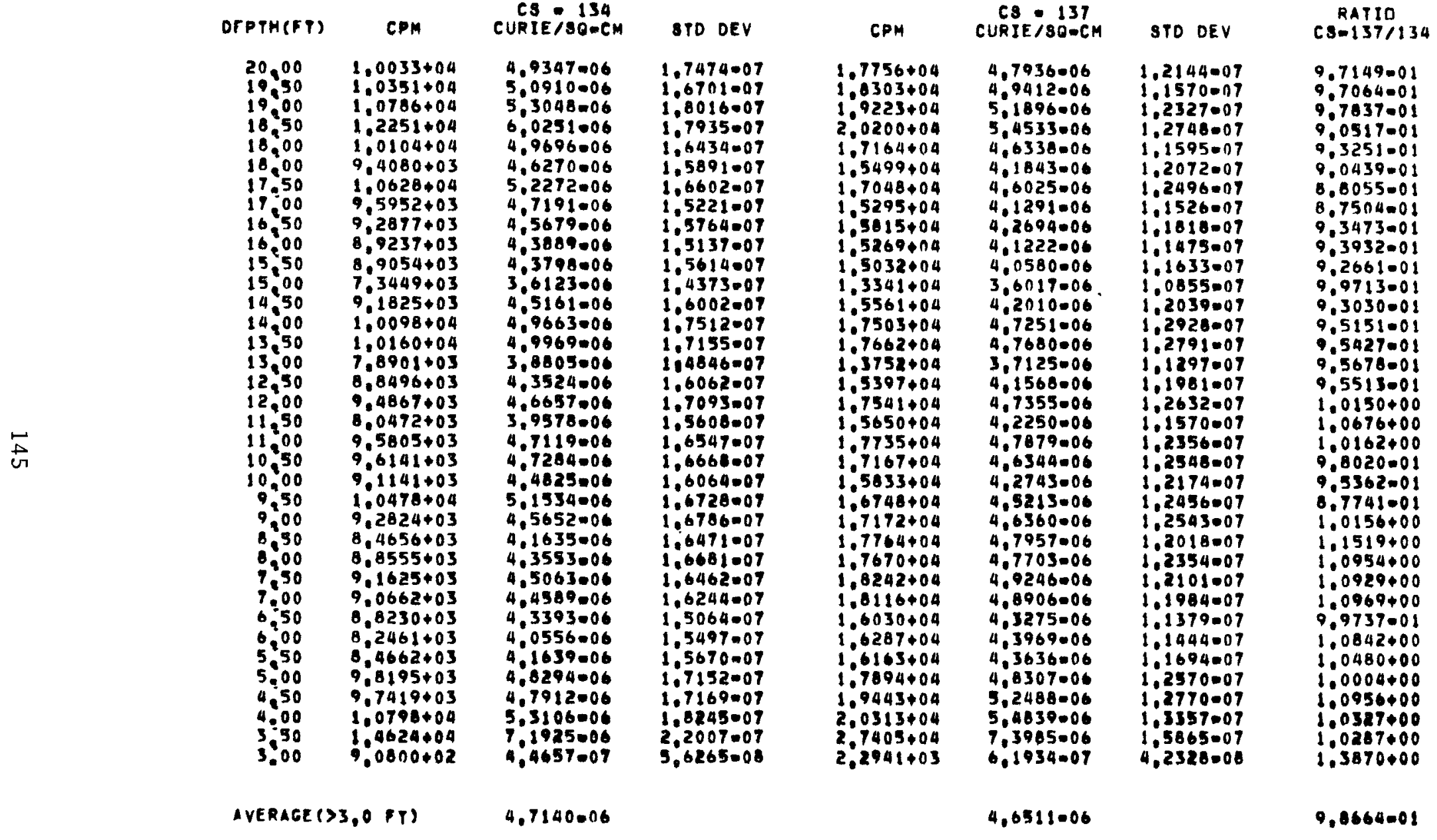

Standard deviation shown is that associated with counting statistics only. 
PEACH BOTTOM STEAM GENERATOR GAMMA SCAN, SUPERHEATER TUBE 5 OUTLET.

\begin{tabular}{|c|c|c|c|c|c|c|c|c|}
\hline & DEPTH (FT) & CPM & $\begin{array}{l}\text { CS } 1344 \\
\text { CURIE } 180=C M\end{array}$ & STO DEV & CPM & $\begin{array}{c}\text { C8 } 137 \\
\text { CURIE/80-CM }\end{array}$ & STO OEV & $\begin{array}{c}\text { RATIO } \\
\operatorname{col} 137 / 134\end{array}$ \\
\hline 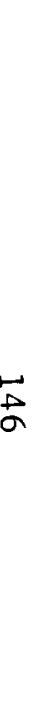 & 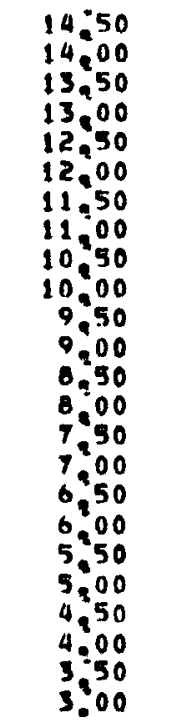 & $\begin{array}{l}1.4208+04 \\
1.4322+04 \\
1.4627+04 \\
1.1719+14 \\
1.4326+04 \\
1.5214+04 \\
1.5408+04 \\
1.4976+04 \\
1.4534+04 \\
1.4414+04 \\
1.2621+04 \\
1.3432+04 \\
1.4765+04 \\
1.388+04 \\
1.3131+04 \\
1.2237+04 \\
1.0256+04 \\
1.1128+04 \\
1.0674+04 \\
1.1316+04 \\
1.2050+04 \\
1.1318+04 \\
1.1514+04 \\
1.7109+03\end{array}$ & $\begin{array}{l}5,0826=06 \\
5,1235=06 \\
5,2328=06 \\
4,1923=06 \\
5,1251=06 \\
5,4427=06 \\
5,5122=06 \\
5,3577=06 \\
5,1995=06 \\
5,1565=06 \\
4,5149=06 \\
4,8050=06 \\
5,2820=06 \\
4,9680=06 \\
4,6976=06 \\
4,3776=06 \\
3,6691=06 \\
3,9808006 \\
3,0184006 \\
4,0481=06 \\
4,3107=06 \\
4,0489=06 \\
4,1192=06 \\
6,1205=07\end{array}$ & 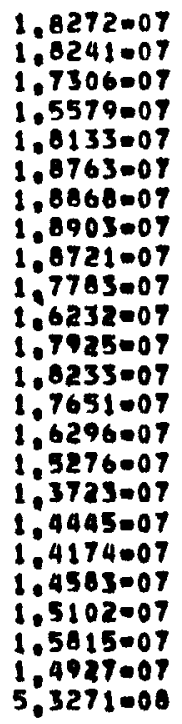 & $\begin{array}{l}2.4838+04 \\
2.5041+04 \\
2.4956+04 \\
1.0898+04 \\
2.4725+04 \\
2.5757+04 \\
2.5567+04 \\
2.6362+04 \\
2.4520+04 \\
2.0010+04 \\
2.1380+04 \\
2.3617+04 \\
2.4613+04 \\
2.4155+04 \\
2.1675+04 \\
2.0072+04 \\
1.7646+04 \\
1.8674+04 \\
1.7461+04 \\
1.8213+04 \\
1.9311+04 \\
1.9517+04 \\
2.0744+04 \\
3.3648+03\end{array}$ & 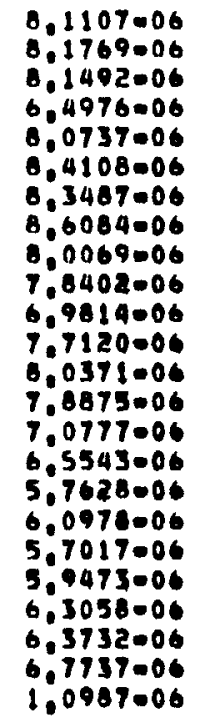 & 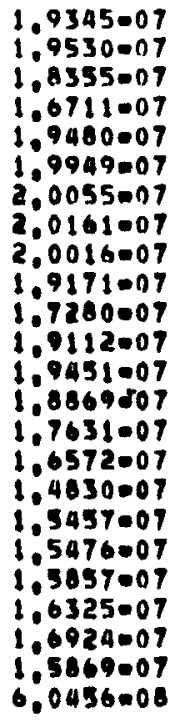 & $\begin{array}{l}1.5959+00 \\
1.5961+00 \\
1.5575+00 \\
1.5500+00 \\
1.5755+00 \\
1.5455+00 \\
1.5147+00 \\
1.6069+00 \\
1.5400+00 \\
1.5206+00 \\
1.5464+00 \\
1.6051+00 \\
1.5217+00 \\
1.5870+00 \\
1.5068+00 \\
1.4974+00 \\
1.5707+00 \\
1.5319+00 \\
1.4933+00 \\
1.4693+00 \\
1.4629+00 \\
1.5742+00 \\
1.6445+00 \\
1.7953+00\end{array}$ \\
\hline & AVEI & $0 \mathrm{FT}$ & $6985=06$ & & & 7.2798006 & & $1.5494 \$ 00$ \\
\hline
\end{tabular}

Standard deviation shown is that associated with counting statistics only. 
PEACH BOTTOM BTEAM genERATOR oAMMA sCAN, BUPERMEATER TUBE 52 INLET.

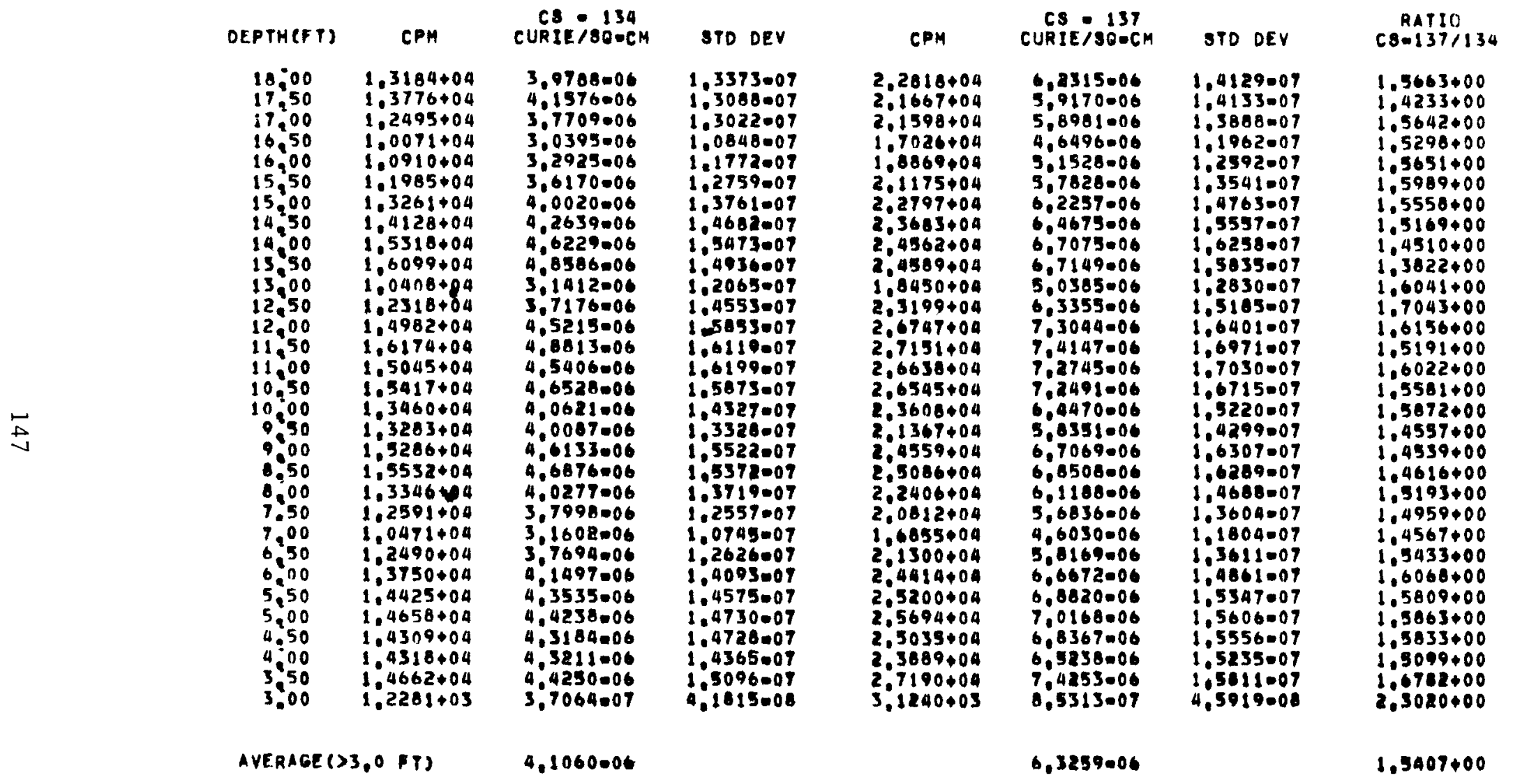

Standard deviation shown is that associated with counting statistics only. 
PEACH BotTOM steam Generator gamma sCAN, EVAPORATOR tUBE 15 INLET.

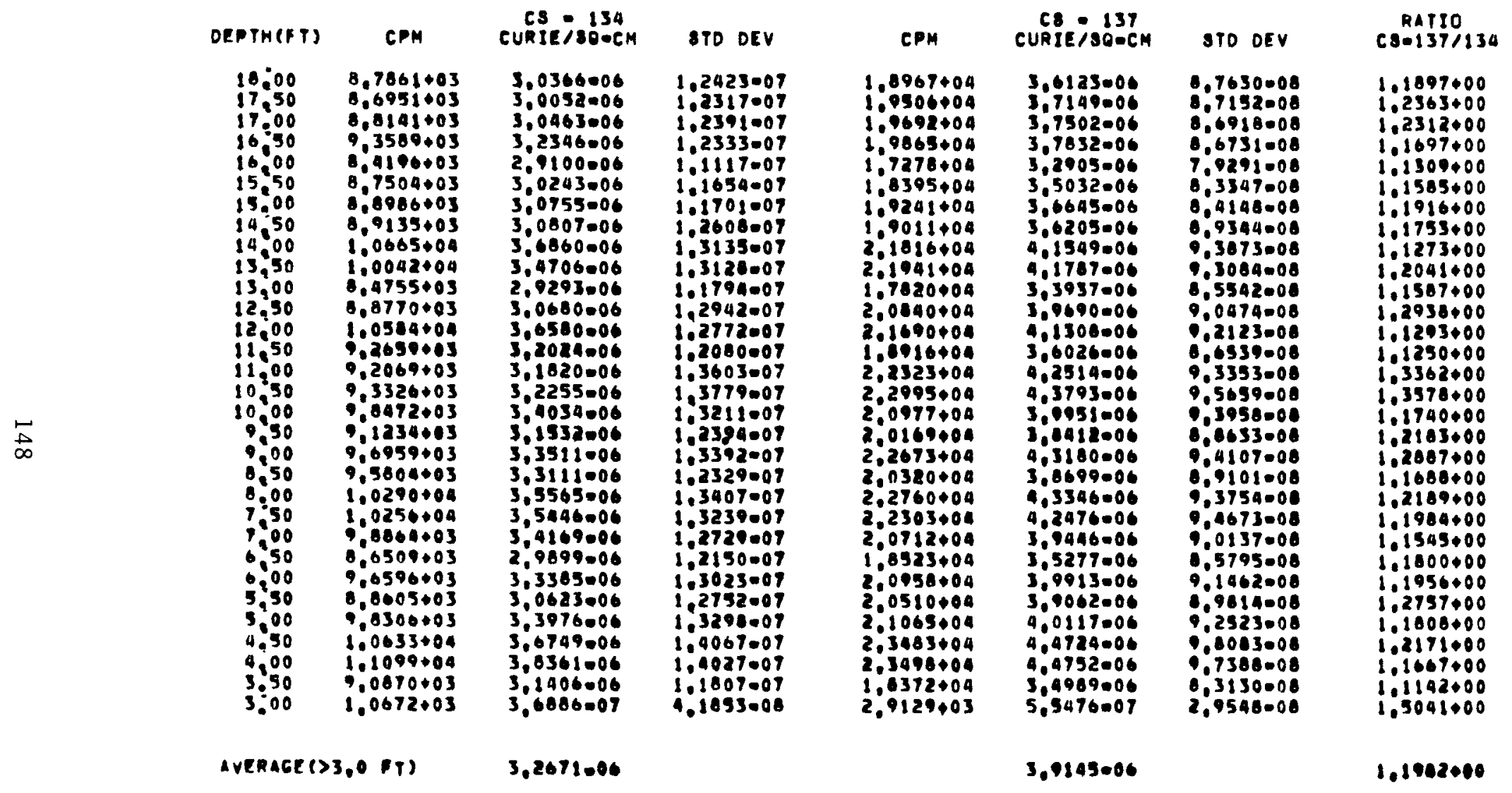

Standard deviation shown is that associated with counting statistics only. 
PEACH BOTTOM STEAM GENERATOR GAMMA BCAN, EVAPURATOR TUBE GS INLET,

\begin{tabular}{|c|c|c|c|c|c|c|c|c|}
\hline & DEPTH (FT) & CPM & $\begin{array}{l}\text { CS } \\
\text { CURIEISO-CM }\end{array}$ & STD DEV & CPM & $\begin{array}{c}\text { CS }=137 \\
\text { CURIE } 180=C M\end{array}$ & 8TD DEV & $\begin{array}{c}\text { RAPIO } \\
\text { C8-137/134 }\end{array}$ \\
\hline & 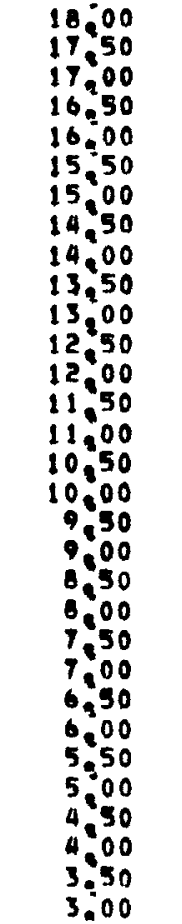 & $\begin{array}{l}9,5520+03 \\
8,8095+03 \\
9,0304+03 \\
9,0850+03 \\
8,1451+03 \\
9,1160+03 \\
8,9722+03 \\
9,6662+03 \\
1,0638+04 \\
1,0823+04 \\
9,8114+03 \\
9,5536+03 \\
1,0688+04 \\
9,9599+03 \\
1,0639+04 \\
1,0399+04 \\
1,0258+04 \\
9,6997+03 \\
9,8720+03 \\
9,3169+03 \\
1,0085+04 \\
1,0679+04 \\
9,1326+03 \\
8,7529+03 \\
9,4462+03 \\
9,9972+03 \\
1,0393+04 \\
1,0937+04 \\
1,1343+04 \\
9,5155+03 \\
8,6125+02\end{array}$ & $\begin{array}{l}2,7943=06 \\
2,5771=06 \\
2,6417=06 \\
2,6577=06 \\
2,3927=06 \\
2,6667=06 \\
2,6248=06 \\
2,8277=06 \\
3,1119=06 \\
3,1660=06 \\
2,8702=06 \\
2,7948=06 \\
3,1267=06 \\
2,9136=06 \\
3,1123=06 \\
3,0420=06 \\
3,0008=06 \\
2,8375=06 \\
2,8879=06 \\
2,7253=06 \\
2,9501006 \\
3,1240=06 \\
2,6716=06 \\
2,9605=06 \\
2,7639=06 \\
2,9245=06 \\
3,0404=06 \\
3,1994=06 \\
3,3183=06 \\
2,7836=06 \\
2,9194=07\end{array}$ & 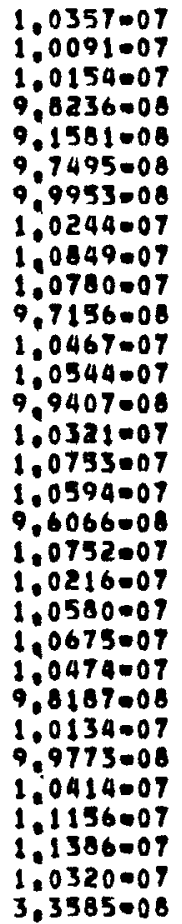 & 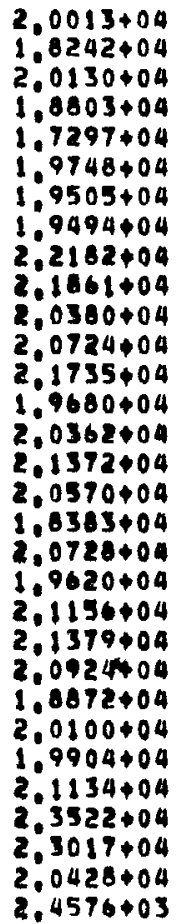 & $\begin{array}{l}3,3105=06 \\
3,0175=06 \\
3,3297=06 \\
3,1103=06 \\
2,8612=06 \\
3,2667=06 \\
3,2264=06 \\
3,2247=06 \\
3,6692=06 \\
3,6161=06 \\
3,3711=06 \\
3,4281=06 \\
3,595=06 \\
3,2553=06 \\
3,3602=06 \\
3,5353=06 \\
3,4026=06 \\
3,0409=06 \\
3,4288=06 \\
3,2454=06 \\
3,4996006 \\
3,3364=06 \\
3,4612=06 \\
3,11217=06 \\
3,3349=06 \\
3,2925=06 \\
3,4959006 \\
3,8908=06 \\
3,8073=06 \\
3,3791=06 \\
4,0652=07\end{array}$ & 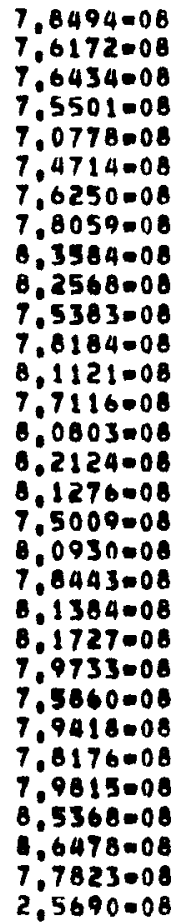 & $\begin{array}{l}1.1848+00 \\
1.1710+00 \\
1.2606+00 \\
1.1704+00 \\
1.2009+00 \\
1.2251+00 \\
1.2293+00 \\
1.1405+00 \\
1.1792+00 \\
1.1422+00 \\
1.1746+00 \\
1.2267+00 \\
1.1499+00 \\
1.1174+00 \\
1.0823+00 \\
1.1622+00 \\
1.1340+00 \\
1.0718+00 \\
1.1874+00 \\
1.1908+00 \\
1.1863+00 \\
1.1321+00 \\
1.2957+00 \\
1.2193+00 \\
1.2031+00 \\
1.1259+00 \\
1.1499+00 \\
1.2162+00 \\
1.1474+00 \\
1.2140+00 \\
1.6137+00\end{array}$ \\
\hline & AVERAGE (? & $3.0 \mathrm{FT}$ & $2,8699-06$ & & & $3.3704=06$ & & 1.1744400 \\
\hline
\end{tabular}


PEACh bottom steam generator gamma scan, superheater tube 5 INLET.

\begin{tabular}{|c|c|c|c|c|c|c|c|c|}
\hline & DEPTH(FT) & CPM & $\begin{array}{c}C 8=134 \\
\text { CURIE } 130-C M\end{array}$ & STO DEV & CPM & $\begin{array}{c}\text { CS }=137 \\
\text { CURIE/SB=CM }\end{array}$ & BTO DEV & $\begin{array}{c}\text { RATIO } \\
\text { Cs-137/434 }\end{array}$ \\
\hline Ẽ & 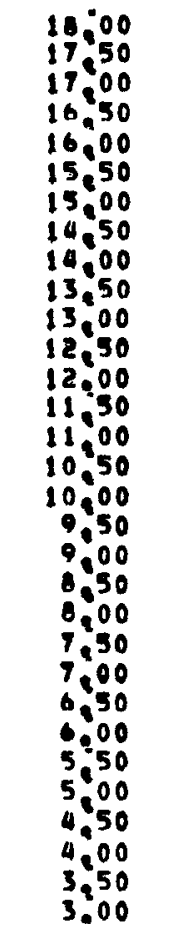 & 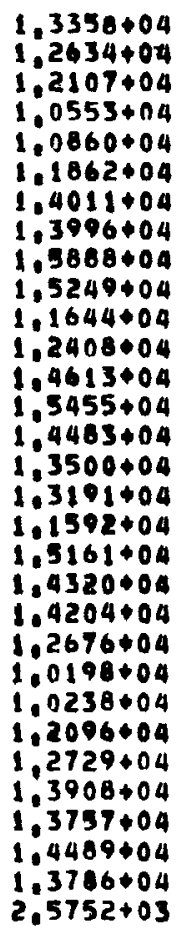 & $\begin{array}{l}5,2139=06 \\
4,9312=06 \\
4,7257=06 \\
4,1109006 \\
4,2389006 \\
4,6299006 \\
5,4606006 \\
5,4630=06 \\
6,2015006 \\
5,9520006 \\
4,5449006 \\
4,8431006 \\
5,7037006 \\
6,0323006 \\
5,6531006 \\
5,2694006 \\
5,1487=06 \\
4,5446006 \\
5,9175006 \\
5,5892006 \\
5,5442006 \\
4,9477006 \\
3,9805006 \\
3,9959006 \\
4,9213006 \\
4,9685=06 \\
5,9284006 \\
5,9396006 \\
5,6551006 \\
5,3809=06 \\
1,0052006\end{array}$ & 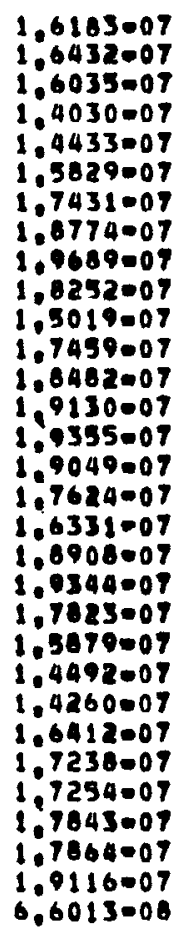 & 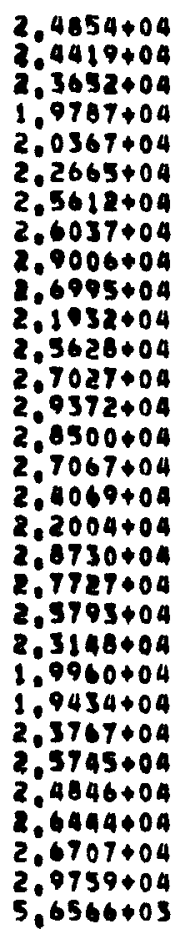 & 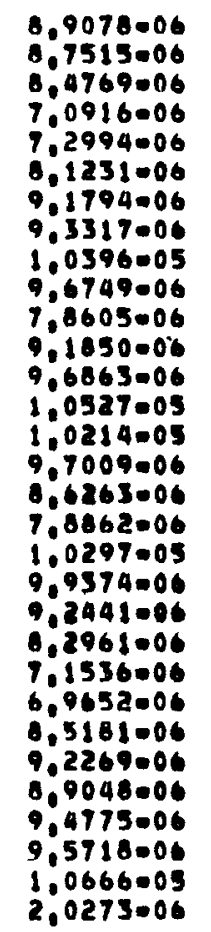 & 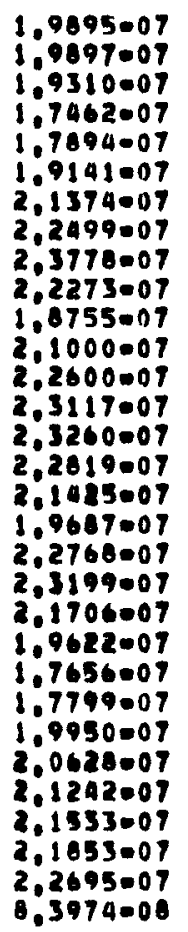 & $\begin{array}{l}1.7086+00 \\
1.7949+00 \\
1.7939+00 \\
1.7219+00 \\
1.7222+00 \\
1.7346+00 \\
1.6787+00 \\
1.7083+00 \\
1.6765+00 \\
1.6256+00 \\
1.7297+00 \\
1.8967+00 \\
1.6984+00 \\
1.7452+00 \\
1.6070+00 \\
1.8411+00 \\
1.6736+00 \\
1.7438+00 \\
1.7402+00 \\
1.7791+00 \\
1.6075+00 \\
1.6769+00 \\
1.7973+00 \\
1.7432+00 \\
1.6043+00 \\
1.8572+00 \\
1.6403+00 \\
1.7652+00 \\
1.6927+00 \\
1.9823+00 \\
2.0171+00\end{array}$ \\
\hline & AVERAGE (S & $3.0 \mathrm{FT}$ & $5,1387.06$ & & & $0.9725=06$ & & $1.7461+00$ \\
\hline
\end{tabular}

Standard deviation shown is that associated with counting statistics only. 


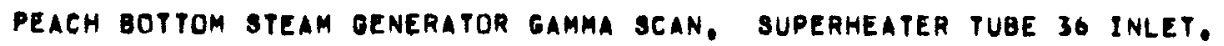

\begin{tabular}{|c|c|c|c|c|c|c|c|c|}
\hline & DEPTH(FT) & CPM & $\begin{array}{l}\text { CS } 134 \\
\text { CURIE } \\
\text { CUOACM }\end{array}$ & STD DEV & CPM & $\begin{array}{l}\text { CS } 137 \\
\text { CURIE } 180=\mathrm{CM}\end{array}$ & $8 T 0$ DEV & $\begin{array}{c}\text { AAT10 } \\
\cos =137 / 134\end{array}$ \\
\hline 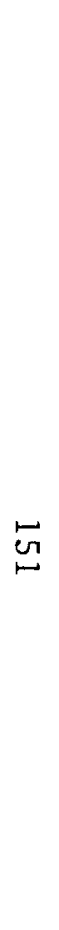 & 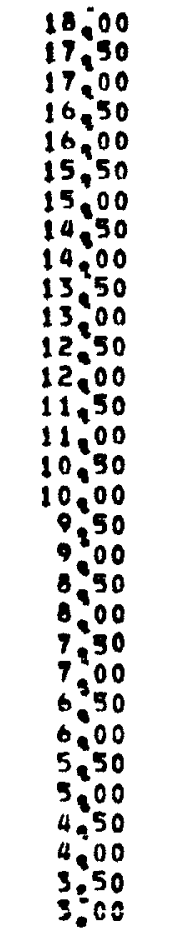 & $\begin{array}{l}1.3971+04 \\
1.3371+04 \\
1,2977+04 \\
1.1183+04 \\
1.0707+04 \\
1.2622+04 \\
1.3620+04 \\
1.6298+04 \\
1.6860+04 \\
1.5019+04 \\
1.2484+04 \\
1.3494+04 \\
1.4799+04 \\
1.6485+04 \\
1.6396+04 \\
1.6132+04 \\
1.3404+04 \\
1.2673+04 \\
1.5676+04 \\
1.5326+04 \\
1.3962+04 \\
1.1743+04 \\
1.0289+04 \\
1.1888+04 \\
1.3731+04 \\
1.4813+04 \\
1.5263+04 \\
1.5174+04 \\
1.4233+04 \\
1.5700+04 \\
1.7617+03\end{array}$ & 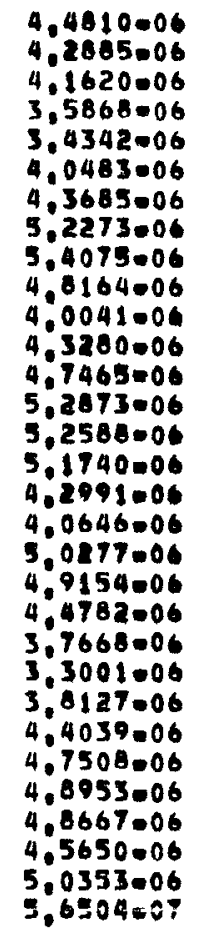 & 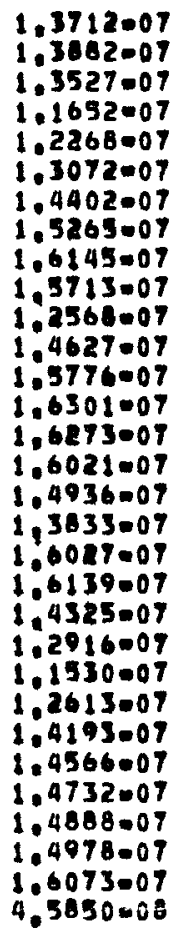 & $\begin{array}{l}2,3693+04 \\
2,4723+04 \\
2,3704+04 \\
1,8620+04 \\
1,9696+04 \\
2,2424+04 \\
2,4690+04 \\
2,7596+04 \\
2,9013+04 \\
2,5062+04 \\
2,1909+04 \\
2,4696+04 \\
2,8336+04 \\
2,9946+04 \\
2,8692+04 \\
2,8987+04 \\
2,6272+04 \\
2,2713+04 \\
2,7356+04 \\
2,8432+04 \\
2,4428+04 \\
2,1100+04 \\
1,7691+04 \\
2,1553+04 \\
2,4640+04 \\
2,5119+04 \\
2,5496+04 \\
2,7345+04 \\
2,5625+04 \\
3,0009+04 \\
4,4118+03\end{array}$ & 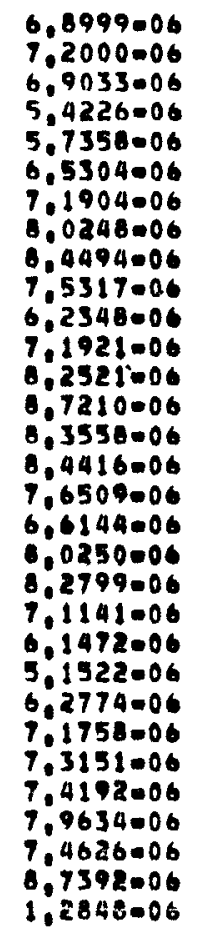 & 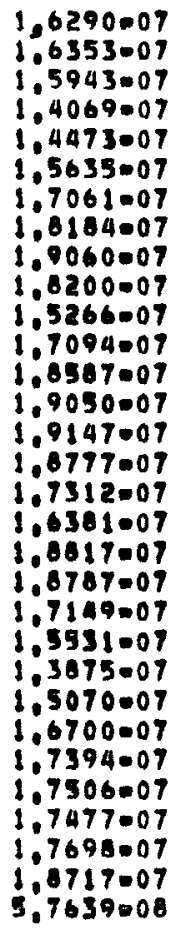 & $\begin{array}{l}1.5399+00 \\
1.6790+00 \\
1.6588+00 \\
1.5119+00 \\
1.6704+00 \\
1.6132+00 \\
1.6461+00 \\
1.5353+00 \\
1.5626+00 \\
1.5639+00 \\
1.5572+00 \\
1.6619+00 \\
1.7387+00 \\
1.6496+00 \\
1.5691+00 \\
1.6317+00 \\
1.7798+00 \\
1.6275+00 \\
1.5963+00 \\
1.6846+00 \\
1.5887+00 \\
1.6321+00 \\
1.5613+00 \\
1.6466+00 \\
1.6295+00 \\
1.5399+00 \\
1.5157+00 \\
1.6364+00 \\
1.6349+00 \\
1.7357+00 \\
2.2740+00\end{array}$ \\
\hline & AVERAGE() & $3.0 \mathrm{PT}$ & 4.4934 .06 & & & $7.2807=06$ & & $1,6203+00$ \\
\hline
\end{tabular}


DEACH BotTOM steam generator gamMa gCan, SUPERHEater tube 108 INLET,

\begin{tabular}{|c|c|c|c|c|c|c|c|c|}
\hline & jentw $(e, 1)$ & CPM & $\begin{array}{c}\text { CS } \\
\text { CURIE } 134 \\
\end{array}$ & 8TD DEV & CPM & $\begin{array}{c}\text { CS } \\
\text { CURIE/ } 137 \\
\text { COCM }\end{array}$ & STO DEV & $\begin{array}{c}\text { RATIO } \\
\text { CS=137/134 }\end{array}$ \\
\hline in & 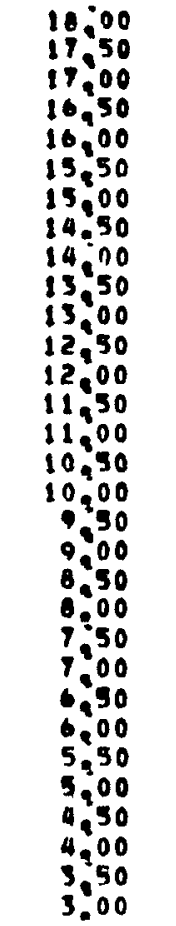 & 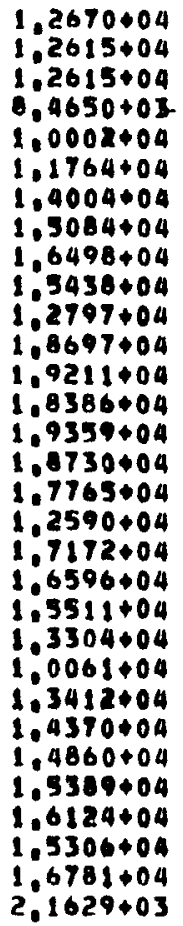 & 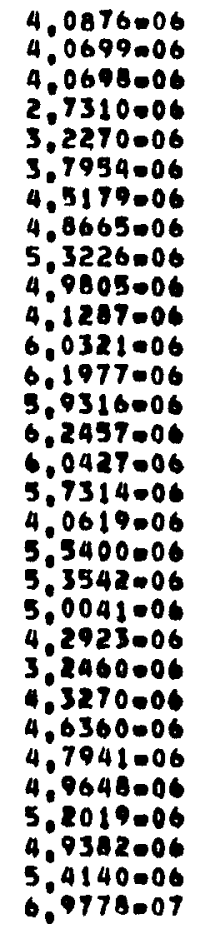 & 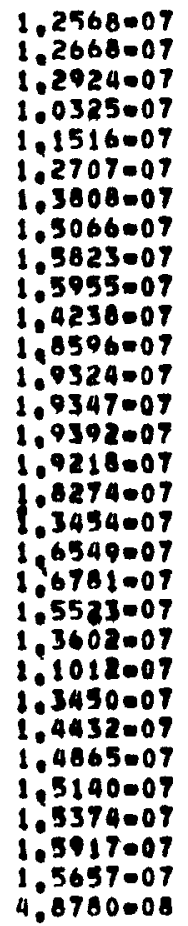 & 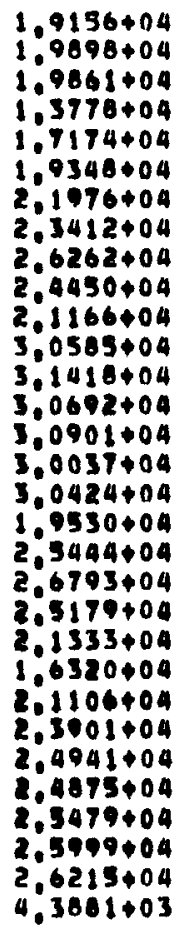 & 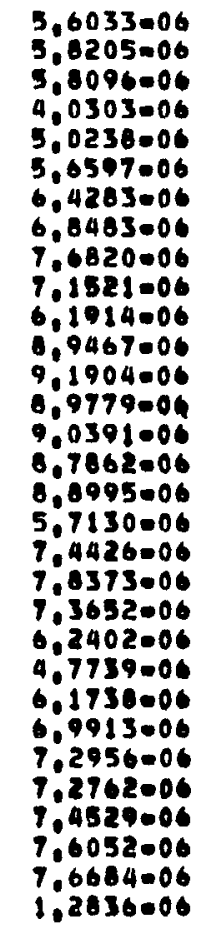 & 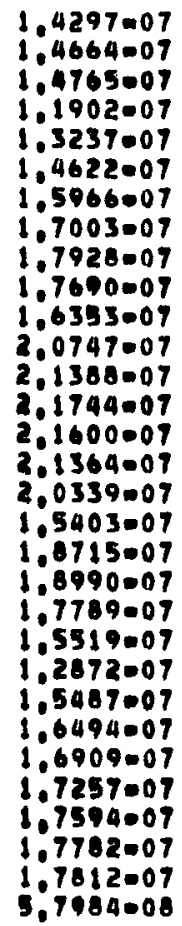 & $\begin{array}{l}1.3709+00 \\
1.4302+00 \\
1.4276+00 \\
1.4759+00 \\
1.5569+00 \\
1.4913+00 \\
1.4230+00 \\
1.4074+00 \\
1.4434+00 \\
1.4361+00 \\
1.4997+00 \\
1.4833+00 \\
1.4830+00 \\
1.5137+00 \\
1.4474000 \\
1.4541+00 \\
1.5529+00 \\
1.4066+00 \\
1.3436+00 \\
1.4639+00 \\
1.4720+00 \\
1.4539+00 \\
1.4708+00 \\
1.4269+00 \\
1.5082+00 \\
1.5219+00 \\
1.4637+00 \\
1.4328+00 \\
1.5402+00 \\
1.4165+00 \\
1.8397+00\end{array}$ \\
\hline & AVERAGE (? & .0 FT & 0.7017 .00 & & & $0.9973-06$ & & $1.4003+00$ \\
\hline
\end{tabular}

Standard deviation shown is that associated with counting statistics only. 
PEACH BotTOM STEAM GENERATOR GAMMA SCAN, SUPERHEATER TUBE 21 INLET.

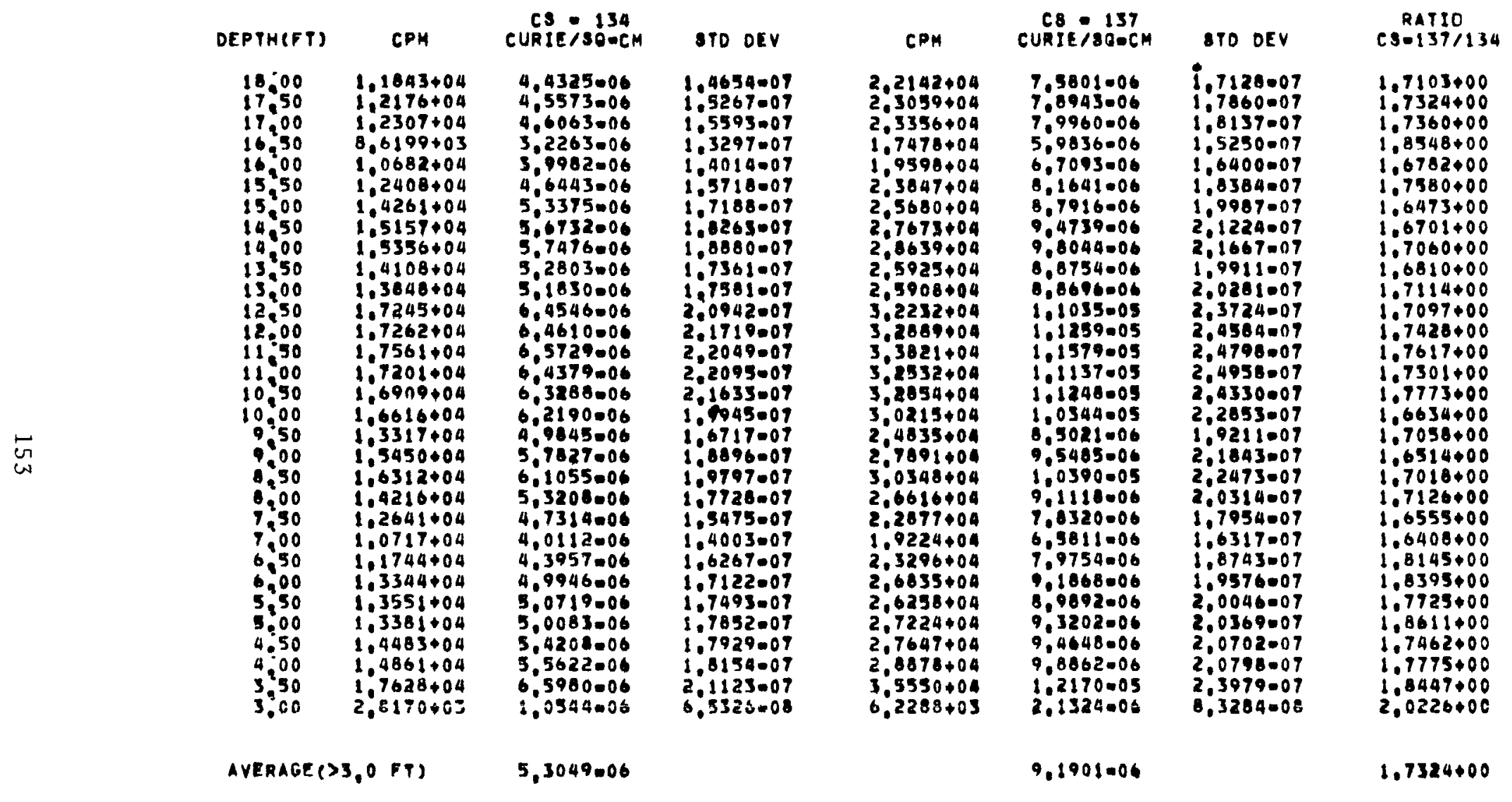


PEACH BOTTOM STEAM GENERATOR GAMMA SCAN, SUPERHEATER TUBE 66 INLET,

\begin{tabular}{|c|c|c|c|c|c|c|c|c|}
\hline & DEPTH(FT) & CPM & $\begin{array}{l}\text { CS } 134 \\
\text { CURIE/SONCM }\end{array}$ & STO DEV & CPM & $\begin{array}{c}\text { CS } 137 \\
\text { CURIE } 180=\mathrm{CM}\end{array}$ & STD DEV & $\begin{array}{c}\text { RATIO } \\
\cos =137 / 134\end{array}$ \\
\hline G & 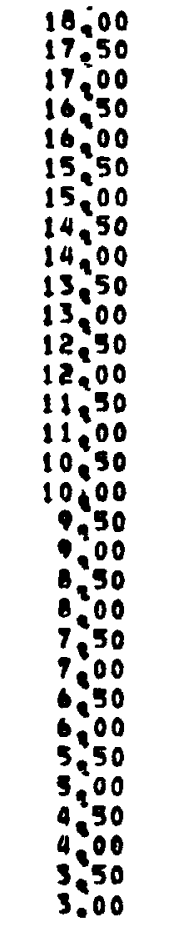 & 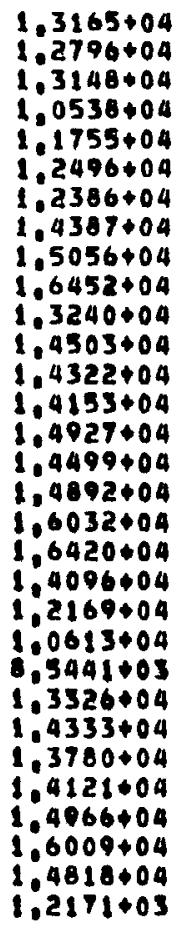 & 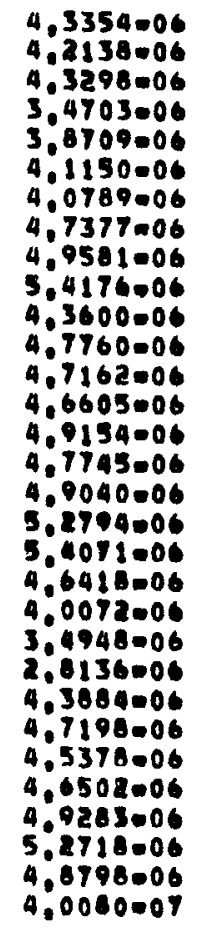 & 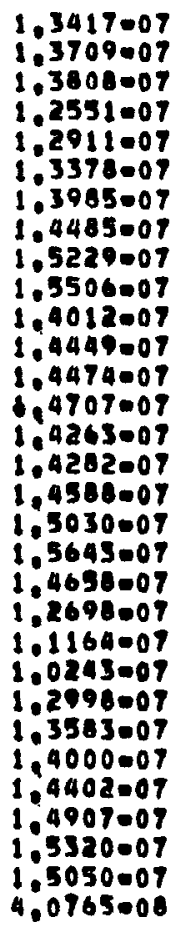 & 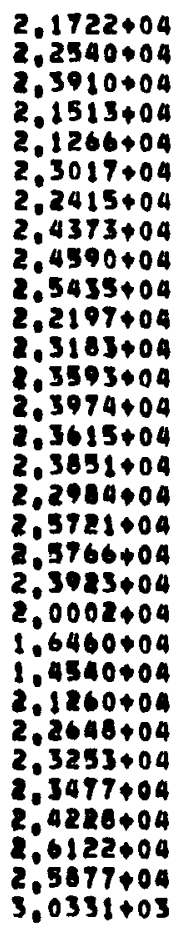 & 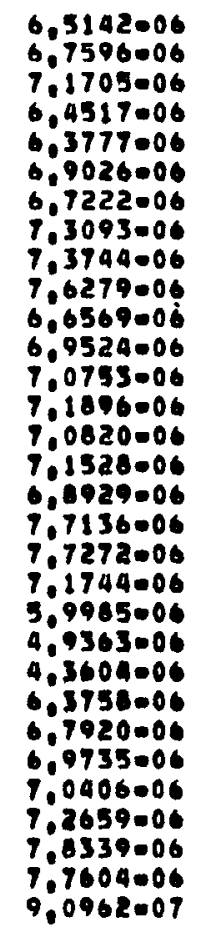 & 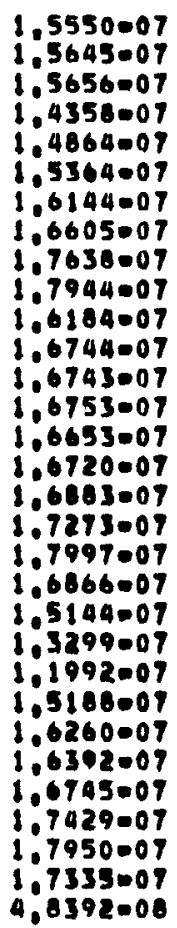 & $\begin{array}{l}1.5029+00 \\
1.6043+00 \\
1.6562+00 \\
1.8592+00 \\
1.6477+00 \\
1.6776400 \\
1.6482+00 \\
1.5429+00 \\
1.4675+00 \\
1.4081+00 \\
1.5269+00 \\
1.4556+00 \\
1.5003+00 \\
1.5424+00 \\
1.4409+00 \\
1.4982+00 \\
1.4057+00 \\
1.4612+00 \\
1.4292+00 \\
1.5457+00 \\
1.4970+00 \\
1.4126+00 \\
1.5499+00 \\
1.4530+00 \\
1.4391+00 \\
1.5369+00 \\
1.5142+00 \\
1.4744000 \\
1.4861+00 \\
1.5904+00 \\
2,2697+00\end{array}$ \\
\hline & AVERAGE (? & $3.0(1)$ & 4.5218006 & & & $0.8721=06$ & & $1,5190,00$ \\
\hline
\end{tabular}

Standard deviation shown is that associated with counting statistics only. 
PEACH BOTTOM STEAM GENERATOR GAMMA SCAN, EVAPORATOR TUBE 51 INLET,

\begin{tabular}{|c|c|c|c|c|c|c|c|c|}
\hline & DEPTH (FT) & CPM & $\begin{array}{c}\text { CS } 134 \\
\text { CURIE } 130=C M\end{array}$ & STO DEV & CPM & $\begin{array}{c}C 8-137 \\
\text { CURIE/SO-CM }\end{array}$ & STO DEV & $\begin{array}{c}\text { RATIO } \\
\text { C8-137/134 }\end{array}$ \\
\hline v & 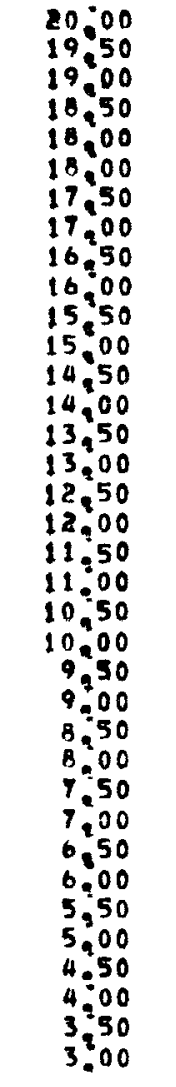 & 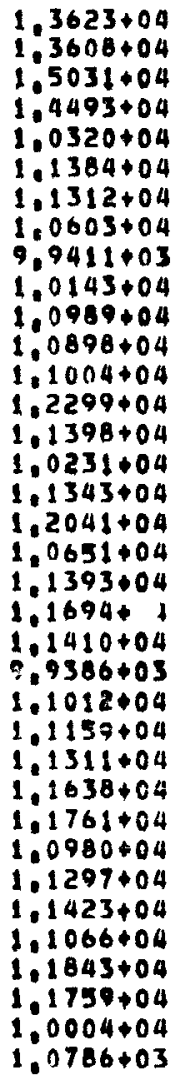 & 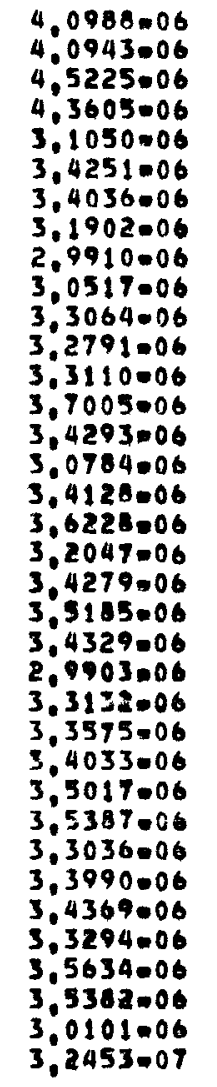 & 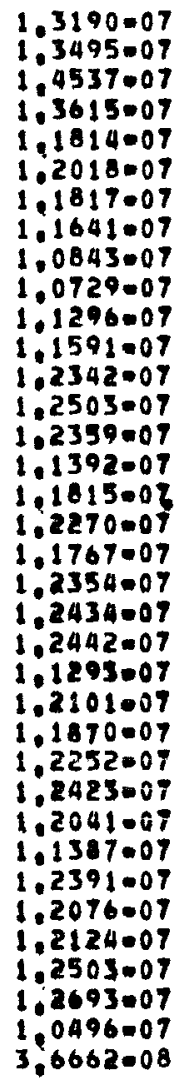 & $\begin{array}{l}2,3644+04 \\
2,4777+04 \\
2,7664+04 \\
2,5575+04 \\
2,0451+04 \\
2,5527+04 \\
2,4596+04 \\
2,4521+04 \\
2,2279+04 \\
2,2596+04 \\
2,4105+04 \\
2,5093+04 \\
2,5970+04 \\
2,6900+04 \\
2,6447+04 \\
2,2863+04 \\
2,5466+04 \\
2,7107+04 \\
2,3553+04 \\
2,6283+04 \\
2,6091+04 \\
2,6693+04 \\
2,2989+04 \\
2,4558+04 \\
2,5110+04 \\
2,5782+04 \\
2,5237+04 \\
2.4937+04 \\
8,3507+04 \\
2,4507+04 \\
2,4681+04 \\
2,4817+04 \\
2,5993+04 \\
2,6167+04 \\
2,0836+04 \\
2,9460+03\end{array}$ & 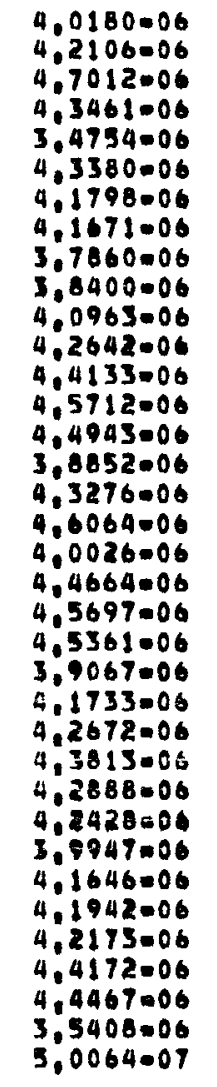 & 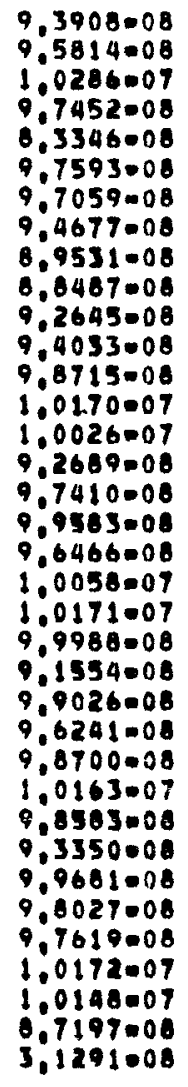 & $\begin{array}{l}9,8035001 \\
1.0285+00 \\
1.0396+00 \\
9.9678001 \\
1.1194+00 \\
1.2666+00 \\
1.2202+00 \\
1.3063+00 \\
1.2659+00 \\
1.2584+00 \\
1.2390+00 \\
1.3005+00 \\
1.3330+00 \\
1.2354+00 \\
1.3107+00 \\
1.2622+00 \\
1.2681+00 \\
1.2716400 \\
1.2491+00 \\
1.3031+00 \\
1.2989+00 \\
1.3215+00 \\
1.3065+00 \\
1.2597+00 \\
1.2710+00 \\
1.2675+00 \\
1.2249+00 \\
1.1990+00 \\
1.2093+00 \\
1.2254+00 \\
1.2204+00 \\
1.2668+00 \\
1.2397+00 \\
1.2569+00 \\
1.1764+00 \\
1.5426+00\end{array}$ \\
\hline & AVERAGES & OFP) & 3,4472006 & & & 4.21520106 & & $1.2220+00$ \\
\hline
\end{tabular}

Standard deviation shown is that associated with counting statistics only. 
PEACH BOTTOM STEAM GENERATOR GAMMA SCAN, SUPERHEATER TUBE 49 INLET,

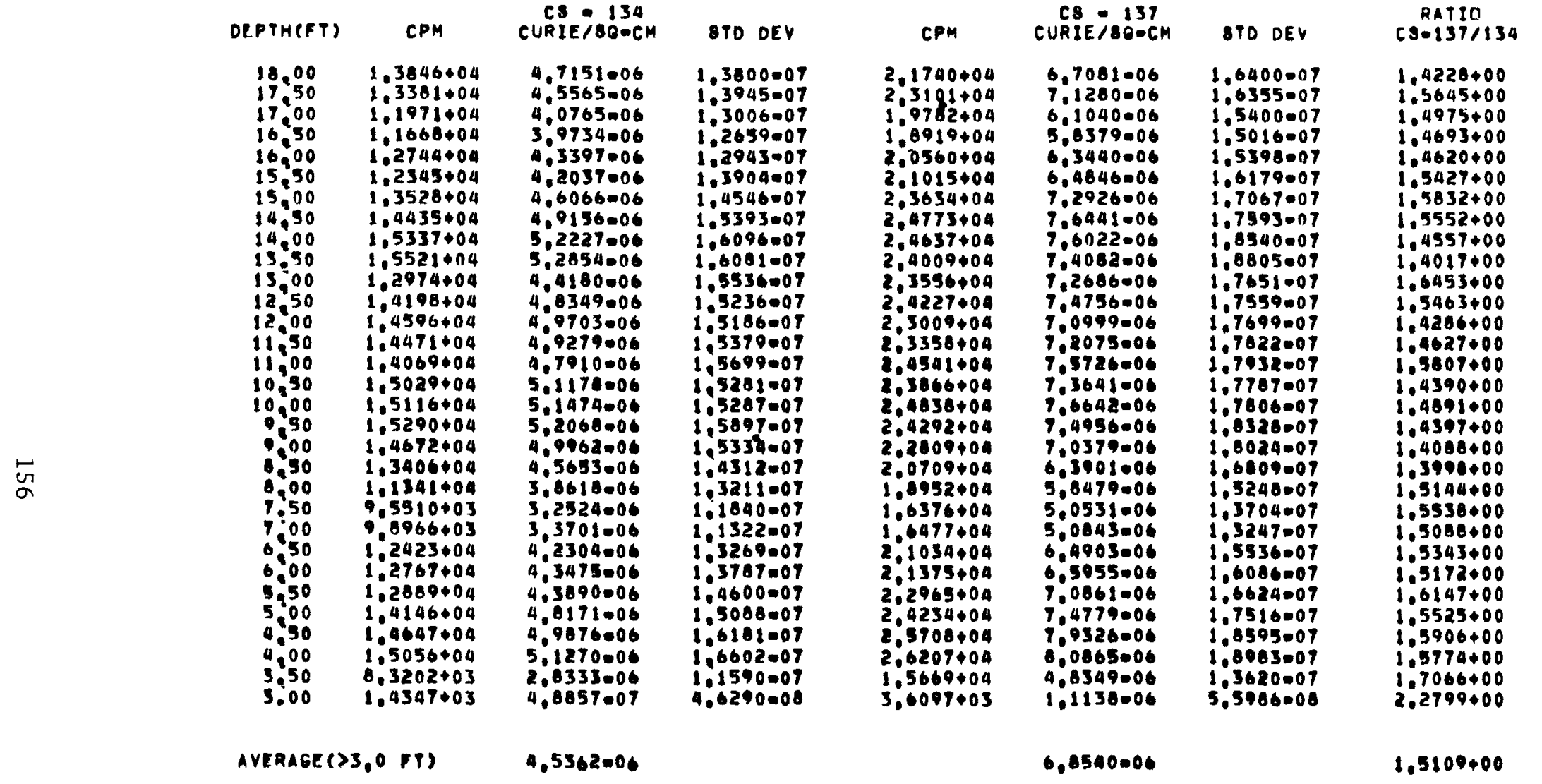

Standard deviation shown is that associated with counting statistics only 
PEACH BOTTOM ITEAM oENERATOR GAMMA BCAN, SUPERHEATER TUBE 52 OUTLET.

\begin{tabular}{|c|c|c|c|c|c|c|c|c|}
\hline & DEPTH(FT) & CPM & $\begin{array}{c}\text { C8 } 134 \\
\text { CURIE/80-CM }\end{array}$ & STO DEV & CPM & CURIE180 137 & STO DEV & $\begin{array}{c}\text { RATIO } \\
\text { Co-137/134 }\end{array}$ \\
\hline ṽ & 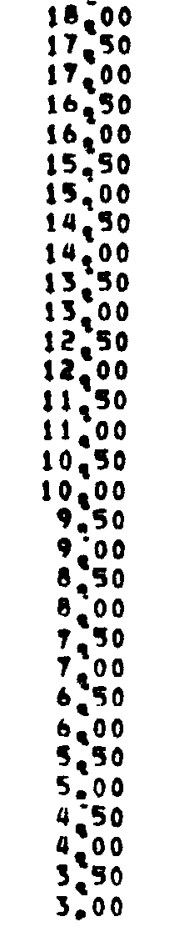 & 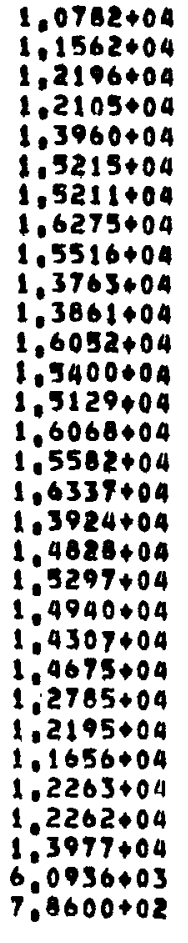 & 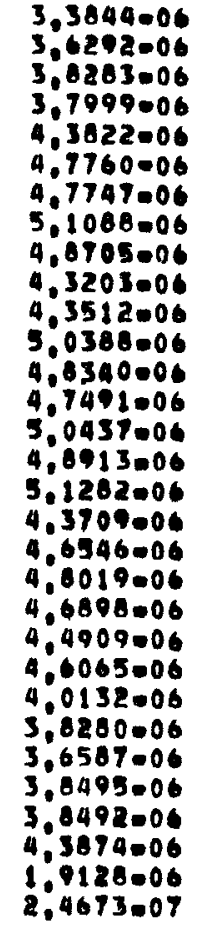 & 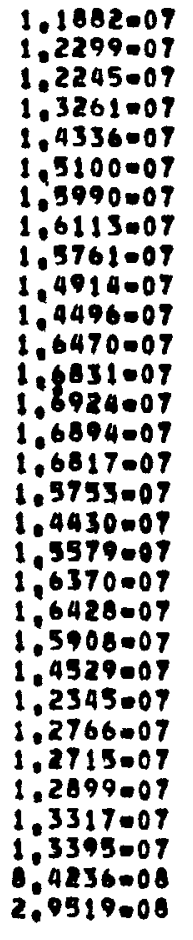 & 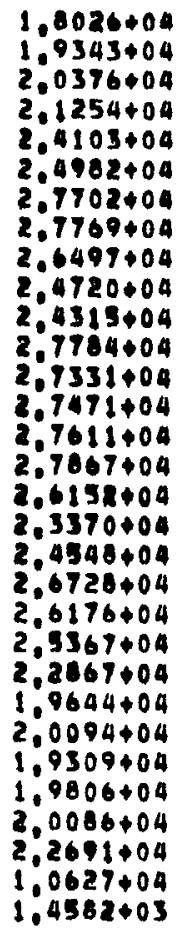 & 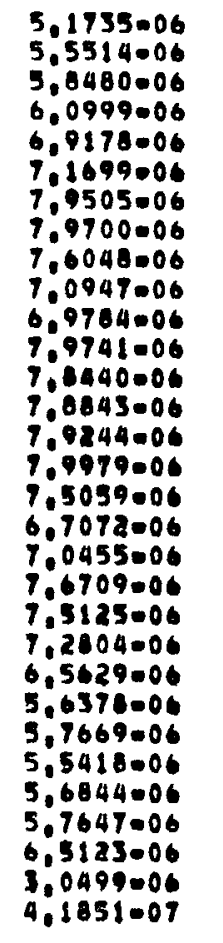 & 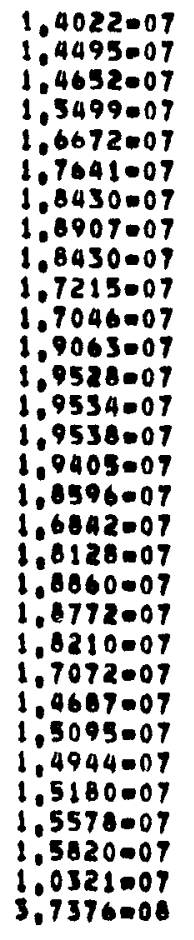 & $\begin{array}{l}1.5287+00 \\
1.5297+00 \\
1.5277+00 \\
1.6054+00 \\
1.5787+00 \\
1.5013+00 \\
1.6653+00 \\
1.5602+00 \\
1.5615+00 \\
1.6423+00 \\
1.6039+00 \\
1.5626+00 \\
1.6228+00 \\
1.6603+00 \\
1.5713+00 \\
1.6353+00 \\
1.4638+00 \\
1.5346+00 \\
1.5138+00 \\
1.5976+00 \\
1.6020+00 \\
1.6213+00 \\
1.4248+00 \\
1.4049+00 \\
1.5066+00 \\
1.5148+00 \\
1.4768+00 \\
1.4978+00 \\
1.4844+00 \\
1.5946+00 \\
1.6964+00\end{array}$ \\
\hline & AVERAGEC ( & $3.0(9)$ & $4,3341=06$ & & & $6,7409=06$ & & $.3553+00$ \\
\hline
\end{tabular}

Standard deviation shown is that associated with counting statistics only. 
PEACH BotTOM STEAM GENERATOR GAMMA SCAN, BUPERHEATER TUBE 36 OUTLET.

\begin{tabular}{|c|c|c|c|c|c|c|c|c|}
\hline & DEPTH (FT) & CPM & $\begin{array}{l}\text { CE } 134 \\
\text { CURIE/SO-CM }\end{array}$ & STO DEV & CPM & $\begin{array}{l}\text { C8 } 137 \\
\text { CURIE/8QOCM }\end{array}$ & 8TD DEV & $\begin{array}{c}\text { Aat1 } 10 \\
\operatorname{cs}-137 / 134\end{array}$ \\
\hline$\vec{\infty}$ & 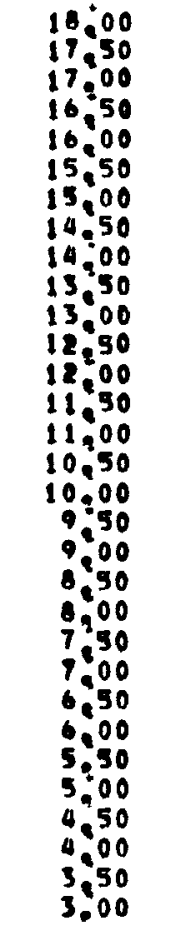 & 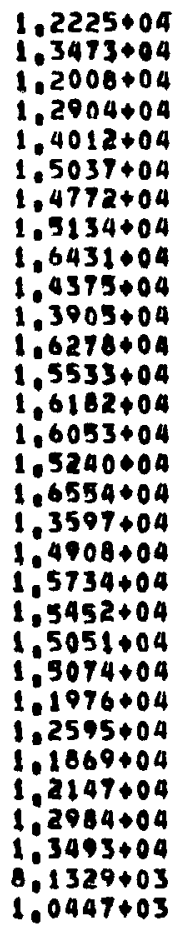 & 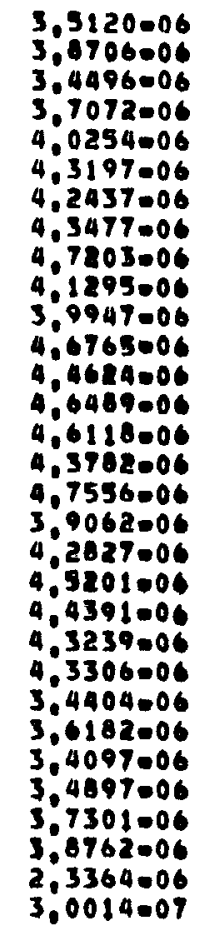 & 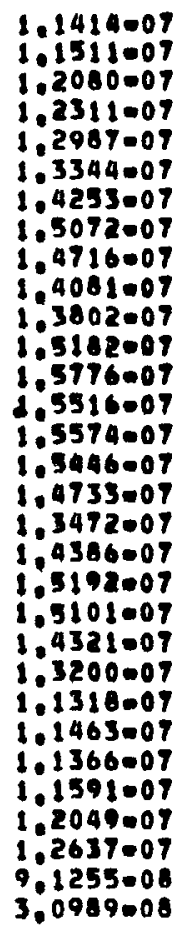 & 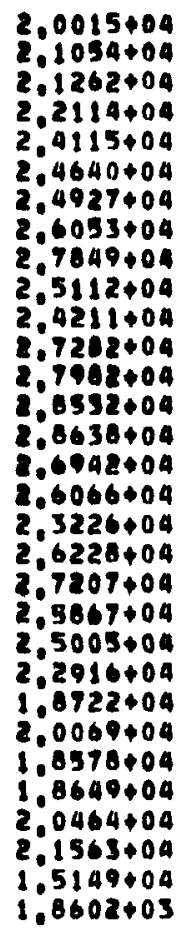 & 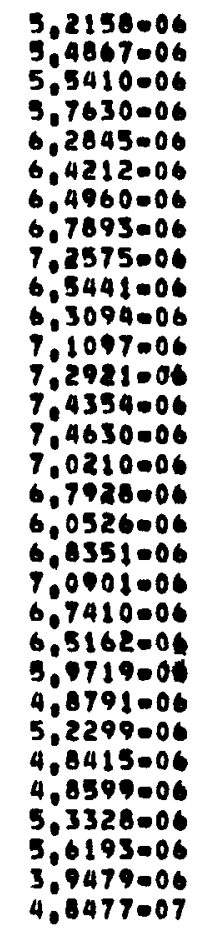 & 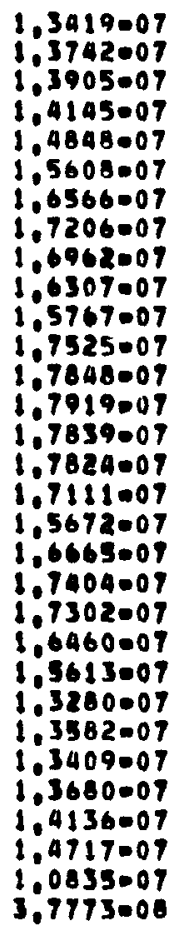 & 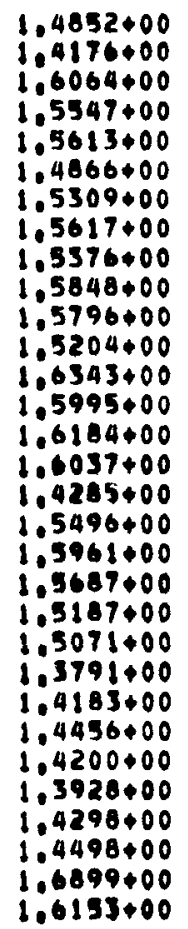 \\
\hline & AVERAGE(S & 3.077 & 4.0519000 & & & $6,1713=06$ & & $1.5231 \bullet 00$ \\
\hline
\end{tabular}

Standard deviation shown is that associated with counting statistics only. 
PEACH bottom steam generator gamma scan, SUPERHEater tUBe 19 OUTLET.

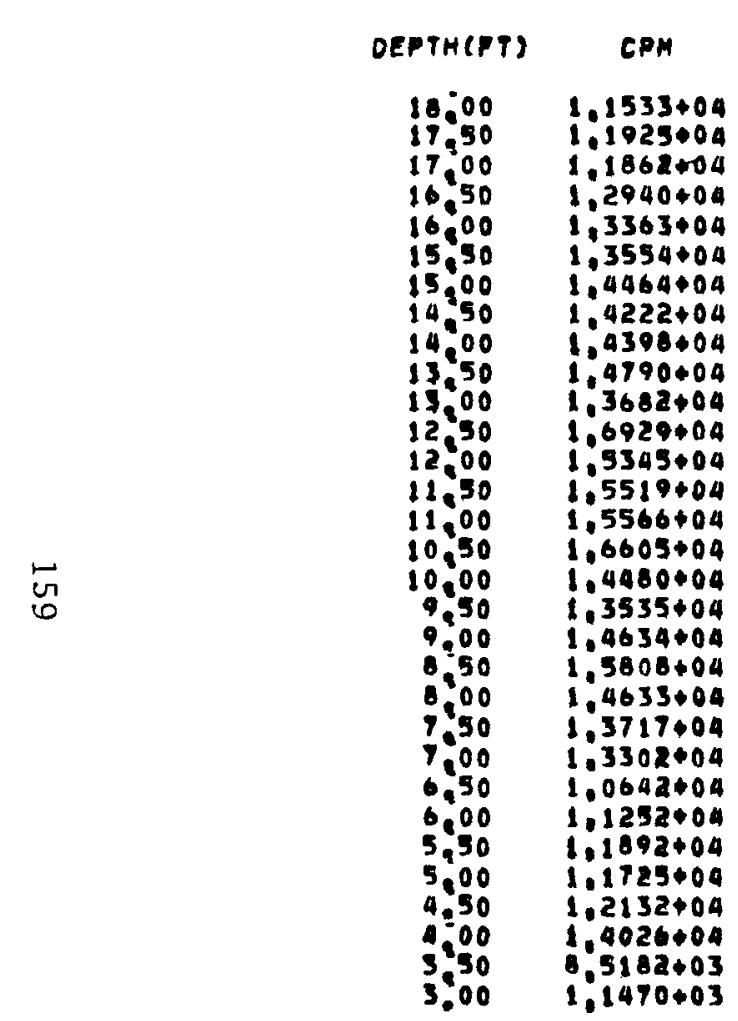

AVERAGE (S3,0 PT)

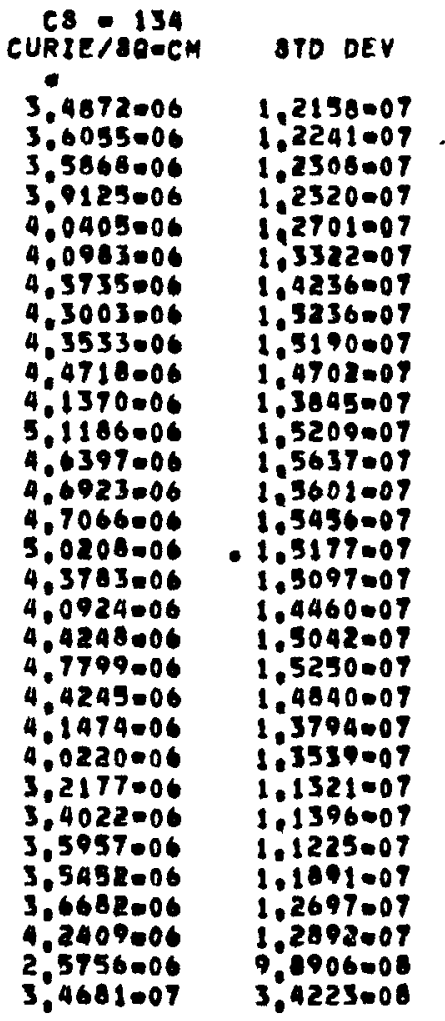

9.1020006

\begin{tabular}{|c|c|c|}
\hline CPM & $\begin{array}{c}\text { C8 } 137 \\
\text { CURIE } 180=\mathrm{CM}\end{array}$ & BPO DEV \\
\hline 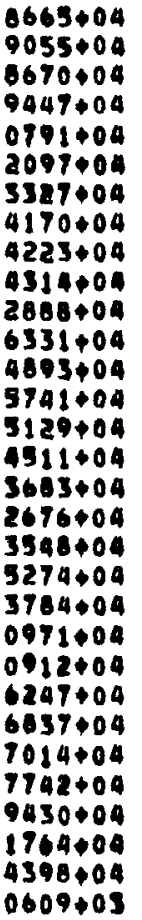 & 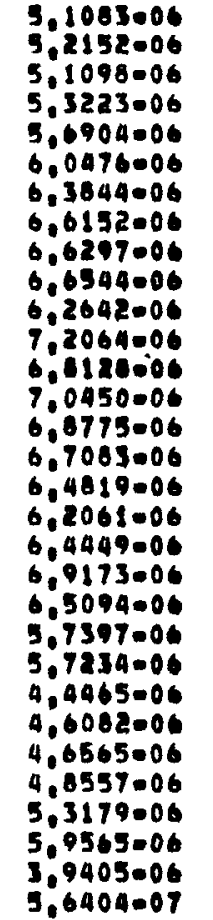 & 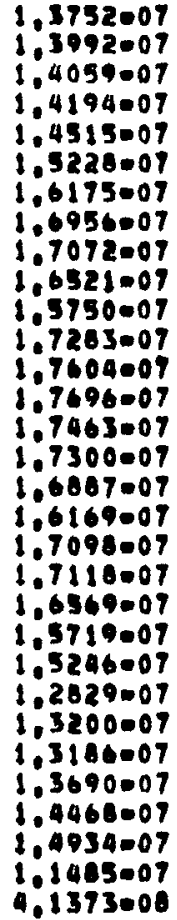 \\
\hline
\end{tabular}

RATIO 1134

1.4650000 $1.4465+00$ $1.4247+00$ $1,3604+00$ $1.4085+00$ $1.4758+00$ $1.4599+00$ 1.5384000 $1,5230+00$ $1.4882+00$ $1,5143+00$ 1.4080400 1. $4685+00$ $1.5015+00$ $1.4613+00$ $1.3362+00$ $1.4806+00$ $1.5166+00$ 1.4567400 1,4473400 $1,4713+00$ 1.3040000 1.3040000 $1.4251+00$ $1.3820+00$ $1.3546 \$ 00$ $1.2951+00$ $1.3698+00$ $1.4499+00$ $1.4047+00$ $1.5301+00$

3.9149000

1.4424400 
PEACH BOTTOM STEAM GENERATOR GAMMA SCAN, SUPERHEATER TUBE 34 OUTLET,

\begin{tabular}{|c|c|}
\hline & CPM \\
\hline 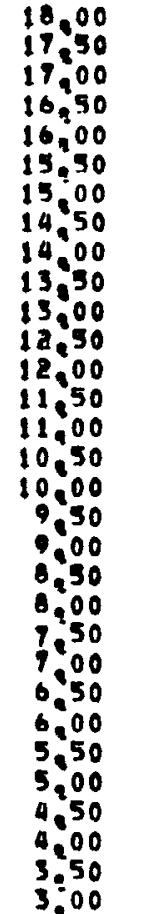 & 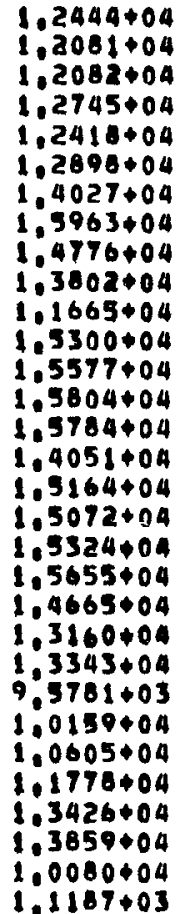 \\
\hline
\end{tabular}

AVERAGE (S3,0 FT)

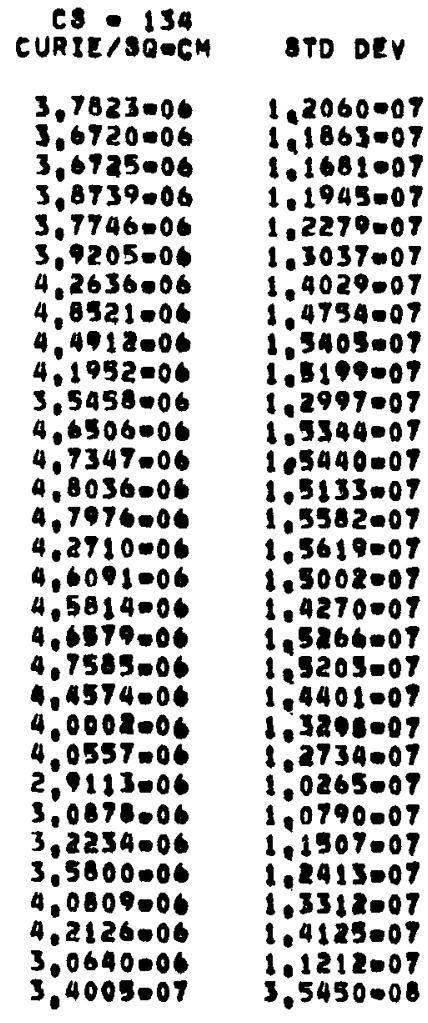

4.0868 .06
CPM

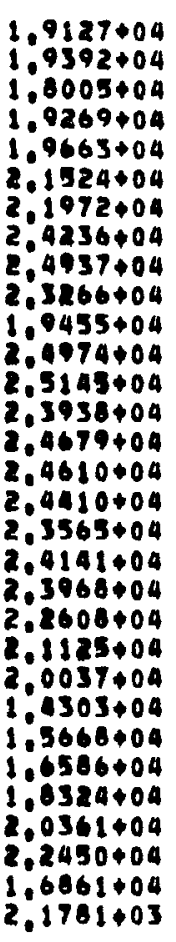

CURIE 18 BSOCM

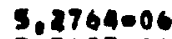

5.3495006

4.9668006

5,3156006

9,4243006

3,9375006

0.0375006

6,605800

6.6858000

6.8792006

C. A162.06

$5,3667.06$

6,034006

6,9366006

6.6036006

0.8071 .06

$6,7809-06$

0.7336006

$0.9007=06$

$6.6596-06$

$6.6117-06$

6.2366006

5,0275006

5,3274006

3. 9457006

4.3222 .06

4.5755 .06

5.0549-06

.

6.6169006

6.1630006

4,6512006
$6,0086=07$

5,0721000 RATIO
C8-1371134

STO OEV

$1.3951+00$

$1.4570+00$

1,3525400

1.4371000

1.5146400

$1.4217+00$

$1.4217+00$

$1.3780+00$

$1.5310+00$

$1.5300+00$

1.5137000

1.4615400

$1.4652+00$

$1.3746+00$

1.4191000

$1.5897+00$

$1.4611+00$

1.4190400

1.4299400

$1.3896+00$

$1.3993+00$

1.4569000

1.3650000

$1.3554+00$

$1.3999+00$

1.4196000

1.4121000

$1,3965+00$

$\begin{array}{ll}1.5190007 & 1.3765+00 \\ 1.6016007 & 1.4702+00 \\ 1.2726007 & 1.3181 .00\end{array}$

$\begin{array}{ll}1.3190007 & 1.3765+00 \\ 1.6016007 & 1.4702+00 \\ 1.2726007 & 1.3181 .00\end{array}$

$\begin{array}{ll}1.2726009 & 1.8151000 \\ 4,2244000 & 1.7671+00\end{array}$

$1.4371+00$ 
PEACH BotTOM BTEAM GENERATOR GAMMA SCAN, SUPERHEATER TUBE GQ OUTLET:

\begin{tabular}{|c|c|c|c|c|c|c|c|c|}
\hline & DEPTHCT & CPM & CURIEI 134 & STO DEV & CPM & $\begin{array}{c}\text { CB } 137 \\
\text { CURIE/80-CM }\end{array}$ & STD DEV & $\begin{array}{c}\text { RAT } 10 \\
\cos 137 / 134\end{array}$ \\
\hline$\stackrel{\vec{\rho}}{\vec{\sigma}}$ & 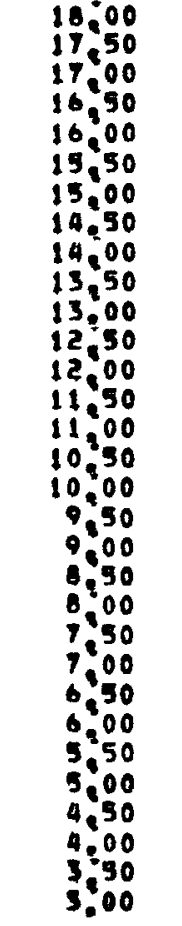 & 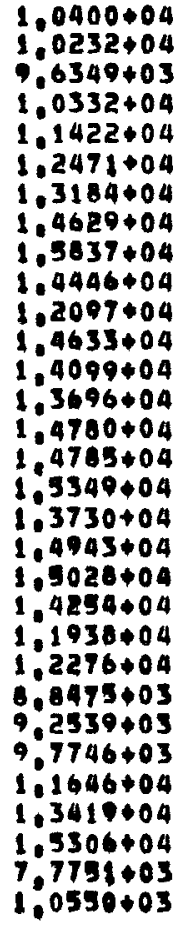 & 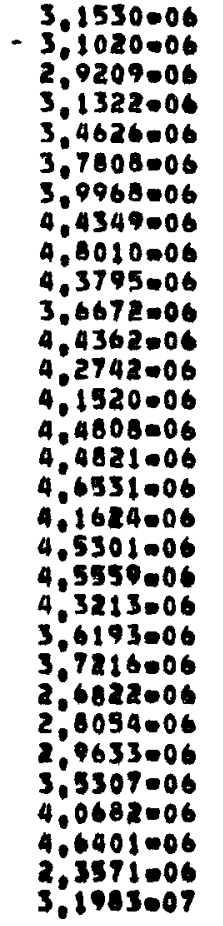 & 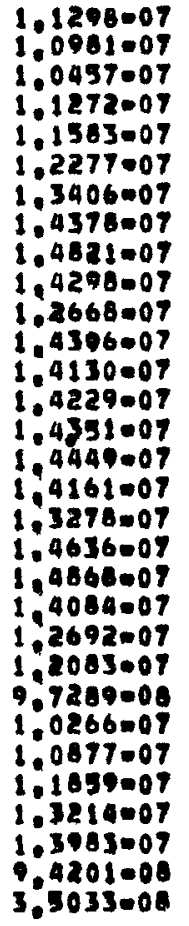 & 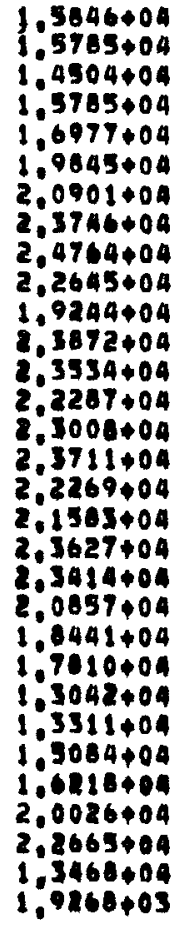 & 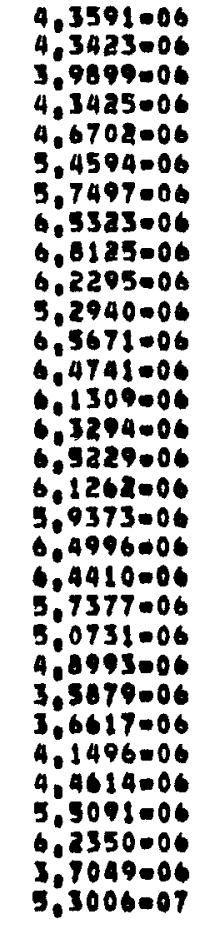 & 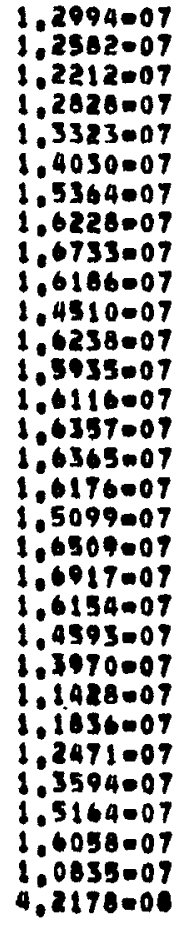 & 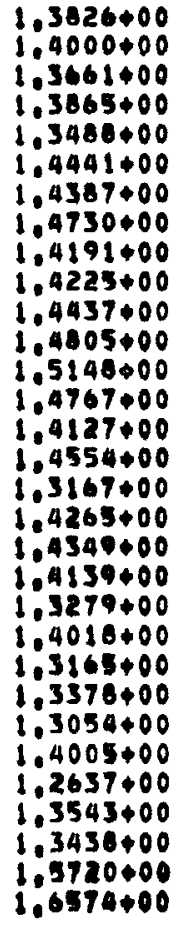 \\
\hline & AYERAGEC? & $3,0 \quad(13$ & $3.4412=06$ & & & 5,3043006 & & 1.4040100 \\
\hline
\end{tabular}


PEACH BOTTOM STEAM GENERATOR GAMMA SCAN, SUPERHEATER TUBE TO OUTLET.

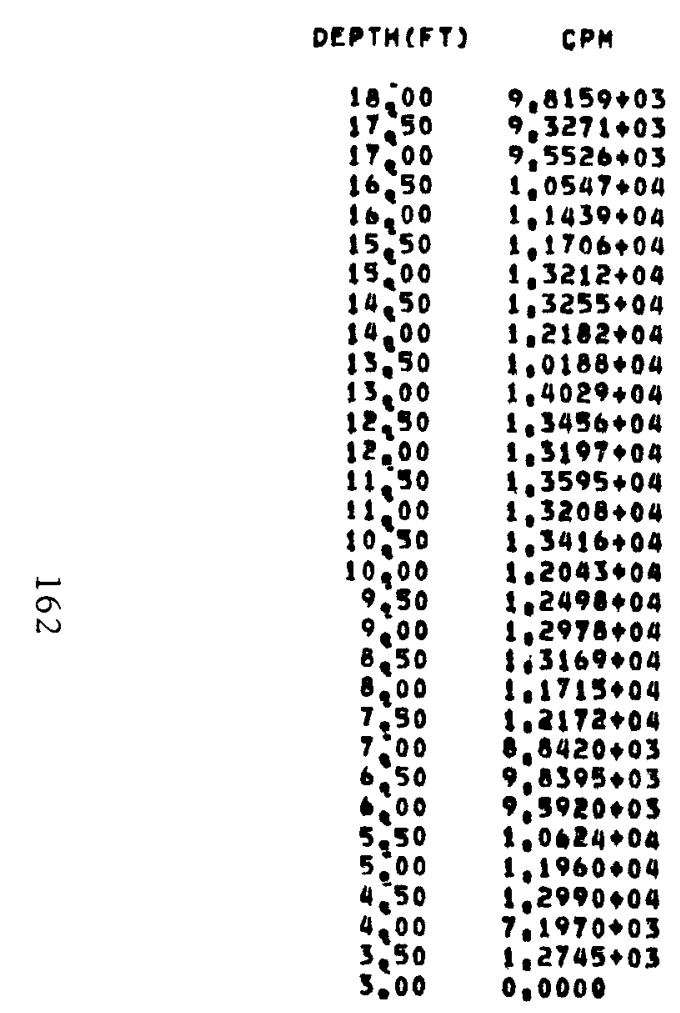

AVERAGE ( 3,0 PT)

\begin{tabular}{|c|c|}
\hline URIE $180-134$ & STD DEV \\
\hline 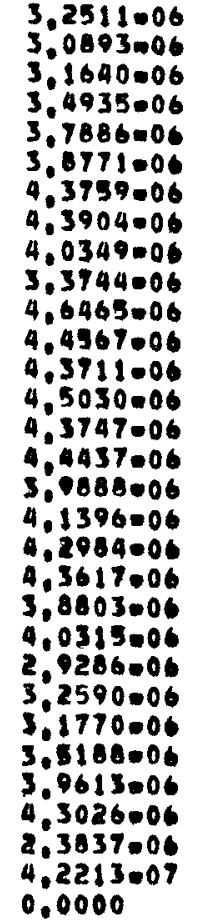 & 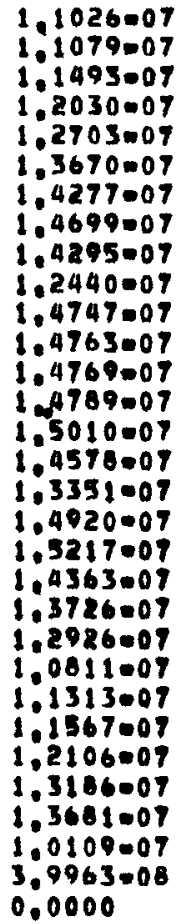 \\
\hline
\end{tabular}

$3.7429=06$

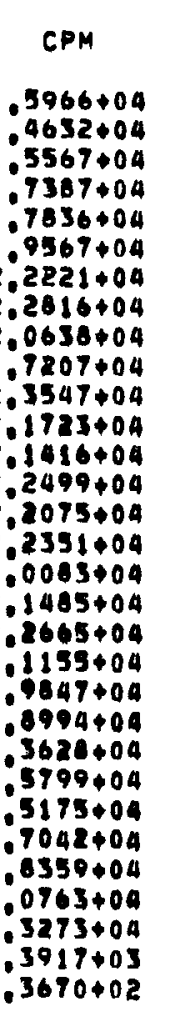

CURIE $180 \mathrm{OCM}$

STD DEV

$\operatorname{RATIO}$

$4.8103-06 \quad 1.3436007$

4.6900006

5.2384 .06

$5,3735=06$

$5,8951=06$

$6.6947=06$

6.8738 .06

6.2176006

5.1040000

7.0940006

$6,8447=04$

6.4520006

6.7785000

6.6507000

$6.7336-00$

6,7336006

6.0506006

$6,4728=06$

6.0284006

$6,3735=06$
3,9794000

3,7225006

4.1037006

$4.7598-06$

$4,5717=06$

5.1342006

$5,5312.06$

$6.2533=06$

3.0987-06

$7.2059=07$

4.1185 .08

1.343600
$1.3189=07$
$1.3577=07$

$1.3577=07$

.4207-07

1.5086007
$1.5880=07$

1.6612 .07

1.6982007

1.6549007

1.4641007

$1.7057-07$

1.7217007

.7324007

.7275007

.7459007

1.7042007

.5701007

.7208007

1.7421007

1,6007007

1.5869007

, $.5339-07$

1.2976007

1.3549007

1.3586007

1.4370007

1.3408007

1.6179007

1.1869007

4.8479000
$1.4633=08$

5,6048006
$1.4797+00$

$1.4271+00$

$1.4825+00$

$1.4996+00$

$1.4184+00$

$1.5206+00$

$1.5300+00$

$1.5656+00$

1.5411400

$1.5364+00$

1.5268400

$1.4686+00$

1.4762000

1.5204400

1.5154000

$1.5170+00$

$1.5637+00$

1.5637400

$1.5887+00$

$14614+00$

$1.4196+00$

$1.4021+00$

1.4606000

1.4391000

$1.4592+00$

$1.3964 \$ 00$

$1.4540+00$

0.0000

$1.4974+00$ 


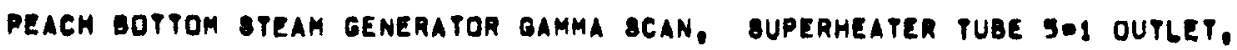

\begin{tabular}{|c|c|c|c|c|c|c|c|c|}
\hline & DEPTH & CPM & $\begin{array}{c}\text { C8 } 134 \\
\text { CURIE/SO-C }\end{array}$ & STD DEV & CPM & $\begin{array}{c}\text { C8 } \\
\text { CURIE/80 } 137 \\
\text { CM }\end{array}$ & STO DEV & $\begin{array}{c}\text { RATIO } \\
\text { Cs-137/134 }\end{array}$ \\
\hline$\stackrel{\bullet}{a}$ & 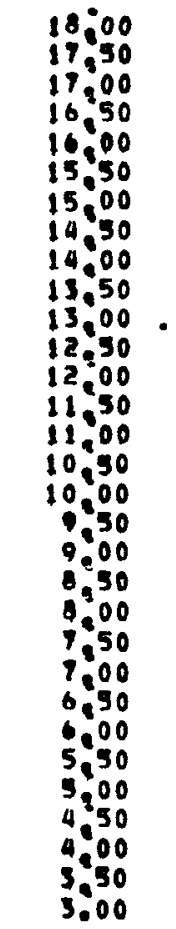 & 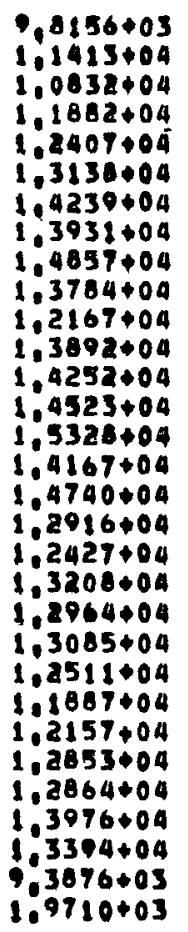 & 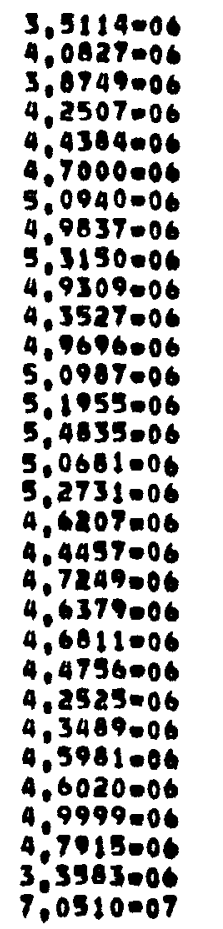 & 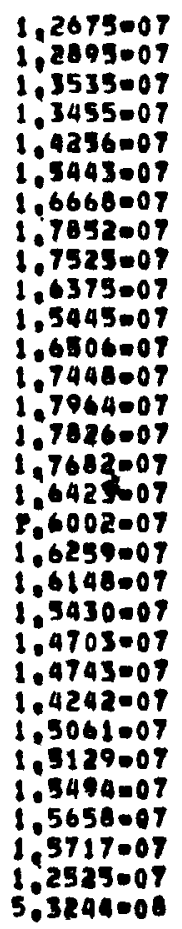 & $\begin{array}{l}1,6687+04 \\
1,8468+04 \\
1,7940+04 \\
1,9068+04 \\
1,9890+04 \\
2,2187+04 \\
2,3294+04 \\
2,5254+04 \\
2,479+04 \\
2,3192+04 \\
2,0031+04 \\
2,2996+04 \\
2,4626+04 \\
2,5242+04 \\
2,5919+04 \\
2,4531+04 \\
2,3109+04 \\
2,2676+04 \\
2,1923+04 \\
2,1472+04 \\
2,0325+04 \\
2,0337+04 \\
2,1500+04 \\
1,9614+04 \\
2,0694+04 \\
2,0911+04 \\
2,1796+04 \\
2,2701+04 \\
2,1403+04 \\
1,7661+04 \\
3,5665+03\end{array}$ & 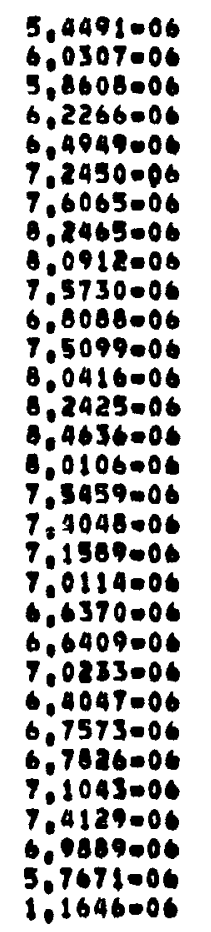 & 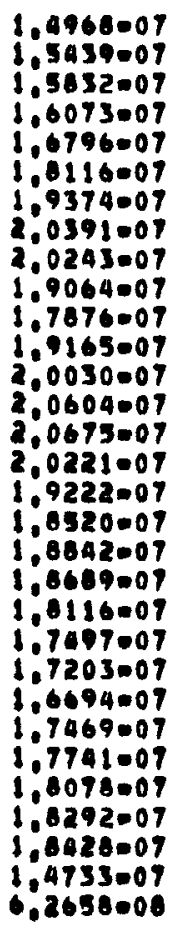 & $\begin{array}{l}1.5519+00 \\
1.4772+00 \\
1.5126+00 \\
1.4650+00 \\
1.4634+00 \\
1.5416+00 \\
1.4934+00 \\
1.6548+00 \\
1.525+00 \\
1.5359+00 \\
1.5644+00 \\
1.5113+00 \\
1.577+00 \\
1.5866+00 \\
1.5436+00 \\
1.5807+00 \\
1.4311+00 \\
1.6027+00 \\
6.6104+00 \\
1.4640+00 \\
1.4318+00 \\
1.4188+00 \\
1.5694+00 \\
1.5062+00 \\
1.5539+00 \\
1.4752+00 \\
1.3438+00 \\
1.4827+00 \\
1.4587+00 \\
1.7174+00 \\
1.6518+00\end{array}$ \\
\hline & AVE & (P) & 4.6387 & & & 1.0847 .06 & & $.5273+00$ \\
\hline
\end{tabular}


PEACH BOTTOM STEAM GENERATOR gamMa sCAN, EVAPURATOR tUBE 50 OUTLET.

\begin{tabular}{|c|c|c|c|}
\hline DEPTHET & CPM & 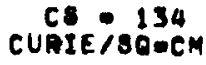 & 8TO DEV \\
\hline 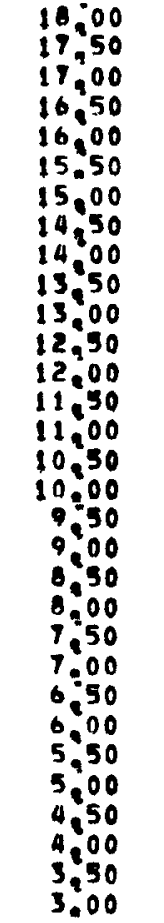 & $\begin{array}{l}9,0926+03 \\
9,5832+03 \\
8,8271+03 \\
7,6775+03 \\
7,5126+03 \\
7,6400+03 \\
7,5829+03 \\
8,7201+03 \\
9,7975+03 \\
9,2086+03 \\
6,8780+03 \\
8,6677+03 \\
8,989+03 \\
8,2082+03 \\
9,6087+03 \\
9,5510+03 \\
8,6560+03 \\
8,8077+03 \\
9,2030+03 \\
7,7050+03 \\
9,0530+03 \\
8,6742+03 \\
7,8600+03 \\
7,2214+03 \\
8,2534+03 \\
8,6025+03 \\
9,5684+03 \\
9,8005+03 \\
9,9551+03 \\
9,0626+03 \\
1,0014+03\end{array}$ & 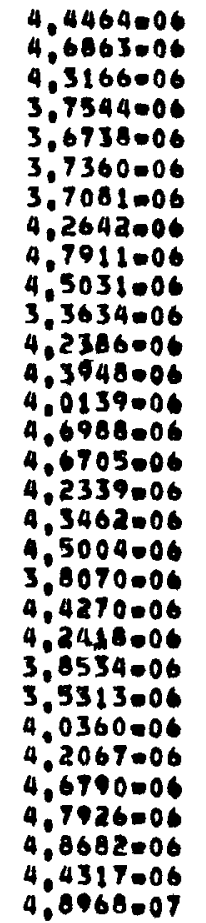 & 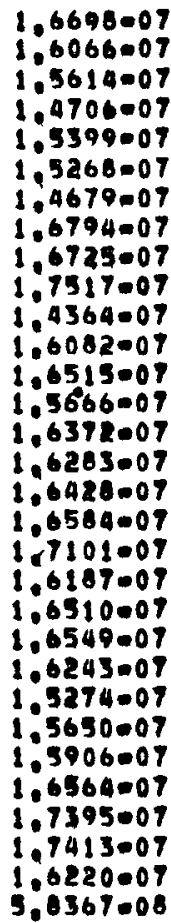 \\
\hline
\end{tabular}

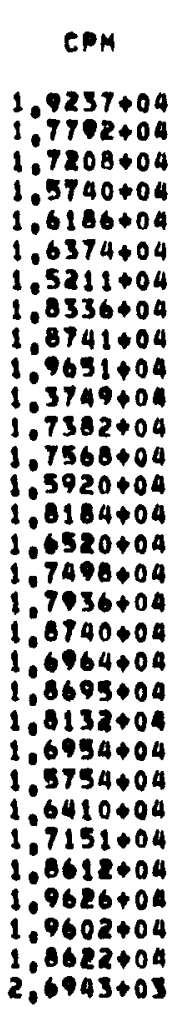

\begin{tabular}{|c|c|}
\hline $\begin{array}{l}C S=137 \\
\text { URIE } 180=C M\end{array}$ & STO DEV \\
\hline 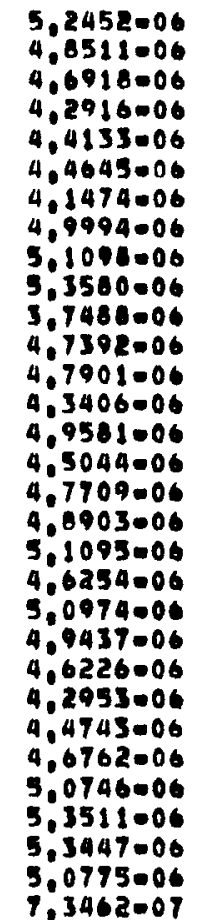 & 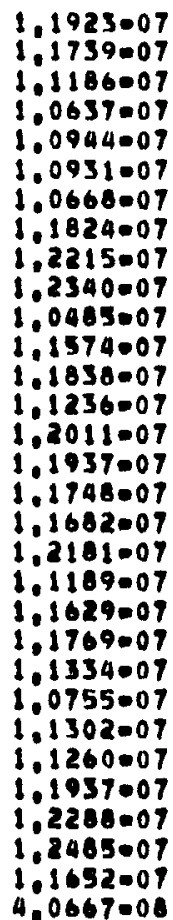 \\
\hline
\end{tabular}

RAT10

$4.2405=06$

$4.7669-06$

$1.1797+00$

$1: 0352+00$

$1.0870+00$

1.1432400

1,2014000

$1.1951+00$

$1.1186+00$

$1.1725+00$

$1,0666+00$

1,0666400

$1.1899+00$

$1.1149+00$

$1.1182+00$

$1.0900+00$

$1.0815+00$

$1.0553+00$

9.6450001

1,1269400

$1,1233+00$

$1.1355+00$

$1.2151+00$

$1.1315+00$

1.1656000

$1.1997+00$

$1.2164+00$

$1.1007+00$

$1.1117+00$

1.0846400

1.1160400

1,1160000

1.0980000

$1.5003 \$ 00$

AVERAGE ( 3,0 FT)

$1.1241+00$

Standard deviation shown is that associated with counting statistics only 


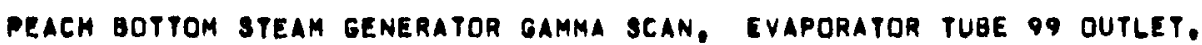

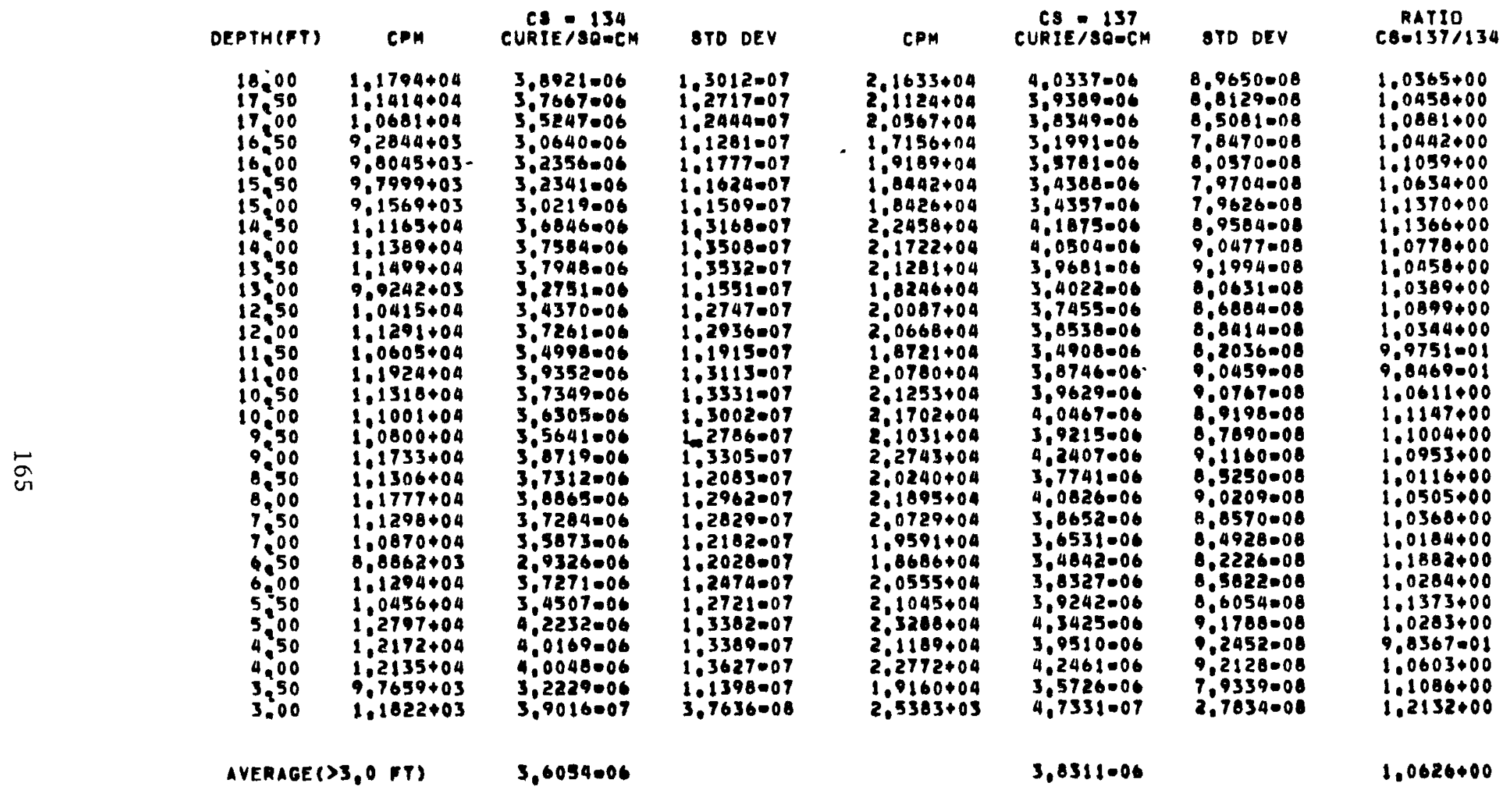


PEACH BOTTOM STEAM GENERATOA gAMMA SCAN, EVAPORATOR TUBE al OUTLET.

\begin{tabular}{|c|c|}
\hline CURIE $180-C M$ & STO DEV \\
\hline 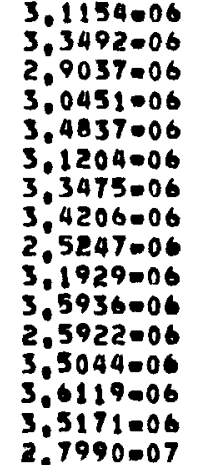 & $\begin{array}{l}1.2080007 \\
1.0728007 \\
1.1094007 \\
1.1914007 \\
1.2771007 \\
1.2260007 \\
1.2265007 \\
1.3047007 \\
1.0670007 \\
1.2756007 \\
1.2955007 \\
1.0634007 \\
1.2186007 \\
1.3457007 \\
1.2527007 \\
3.1967008\end{array}$ \\
\hline
\end{tabular}

$C P 4$
$2,0733+04$
$1,7556+04$
$1,8347+04$
$2,0123+04$
$2,2975+04$
$2,1844+04$
$2,1002+04$
$2,2935+04$
$1.6649+04$
$2,1918+04$
$2,3467+04$
$1,6599+04$
$2,1945+04$
$2,3421+04$
$2,2863+04$
$2,2645+03$

RATIO

\begin{tabular}{|c|c|}
\hline DFPTH(FY) & CPM \\
\hline 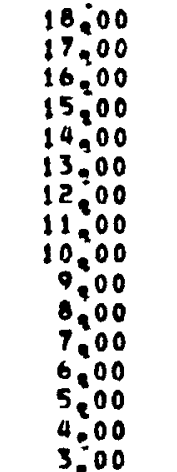 & $\begin{array}{l}1.0091+04 \\
1.0848+04 \\
9.4052+03 \\
9.0632+03 \\
1.1284+04 \\
1.0107+04 \\
1.0843+04 \\
1.1080+04 \\
8.1779+03 \\
1.0342+04 \\
1.1640+04 \\
1.3962+03 \\
1.1351+04 \\
1.1699+04 \\
1.1392+04 \\
9.0662+02\end{array}$ \\
\hline
\end{tabular}

AVERAGE ( 3,0 FT)

3.2215006

CURIEI $130-C M$

GTD DEV

$\cos =137 / 134$

$1,1515+00$

$9.0699-01$

$1.0933+00$

$1.1434+00$

$1.1412+00$

$1.2113+00$

$1,0856+00$

$1.1601+00$

$1.1410+00$

$1.1878+00$

$1.1300+00$

$1.1053+00$

$1.0836+00$

$1.1220+00$

$1.1248+00$

$1.3999+00$

3.6027006

$1.1183+00$ 
PEACH BOTTOM STEAM GENERATOR GAMMA SCAN, EVAPORATOR TUBE 90 OUTLET,

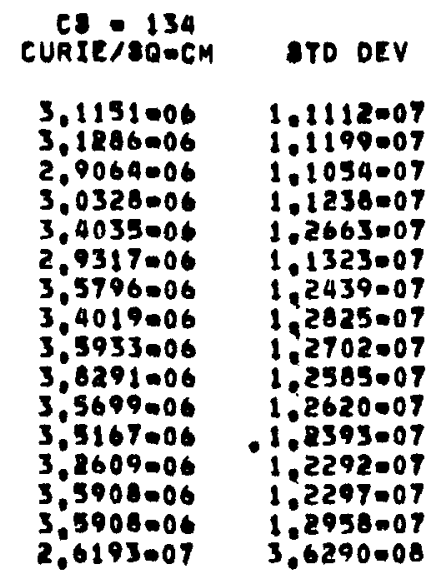

3,3634006

\begin{tabular}{|c|c|}
\hline $\begin{array}{c}C 8=137 \\
\text { CURIE/SO-CM }\end{array}$ & STD DEV \\
\hline $\begin{array}{l}3.2784006 \\
3.3053006 \\
3.3736006 \\
3,3513006 \\
3,9061006 \\
3.4791006 \\
3,9296006 \\
4.0253006 \\
4.1352006 \\
4.2408006 \\
4.0912006 \\
4.1123006 \\
3.8228006 \\
3.9689006 \\
4.2161006 \\
4.3659007\end{array}$ & 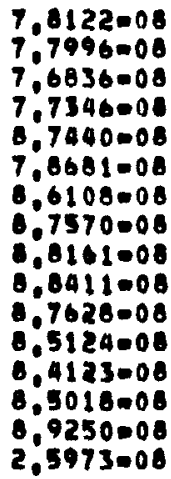 \\
\hline
\end{tabular}

$3.8157-06$ $\underset{\cos }{\operatorname{RAT} 137113}$

$1.0525+00$ $1.1609+00$ $1.1051+00$ $1.1478+00$ $1.1868+00$ $1.0979+00$ 1.1833000 1.1509400 1.1509400 $1.1076+00$ $1.1461+00$ $1.1694+00$ $1.124+00$ $1754+00$ $1.1742+00$

$1.1345+00$ 
PEACH BOTTOM sTEAM GENERATOR GaMMA SCAM, EVAPORATOR TUBE 137 OUTLET.

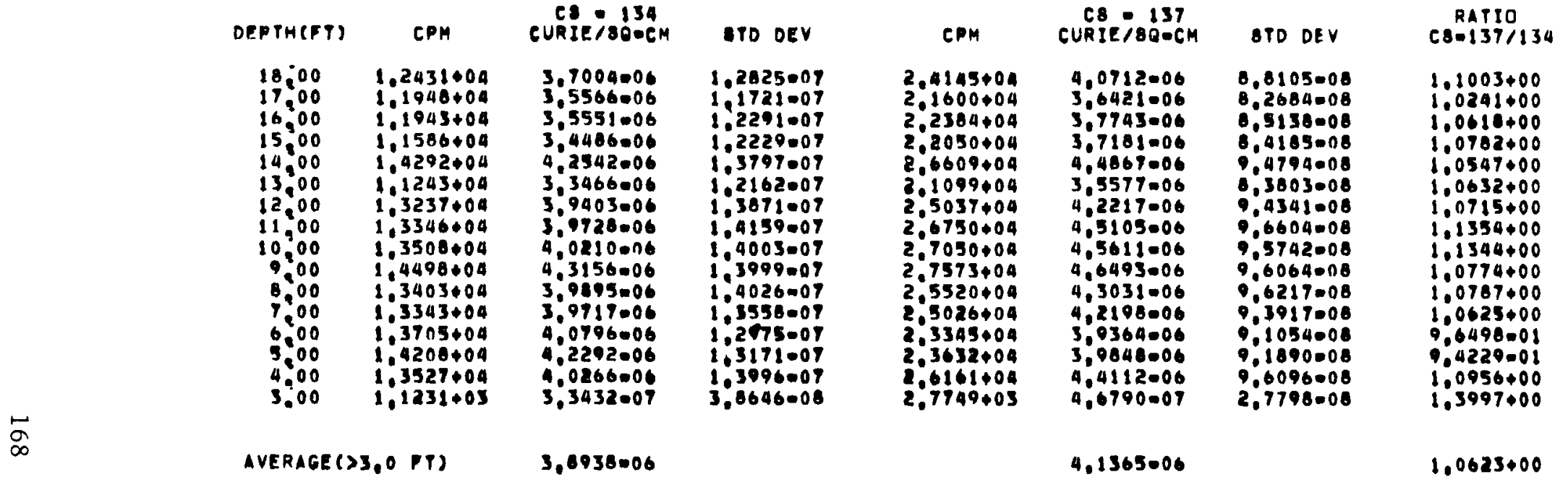

Standard deviation shown is that associated with counting statistics only. 
PEACH BotTOM steam generator gaMma sCAN, EVAPORATOR TUBE 136 OUTLET.

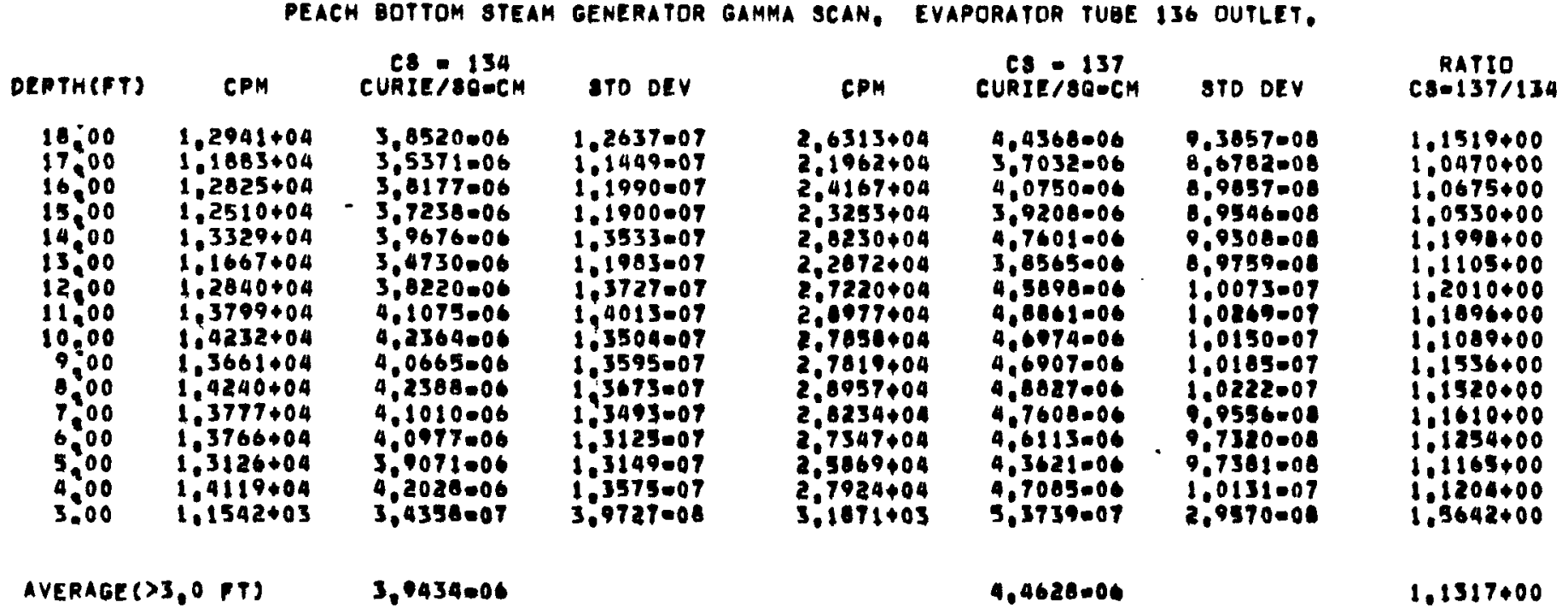


PEACH BOTTOM STEAM GENERATOR gAMMA sCAN. EVAPORATOR TUBE BB OUTLET.

\begin{tabular}{|c|c|c|c|}
\hline DERTHCFT) & CPM & $\begin{array}{c}C 3 \\
\text { CURTE/ } 134 \\
\text { C CM }\end{array}$ & STD DEV \\
\hline $\begin{array}{l}18: 00 \\
17: 00 \\
16: 00 \\
15,00 \\
14,00 \\
13,00 \\
12: 00 \\
11: 00 \\
10: 00 \\
9000 \\
8: 00 \\
7: 00 \\
6: 00 \\
5: 00 \\
9: 00 \\
3,00\end{array}$ & $\begin{array}{l}1.0943+04 \\
1.1196+04 \\
1,1358+04 \\
1.0333+04 \\
1.2701+04 \\
1.0706+04 \\
1.3015+04 \\
1.2491+04 \\
1.3113+04 \\
1.2315+04 \\
1.3538+04 \\
1.2633+04 \\
1.3231+04 \\
1.2848+04 \\
1.3005+04 \\
1.1470+03\end{array}$ & $\begin{array}{l}3,1142006 \\
3,1862006 \\
3,2323006 \\
2,9976006 \\
3,6146006 \\
3,0470006 \\
3,7039006 \\
3,5550006 \\
3,7320006 \\
3,5049006 \\
3,0529006 \\
3,5953-06 \\
3,7654006 \\
3,6565006 \\
3,7012006 \\
3,2643=07\end{array}$ & $\begin{array}{l}1.1206=07 \\
1.1008007 \\
1.0823007 \\
1.0924007 \\
1.2101007 \\
1.0456007 \\
1.2204=07 \\
1.2540=07 \\
1.2318007 \\
1.2345007 \\
1.2262007 \\
1.2055007 \\
1.1013=07 \\
1.1931007 \\
1.2407=07 \\
3.4533=08\end{array}$ \\
\hline
\end{tabular}

\begin{tabular}{|c|c|c|}
\hline CPM & $\begin{array}{l}C 8=137 \\
\text { CURIE/SO-CM }\end{array}$ & STO DEV \\
\hline $\begin{array}{l}.2633+04 \\
.2067+04 \\
1899+04 \\
1041+04 \\
4879+04 \\
1012+04 \\
5892+04 \\
5345+04 \\
5701+04 \\
6832+04 \\
6579+04 \\
66138+04 \\
4952+04 \\
4967+04 \\
5640+04 \\
1972+03\end{array}$ & 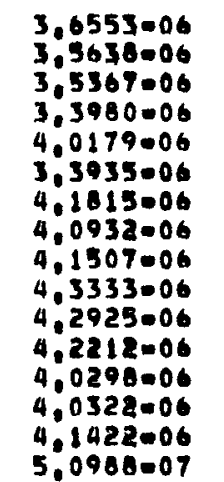 & $\begin{array}{l}8,4422=08 \\
0,3198008 \\
8,1545008 \\
0,2197008 \\
9,1146008 \\
7,9277008 \\
9,1573008 \\
9,3655008 \\
9,1959008 \\
9,2406008 \\
9,2636008 \\
9,0360=08 \\
8,9646008 \\
0,9442=08 \\
9,3121008 \\
2,7089008\end{array}$ \\
\hline
\end{tabular}

$\csc \operatorname{RAT} 137113$

AVERAGE $(3,0 \mathrm{FT})$

3.4839006

3.9361006

$1.1738+00$ $1.1186+00$ $1.0943+000$ $1.1117+00$ $1.1117+00$ $1.1230+00$ $1.1290+00$
$1.1519+00$ $1.1515+00$ $+1123+00$ $1.2565+00$ $1.1142+00$ $1.1742+00$ $1.0703+00$ $1.1028+00$ $1.1193+00$ $1.5621+00$

$1.1298+00$ 
PEACH bottom steam generator gamma scan, EVAPORATOR tUBe 38 outlet.

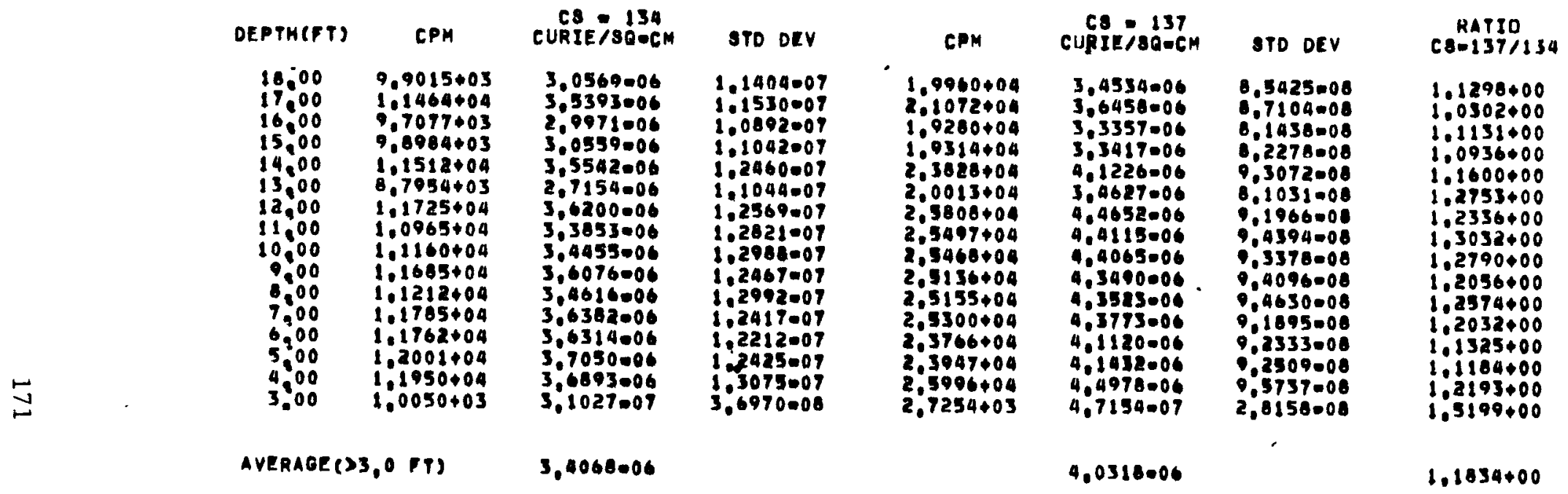


PEACH BOTTOM STEAM GENERATOR GAMMA SCAN. EVAPORATOR TUBE 146 DUTLET.

\begin{tabular}{|c|c|c|c|c|c|c|c|c|}
\hline & DEPTHEFT & CPM & $\begin{array}{c}\text { CS } 134 \\
\text { CUAIE/SOOCM }\end{array}$ & STO DEV & CPM & $\begin{array}{c}C 8 \cdot 137 \\
\text { CURIEI8OCGM }\end{array}$ & STO DEV & $\begin{array}{c}\text { RATIO } \\
\text { C8*137/134 }\end{array}$ \\
\hline & 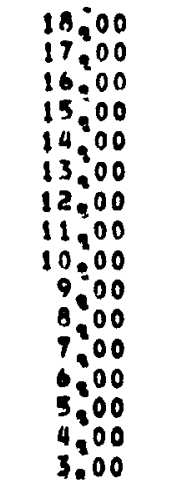 & $\begin{array}{l}1.3692+04 \\
1.0784+04 \\
1.1322+04 \\
1.3401+04 \\
1.4621+04 \\
1.2466+04 \\
1.1798+04 \\
1.3263+04 \\
1.2851+04 \\
1.0061+04 \\
1.2541+04 \\
1.1647+04 \\
1.2351+04 \\
1.4113+04 \\
4.4240+03 \\
1.2206+03\end{array}$ & 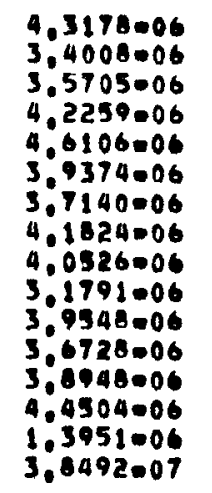 & $\begin{array}{l}1.2461=07 \\
1.1278-07 \\
1.1320007 \\
1.3031007 \\
1.3003007 \\
1.2318007 \\
1.1866007 \\
1.3340007 \\
1.2993-07 \\
1.1099007 \\
1.3123007 \\
1.2025007 \\
1.2260007 \\
1.3344007 \\
7.5022008 \\
3.3107008\end{array}$ & $\begin{array}{l}2,3278+04 \\
2.0556+04 \\
2.1024+04 \\
2.4588+04 \\
2,5369+04 \\
2.2603+04 \\
2.1635+04 \\
2,5063+04 \\
2.4763+04 \\
2.0206+04 \\
2.4688+04 \\
2.1350+04 \\
2.2249+04 \\
2,5166+04 \\
1.1141+04 \\
2.7787+03\end{array}$ & 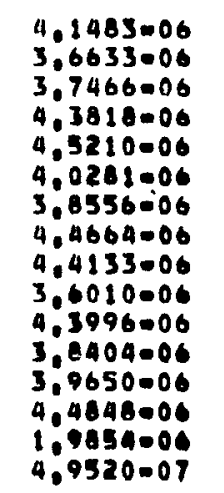 & $\begin{array}{l}9,5630008 \\
8,5698008 \\
8,6524000 \\
9,7650008 \\
9,9239008 \\
9,2777008 \\
9,0860008 \\
9,9227=08 \\
9,6411000 \\
6,3490=08 \\
9,7335=08 \\
0,9513008 \\
9,2925008 \\
9,9329008 \\
5,6969=08 \\
2,5827=08\end{array}$ & $\begin{array}{l}9.0081001 \\
1.0773+00 \\
1.0494+00 \\
1.0370+00 \\
9.0064001 \\
1.0231+00 \\
1.0382+00 \\
1.0680+00 \\
1.0891+00 \\
1.1328+00 \\
1.1125+00 \\
1.0457+00 \\
1.0181+00 \\
1.0078+00 \\
1.0232000 \\
1.2866+00\end{array}$ \\
\hline & AVERAGE ? & $3.0 \mathrm{FT}$ & 3.7706006 & & & 3,0667006 & & 1.0520400 \\
\hline
\end{tabular}

Standard deviation shown is that associated with counting statistics only. 
PEACH BOTTOM STEAM GENERATOR GAMMA SCAN, EVAPORATOR TUBE 116 INLET.

\begin{tabular}{|c|c|}
\hline $\begin{array}{c}\text { CS } 134 \\
\text { CURIE } 180 \text { M }\end{array}$ & STO DEV \\
\hline 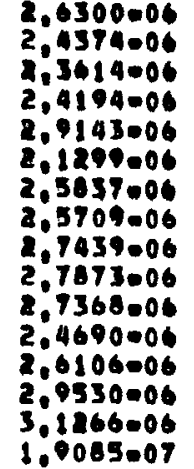 & 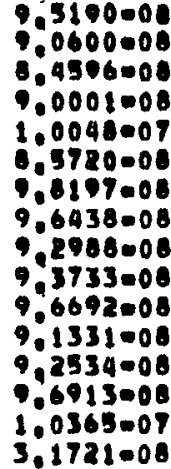 \\
\hline 2.6316006 & \\
\hline
\end{tabular}

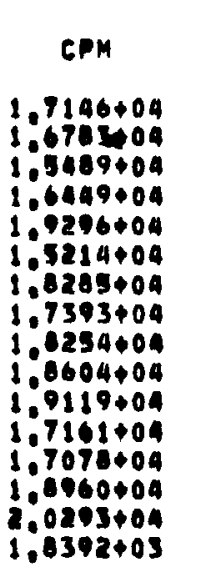

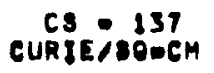
$8 T$ DEV

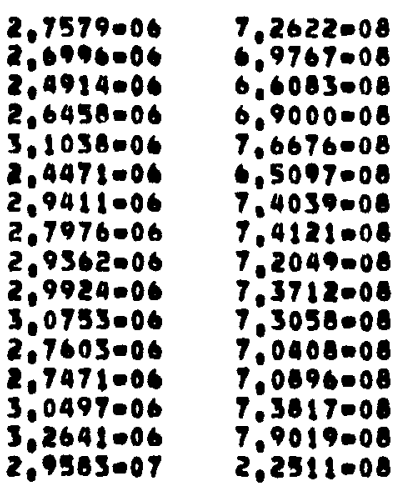

RATIO

\begin{tabular}{|c|c|}
\hline DEPTH $(F T)$ & CPM \\
\hline 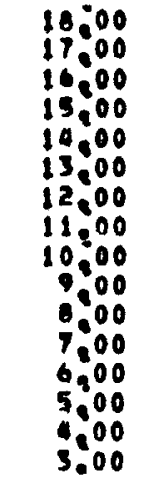 & 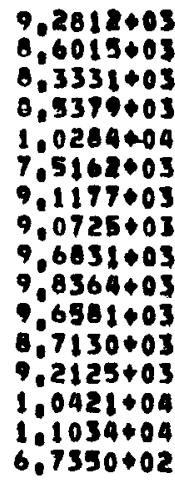 \\
\hline
\end{tabular}

AVERAGE $(23,0 \mathrm{FT})$

2,6316006

$1.0487+00$

1.1076000

$1,0552+00$

$1.0937+00$

$1.0651+00$

$1.1490+00$

$1.1384+00$

$1.0883+00$

1,0902000

1.0737400

$1.01237+00$

$1,1237+00$

1.1161400

$1.0526+00$

1.0320400

$1.0491+00$

2,8473006

$1,0820+00$ 
PEACH BOTTOM STEAM GENERATOR GAMMA BCAN, EVAPORATOR TUBE 156 INLET.

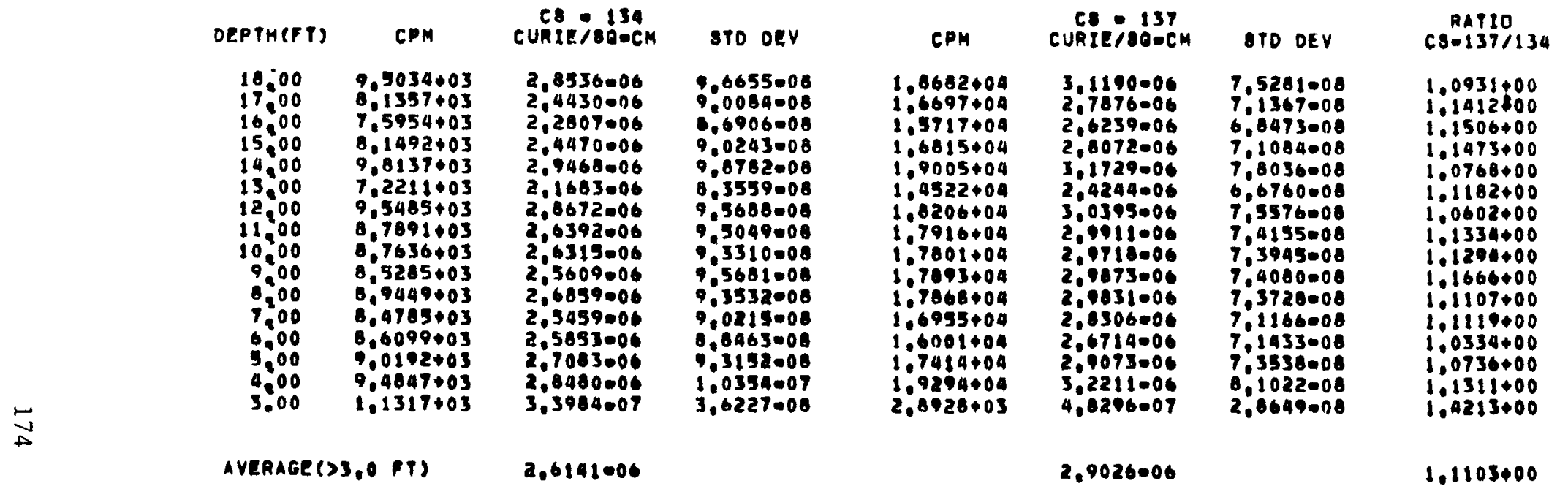

Standard deviation shown is that associated with counting statistics only 
PEACH BOTTOM STEAM gENERATOR GAMMA SCAN, EVAPORATOR TUBE 163 INLET,

\begin{tabular}{|c|c|c|c|c|c|c|c|c|}
\hline & DEPTH(FY) & CPM & $\begin{array}{c}\text { CS } 134 \\
\text { CURIEIOO-CM }\end{array}$ & STO DEV & CPM & $\begin{array}{c}C 3-137 \\
\text { CURIE/SAOCK }\end{array}$ & PTO DEV & $\begin{array}{c}\text { RATIO } \\
\text { C8-137/134 }\end{array}$ \\
\hline & 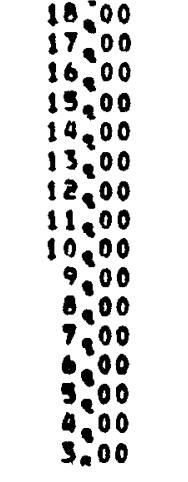 & $\begin{array}{l}9.0331+03 \\
9.2110+03 \\
7.6561+03 \\
8.6152+03 \\
8.6515+03 \\
7.5796+03 \\
8.8662+03 \\
8.2604+03 \\
8.3639+03 \\
8.7702+03 \\
8.0764+03 \\
7.9177+03 \\
7.9129+03 \\
6.7776+03 \\
1.1830+04 \\
1.1170+03\end{array}$ & 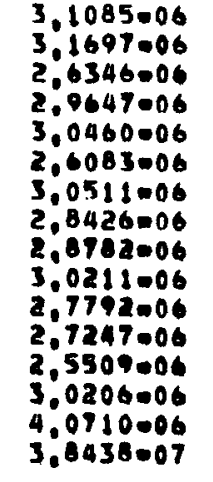 & $\begin{array}{l}1.0692=07 \\
9.9030008 \\
9.7097008 \\
1.0100007 \\
1.10112007 \\
9.3752008 \\
1.0445007 \\
1.0175=07 \\
9.07180008 \\
1.0106=07 \\
1.0185=07 \\
0.7398008 \\
9.1950008 \\
1.0270007 \\
1.2077007 \\
3.2015008\end{array}$ & $\begin{array}{l}1.6993+04 \\
1.6942+04 \\
1.5666+04 \\
1.6473+04 \\
1.7998+04 \\
1.4618+04 \\
1.7638+04 \\
1.6345+04 \\
1.6492+04 \\
1.7041+04 \\
1.6565+04 \\
1.5576+04 \\
1.4197+04 \\
1.6989+04 \\
2.1092+04 \\
2.0472403\end{array}$ & 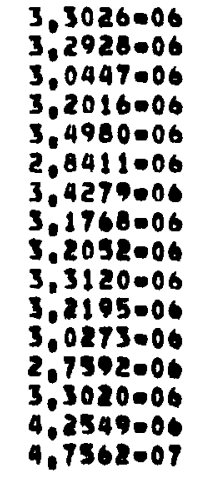 & 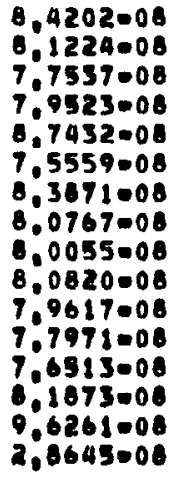 & $\begin{array}{l}1.0625+00 \\
1.0389+00 \\
1.1557+00 \\
1.0800 \$ 00 \\
1.1485+00 \\
1.0893+00 \\
1.1236+00 \\
1.1177+00 \\
1.1137+00 \\
1.0964+00 \\
1.1585+00 \\
1.1111+00 \\
1.0817+00 \\
1.0933+00 \\
1.0453+00 \\
1.2375+00\end{array}$ \\
\hline & AVERAGETS & $3.0 \mathrm{FT}$ & 647.06 & & & $2377 \cdot 00$ & & $1.0988+00$ \\
\hline
\end{tabular}

Standard deviation shown is that associated with counting statistics only 
PEACH BOTTOM STEAM GENERATOR GAMMA SCAN, EVAPORATDR TUBE 124 INLET,

\begin{tabular}{|c|c|c|c|c|c|c|c|c|}
\hline & DEPTH(FT) & CPM & $\begin{array}{c}\text { CS: } 134 \\
\text { CURIE/SOACM }\end{array}$ & STO DEV & CPM & $\begin{array}{l}\text { C8. } 137 \\
\text { CURIEISO-CM }\end{array}$ & STO DEV & $\begin{array}{c}\text { RAT180 } \\
\cos =137 / 134\end{array}$ \\
\hline & 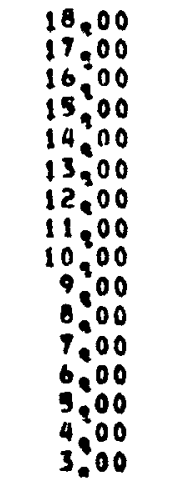 & $\begin{array}{l}9,6199+03 \\
9,0381+03 \\
7,9974+03 \\
6,3311+03 \\
9,8099+03 \\
7,2197+03 \\
9,0806+03 \\
8,7887+03 \\
8,7799+03 \\
9,6140+03 \\
9,5106+03 \\
8,7249+03 \\
8,3329+03 \\
9,3926+03 \\
1.2032+04 \\
5,0250002\end{array}$ & 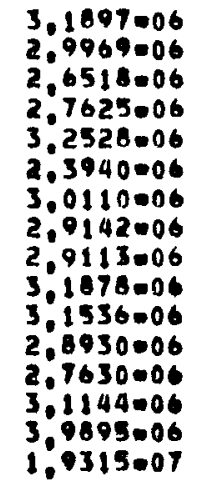 & $\begin{array}{l}1.0613007 \\
1.0058007 \\
9.5130008 \\
9.8814008 \\
1.0839007 \\
9.5618000 \\
1.0598007 \\
1.0331007 \\
1.0216007 \\
1.0454007 \\
1.0158007 \\
1.0056-07 \\
9.4570=08 \\
1.0568007 \\
1.2312007 \\
3.3232=08\end{array}$ & $\begin{array}{l}1.7850+04 \\
1.6865+04 \\
1.5941+04 \\
1.6522+04 \\
1.9112+04 \\
1.4536+04 \\
1.6770+04 \\
1.6781+04 \\
1.7351+04 \\
1.7577+04 \\
1.8301104 \\
1.6947+04 \\
1.5945+04 \\
1.8367+04 \\
2.3437+04 \\
1.9418+03\end{array}$ & $\begin{array}{l}3,3488=06 \\
3,1639006 \\
2,9906=06 \\
3,0995=06 \\
3,5855=06 \\
2,7270006 \\
3,1460006 \\
3,1482006 \\
3,2551=06 \\
3,2975=06 \\
3,4332006 \\
3,1794=06 \\
2,99140006 \\
3,4632006 \\
4,3967006 \\
3,4604007\end{array}$ & 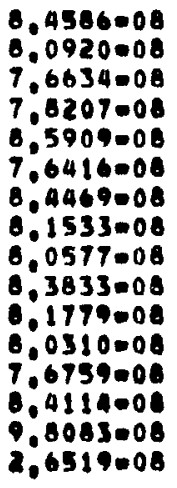 & $\begin{array}{l}1.0500+00 \\
1.0558+00 \\
1.1278+00 \\
1.1221+00 \\
1.1024000 \\
1.1392+00 \\
1.0449+00 \\
1.0804+00 \\
1.1182+00 \\
1.0345+00 \\
1.0888+00 \\
1.0991400 \\
1.0827+00 \\
1.1185+00 \\
1.1022+00 \\
1.9057+00\end{array}$ \\
\hline & AVERAGE (S) & $1,0 \mathrm{FY}$ & 3.0124006 & & & 3.2831006 & & 1.0899 .00 \\
\hline
\end{tabular}

Standard deviation shown is that associated with counting statistics only 
PEACH BOTtOM ateam generator gamma scan, EVAPORATOR TUbE 74 INLET.

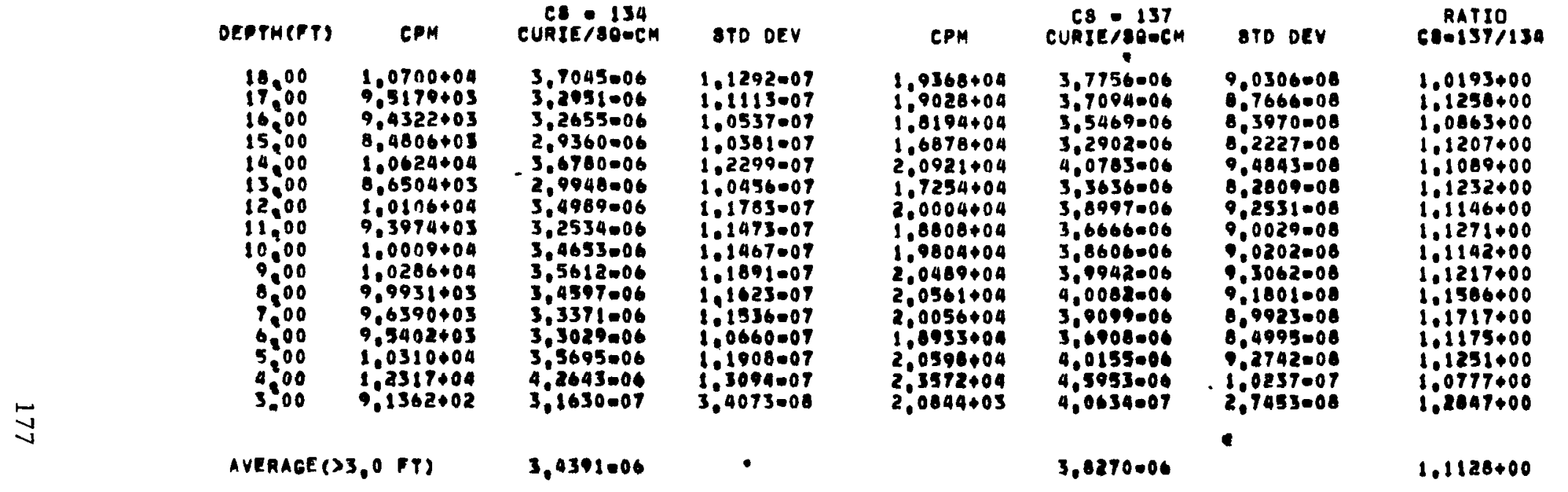

Standard deviation shown is that associated with counting statistics only 


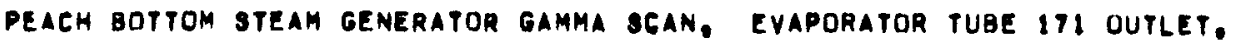

\begin{tabular}{|c|c|c|c|c|c|c|c|c|}
\hline & DEPTH(FT) & CPM & CS 134 & STD DEV & CPM & $\begin{array}{c}\text { CB } \\
\text { CURIE } 137 \\
\end{array}$ & STD DEV & $\begin{array}{c}\text { RAT10 } \\
\operatorname{cs}-137 / 134\end{array}$ \\
\hline & 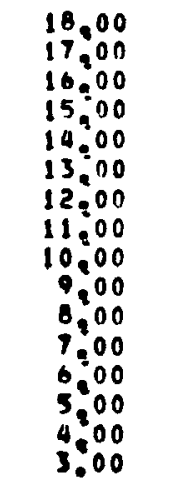 & $\begin{array}{l}1.4170+04 \\
1.1293+04 \\
1.1771+04 \\
1.3020+04 \\
1.3911+04 \\
1.4034+04 \\
1.2128+04 \\
1.3850+04 \\
1.2663+04 \\
1.3056+04 \\
1.2952+04 \\
1.1043+04 \\
1.2929+04 \\
1.3983+04 \\
1.2994+04 \\
1.5196+03\end{array}$ & $\begin{array}{l}5,9446006 \\
4.7375006 \\
4,9379006 \\
5,7974006 \\
5,8357006 \\
5,8873006 \\
5,0876006 \\
5,8101006 \\
5,3123006 \\
5,4769-06 \\
5,4334006 \\
4,6326006 \\
5,4237-06 \\
5,8661006 \\
5,4509006 \\
6,3749009\end{array}$ & $\begin{array}{l}1.7422007 \\
1.5210007 \\
1.6748007 \\
1.0131007 \\
1.7539007 \\
1.8230007 \\
1.6786007 \\
1.8730007 \\
1.7107007 \\
1.7916007 \\
1.8486007 \\
1.6374007 \\
1.6636007 \\
1.7946007 \\
1.6417-07 \\
5,2323008\end{array}$ & 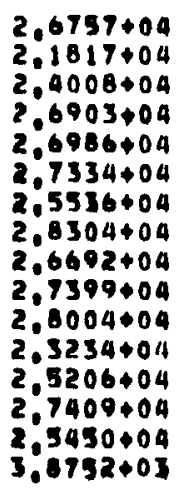 & $\begin{array}{l}6,3447=06 \\
5,1734=06 \\
5,6927-06 \\
6,3793006 \\
6,3988=06 \\
6,4814006 \\
6,0550006 \\
6,7115006 \\
6,3292=06 \\
6,4969006 \\
6,6403006 \\
5,3091006 \\
5,9768-06 \\
6,4993006 \\
6,0348=06 \\
9,1089-07\end{array}$ & $\begin{array}{l}1.3697-07 \\
1.1949007 \\
1.3014007 \\
1.4049007 \\
1.3728-07 \\
1.3969007 \\
1.3058007 \\
1.4581007 \\
1.3336007 \\
1.3847007 \\
1.4260007 \\
1.2727007 \\
1.2965007 \\
1.3807007 \\
1.2803-07 \\
4.1664008\end{array}$ & $\begin{array}{l}1.0674+00 \\
1.0921+00 \\
1.1530+00 \\
1.1005+00 \\
1.0966+00 \\
1.1010+00 \\
1.1903+00 \\
1.1552+00 \\
1.1915+00 \\
1.1863+00 \\
1.2222+00 \\
1.1893+00 \\
1.1021+00 \\
1.1080+00 \\
1.1072+00 \\
1.4415+00\end{array}$ \\
\hline & AVERAGE ( ) & $0 F T$ & 5,4423006 & & & $.1815=06$ & & 1.1358400 \\
\hline
\end{tabular}

Standard deviation shown is that associated with counting statistics only 
PEACH BOTTOM BTEAM GENERATOR GAMMA SCAN, EVAPORATOR TUBE ITI-I OUTLET,

\begin{tabular}{|c|c|c|c|c|c|c|c|c|}
\hline & DEPTH $(F Y)$ & CPM & 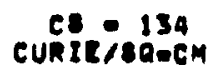 & STO DEV & CPM & $\begin{array}{c}\text { C8 }=137 \\
\text { CURIE/AOSCM }\end{array}$ & STD DEV & $\begin{array}{c}\text { nATIo } \\
\text { C8-137/134 }\end{array}$ \\
\hline & $\begin{array}{l}18: 00 \\
17,00 \\
16,00 \\
15,00 \\
14,00 \\
13,00 \\
12,00 \\
11,00 \\
10,00 \\
9,00 \\
6,00 \\
7,00 \\
6,00 \\
5,00 \\
4,00 \\
3,00\end{array}$ & $\begin{array}{l}1,3240+04 \\
1,0475+04 \\
1,1369+04 \\
1,0544+04 \\
1,3397+04 \\
1,0513+04 \\
1,1065+04 \\
1.3428+04 \\
1.2545+04 \\
1.2702+04 \\
1.3027+04 \\
1.2772404 \\
1.3814+04 \\
1.3126+04 \\
1.3714+04 \\
1.6620+03\end{array}$ & 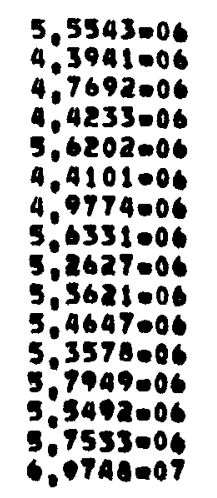 & $\begin{array}{l}1.7038007 \\
1.4940007 \\
1.6201007 \\
1.5374007 \\
1.8213007 \\
1.5935007 \\
1.7806007 \\
1.7060007 \\
1.7708007 \\
1.7325-07 \\
1.7290007 \\
1.7357-07 \\
1.7629007 \\
1.7312007 \\
1.6132007 \\
9.3833008\end{array}$ & $\begin{array}{l}2.6271+04 \\
2,1093+04 \\
2.3398+04 \\
2.2147+04 \\
2.8747+04 \\
2.2799+04 \\
2.6238+04 \\
2.7170+04 \\
2.6221+04 \\
2.6304+04 \\
2.7194+04 \\
2.0554+04 \\
2.7445+04 \\
2.6237+04 \\
2.0149+04 \\
3.5213+03\end{array}$ & 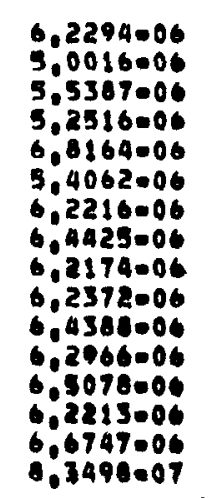 & $\begin{array}{l}1.3050007 \\
1.1611007 \\
1.2474007 \\
1.2014007 \\
1.3078007 \\
1.2306007 \\
1.3627007 \\
1.4057007 \\
1.3689007 \\
1.3460007 \\
1.3345007 \\
1.3316007 \\
1.3629007 \\
1.3529007 \\
1.4224007 \\
4.3591008\end{array}$ & $\begin{array}{l}1.1216+00 \\
1.1383+00 \\
1.1614+00 \\
1.1873+00 \\
1.2129+00 \\
1.2259+00 \\
1.2501+00 \\
1.1438+00 \\
1.1815+00 \\
1.1633+00 \\
1.178400 \\
1.1753+00 \\
1.1231+00 \\
1.1212+00 \\
1.1603+00 \\
1.1972+00\end{array}$ \\
\hline & AVERAGE (X) & .017 & $5,2218.06$ & & & 6,1001006 & & $1.1682+00$ \\
\hline
\end{tabular}

Standard deviation shown is that associated with counting statistics only 
PEACH BOTTOM STEAM GENERATUR GAMMA SCAN, SUPERHEATER TUBE IOU INLET.

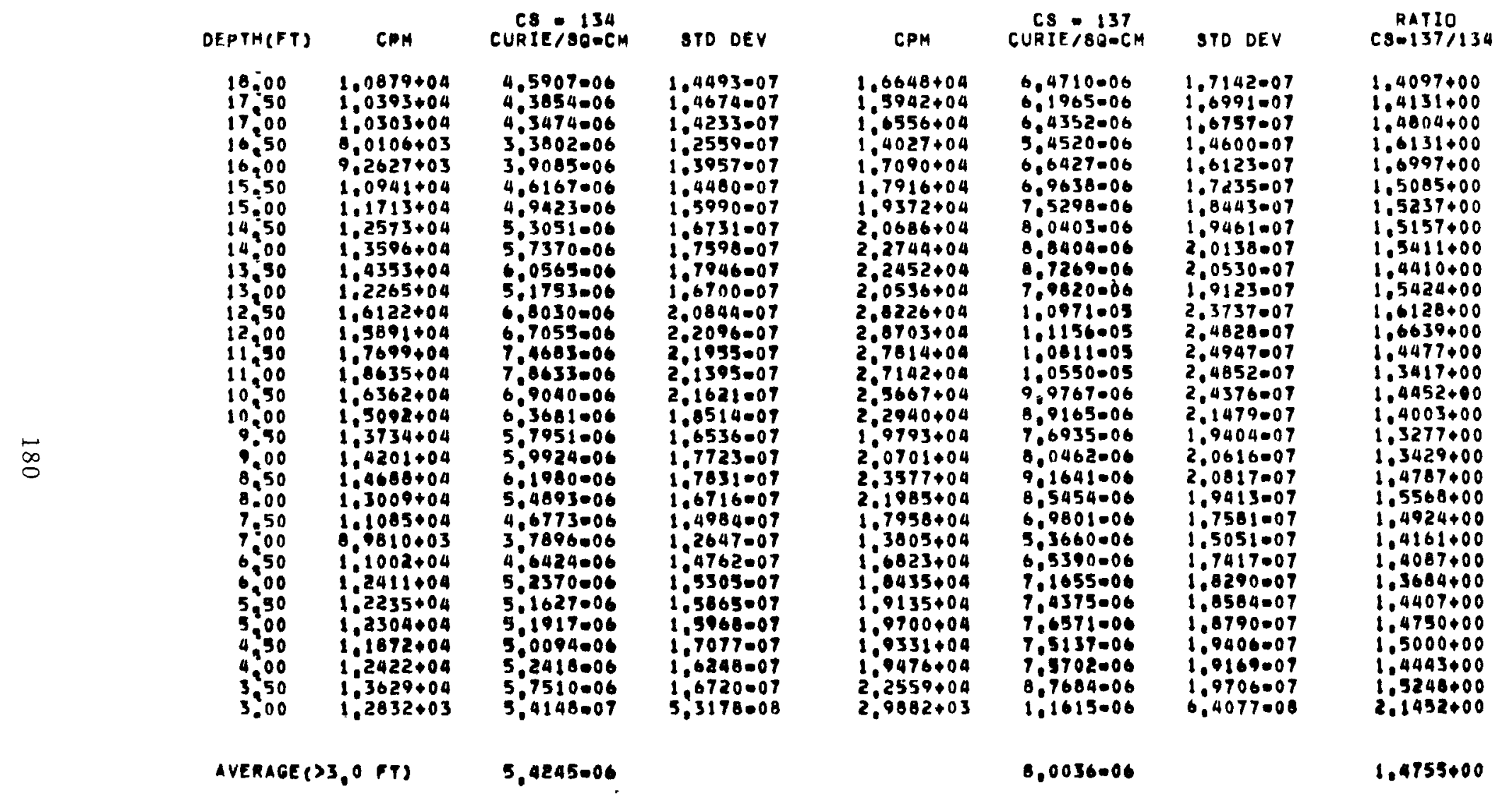

Standard deviation shown is that associated with counting statistics only 
PEACH botTOM STEAM GenERATOR gamMa sCAN, SUPERHEATER TUBE 24 OUTLET.

\begin{tabular}{|c|c|c|c|c|c|c|c|c|}
\hline & DEPTH (FY) & CPM & $\begin{array}{c}C 8=134 \\
\text { CURIE } 180=6 M\end{array}$ & STO DEV & CPM & $\begin{array}{c}\text { C8 } 137 \\
\text { CURIEISO-CM }\end{array}$ & STO DEV & $\begin{array}{c}\text { RAT10 } \\
\cos 137 / 134\end{array}$ \\
\hline$\stackrel{\infty}{\bullet}$ & 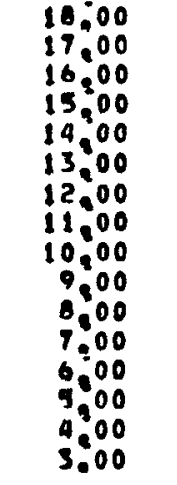 & $\begin{array}{l}1.1603+04 \\
1.2848+04 \\
1,5199+04 \\
1.6527+04 \\
1.3212+04 \\
1.6854+04 \\
1.7927+04 \\
1.7014+04 \\
1.4974+04 \\
1.5630+04 \\
1.6958+04 \\
1.4787+04 \\
1.3667+04 \\
1.2738+04 \\
1.1805+04 \\
1.2725+03\end{array}$ & 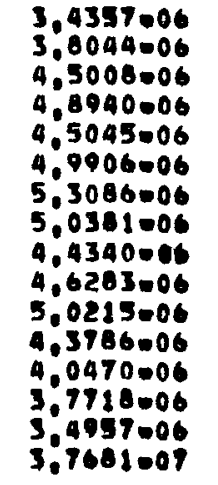 & $\begin{array}{l}1.1116007 \\
1.1933007 \\
1.3418007 \\
1.3091=07 \\
1.4851007 \\
1.9419007 \\
1.6168007 \\
1.6549007 \\
1.5348007 \\
1.4764007 \\
1.5466007 \\
1.3531007 \\
1.2230007 \\
1.2347007 \\
1.2628007 \\
3.1085008\end{array}$ & 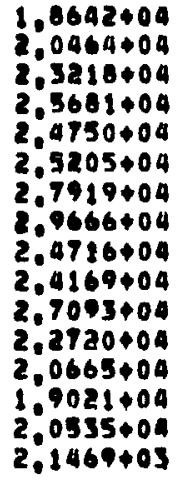 & $\begin{array}{l}5.0043006 \\
5,4935006 \\
6,2328006 \\
6.0939006 \\
6.6439006 \\
6.7661006 \\
7.4947-06 \\
7.9636006 \\
6.6351006 \\
6.4680006 \\
7.0729=06 \\
6.0991006 \\
5.5475006 \\
5.1062006 \\
5.5124006 \\
5.7633007\end{array}$ & $\begin{array}{l}1.3042007 \\
1.3726007 \\
1.5386-07 \\
1.7268007 \\
1.6747007 \\
1.6485007 \\
1.8358007 \\
1.8539007 \\
1.7296007 \\
1.6816007 \\
1.7457007 \\
1.5494007 \\
1.4103007 \\
1.4230007 \\
1.4421007 \\
3.7254008\end{array}$ & $\begin{array}{l}1.4567+00 \\
1.4441+00 \\
1.3849+00 \\
1.4088+00 \\
1.4751+00 \\
1.3559+00 \\
1.4119+00 \\
1.5808+00 \\
1.4965+00 \\
1.4019+00 \\
1.4485+00 \\
1.3930+00 \\
1.3709+00 \\
1.3539+00 \\
1.5771+00 \\
1.5296+00\end{array}$ \\
\hline & AVERAGE C & $0 F(1)$ & 4.4169 .06 & & & $0.3436=06$ & & $1.4362+00$ \\
\hline
\end{tabular}




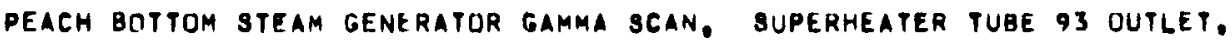

\begin{tabular}{|c|c|c|c|c|c|c|c|c|}
\hline & DEPTH (FT) & CPM & $\begin{array}{c}\text { Cs:134 } \\
\text { CURIE/SOGM }\end{array}$ & STD DEV & CPM & $\begin{array}{c}\text { CS } 137 \\
\text { CURIEISO-CM }\end{array}$ & STO DEV & $\begin{array}{c}R A 180 \\
\cos 137 / 134\end{array}$ \\
\hline & 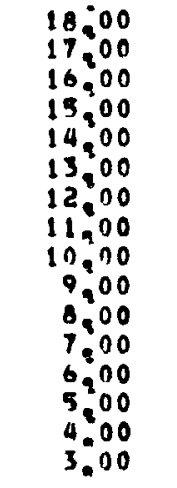 & $\begin{array}{l}0.4857+03 \\
9,2124+03 \\
1,2646+04 \\
1.4049+04 \\
1.3718+04 \\
1.1827+04 \\
1.4621+04 \\
1.4412+04 \\
1.3769+04 \\
1.2725+04 \\
1.4707+04 \\
1.2639+04 \\
1.1571+04 \\
1,0336+04 \\
1.0980+04 \\
5,9500+02\end{array}$ & 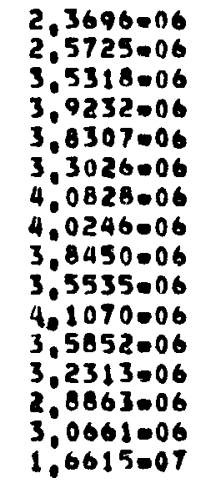 & 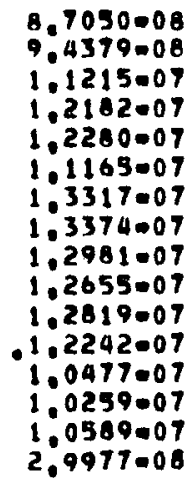 & $\begin{array}{l}1.2780+04 \\
1.4974+04 \\
2.0123+04 \\
2,2214+04 \\
2.1814+04 \\
1.8710+04 \\
2,3596+04 \\
2,3772+04 \\
2,2154+04 \\
2.1214+04 \\
2.1878+04 \\
2.1265+04 \\
1.7100+04 \\
1.6261+04 \\
1.6681+04 \\
1.5342+03\end{array}$ & 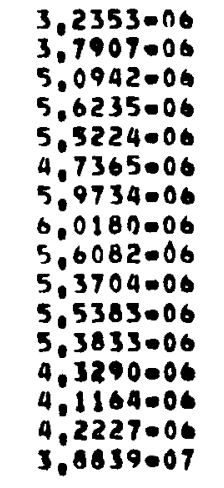 & $\begin{array}{l}1.0386007 \\
1.0993-07 \\
1.3057-07 \\
1.3925007 \\
1.4141007 \\
1.2777-07 \\
1.5057-07 \\
1.5285007 \\
1.4737-07 \\
1.4292007 \\
1.4736007 \\
1.3861007 \\
1.2282007 \\
1.1968007 \\
1.2331007 \\
3.3543008\end{array}$ & $\begin{array}{l}1.3655+00 \\
1.4737+00 \\
1.4425+00 \\
1.4335+00 \\
1.4417+00 \\
1.4343+00 \\
1.4632+00 \\
1.4954+00 \\
1.4587+00 \\
1.5114+00 \\
1.3486+00 \\
1.5017+00 \\
1.3398+00 \\
1.4263+00 \\
1.3773+00 \\
2.3378+00\end{array}$ \\
\hline & AVERAGE (? & $3.0 \mathrm{FT}$ & $3.4608=06$ & & & 4.9708006 & & $1.4363+00$ \\
\hline
\end{tabular}

Standard deviation shown is that associated with counting statistics only 
PEACH BOTTOM STEAM GENERATOR GAMMA SCAN, SUPERHEATEK TUBE 105 INLET,

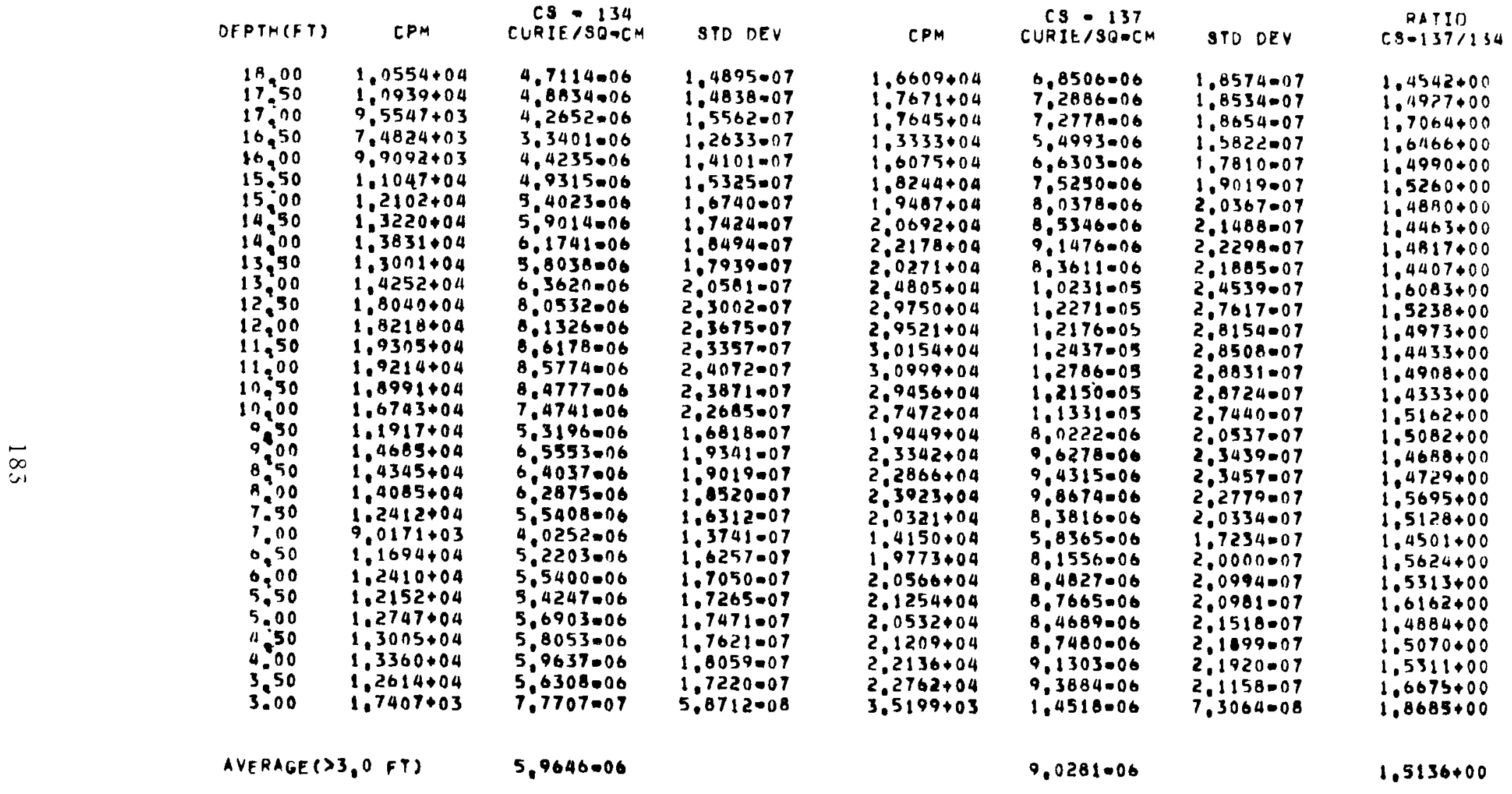


PEACH BOtTOM STEAM GENERATOR gaMma SCAN, SUPERHEATER tUBE 9 QUTLET,

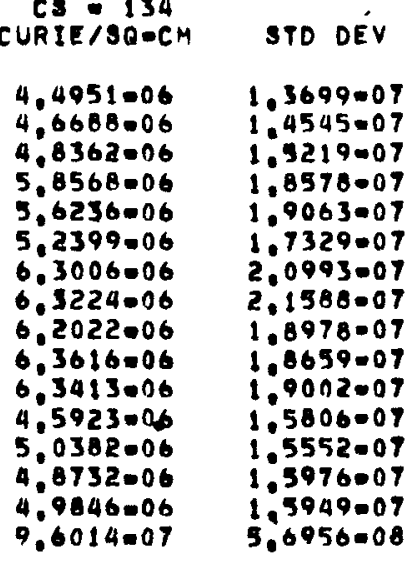

$C P M$
$.8961+04$
$.0189+04$
$1343+04$
$.6430+04$
$.6905+04$
$.4645+04$
$.0099+04$
$0684+04$
$.7969+04$
$.8140+04$
$7356+04$
$1123+04$
$.0926+04$
$1999+04$
$.2084+04$
$9529+03$

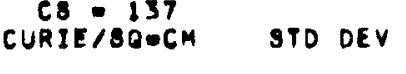

C8. $137 / 13$

DEPTH(FT)

$1.1633+04$

$2.2083+04$

$1.2516+04$

$1.5157+04$

1.3568

$1.6306+0$

$1.6362+04$

$1.6051+04$

$1.6464+04$

$1,6411+04$

$1.1885+04$

1.303904

$1.2612+0$

$2.4849+03$

$9.6014=07$

1.7231007

6.6882006
7.1215006

7.1215006

7.5285006
$9.3257-06$

9,3257006

9.4906006

0.0933006

1.0617 .05

1.0824005

9,8638006

9.9261 .06

9.6494006

7.4510 .06

7.3615006

7.7598000

7.7899006

1.7471006

$1.7231-07$
$1.7746-07$
1.0568007

1.8568007

$2.1997-07$

2.2532 .07

$2,0762.07$

$2.4837=07$

2.5315007

2,2672007

2.2453007

2.2634007

$1.8791=07$

1.9044007

.9339=0

1.9376007
7.2724008

$1.4880+00$

$1.5254+00$

$1.5568+00$

1.5924 .000

$1.6592+00$

$1.6852+00$

$1.7121+00$

$1.5900+00$

$1.5604+00$

$.5218+00$

$1.6226+00$

$1.4652+00$

$1.5925+00$

$1.5629+00$
$1.8198+00$

AVERAGE $(>3.0$ FI)

5.4491006

0.6741006

$1.5918+00$ 


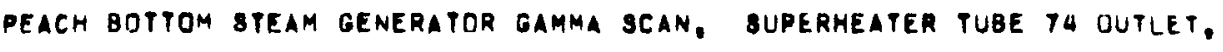

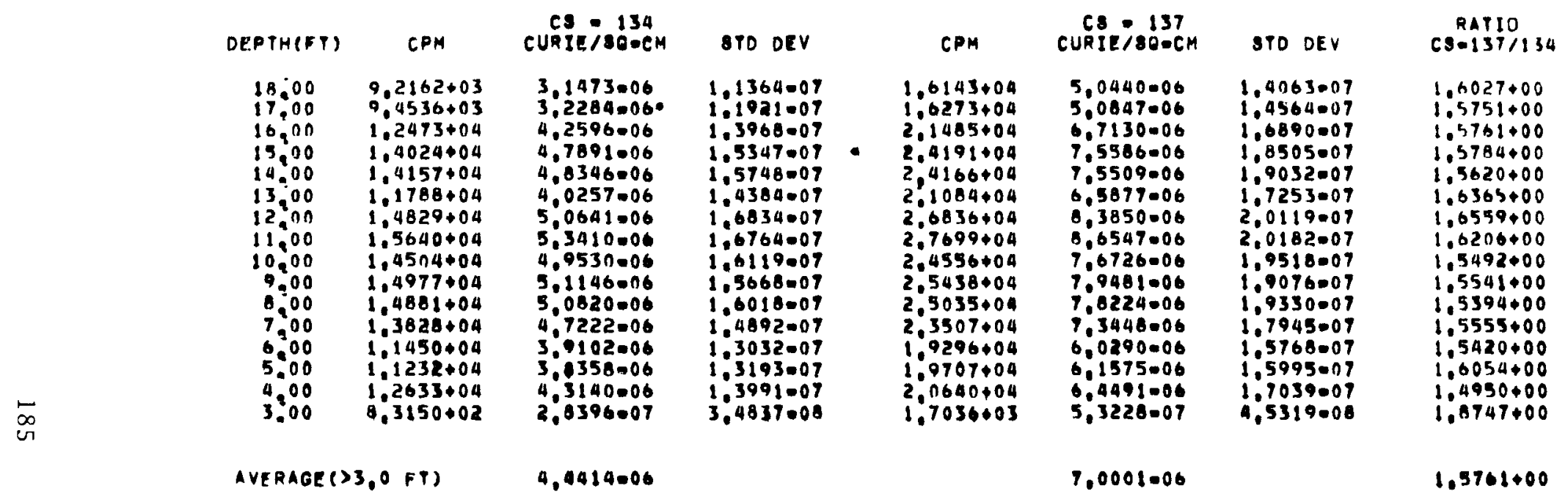


PEACH BotTOM steam generator gamma ocan, superheatea tuge 100 DUTLET,

\begin{tabular}{|c|c|c|c|c|c|c|c|c|}
\hline & DEPTH (PT) & CPM & $\begin{array}{c}C S=134 \\
\text { CURIE/SO-CM }\end{array}$ & STO DEV & CPM & $\begin{array}{c}\text { C8 } 137 \\
\text { CURIE } 180=C M\end{array}$ & STO DEV & $\begin{array}{c}\text { RATIO } \\
\text { C80137/130 }\end{array}$ \\
\hline & 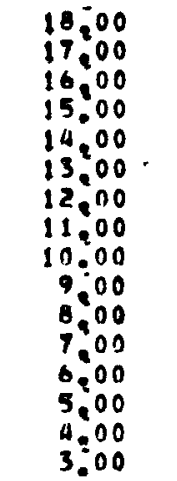 & $\begin{array}{l}9.0307+03 \\
9.6126+03 \\
1,2089+04 \\
1.1878+04 \\
1.2885+04 \\
1,1217+04 \\
1.3666+04 \\
1.3981+04 \\
1.2050 \circ 04 \\
1.2803+04 \\
1.3312+04 \\
1.2544+04 \\
1.2578+04 \\
1.1142+04 \\
1.1195+04 \\
1.2306+03\end{array}$ & $\begin{array}{l}3.7102006 \\
3,9493006 \\
4,9668006 \\
4,8000006 \\
5,2938006 \\
4,6085006 \\
5,6144006 \\
5,7439006 \\
4,9507-06 \\
5,2931006 \\
5,4693006 \\
5,1535006 \\
5,1678006 \\
4,5776006 \\
4.5993006 \\
5,0559007\end{array}$ & $\begin{array}{l}1.4166=07 \\
1.3445007 \\
1.5876007 \\
1.6870-07 \\
1.7109007 \\
1.3093007 \\
1.7920007 \\
1.8100-07 \\
1.7414007 \\
1.7249007 \\
1.7937007 \\
1.6336007 \\
1.5523007 \\
1.5856007 \\
1.5637007 \\
5.1447-08\end{array}$ & $\begin{array}{l}1.0821+04 \\
1.6470+04 \\
2.1058+04 \\
2.1401104 \\
2.3433+04 \\
1.9491+04 \\
2.4599+04 \\
2,4403+04 \\
2.2000404 \\
2,3300+04 \\
2.4468+04 \\
2.1947+04 \\
2.1066+04 \\
1.9612+04 \\
2.0178+04 \\
2,9671+03\end{array}$ & 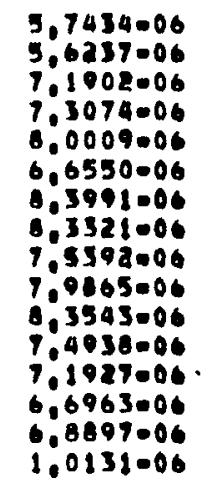 & $\begin{array}{l}1,5870007 \\
1,5344007 \\
1,7006007 \\
1.8739007 \\
1,8741007 \\
1.6873007 \\
1,9009007 \\
1,9998007 \\
1.8903007 \\
1.9263007 \\
1.9701007 \\
1.8422007 \\
1,7099007 \\
1.7509007 \\
1.7455007 \\
5,6530008\end{array}$ & $\begin{array}{l}1.3411+00 \\
1.4241+00 \\
1.4478+00 \\
1.4975+00 \\
1.5115+00 \\
1.4442+00 \\
1.4961+00 \\
1.4507+00 \\
1.5230+00 \\
1.5090+00 \\
1.9276+00 \\
1.4542+00 \\
1.3918+00 \\
1.4630+00 \\
1.4981+00 \\
2.0040+00\end{array}$ \\
\hline & AVERAGE & $F T$ & 4.0319 .06 & & & $.2936=06$ & & $1.4789+00$ \\
\hline
\end{tabular}


PLATEOUT ON ECONOMIZER TUBES $\left(\mu \mathrm{Ci} / \mathrm{cm}^{2}\right)$

BASED ON GM COUNTS CALIBRATED WITH GM AND CATE COUNTS

ON EV-O-102 (AVE >3 FT) AND CORRECT FOIL CALIBRATION

\begin{tabular}{|c|c|c|c|c|c|c|}
\hline \multirow{2}{*}{$\begin{array}{c}\text { Depth } \\
(\mathrm{ft})\end{array}$} & \multicolumn{2}{|c|}{ EC - I - 1} & \multicolumn{2}{|c|}{ EC $-I-41$} & \multicolumn{2}{|c|}{ EC-I -79} \\
\hline & ${ }^{134} \mathrm{Cs}$ & $\overline{137 \mathrm{Cs}}$ & ${ }^{134} \mathrm{Cs}$ & $\overline{137} \mathrm{Cs}$ & ${ }^{134} \mathrm{Cs}$ & $137 \mathrm{Cs}$ \\
\hline 3 & 2.0 & 2.0 & 1.9 & 1.9 & 1.7 & 1.7 \\
\hline 4 & 3.9 & 3.9 & 3.8 & 3.8 & 3.5 & 3.5 \\
\hline 5 & 3.1 & 3.2 & 3.1 & 3.1 & 2.8 & 2.8 \\
\hline 6 & 3.8 & 3.8 & 3.7 & 3.8 & 3.5 & 3.5 \\
\hline 7 & 3.9 & 4.0 & 3.9 & 3.9 & 3.6 & 3.7 \\
\hline 8 & 3.7 & 3.7 & 3.6 & 3.7 & 3.3 & 3.4 \\
\hline 9 & 3.8 & 3.9 & 3.9 & 3.9 & 3.5 & 3.6 \\
\hline 10 & 4.1 & 4.2 & 4.1 & 4.1 & 3.7 & 3.8 \\
\hline 11 & 3.9 & 4.0 & 3.9 & 3.9 & 3.6 & 3.7 \\
\hline 12 & 4.3 & 4.3 & 4.2 & 4.3 & 3.9 & 4.0 \\
\hline 13 & 3.8 & 3.9 & 3.8 & 3.9 & 3.5 & 3.6 \\
\hline 14 & 4.5 & 4.6 & 4.5 & 4.6 & 4.1 & 4.2 \\
\hline 15 & 4.1 & 4.2 & 4.2 & 4.3 & 3.9 & 4.0 \\
\hline 16 & 3.9 & 3.9 & 3.8 & 3.8 & 3.5 & 3.6 \\
\hline 17 & 4.0 & 4.0 & 3.9 & 3.9 & 3.5 & 3.6 \\
\hline 18 & 4.0 & 4.1 & 3.9 & 3.9 & 3.4 & 3.5 \\
\hline \multirow[t]{4}{*}{ AVI } & 3.9 & 4.0 & 3.9 & 3.9 & 3.6 & 3.6 \\
\hline & \multicolumn{2}{|c|}{ EC-I - 107} & \multicolumn{2}{|c|}{ EC-O- 1} & \multicolumn{2}{|c|}{ EC- $-0-41$} \\
\hline & 134 & 137 & $\overline{134}$ & 137 & $\overline{134}$ & 137 \\
\hline & $\mathrm{Cs}$ & $\mathrm{Cs}$ & $\mathrm{Cs}$ & $\mathrm{Cs}$ & $\mathrm{Cs}$ & $\mathrm{Cs}$ \\
\hline 3 & 1.3 & 1.4 & 2.2 & 2.3 & 2.6 & 2.6 \\
\hline 4 & 2.8 & 2.9 & 4.0 & 4.1 & 4.4 & 4.5 \\
\hline 5 & 2.3 & 2.3 & 3.3 & 3.4 & 3.7 & 3.7 \\
\hline 6 & 2.8 & 2.9 & 4.0 & 4.0 & 4.2 & 4.3 \\
\hline 7 & 2.9 & 3.0 & 4.1 & 4.2 & 4.4 & 4.4 \\
\hline 8 & 2.8 & 2.8 & 3.8 & 3.9 & 4.1 & 4.2 \\
\hline 9 & 2.9 & 3.0 & 4.0 & 4.1 & 4.3 & 4.4 \\
\hline 10 & 3.0 & 3.1 & 4.2 & 4.3 & 4.5 & 4.6 \\
\hline 11 & 3.0 & 3.1 & 4.0 & 4.1 & 4.3 & 4.4 \\
\hline 12 & 3.2 & 3.3 & 4.3 & 4.4 & 4.6 & 4.7 \\
\hline 13 & 3.0 & 3.0 & 4.0 & 4.0 & 4.2 & 4.3 \\
\hline 14 & 3.4 & 3.4 & 4.6 & 4.7 & 4.8 & 4.9 \\
\hline 15 & 3.2 & 3.2 & 4.2 & 4.3 & 4.5 & 4.6 \\
\hline 16 & 3.0 & 3.0 & 3.8 & 3.9 & 4.0 & 4.0 \\
\hline 17 & 3.0 & 3.0 & 4.0 & 4.1 & 4.3 & 4.4 \\
\hline 18 & 2.9 & 3.0 & 4.1 & 4.2 & 4.4 & 4.5 \\
\hline AVE & 2.9 & 3.0 & 4.0 & 4.1 & 4.3 & 4.4 \\
\hline
\end{tabular}

(Continued) 


\begin{tabular}{|c|c|c|c|c|c|c|}
\hline \multirow[b]{2}{*}{$\begin{array}{l}\text { Depth } \\
(\mathrm{ft})\end{array}$} & \multicolumn{2}{|c|}{ EC-0-79 } & \multicolumn{2}{|c|}{ EC-0-107 } & \multicolumn{2}{|c|}{$E C-I-9$} \\
\hline & ${ }^{134} \mathrm{Cs}$ & ${ }^{137} \mathrm{Cs}$ & ${ }^{134} \mathrm{Cs}$ & ${ }^{137 \mathrm{Cs}}$ & $\overline{134 \mathrm{Cs}}$ & ${ }^{137} \mathrm{Cs}$ \\
\hline 3 & 2.5 & 2.6 & 2.3 & 2.3 & 2.0 & 2.1 \\
\hline 4 & 4.6 & 4.7 & 4.6 & 4.7 & 3.7 & 3.8 \\
\hline 5 & 3.8 & 3.9 & 3.8 & 3.8 & 3.0 & 3.1 \\
\hline 6 & 4.4 & 4.5 & 4.3 & 4.4 & 3.5 & 3.5 \\
\hline$\neg$ & 4.5 & 4.6 & 4.5 & 4.5 & 3.6 & 3.7 \\
\hline 8 & 4.1 & 4.2 & 4.1 & 4.2 & 3.5 & 3.6 \\
\hline 9 & 4.4 & 4.5 & 4.3 & 4.4 & 3.7 & 3.7 \\
\hline 10 & 4.6 & 4.7 & 4.6 & 4.6 & 3.9 & 4.0 \\
\hline 11 & 4.4 & 4.5 & 4.3 & 4.4 & 3.7 & 3.8 \\
\hline 12 & 4.6 & 4.7 & 4.5 & 4.6 & 4.1 & 4.2 \\
\hline 1.5 & 4.3 & 4.4 & 4.2 & 4.3 & 3.8 & 3.9 \\
\hline 14 & 4.9 & 5.0 & 4.8 & 4.9 & 4.2 & 4.3 \\
\hline 15 & 4.5 & 4.6 & 4.4 & 4.5 & 4.5 & 4.6 \\
\hline 16 & 4.0 & 4.1 & 3.9 & 4.0 & 3.6 & 3.6 \\
\hline 17 & 4.4 & 4.4 & 4.4 & 4.5 & 3.8 & 3.9 \\
\hline 18 & 4.6 & 4.7 & 4.6 & 4.7 & 3.7 & 3.8 \\
\hline$A \cup t$ & 4.4 & 4.5 & 4.4 & 4.4 & 3.8 & 3.8 \\
\hline
\end{tabular}

\begin{tabular}{|c|c|c|c|c|c|c|}
\hline & \multicolumn{2}{|c|}{$E C-I-18$} & \multicolumn{2}{|c|}{ EC-I -60} & \multicolumn{2}{|c|}{ EC-I - 49} \\
\hline & $\overline{134} \mathrm{Cs}$ & $1.37 \mathrm{Cs}$ & ${ }^{134} \mathrm{Cs}$ & ${ }^{137 \mathrm{Cs}}$ & $\overline{134 \mathrm{Cs}}$ & ${ }^{137} \mathrm{Cs}$ \\
\hline 3 & 1.8 & 1.8 & 1.2 & 1.3 & 1.8 & 1.8 \\
\hline 4 & 3.3 & 3.4 & 2.6 & 2.7 & 3.7 & 3.8 \\
\hline 5 & 2.8 & 2.8 & 2.2 & 2.2 & 3.0 & 3.1 \\
\hline 6 & 3.1 & 3.1 & 2.5 & 2.6 & 3.5 & 3.6 \\
\hline i & 3.5 & 3.6 & 2.8 & 2.8 & 3.7 & 3.8 \\
\hline 8 & 3,5 & 3.6 & 2.7 & 2.7 & 3.6 & 3.7 \\
\hline 9 & 3.9 & 4.0 & 3.1 & 3.1 & 3.8 & 3.9 \\
\hline 10 & 3.9 & 4.0 & 3.2 & 3.2 & 4.0 & 4.1 \\
\hline 11 & 3.8 & 3.9 & 3.0 & 3.1 & 3.8 & 3.9 \\
\hline 12 & 4.1 & 4.2 & 3.5 & 3.5 & 4.3 & 4.3 \\
\hline 13 & 3.9 & 4.0 & 3.2 & 3.3 & 3.9 & 4.0 \\
\hline 14 & 4.1 & 4.2 & 3.2 & 3.3 & 4.4 & 4.5 \\
\hline 15 & 3.8 & 3.9 & 3.4 & 3.4 & 4.9 & 5.0 \\
\hline 16 & 3.1 & 3.1 & 2.7 & 2.7 & 3.7 & 3.7 \\
\hline 17 & 3.6 & 3.7 & 3.0 & 3.0 & 4.0 & 4.1 \\
\hline 18 & 3.1 & 3.2 & 2.3 & 2.3 & 3.6 & 3.7 \\
\hline AVE & 3.6 & 3.6 & 3.9 & 3.9 & 3.9 & 3.9 \\
\hline
\end{tabular}




\begin{tabular}{|c|c|c|c|c|c|c|}
\hline \multirow{2}{*}{$\begin{array}{c}\text { Depth } \\
(\mathrm{ft})\end{array}$} & \multicolumn{2}{|c|}{ EC - I -87 } & \multicolumn{2}{|c|}{ EC-I -115} & \multicolumn{2}{|c|}{ EC- $1-94$} \\
\hline & ${ }^{134} \mathrm{Cs}$ & ${ }^{137} \mathrm{Cs}$ & ${ }^{134} \mathrm{Cs}$ & $137 \mathrm{Cs}$ & ${ }^{134} \mathrm{Cs}$ & ${ }^{137} \mathrm{Cs}$ \\
\hline 3 & 1.6 & 1.6 & 1.2 & 1.3 & 1.3 & 1.3 \\
\hline 4 & 3.3 & 3.4 & 2.5 & 2.5 & 2.7 & 2.8 \\
\hline 5 & 2.6 & 2.7 & 2.0 & 2.0 & 2.4 & 2.5 \\
\hline 6 & 3.2 & 3.2 & 2.4 & 2.4 & 2.6 & 2.6 \\
\hline 7 & 3.3 & 3.3 & 2.5 & 2.6 & 3.0 & 3.1 \\
\hline 8 & 3.2 & 3.3 & 2.4 & 2.5 & 3.0 & 3.1 \\
\hline 9 & 3.4 & 3.4 & 2.6 & 2.6 & 3.4 & 3.5 \\
\hline 10 & 3.6 & 3.7 & 2.7 & 2.8 & 3.5 & 3.5 \\
\hline 11 & 3.4 & 3.5 & 2.6 & 2.6 & 3.5 & 3.6 \\
\hline 12 & 3.7 & 3.8 & 2.9 & 2.9 & 3.7 & 3.8 \\
\hline 13 & 3.5 & 3.6 & 2.7 & 2.7 & 3.6 & 3.7 \\
\hline 14 & 3.9 & 4.0 & 2.9 & 2.9 & 3.7 & 3.7 \\
\hline 15 & 4.4 & 4.5 & 3.2 & 3.3 & 3.4 & 3.5 \\
\hline 16 & 3.3 & 3.4 & 2.6 & 2.6 & 2.8 & 2.8 \\
\hline 17 & 3.5 & 3.6 & 2.7 & 2.8 & 3.0 & 3.1 \\
\hline 18 & 3.4 & 3.5 & 2.6 & 2.6 & 2.7 & 2.7 \\
\hline AVE & 3.4 & 3.5 & 2.6 & 2.7 & 3.1 & 3.2 \\
\hline
\end{tabular}

\begin{tabular}{rrr}
\hline & \multicolumn{2}{c}{ EC-I -57} \\
\cline { 2 - 3 } & \multicolumn{1}{c}{ Cs } & 137 Cs \\
\hline 3 & 1.6 & 1.6 \\
5 & 3.2 & 3.3 \\
6 & 2.8 & 2.8 \\
7 & 3.0 & 3.0 \\
8 & 3.5 & 3.5 \\
9 & 3.5 & 3.6 \\
10 & 3.9 & 4.0 \\
11 & 3.9 & 4.0 \\
12 & 3.9 & 4.0 \\
13 & 4.1 & 4.2 \\
14 & 4.2 & 4.3 \\
15 & 4.1 & 4.2 \\
16 & 3.9 & 4.0 \\
17 & 3.1 & 3.1 \\
18 & 3.6 & 3.7 \\
AVE & 3.1 & 3.2 \\
\hline
\end{tabular}


This page intentionally left blank. 
APPENDIX B

TRACEABILITY OF CALIBRATION SOURCES

TO AN NBS STANDARD 
This page intentionally left blank. 
Two types of standard sources were used in the calibration measurements $2 \times 2 \mathrm{~cm}$ weak ( $\sim 10 \mu \mathrm{Ci}$ ) foils and strong ( $\sim 5 \mathrm{mCi}$ ) point sources. These sources were calibrated against NBS Standard Reference Material 4215-C, mixed radionuclide, gamma-ray emission rate, point-source standard. The nuclear gamma-ray emission rates at 1200 EST, September 1, 1975, are shown below.

\begin{tabular}{|c|c|c|c|c|c|c|c|}
\hline \multirow{2}{*}{$\begin{array}{c}\text { Parent } \\
\text { Radio- } \\
\text { Nuclide }\end{array}$} & \multirow{2}{*}{$\begin{array}{c}\text { Gamma-Ray } \\
\text { Energy } \\
(\mathrm{MeV})\end{array}$} & \multirow{2}{*}{$\begin{array}{c}\text { Gamma Rays } \\
\text { Per ntps } \\
\text { Used }\end{array}$} & \multirow[b]{2}{*}{ Half-Life } & \multirow[b]{2}{*}{$\gamma / s$} & \multicolumn{3}{|c|}{ Uncertainty $(\%)$} \\
\hline & & & & & $\begin{array}{c}\text { Random } \\
(99 \% \text { C. L. })\end{array}$ & $\begin{array}{l}\text { System- } \\
\text { atic }\end{array}$ & Total \\
\hline${ }^{109} \mathrm{Cd}$ & 0.088 & & $1.2727 y$ & 913.8 & 1.3 & 3.0 & 4.3 \\
\hline${ }^{57} \mathrm{Co}$ & 0.122 & $0.856 \pm 0.002$ & $271.41 d$ & 1394 & 0.1 & 2.2 & 2.3 \\
\hline${ }^{139} \mathrm{Ce}$ & 0.165 & $0.799 \pm 0.003$ & $137.87 d$ & 1545 & 0.1 & 2.6 & 2.7 \\
\hline${ }^{203} \mathrm{Hg}$ & 0.279 & $0.815 \pm 0.002$ & $46.61 d$ & 3232 & 0.1 & 1.1 & 1.2 \\
\hline${ }^{113} \mathrm{Sn}$ & 0.392 & -- & $115.31 d$ & 3563 & 0.1 & 2.8 & 2.9 \\
\hline${ }^{85} \mathrm{Sr}$ & 0.514 & $0.98 \pm 0.01$ & $64.86 d$ & 5662 & 0.1 & 2.2 & 2.3 \\
\hline${ }^{137} \mathrm{Cs}$ & 0.662 & -- & $30 y$ & 3868 & 0.1 & 2.0 & 2.1 \\
\hline${ }^{60} \mathrm{Co}$ & 1.173 & $0.9988 \pm 0.0002$ & $5.272 y$ & 8525 & 0.1 & 1.3 & 1.4 \\
\hline${ }^{60} \mathrm{Co}$ & 1.333 & 1.00 & & 8535 & 0.1 & 1.3 & 1.4 \\
\hline${ }^{88} \mathrm{Y}$ & 0.898 & $0.950 \pm 0.005$ & $106.63 d$ & 20580 & 0.2 & 2.8 & 3.0 \\
\hline${ }^{88} \mathrm{Y}$ & 1.836 & $0.9937 \pm 0.0002$ & & 21530 & 0.2 & 2.2 & 2.4 \\
\hline
\end{tabular}

The strong sources were calibrated using an IRT $37 \mathrm{cc} \mathrm{Ge}(\mathrm{Li})$ detector. The ${ }^{137} \mathrm{Cs}$ source has IRT identification number $55-137-25$, and the ${ }^{134} \mathrm{Cs}$ source is identified as 55-134-1. Because of the differences in source strengths, the NBS source was counted at $10.2 \mathrm{~cm}$ from the detector, and the ${ }^{134} \mathrm{Cs}$ and ${ }^{137} \mathrm{Cs}$ sources were counted at $164.7 \mathrm{~cm}$. The efficiency curve for this detector at $10.2 \mathrm{~cm}$ is shown in Figure B-1. These efficiencies were 


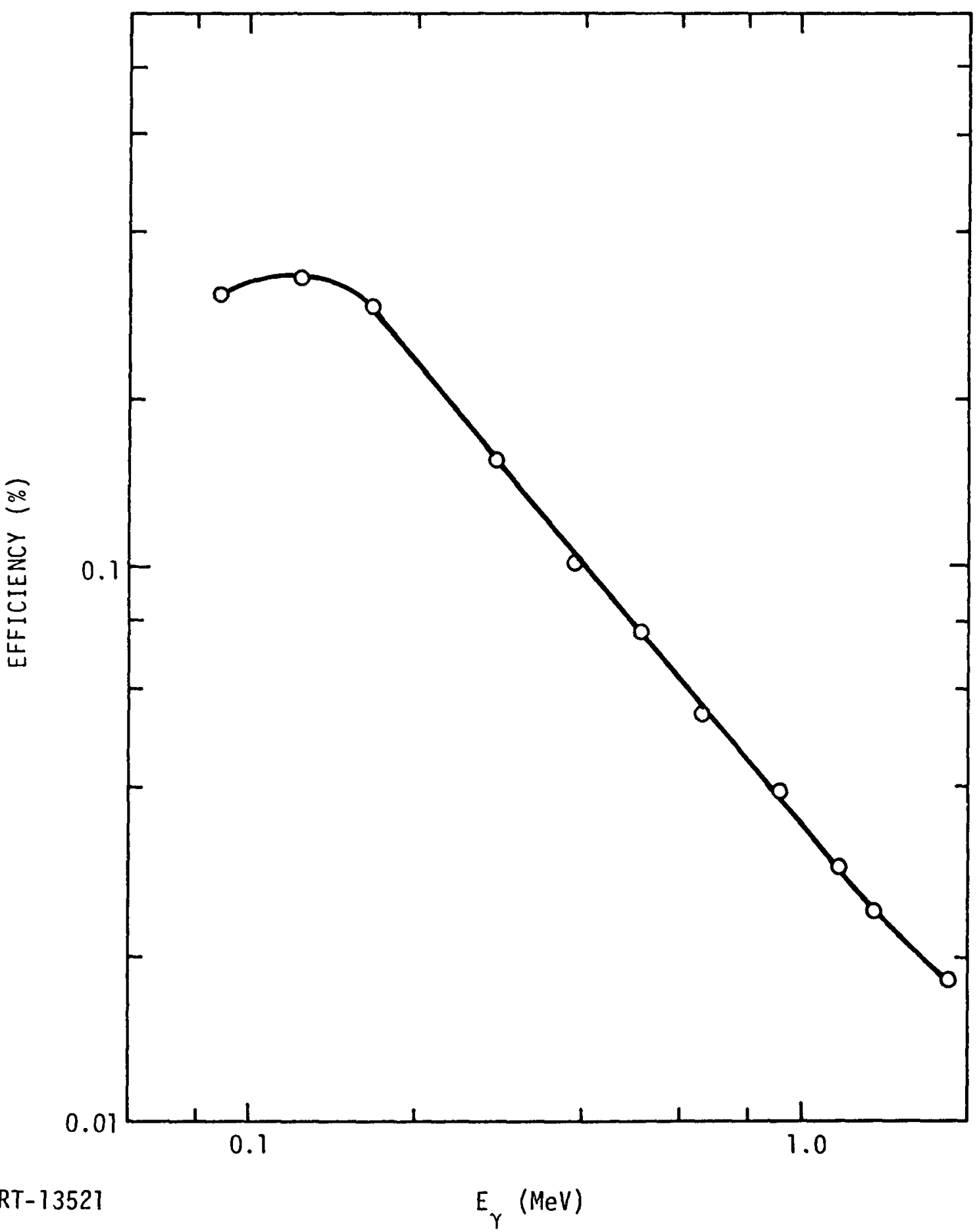

Figure B.1. Calibration of AA detector Ge(Li) at $10.2 \mathrm{~cm}$ 
extrapolated to $164.7 \mathrm{~cm}$ using the $1 / \mathrm{R}^{2}$ relationship, and the strengths of the two sources were determined. On December 11, 1975 (the date of the measurements), the ${ }^{137} \mathrm{Cs}$ source was $3.5 \mathrm{mCi}$, and the ${ }^{134} \mathrm{Cs}$ source was $7.2 \mathrm{mCi}$. Both the $0.605-$ and the $0.796-\mathrm{MeV}$ gamma rays were used to determine the ${ }^{134} \mathrm{Cs}$ source strength.

The foils were also calibrated using this Ge(Li) detector. Five foils each of ${ }^{134} \mathrm{Cs}$ and ${ }^{137} \mathrm{Cs}$ and the NBS standard were counted at a distance of $18.5 \mathrm{~cm}$ from the detector. The identification numbers for the ${ }^{137} \mathrm{Cs}$ foils were $23196-1,-2,-18,-20$, and -22 , and for the ${ }^{134} \mathrm{Cs}$ foils were $23196-26,-28,-30,-31$, and -33 . The average activity of these foils on $8 / 21 / 75$, the day the steam generator calibration data were taken, was $8.8 \mu \mathrm{Ci}$ for ${ }^{137} \mathrm{Cs}$ and $8.2 \mu \mathrm{Ci}$ for ${ }^{134} \mathrm{Cs}$. The precision of all of these calibrations is estimated to be $\pm 5 \%$. 